\title{
Dissecting anatomy education in the medical curriculum
}

Citation for published version (APA):

Bergman, E. M. (2014). Dissecting anatomy education in the medical curriculum. [Doctoral Thesis, Maastricht University]. Datawyse / Universitaire Pers Maastricht. https://doi.org/10.26481/dis.20140630eb

Document status and date:

Published: 01/01/2014

DOI:

10.26481/dis.20140630eb

Document Version:

Publisher's PDF, also known as Version of record

\section{Please check the document version of this publication:}

- A submitted manuscript is the version of the article upon submission and before peer-review. There can be important differences between the submitted version and the official published version of record.

People interested in the research are advised to contact the author for the final version of the publication, or visit the DOI to the publisher's website.

- The final author version and the galley proof are versions of the publication after peer review.

- The final published version features the final layout of the paper including the volume, issue and page numbers.

Link to publication

\footnotetext{
General rights rights.

- You may freely distribute the URL identifying the publication in the public portal. please follow below link for the End User Agreement:

www.umlib.nl/taverne-license

Take down policy

If you believe that this document breaches copyright please contact us at:

repository@maastrichtuniversity.nl

providing details and we will investigate your claim.
}

Copyright and moral rights for the publications made accessible in the public portal are retained by the authors and/or other copyright owners and it is a condition of accessing publications that users recognise and abide by the legal requirements associated with these

- Users may download and print one copy of any publication from the public portal for the purpose of private study or research.

- You may not further distribute the material or use it for any profit-making activity or commercial gain

If the publication is distributed under the terms of Article $25 \mathrm{fa}$ of the Dutch Copyright Act, indicated by the "Taverne" license above, 


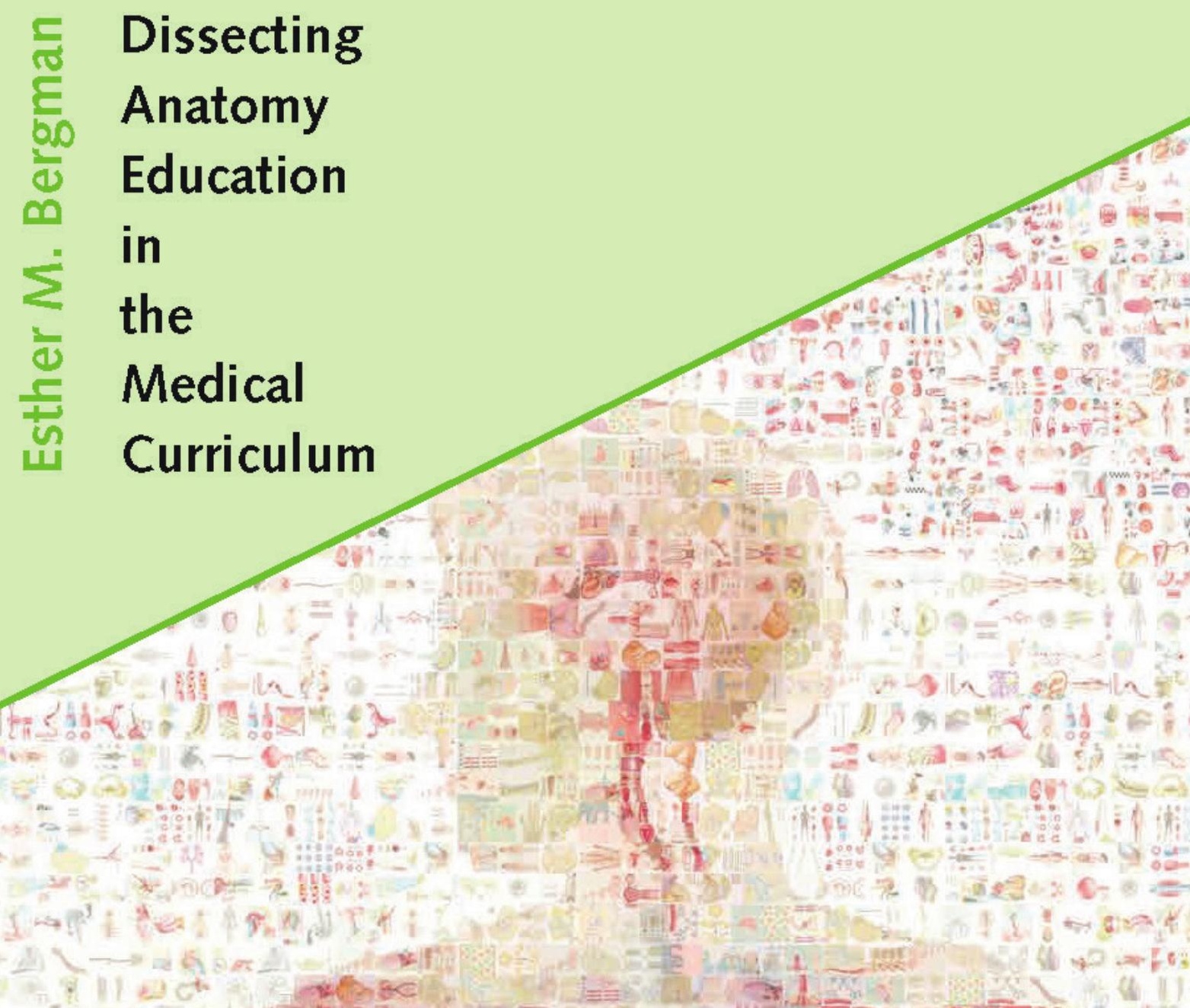

w D b F J

W.

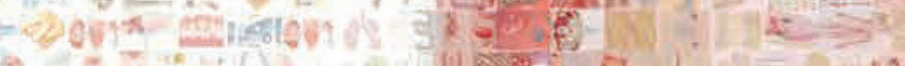

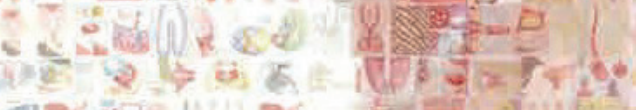

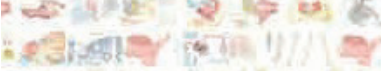

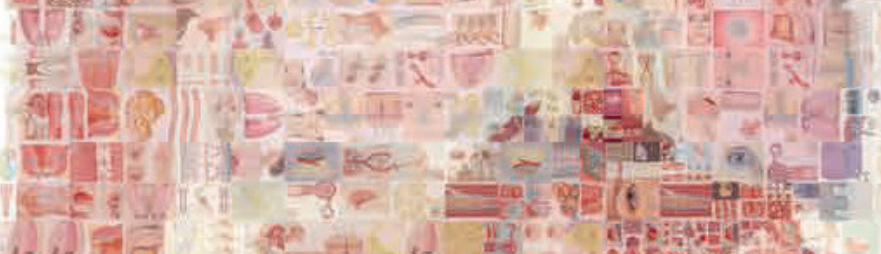

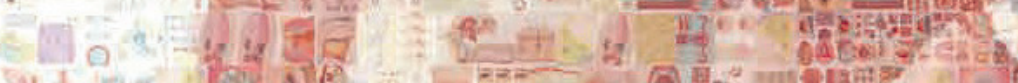

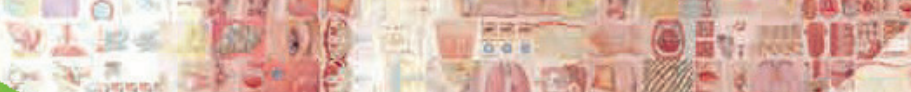

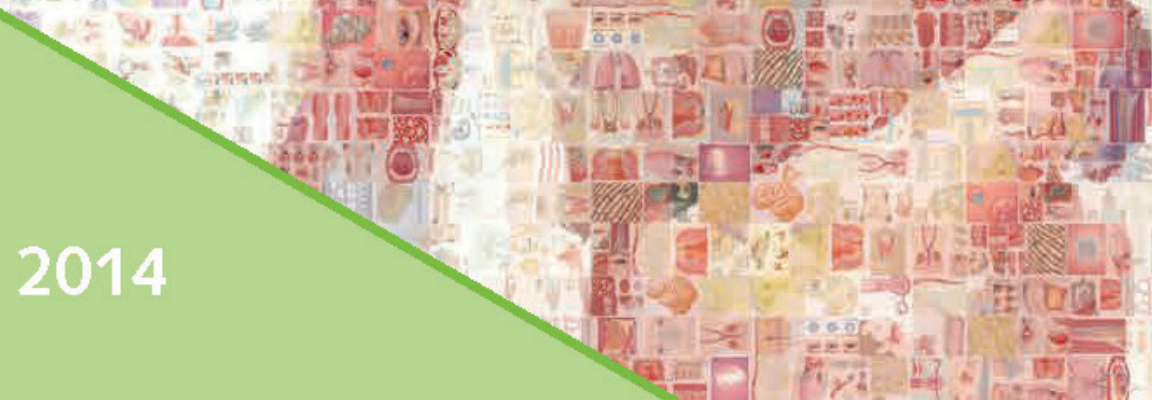

is $\rightarrow \pi \rightarrow$ 
The research reported here was carried out at Daastricht University in Learning!

in the School of Health Professions Education

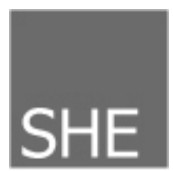

(C) Esther M. Bergman, Maastricht 2014

ISBN 9789461593351

Cover design: Rogier Trompert (www.medical-art.nl)

Production: Datawyse | Universitaire Pers Maastricht 


\title{
Dissecting Anatomy Education in the Medical Curriculum
}

\author{
PROEFSCHRIFT \\ ter verkrijging van de graad van doctor aan de Universiteit Maastricht, \\ op gezag van de Rector Magnificus, Prof. Dr. L.L.G. Soete, \\ volgens het besluit van het College van Decanen, \\ in het openbaar te verdedigen op \\ maandag 30 juni 2014 om 14:00 uur \\ door
}

\section{Esther Maria Bergman}

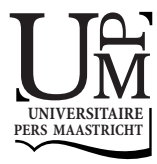




\section{Promotoren}

Prof. dr. A.J.J.A. Scherpbier

Prof. dr. C.P.M. van der Vleuten

\section{Copromotor}

Dr. A.B.H. de Bruin

\section{Beoordelingscommissie}

Prof. dr. A.F.P.M. de Goeij (voorzitter)

Prof. dr. M.G.A. Oude Egbrink

Prof. dr. S.G.F. Robben

Prof. dr. D.J. Ruiter (Radboud Universitair Medisch Centrum Nijmegen)

Prof. dr. M.C. de Ruiter (Leids Universitair Medisch Centrum) 


\section{Aan mijn ouders}

\section{If I have seen further it is by standing on the shoulders of giants}

"If I have seen further it is by standing on the shoulders of giants" is found in a letter of Isaac Newton. The original Latin nanos gigantum humeris insidentes (dwarfs standing on the shoulders of giants) has a contemporary Western interpretation meaning 'one who discovers by building on previous discoveries'. It is also described as: "we [the dwarfs] master their [the giants] wisdom and move beyond it. Due to their wisdom we grow wise and are able to say all that we say, but not because we are greater than they" (Isaiah di Trani). 



\section{Table of contents}

$\begin{array}{lll}\text { Chapter } 1 \text { General introduction } & 9\end{array}$

$\begin{array}{ll}\text { Chapter } 2 \text { How much anatomy is enough? } & 19\end{array}$

Anatomical Sciences Education 2008, 1(4): 184-188

Chapter 3 Why don't they know enough about anatomy? A narrative 31 review.

Medical Teacher 2011, 33(5): 403-409

Chapter 4 Influences on anatomical knowledge. The complete arguments.

71 Clinical Anatomy 2014, 27(3): 296-303

Chapter 5 Students' perceptions of anatomy across the undergraduate problem-based learning medical curriculum. A

phenomenographical study.

BMC Medical Education 2013, 13: 152

Chapter 6 Constructive, collaborative, contextual and self-directed learning in surface anatomy education.

Anatomical Sciences Education 2013, 6(2): 114-124

Chapter 7 Effects of learning content in context on knowledge acquisition and recall. A pretest-posttest control group design.

Submitted for publication

Chapter 8 General discussion

Summary

Samenvatting (Summary in Dutch)

Verklarende woordenlijst

Dankwoord

Curriculum Vitae

She Dissertation Series 

CHAPTER 1

General introduction 
Chapter 1 - General introduction 
"The order in which subjects are taken up [in a medical curriculum] is largely determined by considerations inherent in the subjects themselves. Anatomy - the study of the architecture of the body - comes logically first. It is indeed the oldest of laboratory sciences, and so fundamental in medical study that for a time the student may well defer all other subjects whatsoever."

$$
\text { Abraham Flexner }{ }^{1} \text { (1910) page } 61
$$

Anatomy has historically been the underpinning of training in medicine. Flexner (1910) suggested providing instruction in anatomy (including histology and embryology), physiology and biochemistry in the first year of the medical curriculum. Since then, these subjects have been referred to as 'the basic sciences'. A firm foundation of basic science knowledge is considered to assist in the acquisition and retention of clinical knowledge, assist in the development of clinical skills, and be indispensable for good clinical reasoning (Dangerfield et al. 2000; Fasel et al. 2005; Raftery 2006; Kaufman et al. 2008). However, the role and position of the basic sciences in the medical curriculum, and thus anatomy education, are under debate (Norman 2000; Fincher et al. 2009; Norman 2012). This thesis is focused on anatomy education in the undergraduate medical curriculum. More specifically, it focuses on a medical curriculum of six years, which students enter into after completing high school around the age of 18 .

\section{FROM TRADITIONAL TO INNOVATIVE CURRICULA: CHANGES IN BASIC SCIENCE EDUCATION}

In a 'traditional' curriculum, basic sciences have a clear position and function, which is described below somewhat simplistically. The first years usually focus on basic sciences while subsequent years deal exclusively with clinical education and skills training. Learning is viewed as an accumulation of knowledge. A firm foundation of basic science knowledge is considered an absolute requirement for clinical reasoning, and knowledge of normal structure and function is thought necessary to understand abnormal structure and function. This fundament of basic science knowledge is concentrated in a 'preclinical phase', usually lasting four years. Each basic science is presented in an isolated course, which is strictly department-based and with little or no integration across disciplines. Courses consist mainly of lectures and teacher-

\footnotetext{
${ }^{1}$ Abraham Flexner, an educational scholar, assessed medical education in the United States and Canada (at the behest of the Carnegie Foundation and the American Medical Association). His report initiated reforms that reflected fundamentally different underpinnings than what had been in place at the time, and which remain at the core of current medical education today.
} 
centred instruction in laboratories. There is little deliberate instruction in the application of basic sciences to clinical problems and limited student-patient interaction (Swanson and Case 1997; Drake 1998; Dahle et al. 2002). Basic clinical skills, like taking a patient history, communicating with patients, and performing a structured physical examination, are taught in the 'clinical phase', at the beginning of clerkships, or not at all. The traditional curriculum exists "primarily for its efficiency, not necessarily for its effectiveness" [page s118] (Way et al. 2000). The shift from more traditional to modern curricula, starting in the late 1970s and increasing exponentially around the world in the past two decades, is prompted by two main issues: 1) the problem of transfer, which changed the view on effective teaching, and 2) the changing content and duration of the medical curriculum.

Transfer is described as using knowledge acquired in one context to solve a new problem in another context (Norman 2009). Transfer is more difficult than we might think. From the perspective of students, it is described as the 'shock of practice': the difficulties in applying knowledge and skills that students experience when they make the transition from learning in a classroom setting to facing real patients in the hospital (Prince et al. 2000). "Medical educators have certainly recognised the issue. Stories of medical students who have learned the basic science, passed the examinations, but were then unable to apply this knowledge to solve or explain problems, are commonplace" [page 808] (Norman 2009). Thus both students and teachers were dissatisfied with the basic sciences being taught unrelated to each other and to the students' future practice. In modern curricula, basic sciences are taught simultaneously and in an interrelated manner, which is called horizontal integration; clinical sciences are frequently introduced in the early years of the curriculum and are integrated with the basic sciences and vice versa, which is called vertical integration (Dahle et al. 2002). Consequently, traditional curricula can be represented by an $H$ shape and innovative curricula by a $Z$ shape (figure 1.1). Furthermore, research on the psychology of learning has changed the views on how the subjects in the curriculum should be taught to facilitate knowledge acquisition, recall and transfer. Consequently, education (of the basic sciences) in modern curricula has shifted from teacher-centred and lecture-based to student-centred, self-directed and active learning (Dolmans et al. 2005). Whereas students may have the impression in traditional curricula that they are studying basic sciences because they have to, modern curricula elicit intrinsic motivation and thus student engagement. 

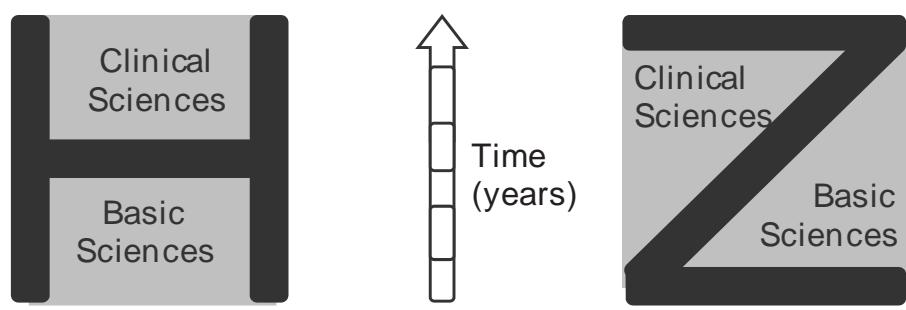

Figure 1.1 The traditional curriculum can be represented by an $\mathrm{H}$ shape, with all clinical sciences taught later in the curriculum. Modern curricula can be represented by a $\mathbf{Z}$ shape, where students are introduced to clinical sciences at the beginning of the curriculum.

Simultaneously with the changing view on effective teaching, the content and duration of the medical curriculum changed. Since the end of World War II, the amount of scientific knowledge with potential relevance to medical practice has expanded rapidly (Clough et al. 2004; Finnerty et al. 2010). Additional subjects like genetics and molecular biology have found their way into modern medical curriculum. This explosion of knowledge paradoxically coincides with a trend in many countries toward shorter undergraduate medical training programs and calls for even further reduction (Emanuel and Fuchs 2012). It has been recognised that the amount of basic sciences information is far too large to include everything in the undergraduate curriculum (Swanson and Case 1997; Clough et al. 2004; Woloschuk et al. 2004). If that is not troublesome enough, significant parts of what students learn today will be outdated soon: "We can be certain that the doctors of tomorrow will be applying knowledge and deploying skills which are at present unforeseen" (General Medical Council, 1993) [page 131] (Monkhouse and Farrell 1999). To help students deal with both issues, lifelong learning skills (e.g. reflection) have been added to the modern curriculum. Furthermore, the complexity of contemporary medical practice has contributed to curricular expansion, leading to the inclusion of behavioural (interpersonal skills, communication, professional behaviour), ethical and management knowledge and skills (Finnerty et al. 2010).

\section{PROBLEM-BASED LEARNING}

Modern curricula can be approached in many ways, one of which is problem-based learning (PBL) (Schmidt 1983). The strengths of problem-based learning are derived from the four learning principles underpinning it: contextual, constructive, collaborative and self-directed learning (Dolmans et al. 2005) (see textbox 1.1). Basic to $\mathrm{PBL}$ is that student learning is organised around problems (patient cases, patient 
problem scenarios, professional problems). Tutorial groups consisting of a small group of students (e.g. on average 10 students) and their tutor (facilitator) meet regularly (e.g. twice per week) to discuss a problem. These problems consist of a description of one or several phenomena, which students try to explain in terms of underlying (biomedical or psychosocial) processes, using their prior knowledge, opinions, and preexisting ideas. During this discussion, students discover what they already know and what they do not know. They then develop learning objectives to which they seek answers during the self-study phase by making use of faculty resources (lectures, laboratory sessions, skills training, etc.) and/or studying relevant literature. The initial discussion helps them determine both the direction and extent of study they need to undertake (Dolmans and Schmidt 1994; Dolmans et al. 2005). During the first part of the next tutorial group meeting, students discuss their answers to the learning objectives and thus acquire a deep understanding of the problem. Then they are presented with a new problem and the cycle starts again.

\section{Text box 1.1: The four learning principles underpinning PBL}

(Dolmans et al. 2005)

Constructive learning principle Learners should be involved actively and should be stimulated towards activation of prior knowledge, elaboration, and deep learning, because this leads to deeper and richer understanding and better use of knowledge.

Collaborative learning principle Learners should be stimulated to interact with each other because these interactions may positively influence learning.

Contextual learning principle Learners are preferably exposed to a professionally relevant context and confronted with cases or problems from multiple perspectives, because this stimulates transfer of knowledge.

Self-directed learning principle Learners should be stimulated to be aware of their prior knowledge and should be stimulated to regulate or direct their learning process both from a motivational and a cognitive perspective.

\section{CONCERNS ABOUT PRESENT-DAY ANATOMY EDUCATION}

The rapid implementation of integrated curricula and the use of educational approaches that differ from traditional didactic methods have given rise to concern about the level of basic science knowledge attained by students graduating from 
modern integrated programs. "[A] potential disadvantage [of $P B L]$ is that students may become more interested in the clinical aspects of a problem and neglect the underlying basic science knowledge" [page 608] (O'Neill 2000). Students have indeed reported a tendency to skip the initial exploration of probable causes and underlying mechanisms of patient problems and not bother to formulate appropriate learning objectives related to basic sciences. Instead, they confine themselves to looking up a diagnosis and its associated symptoms and treatments (Prince et al. 2000). With respect to anatomy, there is an ongoing debate about whether PBL can effectively replace traditional teaching. Of all basic sciences "anatomy, with a defined knowledge base, is probably the most resistant to change, [since] PBL focuses more on understanding the material rather than [on] reproducing and rote memorization" (and Goodenough 1998). Especially the frequent abandonment of cadaveric dissection by students as a teaching method has given rise to much debate (Aziz et al. 2002; Older 2004; Raftery 2006). The results of a survey by Waterston and Stewart (2005) indicate that the majority of clinicians believe that anatomy is not adequately taught, and as a result, students' knowledge is below the minimum necessary for safe medical practice. The decline in anatomical knowledge has been cited as one reason for increasing surgical errors and the consequent increases in medico-legal litigation (Ellis 2002; Older 2004).

\section{MAIN ARGUMENT AND RESEARCH QUESTION}

For many clinical specialties, the human body is the focus of investigation and intervention on a daily basis, and therefore accurate knowledge of anatomy and individual variations is vital to ensuring safe and efficient clinical practice (Fasel et al. 2005; Raftery 2006; Turney 2007). The basic sciences are also thought to be important for preparing students for the future, as students who have a sound knowledge of the structure and function of the human body will probably deal best with developments in medical practice such as new diagnostic technology and surgical approaches (Monkhouse and Farrell 1999). There is a general consensus that medical students definitely cannot do without anatomical knowledge, and consequently without anatomy education, although opinions may differ as to its scope. Whether or not there is a decline in knowledge will be left undisputed. Mapping the development of anatomical knowledge over the continuum of medical training may yield valuable information about how theoretical basic science knowledge transforms into clinically applicable skills and practices (Wilhelmsson et al. 2010). Extensive education in anatomy (and the other basic sciences) is no longer self-evident. The packed curriculum and the competition for teaching time mean that the available time needs 
to be used as effectively as possible. The main research question in this thesis is therefore: How can anatomy education be optimised? Although quite varied, the current literature on anatomy education appears to focus on methods of teaching (Regan de Bere and Mattick 2010), but it seems pertinent to consider the why, what, when, where and who together with the how of anatomy education. To formulate an answer to these questions, this thesis starts with a broad research strategy in the first studies by identifying the factors that influence anatomical knowledge. In the last studies, the strategy is narrowed down by manipulating a small number of factors in an experimental design to investigate their influence on the perceived and actual anatomical knowledge of students.

\section{OVERVIEW OF STUDIES IN THIS THESIS}

A total of six studies were conducted to answer the research question on how anatomy education can be optimised. These will be described here briefly to provide an outline for the thesis.

Chapters 2 to 5 have a broad research strategy. In Chapter 2, we contribute to the debate on anatomy education by reviewing research that addresses the relationship between students' anatomical knowledge and the use of innovative and traditional educational approaches. Chapters $\mathbf{3}$ and $\mathbf{4}$ explore the opinions of clinicans and anatomists and aim to identify all possible factors that influence anatomical knowledge of students, and the empirical evidence to support these claims. Students themselves have been reported to be even more severe in their judgment of their anatomical knowledge than clinicians and anatomists. As they place such a high demand on their anatomical knowledge, we thought it would be likely that they had strong opinions concerning anatomy education. Chapter $\mathbf{5}$ therefore serves to identify factors that influence anatomical knowledge by asking students about their preferences in learning anatomy.

Based on the information gathered in the studies mentioned above, we were able to narrow down the research strategy as we gradually obtained a clearer idea of how to improve anatomy education. In Chapter 6 we describe a very practical example for anatomy teachers on how the constructive, collaborative, contextual and self-directed learning principles can be applied to surface anatomy education. Chapter 7 focuses on learning anatomy in the context of a paper-patient case, exploring the requirements that the patient case needs to meet to optimally stimulate knowledge acquisition and recall.

As the chapters in this thesis have been published as individual journal articles, repetitions and overlap across chapters are inevitable. 


\section{REFERENCES}

Aziz M.A., McKenzie J.C., Wilson J.S., Cowie R.J., Ayeni S.A. \& Dunn B.K. (2002). The human cadaver in the age of biomedical informatics. Anat Rec, 269(1): 20-32.

Clough R.W., Shea S.L., Hamilton W.R., Estavillo J.A., Rupp G., Browning R.A. \& Lal S. (2004). Weaving basic and social sciences into a case-based, clinically oriented medical curriculum: one school's approach. Acad Med, 79(11): 1073-1083.

Dahle L.O., Brynhildsen J., Behrbohm Fallsberg M., Rundquist I. \& Hammar M. (2002). Pros and cons of vertical integration between clinical medicine and basic science within a problem-based undergraduate medical curriculum: examples and experiences from Linkoping, Sweden. Med Teach, 24(3): 280-285.

Dangerfield P., Bradley P. \& Gibbs T. (2000). Learning gross anatomy in a clinical skills course. Clin Anat, 13(6): 444-447.

Dolmans D.H., De Grave W., Wolfhagen I.H. \& Van der Vleuten C.P. (2005). Problem-based learning: future challenges for educational practice and research. Med Educ, 39(7): 732-741.

Dolmans D.H. \& Schmidt H.G. (1994). What drives the student in problem-based learning? Med Educ, 28(5): 372-380.

Drake R.L. (1998). Anatomy education in a changing medical curriculum. Anat Rec, 253(1): 28-31.

Ellis H. (2002). Medico-legal Litigation and its Links with Surgical Anatomy. Surgery, 20(8): i-ii.

Emanuel E.J. \& Fuchs V.R. (2012). Shortening medical training by 30\%. JAMA, 307(11): 1143-1144.

Fasel J.H., Morel P. \& Gailloud P. (2005). A survival strategy for anatomy. Lancet, 365(9461): 754.

Fincher R.M., Wallach P.M. \& Richardson W.S. (2009). Basic science right, not basic science lite: medical education at a crossroad. [Review]. J Gen Intern Med, 24(11): 1255-1258.

Finnerty E.P., Chauvin S., Bonaminio G., Andrews M., Carroll R.G. \& Pangaro L.N. (2010). Flexner revisited: the role and value of the basic sciences in medical education. Acad Med, 85(2): 349-355.

Flexner A. (1910). Medical Education in the United States and Canada: A Report to the Carnegie Foundation for the Advancement of Teaching. Bulletin No. 4. Retrieved from http://www.carnegiefoundation.org/elibrary November 2013

Kaufman D.R., Yoskowitz N.A. \& Patel V.L. (2008). Clinical reasoning and biomedical knowledge: implications for teaching. In Higgs J., Jones M.A., Loftus S. \& Christensen N. (Eds.), Clinical reasoning in the health professions. Third edition. (pp. 137-149): Elsevier.

Monkhouse W.S. \& Farrell T.B. (1999). Tomorrow's doctors: today's mistakes? Clin Anat, 12(2): 131-134.

Norman G. (2000). The essential role of basic science in medical education: the perspective from psychology. Clin Invest Med, 23(1): 47-51.

Norman G. (2009). Teaching basic science to optimize transfer. Med Teach, 31(9): 807-811.

Norman G. (2012). The basic role of basic science. Adv Health Sci Educ Theory Pract, 17(4): 453-456.

O'Neill P.A. (2000). The role of basic sciences in a problem-based learning clinical curriculum. Med Educ, 34(8): 608-613.

Older J. (2004). Anatomy: a must for teaching the next generation. Surgeon, 2(2): 79-90.

Percac S. \& Goodenough D.A. (1998). Problem based teaching and learning as a bridge from basic anatomy to clinical clerkships. Surg Radiol Anat, 20(3): 203-207.

Prince K.J., Van De Wiel M., Scherpbier A.J., Van Der Vleuten C.P. \& Boshuizen H.P. (2000). A Qualitative Analysis of the Transition from Theory to Practice in Undergraduate Training in a PBL-Medical School. Adv Health Sci Educ Theory Pract, 5(2): 105-116.

Raftery A. (2006). Anatomy teaching in the UK. Surgery, 25(1): 1-2.

Regan de Bere S. \& Mattick K. (2010). From anatomical 'competence' to complex capability. The views and experiences of UK tutors on how we should teach anatomy to medical students. Adv Health Sci Educ Theory Pract, 15(4): 573-585. 


\section{Chapter 1 - General introduction}

Schmidt H.G. (1983). Problem-based learning: rationale and description. Med Educ, 17(1): 11-16.

Swanson D.B. \& Case S.M. (1997). Assessment in Basic Science Instruction: Directions for Practice and Research. Advances in Health Sciences Education, 2: 71-84.

Turney B.W. (2007). Anatomy in a modern medical curriculum. Ann R Coll Surg Engl, 89(2): 104-107.

Waterston S.W. \& Stewart I.J. (2005). Survey of clinicians' attitudes to the anatomical teaching and knowledge of medical students. Clin Anat, 18(5): 380-384.

Way D.P., Hudson A. \& Biagi B. (2000). Comparison of three parallel, basic science pathways in the same medical college. Acad Med, 75(10 Suppl): S118-120.

Wilhelmsson N., Dahlgren L.O., Hult H., Scheja M., Lonka K. \& Josephson A. (2010). The anatomy of learning anatomy. Adv Health Sci Educ Theory Pract, 15(2): 153-165.

Woloschuk W., Mandin H., Harasym P., Lorscheider F. \& Brant R. (2004). Retention of basic science knowledge: a comparison between body system-based and clinical presentation curricula. Teach Learn Med, 16(2): 116-122. 


\section{CHAPTER 2}

\section{How much anatomy is enough?}




\section{ABSTRACT}

Innovations in undergraduate medical education, such as integration of disciplines and problem based learning, have given rise to concerns about students' knowledge of anatomy. This article originated from several studies investigating the knowledge of anatomy of students at the eight Dutch medical schools. The studies showed that undergraduate students uniformly perceived deficiencies in their anatomical knowledge when they started clinical training regardless of their school's didactic approach. A study assessing students' actual knowledge of clinical anatomy revealed no relationship between students' knowledge and the school's didactic approach. Test failure rates based on absolute standards set by different groups of experts were indicative of unsatisfactory levels of anatomical knowledge, although standards differed markedly between the groups of experts. Good test performance by students seems to be related to total teaching time for anatomy, teaching in clinical context, and revisiting anatomy topics in the course of the curriculum. These factors appeared to outweigh the effects of disciplinary integration or whether the curriculum was problem-based or traditional. 


\section{INTRODUCTION}

The body of scientific knowledge has expanded dramatically over recent decades, with exponential increases in medical knowledge in nearly all disciplines. In the early 1980s, it was increasingly recognized that the body of information with potential relevance to medical practice was far too large for instructors to teach or for students to learn. To put it differently, it was rapidly becoming impractical to try and include everything in the undergraduate curriculum (Swanson and Case 1997; Clough et al. 2004; Woloschuk et al. 2004). The current explosion of knowledge paradoxically coincides with a trend in many countries toward shorter undergraduate medical training programs. And if that is not bad enough, we know that there is a good chance that what students learn today will be outdated tomorrow: "we can be certain that the doctors of tomorrow will be applying knowledge and deploying skills which are at present unforeseen" (General Medical Council 1993) [page 131] (Monkhouse and Farrell 1999). Therefore, the teaching of more generic competences, such as interpersonal skills and skills for lifelong learning, is being incorporated in medical education. But basic science education, with anatomy education in particular, is probably equally important: "[...] future developments in medical practice [e.g., diagnostic technology or surgical approaches] will best be dealt with by those who have a sound knowledge of the structure and function of the human body" [page 132] (Monkhouse and Farrell 1999). All these developments make it imperative that very careful consideration is given to what medical students need to learn and at which stage of the curriculum.

Medical education has seen changes driven by evidence from the fields of psychology and education. Retention of knowledge is promoted when students are actively involved in their learning; this research finding supports the view from cognitive psychology that learning is a constructive process in which learners connect new information to their existing knowledge networks, thereby forming and strengthening meaningful connections between concepts (Regehr and Norman 1996). This process is optimised when prior knowledge is activated and students elaborate on, discuss, and explain (new) information, for instance, in groups of peers. As a result of this, today, many medical schools have incorporated active learning methods into their courses (Dolmans et al. 2005). Another influential finding is that knowledge retrieval is facilitated when knowledge is acquired in a situation resembling those in which it will be applied (Smith and Vela 2001). Thus, learning based on authentic tasks is expected to facilitate the transfer of knowledge from educational settings to work settings. In order to achieve this, there is a growing tendency to enable students to deal with patient problems early in their studies or even to offer them early contacts with patients (Dornan et al. 2006). This educational insight also explains the movement toward horizontal and vertical integration of disciplines in medical curricula. Horizontal 
integration refers to the integration of different basic science disciplines in one course, while vertical integration is the integration of basic and clinical sciences aimed at presenting basic sciences in context (Dahle et al. 2002).

Apart from disciplinary integration, other didactic approaches have left their mark on medical education. A shift is noticeable from 'traditional' teacher-centred education, relying heavily on lectures with students as passive recipients of information, to 'innovative' student-centred education focused on active, self-directed learning by students either individually or in groups. Today, student-centred learning approaches are being implemented by more and more medical schools around the world (Van der Vleuten et al. 1996).

The rapid rise of integrated curricula and approaches that are a departure from traditional didactic methods has given rise to concern about the level of knowledge attained by students graduating from innovative programs, for basic sciences in general, and for anatomy in particular. However, concerns of teachers and clinicians are mostly anecdotal and expressed informally. Anatomists (and surgeons involved in the higher surgical examinations) have commented on the decline of students' knowledge and their lack of understanding of anatomy in discussions, anatomical meetings, and other forums (Heylings 2002). "The students' knowledge of anatomy is lamentable. I cannot ignore this remark because I hear an increasing number of clinicians in Britain say it" [page 834] (Monkhouse 1992). Waterston and Stewart (2005) gathered clinicians' opinions on this subject with a survey. Their results indicate that the majority of clinicians believe that anatomy is not adequately taught, and as a result, students' knowledge is below the minimum necessary for safe medical practice.

With this article we want to contribute to the debate on the current situation in undergraduate anatomy education. Our contribution is found in our research addressing the questions of how much anatomical knowledge is enough and whether the levels of students' anatomical knowledge are related to the use of innovative or traditional educational approaches. Additionally, we will explore which educational strategies may offer the best chance of raising the level of anatomical knowledge, both in volume and in detail.

\section{DO PROBLEM-BASED LEARNING STUDENTS HAVE ACTUAL OR ONLY PERCEIVED DEFICIENCIES IN ANATOMICAL KNOWLEDGE?}

True problem-based learning (PBL) curricula are characterized by full horizontal and vertical integration and self-directed learning. From the start of undergraduate training, students tackle authentic problems and are offered ample experience with clinical practice. Students work in small (tutorial) groups, with teachers as facilitators 
of the learning process. Many other so-called PBL curricula exist, in which different levels of application of the PBL format are supplemented with other didactic approaches. PBL, although being around for many years, is in general still labelled as one of the 'innovative' didactic approaches. For the clarity of this article, (the mentioned) PBL curricula are not further discussed.

Students attending schools where PBL is the predominant approach have repeatedly stated that basic science knowledge is essential for their preparation for medical practice and that they find the programs of their schools wanting in this respect (Woodward and Ferrier 1983; Prince et al. 2000; Prince et al. 2005a). In a study by Prince et al. (2000), students in a PBL program reported a tendency in tutorial groups to skip the initial exploration of probable causes and underlying mechanisms of a problem and start by looking up a diagnosis and its associated symptoms. Students said that even though the cases they were given to resolve were quite realistic, they managed to come up with the correct diagnosis within minutes and did not bother to formulate appropriate learning objectives. This may reflect a similar mechanism to that observed by O'Neill (2000), namely that in PBL a "potential disadvantage is that students may become more interested in the clinical aspects of a problem and neglect the underlying basic science knowledge, though this has not been formally reported" [page 608]. More importantly, he suggests that the focus on diagnostic problems in PBL interferes with the building of an appropriate conceptual framework, which students can use for continued learning of basic sciences. Drake (1998) also warns that some students may not do well in PBL (in its strictest form), because they are unable to cope with this type of self-directed learning. He also worries that some students will not fill the gaps in their knowledge if left to their own devices. This may be important because "true understanding [...] is defined not simply by the quantity of information that a person possesses, but by the extent to which this information is organized into a coherent, mutually supportive network of concepts and examples" [page 991] (Regehr and Norman 1996). In other words, without an appropriate framework, students' ability to retain and acquire basic science knowledge may be compromised. These views are in contrast to claims that PBL stimulates retention and acquisition of basic science knowledge (continued learning). A number of reviews comparing the basic science knowledge of PBL-students and non-PBL-students (Albanese and Mitchell 1993; Vernon and Blake 1993; Alleyne et al. 2002) yielded conflicting and inconclusive evidence. Some studies showed PBL graduates to have less basic science knowledge than traditionally trained students, whereas other studies reported no differences. With respect to anatomy, there is also an ongoing debate whether PBL can effectively replace traditional teaching. Of all basic sciences "anatomy, with a defined knowledge base, is probably the most resistant to change," since "PBL focuses more on 
understanding the material rather than [on] reproducing and rote memorisation" [page 203] (Percac and Goodenough 1998).

In order to substantiate perceived deficiencies in anatomical knowledge of PBL students, empirical studies have examined whether PBL and non-PBL students differed in self-perceived knowledge of anatomy at the start of clerkships in Year 4 of the 6year undergraduate curriculum in the Netherlands. It turned out that perceived insufficiency of anatomical knowledge was equally widespread among students of schools with innovative and traditional curricula (Custers and Cate 2002; Prince et al. 2003). Most students said they had learned less about anatomy than they deemed necessary and they expected to learn substantially more during the upcoming clerkships. Basically, all students were insecure about their level of anatomical knowledge and felt they did not know enough.

In a subsequent study, students' actual anatomical knowledge was assessed by a case-based anatomy test (questions about anatomy based on clinical cases) containing 142 multiple choice items. Interestingly, the differences between the schools were significant but unrelated to PBL: PBL students had similar test scores to the other students (Prince et al. 2003).

In all, this empirical verification points to the conclusion that differences between students in perceived and actual knowledge of anatomy are not related to innovative (PBL) or traditional curricula. Despite being clear, this is only partly a reassuring conclusion.

\section{DO STUDENTS KNOW ENOUGH ABOUT ANATOMY?}

The obvious question to ask next is whether students actually possess enough anatomical knowledge or not. But establishing how much anatomical knowledge is enough is not a straightforward matter. In a subsequent study we interpreted students' results on the case-based anatomy test, using standards arrived at by different groups of experts to determine whether the students knew enough or not, that is whether they passed or failed the test. Four expert panels consisting of fourth year students (other students than the ones sitting the clinical anatomy test), recently graduated doctors, clinicians (all from a different speciality), and anatomists (Prince et al. 2005b), respectively set a standard using a specific and rigorous item-by-item judgement procedure (Angoff procedure; Cusimano (1996)). Many students failed by the experts' standards, which differed markedly between the groups. Fourth year students set the most stringent standard, failing $64 \%$ of the students! Remember that our previous study revealed that fourth year students felt extremely uncertain about their anatomical knowledge. The recently graduated doctors were most lenient, failing 
only $26 \%$ of the students. Apparently, expectations in this group had shifted following the reality check of completing undergraduate medical training. Interestingly, there was stronger agreement on the standard within this group than among the students. Next in leniency came the anatomists (failing $42 \%$ ) followed by the clinicians (58\%). Two conclusions stand out from this study: there is agreement that students' anatomical knowledge is unsatisfactory but no agreement on which level of knowledge is acceptable. Similar findings were reported for pharmacology and genetics (Vollebregt 2004; Baars et al. 2005). From this perspective, the problem does not just seem to be the deficiency of students' anatomical knowledge but a more general difficulty of establishing the minimal content of medical curricula and how much anatomical knowledge students should have at the end of undergraduate training. Although attempts have been made (Leonard et al. 1996; McHanwell et al. 2007), these examples also show that consensus of what the minimal content should be does not exist at the moment.

So far our explorations of undergraduate students' knowledge of anatomy have produced no evidence of a relationship between knowledge levels and innovative or traditional didactic educational approaches. At the start of undergraduate clinical training in Year 4, students of innovative and traditional schools in the Netherlands were equally worried about their presumably inadequate knowledge. They were probably right for, even by the most lenient standard, the anatomical knowledge of a quarter of the students was not up to the mark. This begs the question of what we can do to remedy this state of affairs. We have found some potential clues in different studies.

\section{OTHER FACTORS AFFECTING STUDENTS' ANATOMICAL KNOWLEDGE}

There are still other factors that may affect students' anatomical knowledge. One of these factors is 'time on task'. Complaints about the reduction in curricular time dedicated to anatomy and the shortage of suitable staff to teach anatomy have been reported before (Monkhouse 1992; Pabst 1993). When we explored the differences in knowledge between students from different schools, we found that differences in the amount of time spent on anatomy covaried with students' performance to some extent. It should not come as a surprise that spending more time on a subject results in more knowledge; time on task does indeed increase knowledge (Verhoeven et al. 2002). But clearly in today's medical curricula, all disciplines are facing the problem of being allocated less time to cover more knowledge. Simply increasing time on task may be effective but it is just not feasible. So we need to explore further. 
Another factor that seemed to be associated with differences in anatomical knowledge was the frequency of their recurrence in the course of the curriculum. Like the effect of time on task, this too makes intuitive sense, and there is some evidence in the literature to support this (Blunt and Blizard 1975). If revisiting topics is effective, this may imply that anatomy should not be presented in the curriculum as a one shot event but distributed throughout the curriculum, with subject matter being revisited and extended repeatedly. Developing spiral curricula has been advocated in the literature (Harden et al. 1984). However, while clinical topics are regularly integrated into the early years of medical curricula, integrating basic sciences in the later curricular years seems a tougher task (McCrorie 2000; O'Neill 2000; Prince et al. 2005a; Whitcomb 2006). Whitcomb (2006) referred to a report of the Association of American Medical Colleges in 2001 stating that "schools had not done enough to integrate content drawn from the biomedical [basic] sciences into the third and fourth years of the curriculum" [page 413]. The amount of time devoted to basic sciences is therefore perceived as being diminished, resulting in diminished growth and lower levels of basic science knowledge in students. Anatomy is the basic science for which concern about its continued place in any undergraduate curriculum is strongest (O'Neill 2000). There is widespread support among clinicians for more vertical integration of anatomy teaching throughout the undergraduate curriculum (Waterston and Stewart 2005).

Our exploration of anatomy training grew even more interesting when we found the highest levels of anatomical knowledge among the students who were taught anatomy in a clinically meaningful context-such as patient problems, and diagnostic and therapeutic features. This was clearly true for the two schools with the best anatomy results in the comparison. At the time of the study, one of these schools offered a traditional and the other one a PBL curriculum, but they both taught anatomy in a clinical context. Possibly, the effects of clinically oriented teaching combined with recurrence of topics in the curriculum are more powerful than those of traditional or innovative didactics (Prince et al. 2003).

\section{IMPLICATIONS FOR ANATOMY TEACHING}

Our explorations of the question of how much anatomical knowledge is enough and which educational strategies are likely to enhance anatomical knowledge have produced some interesting insights.

First and foremost, PBL and traditional training do not have a differential impact on students' anatomical knowledge. PBL does not appear to be associated with more or less anatomical knowledge. For some, this may be reassuring, and for others disappointing. We must keep in mind however that PBL was not introduced to help 
students acquire larger amounts of knowledge but to foster their ability to apply what they have learned. More than other approaches, PBL is supposed to facilitate integration of students' knowledge, transfer of concepts to new problems, application of basic science concepts to clinical problems, intrinsic interest in subject matter and development of skills to solve problems, learning how to learn, self-directed learning, and motivation for lifelong learning (Norman and Schmidt 1992; Dahle et al. 2002). There are some modest indications in the literature that PBL students perform better on clinical reasoning tasks (Schmidt et al. 1996; Schuwirth et al. 1999). Our exploration puts this claim in a slightly different light.

It seems that the effects of certain educational principles are more powerful than those of didactic approaches, such as PBL or traditional lecture-based teaching. One of these principles seems to be the insight from cognitive psychology that learning is facilitated when it occurs in a meaningful context (Schmidt 1993). Most PBL courses are characterized by contextual learning, but traditional, lecture-based curricula are equally suitable for presenting anatomy embedded in a clinical context. As discussed earlier, time on task and a spiral curriculum are other principles that seem to be making a difference too. If we wish to improve our anatomy teaching, maybe we had better start looking to these principles.

The second conclusion is that there is disagreement about how much anatomy is sufficient. Although there appears to be general agreement that there is room for improvement in students' anatomical knowledge, experts displayed disturbing discrepancies in their judgements of how much knowledge was enough. We question how realistic these expectations are. It is interesting to note the sharp distinction in standards set by fourth-year students and recently graduated doctors. On the brink of undertaking clinical responsibilities during clerkships, students appear to experience the strongest uncertainties and therefore may be inclined to make high demands on knowledge levels. The reality check of undergraduate clinical training appears to be reflected in the downward adjustment of the standards of the recent graduates. It is interesting that (in)security about knowledge is also not related to PBL. Of note were also the extreme expectations of the clinicians. It makes one wonder whether students' insecurity is not partly fed by the expectations evinced by their teachers. In the absence of consensus among experts, we need to explore ways of developing guidelines that set out clearly what students are expected to know. Obviously, this will require extensive interdisciplinary discussions combined with reality checks to ensure that guidelines are underpinned by realistic expectations. The insecurity reported by students should be a stimulus to provide such guidelines. Finally, the marked differences in expectations between groups of experts may partly explain the inconclusive and varying results of previous research into the effectiveness of PBL in equipping students with basic science knowledge. 
Regardless of how much anatomy actually is enough, our explorations have revealed some indications as to how anatomy teaching can be improved. We should apply these findings to try and advance our educational practice, but we should also conduct more research in this area. The ideas we have put forward in this article are the upshot of explorations of an existing data set. Further research should be directed at the systematic gathering of data to provide more solid underpinnings for our tentative conclusions. 


\section{REFERENCES}

Albanese M.A. \& Mitchell S. (1993). Problem-based learning: a review of literature on its outcomes and implementation issues. Acad Med, 68(1): 52-81.

Alleyne T., Shirley A., Bennett C., Addae J., Walrond E., West S. \& Pinto Pereira L. (2002). Problem-based compared with traditional methods at the Faculty of Medical Sciences, University of the West Indies: a model study. Med Teach, 24(3): 273-279.

Baars M.J., Scherpbier A.J., Schuwirth L.W., Henneman L., Beemer F.A., Cobben J.M., Hennekam R.C., Verweij M.M., Cornel M.C. \& Ten Kate L.P. (2005). Deficient knowledge of genetics relevant for daily practice among medical students nearing graduation. Genet Med, 7(5): 295-301.

Blunt M.J. \& Blizard P.J. (1975). Recall and retrieval of anatomical knowledge. Br J Med Educ, 9(4): 252-263.

Clough R.W., Shea S.L., Hamilton W.R., Estavillo J.A., Rupp G., Browning R.A. \& Lal S. (2004). Weaving basic and social sciences into a case-based, clinically oriented medical curriculum: one school's approach. Acad Med, 79(11): 1073-1083.

Cusimano M.D. (1996). Standard setting in medical education. Acad Med, 71(10 Suppl): S112-120.

Custers E.J. \& Cate O.T. (2002). Medical students' attitudes towards and perception of the basic sciences: a comparison between students in the old and the new curriculum at the University Medical Center Utrecht, The Netherlands. Med Educ, 36(12): 1142-1150.

Dahle L.O., Brynhildsen J., Behrbohm Fallsberg M., Rundquist I. \& Hammar M. (2002). Pros and cons of vertical integration between clinical medicine and basic science within a problem-based undergraduate medical curriculum: examples and experiences from Linkoping, Sweden. Med Teach, 24(3): 280-285.

Dolmans D.H., De Grave W., Wolfhagen I.H. \& van der Vleuten C.P. (2005). Problem-based learning: future challenges for educational practice and research. Med Educ, 39(7): 732-741.

Dornan T., Littlewood S., Margolis S.A., Scherpbier A., Spencer J. \& Ypinazar V. (2006). How can experience in clinical and community settings contribute to early medical education? A BEME systematic review. Med Teach, 28(1): 3-18.

Drake R.L. (1998). Anatomy education in a changing medical curriculum. Anat Rec, 253(1): 28-31.

Harden R.M., Sowden S. \& Dunn W.R. (1984). Educational strategies in curriculum development: the SPICES model. Med Educ, 18(4): 284-297.

Heylings D.J. (2002). Anatomy 1999-2000: the curriculum, who teaches it and how? Med Educ, 36(8): 702710.

Leonard R.J., Acland R., Aguyr A., Blevins C., DR C., Collins J., Dalley A.F., Dolph J., Hagedoorn J., Hoos P., Jones D., Mathers L., McFee R., Mennin S.P., Negulesco J., Nelson M., Olson T., Page D., Pawlina W., Petterborg L., Price J., Spielman J. \& Younoszai R. (1996). A clinical anatomy curriculum for the medical student of the 21st century: Gross anatomy. Clin Anat, 9: 71-99.

McCrorie P. (2000). The place of the basic sciences in medical curricula. Med Educ, 34(8): 594-595.

McHanwell S., Davies D., Morris J., Parkin I., Whiten S., Atkinson M., Dyball R., Ockleford C., Standring S. \& Wilton J. (2007). A core syllabus in anatomy for medical students - Adding common sence to need to know. Eur J Anat, 11 (Supplement 1): 3-18.

Monkhouse W.S. (1992). Anatomy and the medical school curriculum. Lancet, 340(8823): 834-835.

Monkhouse W.S. \& Farrell T.B. (1999). Tomorrow's doctors: today's mistakes? Clin Anat, 12(2): 131-134.

Norman G.R. \& Schmidt H.G. (1992). The psychological basis of problem-based learning: a review of the evidence. Acad Med, 67(9): 557-565.

O'Neill P.A. (2000). The role of basic sciences in a problem-based learning clinical curriculum. Med Educ, 34(8): 608-613.

Pabst R. (1993). Gross anatomy: an outdated subject or an essential part of a modern medical curriculum? Results of a questionnaire circulated to final-year medical students. Anat Rec, 237(3): 431-433. 
Percac S. \& Goodenough D.A. (1998). Problem based teaching and learning as a bridge from basic anatomy to clinical clerkships. Surg Radiol Anat, 20(3): 203-207.

Prince K.J., Boshuizen H.P., van der Vleuten C.P. \& Scherpbier A.J. (2005a). Students' opinions about their preparation for clinical practice. Med Educ, 39(7): 704-712.

Prince K.J., Scherpbier A.J., van Mameren H., Drukker J. \& van der Vleuten C.P. (2005b). Do students have sufficient knowledge of clinical anatomy? Med Educ, 39(3): 326-332.

Prince K.J., Van De Wiel M., Scherpbier A.J., Can Der Vleuten C.P. \& Boshuizen H.P. (2000). A Qualitative Analysis of the Transition from Theory to Practice in Undergraduate Training in a PBL-Medical School. Adv Health Sci Educ Theory Pract, 5(2): 105-116.

Prince K.J., van Mameren H., Hylkema N., Drukker J., Scherpbier A.J. \& van der Vleuten C.P. (2003). Does problem-based learning lead to deficiencies in basic science knowledge? An empirical case on anatomy. Med Educ, 37(1): 15-21.

Regehr G. \& Norman G.R. (1996). Issues in cognitive psychology: implications for professional education. Acad Med, 71(9): 988-1001.

Schmidt H.G. (1993). Foundations of problem-based learning: some explanatory notes. Med Educ, 27(5): 422-432.

Schmidt H.G., Machiels-Bongaerts M., Hermans H., ten Cate T.J., Venekamp R. \& Boshuizen H.P. (1996). The development of diagnostic competence: comparison of a problem-based, an integrated, and a conventional medical curriculum. Acad Med, 71(6): 658-664.

Schuwirth L.W., Verhoeven B.H., Scherpbier A.J., Mom E.M., Cohen-Schotanus J., Van Rossum H.J. \& Van Der Vleuten C.P. (1999). An Inter- and Intra-University Comparison With Short Case-Based Testing. Adv Health Sci Educ Theory Pract, 4(3): 233-244.

Smith S.M. \& Vela E. (2001). Environmental context-dependent memory: a review and meta-analysis. Psychon Bull Rev, 8(2): 203-220.

Swanson D.B. \& Case S.M. (1997). Assessment in basic science instruction: directions for practice and research. Adv Health Sci Educ Theory Pract, 2(1): 71-84.

Van der Vleuten C.P.M., Scherpbier A.J.J.A., Wijnen W.H.F.W. \& Snellen H.A.M. (1996). Flexibility in learning: a case report on problem-based learning. International Higher Education, 1: 17-24.

Verhoeven B.H., Verwijnen G.M., Scherpbier A.J. \& van der Vleuten C.P. (2002). Growth of medical knowledge. Med Educ, 36(8): 711-717.

Vernon D.T. \& Blake R.L. (1993). Does problem-based learning work? A meta-analysis of evaluative research. Acad Med, 68(7): 550-563.

Vollebregt J.A. (2004). From learning objectives to student's competences. Tranformation into a pharmacotherapy context-learning programme. Unpublished PhD Dissertation, VU University Amsterdam, Amsterdam.

Waterston S.W. \& Stewart I.J. (2005). Survey of clinicians' attitudes to the anatomical teaching and knowledge of medical students. Clin Anat, 18(5): 380-384.

Whitcomb M.E. (2006). The teaching of basic sciences in medical schools. Acad Med, 81(5): 413-414.

Woloschuk W., Mandin H., Harasym P., Lorscheider F. \& Brant R. (2004). Retention of basic science knowledge: a comparison between body system-based and clinical presentation curricula. Teach Learn Med, 16(2): 116-122.

Woodward C.A. \& Ferrier B.M. (1983). The content of the medical curriculum at McMaster University: graduates' evaluation of their preparation for postgraduate training. Med Educ, 17(1): 54-60. 


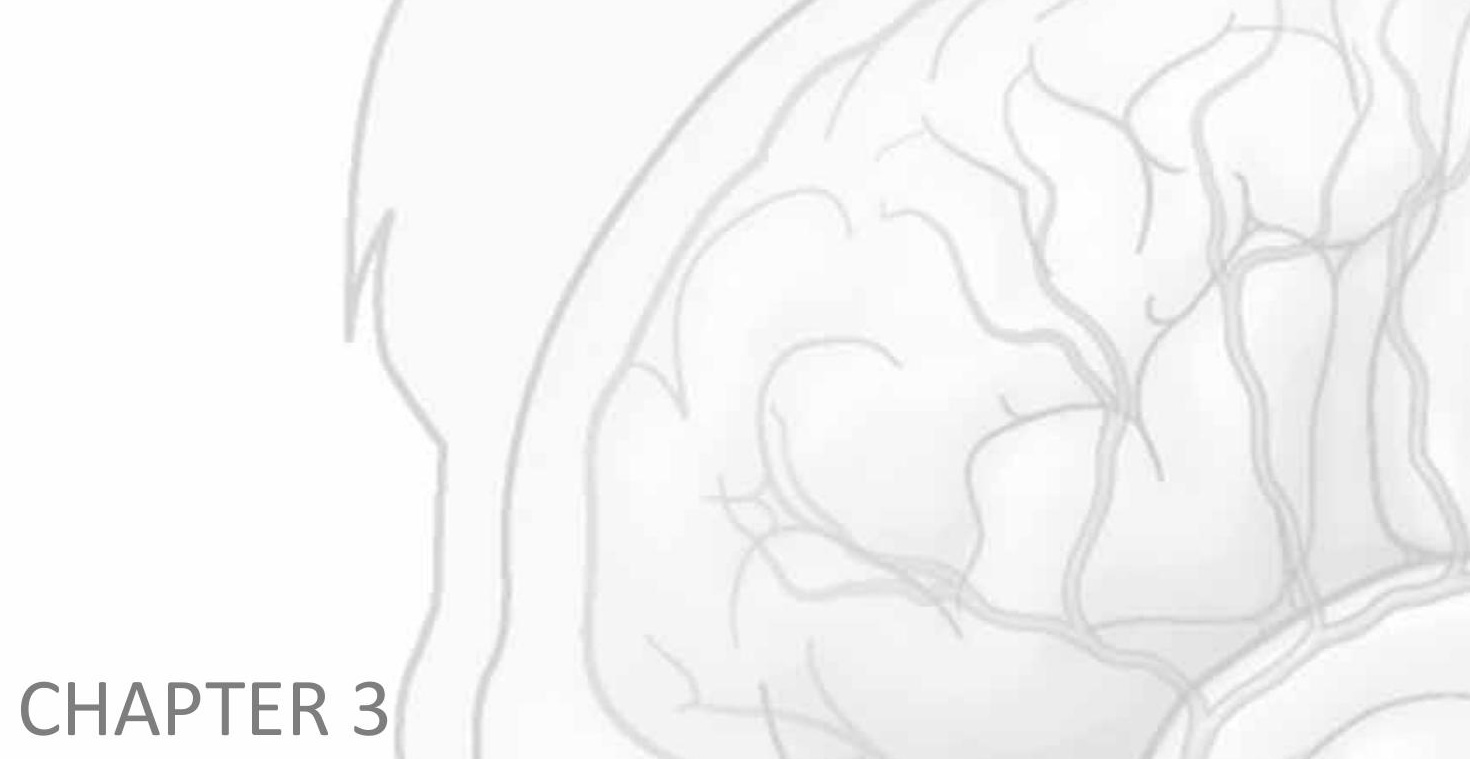

\section{Why don't they know enough about anatomy? A narrative review}

Bergman EM, Van der Vleuten CPM and Scherpbier AJJA (2011). Why don't they know enough about anatomy? A narrative review. Medical Teacher, 33(5): 403-409 


\section{ABSTRACT}

\section{Background}

Publications in a variety of journals have described the problem of medical students' decreasing anatomical knowledge. Interestingly, the number of people making this assertion is growing, despite a lack of empirical evidence that today's medical graduates actually know less about anatomy than medical students in the past. Nevertheless, many people are claiming that students' anatomical knowledge is impaired due to negative effects from several factors, including teaching by nonmedically qualified teachers, diminished use of cadaver dissection as a teaching tool and neglect of vertical integration of anatomy teaching.

\section{Aim}

To find empirical evidence for the factors claimed to have an influence on anatomical knowledge of students.

\section{Method}

A literature search.

Results

There is a lack of sufficient quantity and quality of information within the existing literature to support any of the claims, but the gathered literature did reveal some fascinating insights which are discussed.

\section{Conclusion}

Anatomy education should be made as effective as possible, as nobody will deny that medical students cannot do without anatomical knowledge. Because of promising findings in the areas of teaching in context, vertical integration and assessment strategies, it is recommended that future research into anatomy education should focus on these factors. 


\section{INTRODUCTION}

"For doctors, the human body is the focus of investigation and intervention on a daily basis" [page 104] (Turney 2007). Both anatomists and clinicians agree that accurate knowledge of anatomy and individual variations is vital to ensure safe and efficient clinical practice. It also underpins the development and retention of clinical knowledge and skills (Dangerfield et al. 2000; Fasel et al. 2005; Raftery 2006). It is therefore worrying that publications in diverse journals have highlighted the problem of decreased anatomical knowledge of today's medical students, which, in a worst case scenario, might lead to medical errors. Despite the absence of empirical evidence for the existence of this problem, it is persistently emphasised by authors who lay the blame for it on one or more of the following factors:

\section{- Anatomy is taught by non-medically qualified teachers}

Anatomy is increasingly taught by staff with nonmedical backgrounds, who may lack insight into the reasons why a subject is taught or why it is relevant from a clinical perspective.

- The absence of a core anatomy curriculum

In order to fit the anatomy curriculum into the available time, in some cases, all aspects of anatomy were pruned, irrespective of vocational relevance. This included deleting specific body regions, embryology and/or histology from the educational programme.

- Decreased use of dissection as a teaching tool

Anatomy teaching by the time-honoured method of cadaveric dissection is decreasing, mostly due to time and/or money constraints.

- Anatomy is not taught in context

Anatomy should be taught within relevant contexts, such as clinical skills, pathology or radiology.

- Integrated curricula (problem-based learning or systems-based curricula)

In integrated curricula, basic and clinical sciences are taught simultaneously (horizontal integration), with clinical sciences being introduced in the early years while continued attention is being paid to basic sciences in the later years of the curriculum (vertical integration). Additionally, many medical schools with integrated curricula have abandoned formal basic science teaching and instead stimulate students to explore these areas through 'self-directed learning', supervised by (non-medical) facilitators. Within these curricula, anatomy is likely to be taught piecemeal, and it is claimed that students no longer gain a coherent, overall picture of the anatomy of the whole body.

- The way anatomical knowledge is assessed

For practical reasons, anatomical knowledge is increasingly assessed by multiple 
choice type questions, wherein good 'power-test takers' often do well through their ingenuity in eliminating distracter items (Cahill and Leonard 1999). What is also considered alarming is elimination of the requirement of minimal competence in each of the disciplines tested.

- Decrease in anatomy teaching time

The multitude of subjects and competencies to be taught in the undergraduate medical curriculum has diminished the amount of time available for anatomy education.

- Neglect of vertical integration of anatomy teaching

Vertical integration within curricula is often unidirectional. Whilst clinical topics are integrated in the early years of the medical curriculum (traditionally the time slot for basic science teaching like anatomy), it is perceived to be far less common for basic sciences to be taught in the later years of the curriculum.

The above factors were extracted from 32 articles (see Table 3.1 in appendix 1) published after 1990 (29 different first authors, nine of which held their primary posts in an anatomy department). The articles were published in educational, anatomical, surgical or radiological journals, but also in general medical journals such as the British Medical Journal and The Lancet. Most articles were retrieved by a search for keywords in the title, others by scrutinising references of relevant articles; they were mostly published as an editorial, letter/correspondence, commentary, essay or matter for debate and generally contained very little information to underpin the statements that were made. Considering the serious implications of the claim that anatomical knowledge is being eroded as well as the current lack of firm evidence to support it, we investigated whether the claim holds some truth and, if so, which factors influence it. The eight factors listed above served as the starting point for a review aimed at identifying empirical evidence to support, and help deal with, their negative effects. After describing the methods of our systematic literature search, we discuss what the review revealed in relation to each factor. Finally, we discuss the findings and present conclusions with recommendations for further research.

\section{METHODS}

Keywords were selected for each factor and used to search Pubmed and Medline. All searches were limited by language (English, Dutch and German) and publication date (1950 - 2007). The titles and abstracts of the retrieved articles were screened, after which the full text of potentially relevant articles was printed and read. Next, a reference search of these relevant articles was performed (Figure 3.1 shows a search 
flow profile). Studies conducted among students of disciplines other than medicine (e.g. physiotherapy, radiology, dentistry, veterinary medicine, occupational therapy or nursing) were excluded.

\section{THE INFLUENCE OF TEACHING OF ANATOMY BY NON-MEDICALLY QUALIFIED TEACHERS}

The argument that anatomical knowledge is negatively influenced when it is taught by non-medically qualified staff raises two questions: 1 ) is it true that anatomy is increasingly taught by non-medically qualified staff and 2) if so, does this affect students' anatomical knowledge? There does seem to be a trend throughout the world for anatomy to be increasingly taught by non-medically qualified teaching staff (see Table 3.2 in appendix 1). The most convincing data to support this were published by Pryde \& Black (2005)), who revealed that between 1983/1984 and 2003/2004, the percentage of medically qualified anatomy teachers in the five medical faculties of Scotland decreased from $56 \%$ to $41 \%$. Furthermore, some studies reported that medically qualified anatomy teachers were generally older than their non-medically qualified colleagues. Van Mameren (2004) showed for example that only 38\% of anatomy teachers in the eight medical faculties of The Netherlands were medically qualified and that of this percentage more than three quarters were aged 50 years or older. This suggests replacement of older, medically qualified, by younger, nonmedically qualified, teachers, who may be appointed for other qualities than their medical knowledge. Unfortunately, none of the studies we reviewed examined if there was a connection between the qualifications of teaching staff and students' knowledge of anatomy; so, question two remains unanswered.

An argument that is frequently put forward in discussions on the qualifications of anatomy teaching staff is that researchers and clinicians are only interested in teaching (at the frontier of knowledge) in their particular areas of expertise, which does not help students to build a solid knowledge base. Halasz (1999) proposed the following interesting solution: "What are the alternatives? For one, we can get the competent non-specialist to teach. A person who knows what is broadly important and applicable is much better able to instruct a student than the super-specialist who, in his or her very expertise, often lacks perspective" [page 6]. Competent is the operative word in this citation. For, based on the assumption that students' knowledge is strongly influenced by 'who teaches', qualifications may be relevant but not necessarily decisive for the quality of teaching. For example, individual teachers' enthusiasm for 


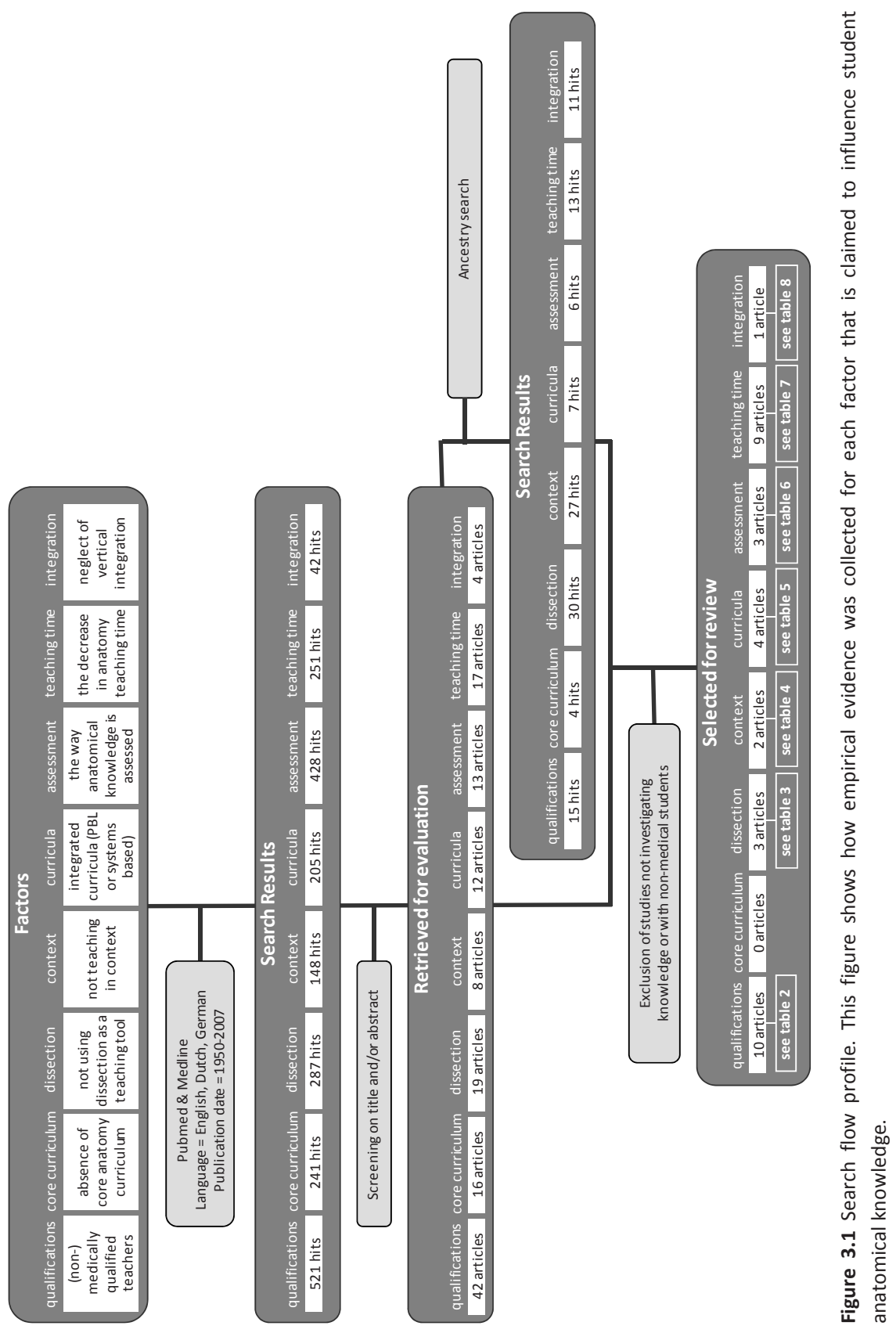


teaching and didactic abilities may carry much more weight than their professional background.

Another interesting, but very different, aspect is student-staff ratios, which were reported in some articles on anatomy teaching staff. Pryde \& Black (2005) found that between $1983 / 1984$ and $2003 / 2004$, student-staff ratios in the five medical faculties in Scotland increased from 20:1 to 58:1. In other words, by 2004, the number of students per teacher had more than doubled! One may wonder whether decreasing (or at best stable) staff numbers and increasing student numbers (resulting in for example less time to assist individual students with difficult subjects) may have had a negative impact on students' knowledge of anatomy. It seems worthwhile to conduct further research to establish the severity of this problem and look for ways to deal with it, such as the use of peer-to-peer teaching methods.

\section{THE INFLUENCE OF THE ABSENCE OF A (NATIONAL) CORE ANATOMY CURRICULUM}

In some countries, medical schools are subject to inspection by external regulators (for example the General Medical Council in the UK) to ensure a high quality of education. Guidelines from these regulators are unfortunately "fairly non-specific concerning the factual knowledge expected of graduates but are fairly comprehensive with regard to the requirements for clinical, generic and attitudinal skills" [page 231] (Bradley 2001). In order to overcome this problem, some authors have created a list of anatomical structures that students should know, in an attempt to define a core anatomy curriculum (Leonard et al. 1996; Griffioen et al. 1999; McHanwell 2007). However, there is little agreement among authors on the content of such lists and authors do not define the depth of the required knowledge (e.g. for a muscle: to be able to recognize the muscle in the human body, know attachment sites, innervations, function, variations, etc.). Some researchers have asked students in different stages of the undergraduate curriculum (Moxham and Plaisant 2007) or after finishing their studies (Richardson 1983; Cottam 1999) whether they thought the contents of their anatomy course were of sufficient clinical relevance. While concurring to a certain degree, students also showed considerable differences of opinion on and between specific subjects.

Unfortunately, none of the articles we reviewed reported a study investigating (the absence of) a core curriculum and its effect on anatomical knowledge. Most articles in which reference was made to a core anatomy curriculum reported that the content of an anatomy course/curriculum was debated (Evans \& Watt (2005): "[...] the anatomy staff have used their collective experience in conjunction with discussion and input from clinical colleagues across a range of disciplines" [page 23]) but did not 
describe the outcome of this debate (e.g. a list of structures), let alone any effect on students' knowledge. Extensive descriptions of anatomy course content are limited to articles dealing with postgraduate specialist training (MacLean et al. 1996; Kilroy and Driscoll 2006).

If a national core anatomy curriculum were in place, teachers (basic science and clinical) would know what students were expected to learn and it would help students to attain that knowledge. Although getting anatomists and clinicians to agree upon a core curriculum may seem a daunting task (see studies of Koens et al. (2005b; 2006)), it is probably not an unattainable goal. An important contribution to this discussion is the recent publication of 'AMEE Guide no 41. The place of anatomy in medical education' (Louw et al. 2009), which describes an ideal course which is 'principle based and problem oriented'. The authors focus on the definition of and distinction between 'general' and 'specific' anatomies, and how these can be taught by using different teaching methods, learning materials and assessment programmes.

\section{THE INFLUENCE OF NOT USING DISSECTION AS A TEACHING TOOL IN ANATOMY EDUCATION}

The teaching tools used in anatomy education can roughly be divided into five categories: 1) cadaver related, 2) clinically related, 3) computer/internet related, 4) other material related (e.g. models or books) and 5) other (e.g. lectures, practical classes or problem-based learning; PBL tutorials). Winkelmann (2007) conducted an extensive review study, comparing how dissection of a cadaver by students and the use of prosections (cadavers previously dissected by others) affected students' anatomical knowledge. Although comparison was hindered by the fact that the studies included in the review differed in more than one variable, traditional dissection appeared to offer a slight added benefit compared to prosections. In this review, we included only articles in which dissection by students was compared to teaching tool other than prosections. Although not straightforward, the results again seem to be slightly in favour of dissection. More importantly, however, a combination of teaching tools appeared to yield the best performances (see Table 3.3 in appendix 1). Biasutto et al. (2006), for example, found better results for students who only dissected cadavers compared to students who only used computer resources, but reported that the best scores were found in the group of students who learnt by both dissection and the use of computer resources.

The inconclusive findings concerning the influence of different anatomy teaching tools on student knowledge may be related to the fact that tools like computer models are more helpful in learning complex anatomical structures (e.g. the inner ear, bones 
of the skull or the brain). Students may get a better understanding of complex structures from 3D computer models, which enable zooming and rotation, whereas less complex structures (e.g. abdominal organs) can easily be studied from a textbook or cadaveric material. An interesting finding in this respect is that medical staff (both anatomists and clinicians) seems to want to keep dissection as a teaching tool (Patel and Moxham 2006), whereas students do not always rate dissection as the most useful tool for learning anatomy (Nnodim 1988; Dinsmore et al. 1999; Azer and Eizenberg 2007). Furthermore, recent research has shown that a dissection course is not a uniform learning experience (Winkelmann et al. 2007). Different students may very well have different approaches in dealing with a dissection course (or other teaching methods for that matter), therefore undergoing divergent learning experiences, which may result in difference in amount and form of knowledge between individual students.

While human cadaver dissection may seem to be on the way out in undergraduate medical education (substituted by other teaching tools), it is definitely gaining popularity in postgraduate training (Wong and Stewart 2004). Authors advocating the use of dissection in undergraduate education frequently mention its benefits for other learning objectives besides anatomical knowledge, such as professionalism, manual dexterity, teamwork, self- and peerevaluation, ethics, etc. (Aziz et al. 2002; Rizzolo 2002; Gregory et al. 2009).

Last but not least, results from Erkonen et al. (1992) and Stanford et al. (1994) could indicate that different teaching tools aid students in learning different knowledge, as the studies showed that whether learning anatomy from computed tomography (CT) images or cadaver had different effects on test questions using CT images or cadavers $(p<0.0001)$. This is in agreement with results of Biasutto et al. (2006) mentioned above. Based on these considerations, we would recommend that future research should concentrate on what and how students learn from dissection and other teaching tools before drawing conclusions in favour of the either method.

\section{THE INFLUENCE OF NOT TEACHING ANATOMY IN CONTEXT}

Interestingly, teaching in context is not a new argument; in fact, it was advocated more than a century ago: "One lecture [...] by a good anatomist [...] who is neither ignorant nor careless of the work of a surgeon, or the duties of a physician, on a good welldeveloped living subject, would do more real good than six months' lectures on minute anatomy [...]" [page 545] (Prosser 1868). The contexts that are commonly used in anatomy teaching can be roughly divided into four categories: 1) clinical skills (physical examination), 2) pathology (e.g. cancer, neurological diseases, musculoskeletal 
problems), 3) radiology (e.g. interpreting X-rays, CT, ultrasound) and 4) surgical procedures (e.g. appendectomy or endoscopic/laparoscopic procedures). In many studies, students reported more positive attitudes/perceptions in relation to a course teaching anatomy in context than in relation to traditional course formats (Fitzpatrick et al. 2001). A few studies have compared students' anatomical knowledge before and after a course in which anatomy was taught in context (see Table 3.4 in appendix 1). Unsurprisingly, students knew more after the course than they did before it, but the study methods used preclude any firm conclusions as to whether this was due to teaching in context or to course attendance irrespective of teaching method (more time spent learning leads to more knowledge). Our literature search yielded not one study comparing the results of teaching anatomy within and out of context.

Studies by Koens et al. (2003; 2005a) showed that creating a context that actually facilitates learning, retention and transfer of knowledge is not as straightforward as is often thought. To reach those goals, creating a context may have to go much further than, for example, introducing a CT scan to facilitate the learning of the anatomy of the abdomen. Currently, we do not yet fully understand all the (im)possibilities of teaching (anatomy) in context.

\section{THE INFLUENCE OF INTEGRATED CURRICULA (PROBLEM-BASED LEARNING OR SYSTEMS-BASED CURRICULUM)}

A meta-analysis examining the effectiveness of problem-based learning ( $P B L$ ), conducted in 1993 by Vernon \& Blake (1993), reported that: "PBL was found to be significantly superior with respect to students' programme evaluations (i.e. students' attitudes and opinions about their programmes) [...] and measures of students' clinical performance [...]. PBL and traditional methods did not differ on miscellaneous tests of factual knowledge [...] and tests of clinical knowledge [...]" [page 550]. Two more recent meta-analysis show similar results (Colliver 2000; Newman 2003).

Studies that specifically address the influence of PBL and systems-based curricula on anatomical knowledge are few (see Table 3.5 in appendix 1). Their results show no clear benefits or drawbacks of integrated curricula compared to traditional ones. Studies examining the difference in basic science knowledge (including anatomy) between students in different curricula (Alleyne et al. 2002; Woloschuk et al. 2004) were also inconclusive.

The available evidence, or lack of it, shows that the effect of innovative curricula on anatomical knowledge remains to be ascertained, although it is doubtful whether this will ever be done conclusively. On a slightly differing note, the authors of a curriculum comparison study (Prince et al. 2003) suggested that the educational 
approach underpinning a curriculum may not be the strongest determinant of students' anatomical knowledge. This observation was prompted by results showing that better scores in anatomical knowledge appeared to be related to whether anatomical aspects were revisited during the course of the undergraduate curriculum. The amount of time devoted to anatomy teaching, repetition and teaching in context may have a much stronger impact than whether or not a school has an integrated or a traditional curriculum. However, further research will have to provide evidence to underpin this notion.

\section{THE INFLUENCE OF THE WAY ANATOMICAL KNOWLEDGE IS ASSESSED}

Many articles describe different ways to assess students' anatomical knowledge. Frequently used methods are: 1) multiple choice questions (MCQs), 2) short answer questions, 3) essay questions, 4) identifying structures in a picture or cadaver (either MCQ or short answer) and 5) drawing structures. Tests can be of the pen and paper type, computer based or oral. Research has shown that MCQs and open questions are equally effective in assessing students' knowledge at the time of the test, in other words, both types of question discriminate between the 'good' and the 'bad' students, despite some exceptions relating to individual students (Barnett 1960).

When we searched the literature for this review, we were surprised to note that most of the articles on assessment methods in anatomy education dated from the period 1960-1980. Furthermore, our search revealed only three articles comparing different methods for assessing anatomical knowledge (see Table 3.6 in appendix 1). The results seem to indicate that the sole use of MCQs and/or the lack of a minimal requirement for each tested discipline have indeed a negative effect on students' study behaviour and retention of knowledge. This seems consistent with other research outside health-related education (Sax and Collett 1968; Gill et al. 1978; Gay 1980).

\section{The influence of decreased time for anatomy education}

As with the influence of non-medically qualified teachers, the supposed negative effects of reduced teaching time raise two questions: 1 ) has teaching time for anatomy actually decreased and 2) if so, has this affected students' anatomical knowledge? The review offers an answer to the first question only (see Table 3.7 in appendix 1). Designated teaching time for anatomy did, in fact, decrease during the past decades. For example, mean total teaching time (including lectures, practical sessions and 
tutorials) for gross anatomy at five medical schools in Scotland decreased from 382 hours in $1983 / 1984$ to 151 hours in $2003 / 2004$, a reduction by more than $50 \%$ ! This is all the more interesting in light of findings in the same institutions during the same period, showing a more than $50 \%$ rise in student-staff ratios (Pryde and Black 2005).

In the absence of studies linking teaching time to knowledge results, question two again has to remain unanswered. Those undertaking further research on this subject are advised to consider the following possibility. When decreases in teaching time are calculated, time is usually measured as the number of hours (either lecture or laboratory time) of teacher-student contact. What is generally ignored is the possibility that a decrease of contact hours does not automatically imply that students spend less time learning anatomy. The decrease in contact hours may be counterbalanced by more self-study time. So, in order to gain a realistic insight into how much time students devote to learning anatomy, it is important to also look at time for self-study, especially in curricula with a self-directed learning approach.

\section{THE INFLUENCE OF NEGLECT OF VERTICAL INTEGRATION OF ANATOMY EDUCATION}

We found only one article investigating anatomy education in the later, traditionally clinical, years of the undergraduate curriculum and its effects on students' anatomical knowledge (see Table 3.8 in appendix 1). Again, the methods used preclude conclusions regarding the attribution of reported improved knowledge to vertical integration or to the mere fact that a course was offered.

There is a scarcity of articles on vertical integration of anatomy (only 42 articles in the systematic literature search, less than one-third of the number of articles on the other factors). Few researchers have investigated how anatomy was vertically integrated in a curriculum (Evans and Watt 2005), how this was achieved, why vertical integration is important, or how it affects the perceptions/attitudes of medical students concerning anatomy education (Brynhildsen et al. 2002). This paucity of studies is surprising, since vertical integration of anatomy is greatly desired (Waterston and Stewart 2005) and considered helpful in solving several issues: 1) it increases teaching time, 2) teaching can be a collaborative effort of basic science experts and clinicians (increasing the clinical relevance of what is taught), 3) it promotes repetition in teaching and learning and 4) it offers increased opportunities for teaching in context (e.g. teaching the anatomy that is relevant to a specific clinical rotation). Further research on vertical integration of anatomy education is therefore strongly recommended. 


\section{DISCUSSION AND CONCLUSION}

The results of this narrative review reveal a scarcity of studies dealing with the factors identified as potentially influencing anatomical knowledge. In addition, the studies we did find were lacking in methodological quality. Consequently, the review offers no basis for firm conclusions, and only conflicting conclusions at best. In other words, there appears to be a lack of empirical evidence to support the claimed influence of any of the proposed factors. One may wonder why this should be so.

A first explanation might be that the assumed deterioration of anatomical knowledge levels is a perception arising from generation conflict. This interpretation is supported by the fact that complaints of declining anatomical knowledge were also heard in decades preceding the period we studied (Taylor and Wilson 1975). It is not uncommon for a generation to complain that younger generations are less capable of many things, whether it be driving a car, saving money, maintaining relationships, doing arithmetic or reproducing anatomical knowledge. Although this may seem a plausible explanation at first sight, things are probably far more complex. All the studies we found examined only one factor, but it may well be the case that, in practice, a combination of factors is at stake in the actual or perceived decline of students' anatomical knowledge. And, it is equally likely that the crucial factors are others than the ones we examined. It may, for instance, be fruitful to explore the influence of different student-staff ratios.

Whether or not students' anatomical knowledge is decreasing, and whether or not this will endanger doctors' professional performance, it remains highly relevant to identify factors that play a role in the acquisition of anatomical knowledge. There is a general consensus that medical students definitely cannot do without anatomical knowledge, and consequently without anatomy education, although opinions may differ as to its scope. However, in medical education today, the key question regarding anatomy education increasingly focuses on how education can be made as effective as possible. Following are some considerations which may give direction in the search of an answer to this question.

An interesting theme within educational research on teaching in context is the notion of 'transfer': using a concept learnt in one context to solve a problem in a different context. "Stories of medical students who have learnt the basic science, passed the examinations, but were then unable to apply this knowledge to solve or explain problems, are commonplace. Typically, this dissociation is viewed as an issue of learning out of context, and proposed solutions attempt to integrate the basic science better with the clinical problems" [page 808] (Norman 2009). Creating an adequate context to teach in (as described earlier), but also retrieving a learnt concept to solve a new problem are more difficult than one might think (Norman 2009). However, results 
reported by Woods et al. (2005, 2007a, 2007b) indicate that teaching in context aids retention of basic science and clinical knowledge, diagnostic reasoning and correct clinical diagnosis ('transfer'). Thus, teaching in context may not only increase anatomical knowledge but also improve its application in problem solving.

An issue concerning assessment of basic science knowledge that every teacher should be aware of is dealt with by Swanson and Case (1997): "The amount of material to be learned in a typical basic science course is overwhelming, and students must make choices of what to study. Because medical students are highly motivated and academically strong, they want to perform well on tests, and they look to tests for guidance on what material is worth studying. To the extent that tests are congruent with major course goals, the tests will appropriately communicate what should be learnt. To the extent that there is a mismatch between course goals and tests, assessment may well focus student preparation and learning in unfortunate directions" [page 74]. In a recently published overview of cognitive psychology research on the relationship between learning and assessment, Larsen et al. (2008) suggest that choosing a method of assessment should depend on the goal of the assessment, although further research is needed to confirm this. If the goal is to measure factual knowledge at the moment the test is taken and to distinguish the 'good' from the 'bad' students, there are no limitations to the use of MCQs. If there are other goals as well, such as to stimulate study behaviour, improve retention of knowledge and/or measure ability to apply knowledge in problem-solving, other assessment methods are probably preferable. Swanson and Case (1997) seem to agree with this when they write: "Clearly, in order to encourage learning for understanding, assessments need to test more than recall of isolated facts. Instead, assessments should focus on application of basic science knowledge, often to clinical situations, and on integration of knowledge across topics and courses to achieve a coordinated, crossdisciplinary understanding of those situations. [...] Research on assessment must directly consider the likely impact that alternate assessment plans (including content and frequency as well as method) will have on student learning activities and outcomes" [page 74].

Last but not least, one might want to know what students think of their anatomical knowledge. As the perceptions of anatomists and clinicians about their knowledge might be inaccurate, there are indications that students are even more severe in their judgement of their anatomical knowledge (Prince et al. 2005), although it is not clear why students should place such high demands on anatomical knowledge. However, since students clearly feel strongly about anatomical knowledge, they are also likely to have strong opinions concerning factors influencing that knowledge and may well be able to tell us how they would like to go about in learning their anatomy. A nice example in the direction of the latter is the study of Wilhelmsson et al. (2009), in 
which the approach to learning anatomy of second year medical students is explored by means of individual, semi-structured interviews. More extensive research in the aforementioned areas may shed a different light on, and add pieces to the puzzle of, how to increase the effectiveness of anatomy education.

Based on promising research findings so far, or on prospects of a contribution to more than one area of concern, we propose that research should focus on the following factors: the possibilities of teaching in context, the implementation of vertical integration and the implementation of assessment strategies. Interestingly, anatomy education is probably only a special case of the general effects of these factors. Findings in these areas may well have wider application than anatomy education and extend to all basic and maybe other sciences as well.

\section{Acknowledgements}

The authors thank Ida Smailbegovic and Robbert Duvivier for their assistance in searching the literature and support in brainstorming about the discussion and conclusion sections. 


\section{REFERENCES}

Abu-Hijleh M.F., Chakravarty M., Al-Shboul Q., Kassab S. \& Hamdy H. (2005). Integrating applied anatomy in surgical clerkship in a problem-based learning curriculum. Surgical and Radiologic Anatomy, 27(2): 152-157.

Adibi I., Hasani N., Ashoorioun V., Sadrearhami S. \& Monajemi A.R. (2007). Integrating physical examination and trunk anatomy; a new course for second year medical students. Medical Teacher, 29(9): 975-977.

Alleyne T., Shirley A., Bennett C., Addae J., Walrond E., West S. \& Pinto Pereira L. (2002). Problem-based compared with traditional methods at the Faculty of Medical Sciences, University of the West Indies: a model study. Medical Teacher, 24(3): 273-279.

Auer R.N. \& McDonald D.S. (2003). Anatomy is still essential. Canadian Medical Association Journal, 168(7): 829.

Azer S.A. \& Eizenberg N. (2007). Do we need dissection in an integrated problem-based learning medical course? Perceptions of first- and second-year students. Surgical and Radiologic Anatomy, 29(2): 173180.

Aziz M.A., McKenzie J.C., Wilson J.S., Cowie R.J., Ayeni S.A. \& Dunn B.K. (2002). The human cadaver in the age of biomedical informatics. The Anatomical Record, 269(1): 20-32.

Barnett C.H. (1960). Tests of anatomical knowledge. Lancet, 2(7144): 254-256.

Beaty H.N. (1990). Changes in medical education should not ignore the basic sciences. Academic Medicine, 65(11): 675-676.

Biasutto S.N., Caussa L.I. \& Criado del Rio L.E. (2006). Teaching anatomy: cadavers vs. computers? Annals of Anatomy, 188(2): 187-190.

Blevins C.E. \& Cahill D.R. (1973). Gross anatomy: current courses, training programs, and prospective needs. Journal of Medical Education, 48(3): 264-270.

Bradley P. (2001). Curricular change--cutting anatomy to the core. European Journal of Morphology, 39(4): 231-234.

Brynhildsen J., Dahle L.O., Behrbohm Fallsberg M., Rundquist I. \& Hammar M. (2002). Attitudes among students and teachers on vertical integration between clinical medicine and basic science within a problem-based undergraduate medical curriculum. Medical Teacher, 24(3): 286-288.

Cahill D.R. \& Leonard R.J. (1999). Missteps and masquerade in American medical academe: clinical anatomists call for action. Clinical Anatomy, 12(3): 220-222.

Cahill D.R., Leonard R.J. \& Marks S.C., Jr. (2000). A comment on recent teaching of human anatomy in the United States. Surgical and Radiologic Anatomy, 22(2): 69-71.

Carmichael S.W., Haines D.E. \& Drake R.L. (2002). Education in the anatomical sciences: The common goals of societies. The Anatomical Record, 269(2): 67.

Charlton B. (1991). Anatomy past and present. British Medical Journal, 302(6783): 1001-1002.

Collins (1994). Status of gross anatomy in the US and Canada: Dilemma for the 21st century. Clinical Anatomy.

Colliver J.A. (2000). Effectiveness of problem-based learning curricula: research and theory. Academic Medicine, 75(3): 259-266.

Cottam W.W. (1999). Adequacy of medical school gross anatomy education as perceived by certain postgraduate residency programs and anatomy course directors. Clinical Anatomy, 12(1): 55-65.

Coupland R.E. (1975). Letter: Staffing problems in anatomy. Lancet, 2(7945): 1144.

Dangerfield P., Bradley P. \& Gibbs T. (2000). Learning gross anatomy in a clinical skills course. Clinical Anatomy, 13(6): 444-447.

Dinsmore C.E., Daugherty S. \& Zeitz H.J. (1999). Teaching and learning gross anatomy: dissection, prosection, or "both of the above?". Clinical Anatomy, 12(2): 110-114. 
Drake R.L. (1998). Anatomy education in a changing medical curriculum. The Anatomical Record, 253(1): 2831.

Drake R.L. (2002). Meeting the challenge: the future of the anatomical sciences in medical school curricula. The Anatomical Record, 269(2): 68.

Drake R.L., Lowrie D.J., Jr. \& Prewitt C.M. (2002). Survey of gross anatomy, microscopic anatomy, neuroscience, and embryology courses in medical school curricula in the United States. The Anatomical Record, 269(2): 118-122.

Ellis H. (2002). Medico-legal Litigation and its Links with Surgical Anatomy. Surgery, 20(8): i-ii.

Erkonen W.E., Krachmer M., Cassell M.D., Albanese M.A. \& Stanford W. (1992). Cardiac anatomy instruction by ultrafast computed tomography versus cadaver dissection. Investigative Radiology, 27(9): 744-747.

Evans D.J. \& Watt D.J. (2005). Provision of anatomical teaching in a new British medical school: getting the right mix. Anatomical Record. Part B, New Anatomist, 284(1): 22-27.

Fasel J.H., Morel P. \& Gailloud P. (2005). A survival strategy for anatomy. Lancet, 365(9461): 754.

Fitzgerald T. (1992). Undergraduate medical anatomy teaching. Journal of Anatomy, 181 (Pt 2): 381.

Fitzpatrick C.M., Kolesari G.L. \& Brasel K.J. (2001). Teaching anatomy with surgeons' tools: use of the laparoscope in clinical anatomy. Clinical Anatomy, 14(5): 349-353.

Fraser R.C. (1991). Undergraduate medical education: present state and future needs. British Medical Journal, 303(6793): 41-43.

Gartner L.P. (2003). Anatomical sciences in the allopathic medical school curriculum in the United States between 1967-2001. Clinical Anatomy, 16(5): 434-439.

Gay L. (1980). The comparative effects of multiple-choice versus short-answer tests on retention. Journal of Educational Measurement, 17(1): 45-50.

Gill A.A., Marmo N.A. \& Shuster J.J. (1978). The effectiveness of laboratory vs written examinations in an anatomy course. The American Journal of Occupational Therapy, 32(1): 26-30.

Gregory J.K., Lachman N., Camp C.L., Chen L.P. \& Pawlina W. (2009). Restructuring a basic science course for core competencies: an example from anatomy teaching. Medical Teacher, 31(9): 855-861.

Griffioen F., Drukker J., Hoogland P. \& Godschalk M. (1999). General Plan Anatomy, Objectives of the teaching of anatomy/embryology in medical curricula in the Netherlands. European Journal of Morphology, 37(4-5): 288-325.

Halasz N.A. (1999). We create and can remove the roadblocks to good basic science education. Academic Medicine, 74(1): 6-7.

Hanna S.J. \& Freeston J.E. (2002). Importance of anatomy and dissection: the junior doctor's viewpoint. Clinical Anatomy, 15(5): 377-378.

Heylings D.J. (2002). Anatomy 1999-2000: the curriculum, who teaches it and how? Medical Education, 36(8): 702-710.

Hinduja K., Samuel R. \& Mitchell S. (2005). Problem-based learning: is anatomy a casualty? Surgeon, 3(2): 8487.

Hobsley M. (1976). Assessment of anatomy in the Primary FRCS. Annals of the Royal College of Surgery of England, 58(5): 382-384.

Jones D.G. \& Harris R.J. (1998). Curriculum developments in Australasian anatomy departments. Clinical Anatomy, 11(6): 401-409.

Kaufman M.H. (1997). Anatomy training for surgeons--a personal viewpoint. Journal of the Royal College of Surgeons of Edinburgh, 42(4): 215-216.

Kilroy D. \& Driscoll P. (2006). Determination of required anatomical knowledge for clinical practice in emergency medicine: national curriculum planning using a modified Delphi technique. Emergency Medicine Journal 23(9): 693-696.

Koens F., Custers E.J. \& ten Cate O.T. (2006). Clinical and basic science teachers' opinions about the required depth of biomedical knowledge for medical students. Medical Teacher, 28(3): 234-238. 
Koens F., Mann K.V., Custers E.J. \& Ten Cate O.T. (2005a). Analysing the concept of context in medical education. Medical Education, 39(12): 1243-1249.

Koens F., Rademakers J.J. \& Ten Cate O.T. (2005b). Validation of core medical knowledge by postgraduates and specialists. Medical Education, 39(9): 911-917.

Koens F., Ten Cate O.T. \& Custers E.J. (2003). Context-dependent memory in a meaningful environment for medical education: in the classroom and at the bedside. Advances in Health Sciences Education: Theory and Practice, 8(2): 155-165.

Krackov S.K., Preston W. \& Rubin P. (1990). Effects of an oncology elective on first-year medical students' knowledge and attitudes about cancer. Journal of Cancer Education, 5(1): 43-49.

Larsen D.P., Butler A.C. \& Roediger H.L., 3rd (2008). Test-enhanced learning in medical education. Medical Education, 42(10): 959-966.

Leonard R.J., Acland R., Aguyr A., Blevins C., DR C., Collins J., Dalley A.F., Dolph J., Hagedoorn J., Hoos P., Jones D., Mathers L., McFee R., Mennin S.P., Negulesco J., Nelson M., Olson T., Page D., Pawlina W., Petterborg L., Price J., Spielman J. \& Younoszai R. (1996). A clinical anatomy curriculum for the medical student of the 21st century: Gross anatomy. Clinical Anatomy, 9: 71-99.

Louw G., Eizenberg N. \& Carmichael S.W. (2009). The place of anatomy in medical education: AMEE Guide no 41. Medical Teacher, 31(5): 373-386.

Lukic I.K., Gluncic V., Katavic V., Petanjek Z., Jalsovec D. \& Marusic A. (2001). Weekly quizzes in extendedmatching format as a means of monitoring students' progress in gross anatomy. Annals of Anatomy, 183(6): 575-579.

Macchi V., Munari P.F., Ninfo V., Parenti A. \& De Caro R. (2003). A short course of dissection for second-year medical students at the School of Medicine of Padova. Surgical and Radiologic Anatomy, 25(2): 132138.

MacLean T.A., Wagner M.J. \& Nagy F. (1996). Clinical anatomy: a review course for emergency medicine residents. Journal of Emergency Medicine, 14(3): 383-387.

McCrorie P. (2000). The place of the basic sciences in medical curricula. Medical Education, 34(8): 594-595.

McHanwell (2007). A Core Syllabus in Anatomy dor MedicalStudents - adding common sense to need to know. European Journal of Anatomy, 11: 15.

McKeown P.P., Heylings D.J., Stevenson M., McKelvey K.J., Nixon J.R. \& McCluskey D.R. (2003). The impact of curricular change on medical students' knowledge of anatomy. Medical Education, 37(11): 954-961.

Monkhouse W.S. (1992). Anatomy and the medical school curriculum. Lancet, 340(8823): 834-835.

Monkhouse W.S. \& Farrell T.B. (1999). Tomorrow's doctors: today's mistakes? Clinical Anatomy, 12(2): 131134.

Moqattash S., Harris P.F., Gumaa K.A. \& Abu-Hijleh M.F. (1995). Assessment of basic medical sciences in an integrated systems-based curriculum. Clinical Anatomy, 8(2): 139-147.

Moxham B.J. \& Plaisant O. (2007). Perception of medical students towards the clinical relevance of anatomy. Clinical Anatomy, 20(5): 560-564.

Newman M. (2003). A pilot systematic review and meta-analysis on the effectiveness of problem based learning. Newcastle: Learning \& Teaching Subject Network for Medicine, Dentistry and Veterinary Medicine.

Nnodim J.O. (1988). Learning human anatomy: student preferences of methods in a Nigerian medical school. Medical Education, 22(5): 412-417.

Norman G. (2007). How basic is basic science? Advances in Health Sciences Education: Theory and Practice, 12(4): 401-403.

Norman G. (2009). Teaching basic science to optimize transfer. Medical Teacher, 31(9): 807-811.

Older J. (2004). Anatomy: a must for teaching the next generation. Surgeon, 2(2): 79-90.

Paalman M.H. (2000). Why teach anatomy? Anatomists respond. The Anatomical Record, 261(1): 1-2.

Pabst R. (1992). Teaching of anatomy. Lancet, 340(8833): 1474. 
Pabst R. (1994). Teaching gross anatomy: an important topic for anatomical congresses and journals? Surgical and Radiologic Anatomy, 16(1): 1-2.

Park A., Schwartz R.W., Witzke D.B., Roth J.S., Mastrangelo M., Birch D.W., Jennings C.D., Lee E.Y. \& Hoskins J. (2001). A pilot study of new approaches to teaching anatomy and pathology. Surgical Endoscopy, 15(3): 245-250.

Patel K.M. \& Moxham B.J. (2006). Attitudes of professional anatomists to curricular change. Clinical Anatomy, 19(2): 132-141.

Prince K.J., Scherpbier A.J.A.A., van Mameren H., Drukker J. \& van der Vleuten C.P.M. (2005). Do students have sufficient knowledge of clinical anatomy? Medical Education, 39(3): 326-332.

Prince K.J., van Mameren H., Hylkema N., Drukker J., Scherpbier A.J. \& van der Vleuten C.P. (2003). Does problem-based learning lead to deficiencies in basic science knowledge? An empirical case on anatomy. Medical Education, 37(1): 15-21.

Prosser R. (1868). Practical teaching of anatomy and surgery. Lancet, 92(2356): 545-1155.

Pryde F.R. \& Black S.M. (2005). Anatomy in Scotland: 20 years of change. Scottish Medical Journal, 50(3): 9698.

Purkayastha S., Paraskevas P. \& Darzi A. (2007). Make surgeons more active in teaching anatomy at all levels. British Medical Journal, 334(7585): 110.

Raftery A. (2006). Anatomy teaching in the UK. Surgery, 25(1): 1-2.

Reidenberg J.S. \& Laitman J.T. (2002). The new face of gross anatomy. The Anatomical Record, 269(2): 81-88.

Richardson I.M. (1983). Consumer views on the medical curriculum: a retrospective study of Aberdeen graduates. Medical Education, 17(1): 8-10.

Rizzolo L.J. (2002). Human dissection: an approach to interweaving the traditional and humanistic goals of medical education. The Anatomical Record, 269(6): 242-248.

Sax G. \& Collett L.S. (1968). An empirical comparison of the effects of recall and multiple-choice tests on student achievement. Journal of Educational Measurement, 5(2): 169-173.

Scott T.M. (1993). How we teach anatomy efficiently and effectively. Medical Teacher, 15(1): 67-75.

Smith J.A. (2005). Can anatomy teaching make a come back? ANZ Journal of Surgery, 75(3): 93.

Sritharan K. (2005). The rise and fall of anatomy. British Medical Journal.

Stanford W., Erkonen W.E., Cassell M.D., Moran B.D., Easley G., Carris R.L. \& Albanese M.A. (1994). Evaluation of a computer-based program for teaching cardiac anatomy. Investigative Radiology, 29(2): 248-252.

Swanson D.B. \& Case S.M. (1997). Assessment in Basic Science Instruction: Directions for Practice and Research. Advances in Health Sciences Education, 2: 71-84.

Taylor J.R. \& Wilson A.S. (1975). Letter: Prognosis for anatomy. Lancet, 1(7920): 1334.

Turney B.W. (2007). Anatomy in a modern medical curriculum. Annals of the Royal College of Surgery of England, 89(2): 104-107.

Van Engelshoven J.M.A. \& Wilmink J.T. (2001). Teaching Anatomy; a Clinicians View. European Journal of Morphology, 39(4): 235-236.

Van Mameren H. (2004). Source of future teachers of anatomy. Anatomical Record. Part B, New Anatomist, 280(1): 4-5.

Vernon D.T. \& Blake R.L. (1993). Does problem-based learning work? A meta-analysis of evaluative research. Academic Medicine, 68(7): 550-563.

Waterston S.W. \& Stewart I.J. (2005). Survey of clinicians' attitudes to the anatomical teaching and knowledge of medical students. Clinical Anatomy, 18(5): 380-384.

Whitcomb M.E. (2006). The teaching of basic sciences in medical schools. Academic Medicine, 81(5): 413414.

Wilhelmsson N., Dahlgren L.O., Hult H., Scheja M., Lonka K. \& Josephson A. (2009). The anatomy of learning anatomy. Advances in Health Sciences Education: Theory and Practice. 
Williams G. \& Lau A. (2004). Reform of undergraduate medical teaching in the United Kingdom: a triumph of evangelism over common sense. British Medical Journal, 329(7457): 92-94.

Winkelmann A. (2007). Anatomical dissection as a teaching method in medical school: a review of the evidence. Medical Education, 41(1): 15-22.

Winkelmann A., Hendrix S. \& Kiessling C. (2007). What do students actually do during a dissection course? First steps towards understanding a complex learning experience. Academic Medicine, 82(10): 989995.

Woloschuk W., Mandin H., Harasym P., Lorscheider F. \& Brant R. (2004). Retention of basic science knowledge: a comparison between body system-based and clinical presentation curricula. Teaching and Learning in Medicine, 16(2): 116-122.

Wong K. \& Stewart F. (2004). Competency-based training of basic trainees using human cadavers. ANZ Journal of Surgery, 74(8): 639-642.

Woods N.N., Brooks L.R. \& Norman G.R. (2005). The value of basic science in clinical diagnosis: creating coherence among signs and symptoms. Medical Education, 39(1): 107-112.

Woods N.N., Brooks L.R. \& Norman G.R. (2007a). It all make sense: biomedical knowledge, causal connections and memory in the novice diagnostician. Advances in Health Sciences Education: Theory and Practice, 12(4): 405-415.

Woods N.N., Brooks L.R. \& Norman G.R. (2007b). The role of biomedical knowledge in diagnosis of difficult clinical cases. Advances in Health Sciences Education: Theory and Practice, 12(4): 417-426. 


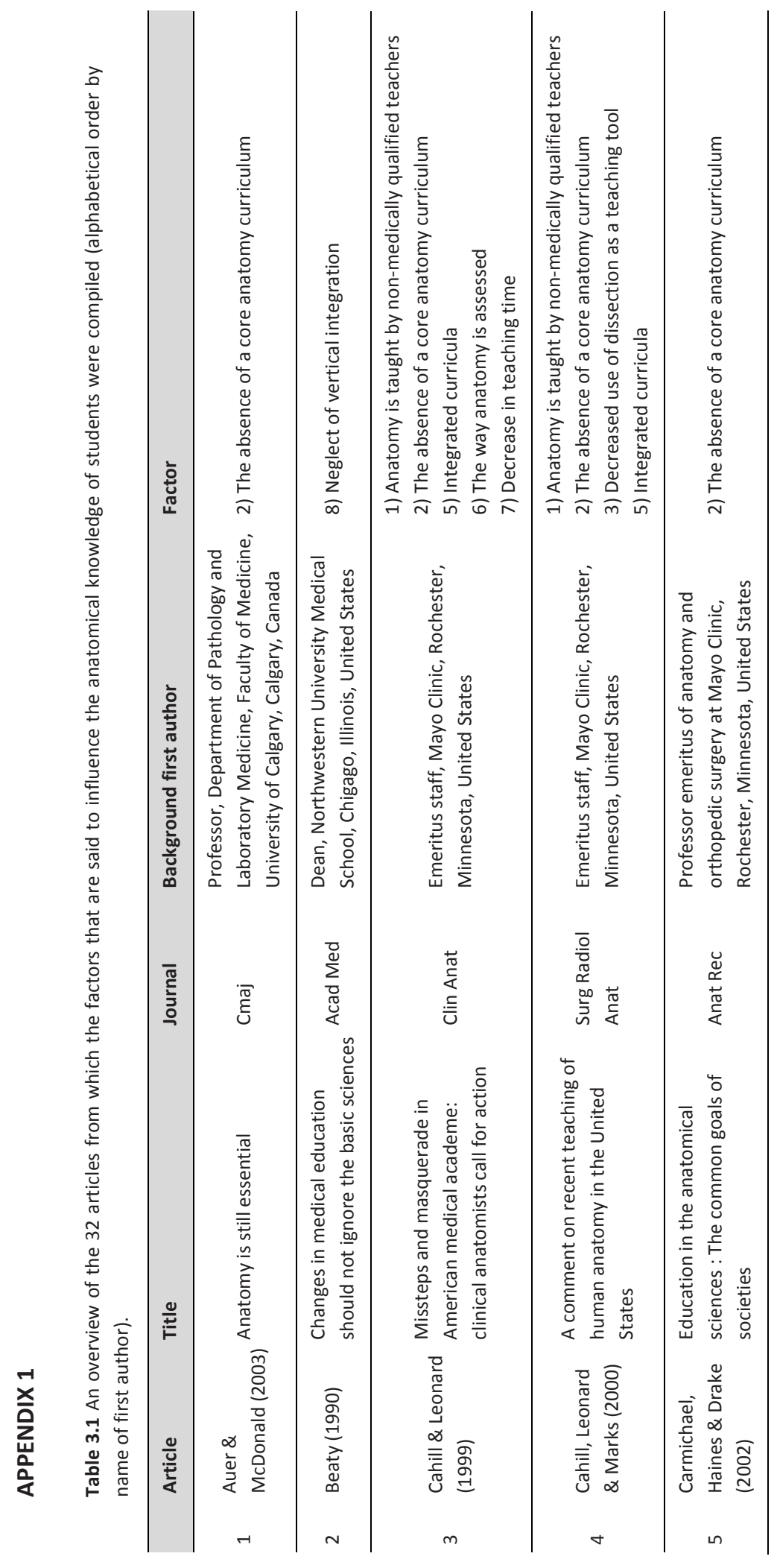




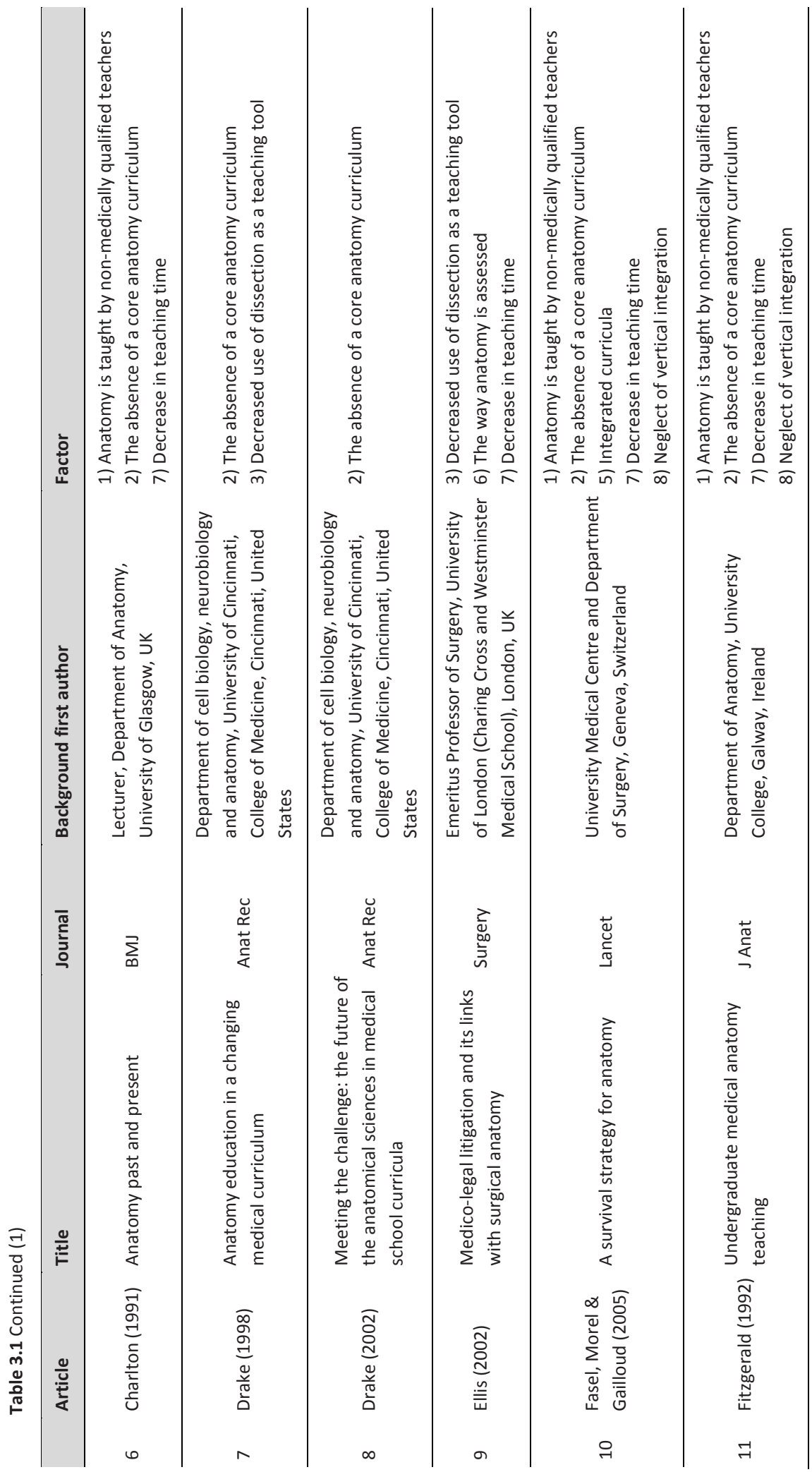




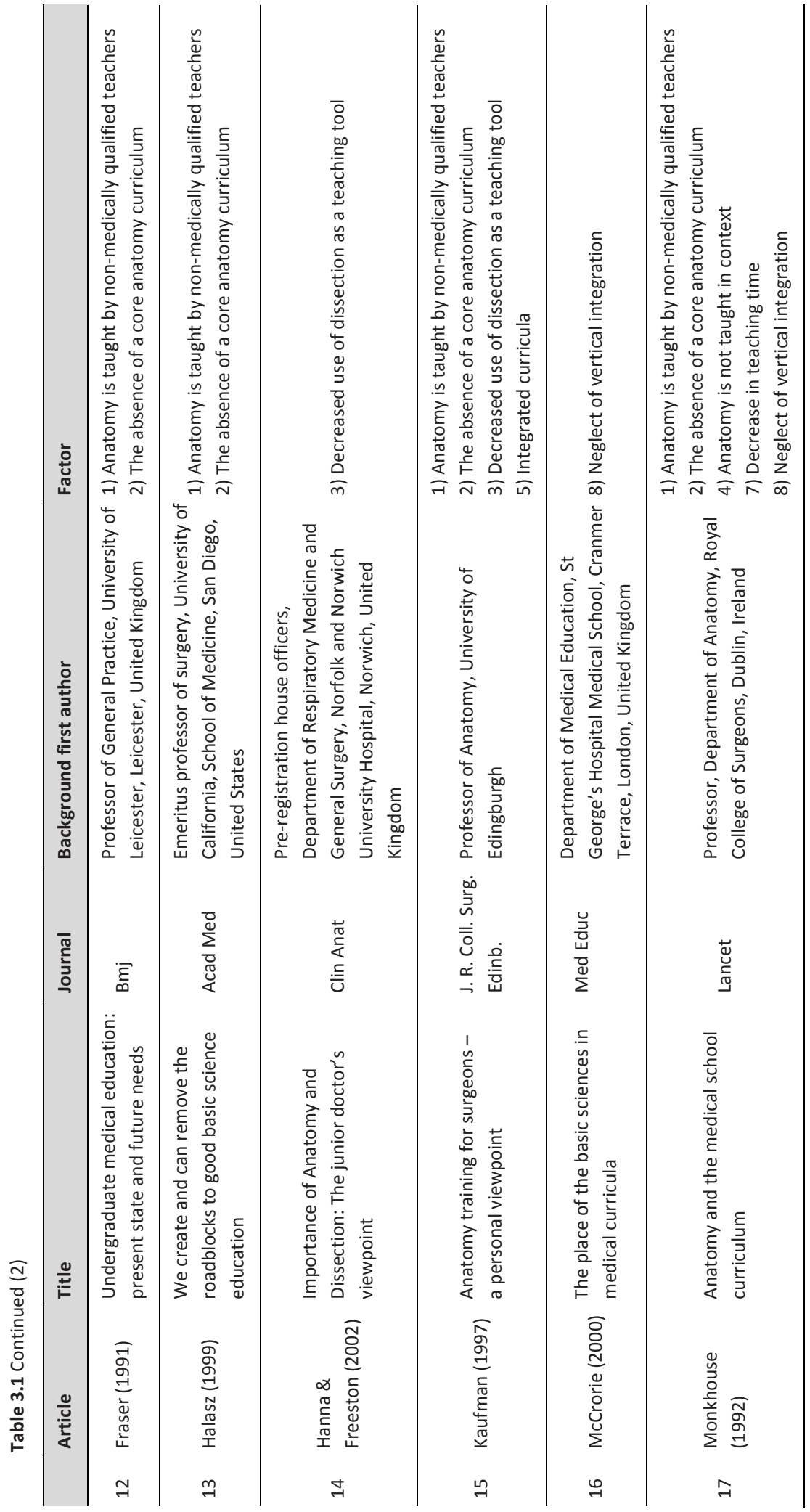




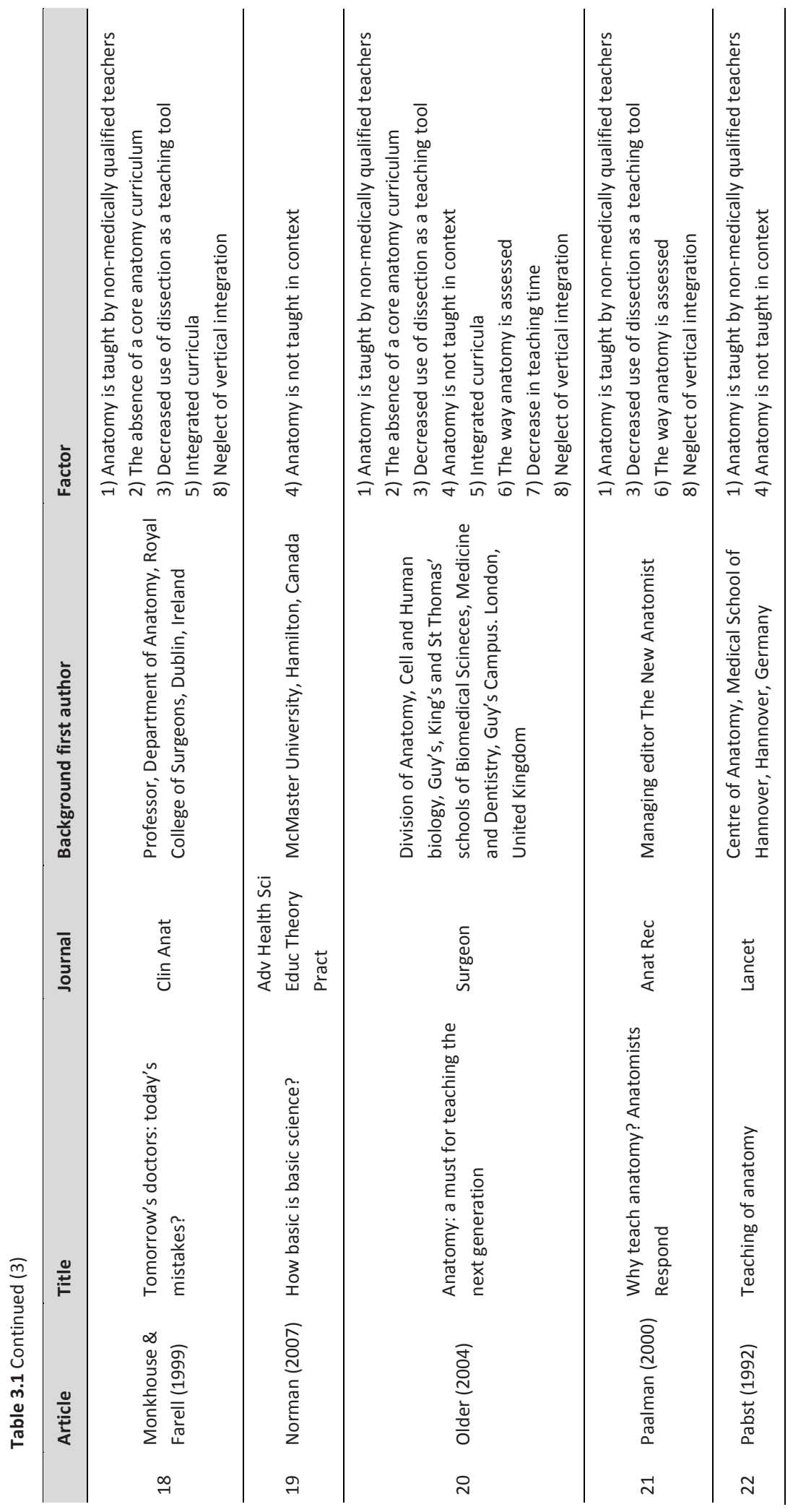




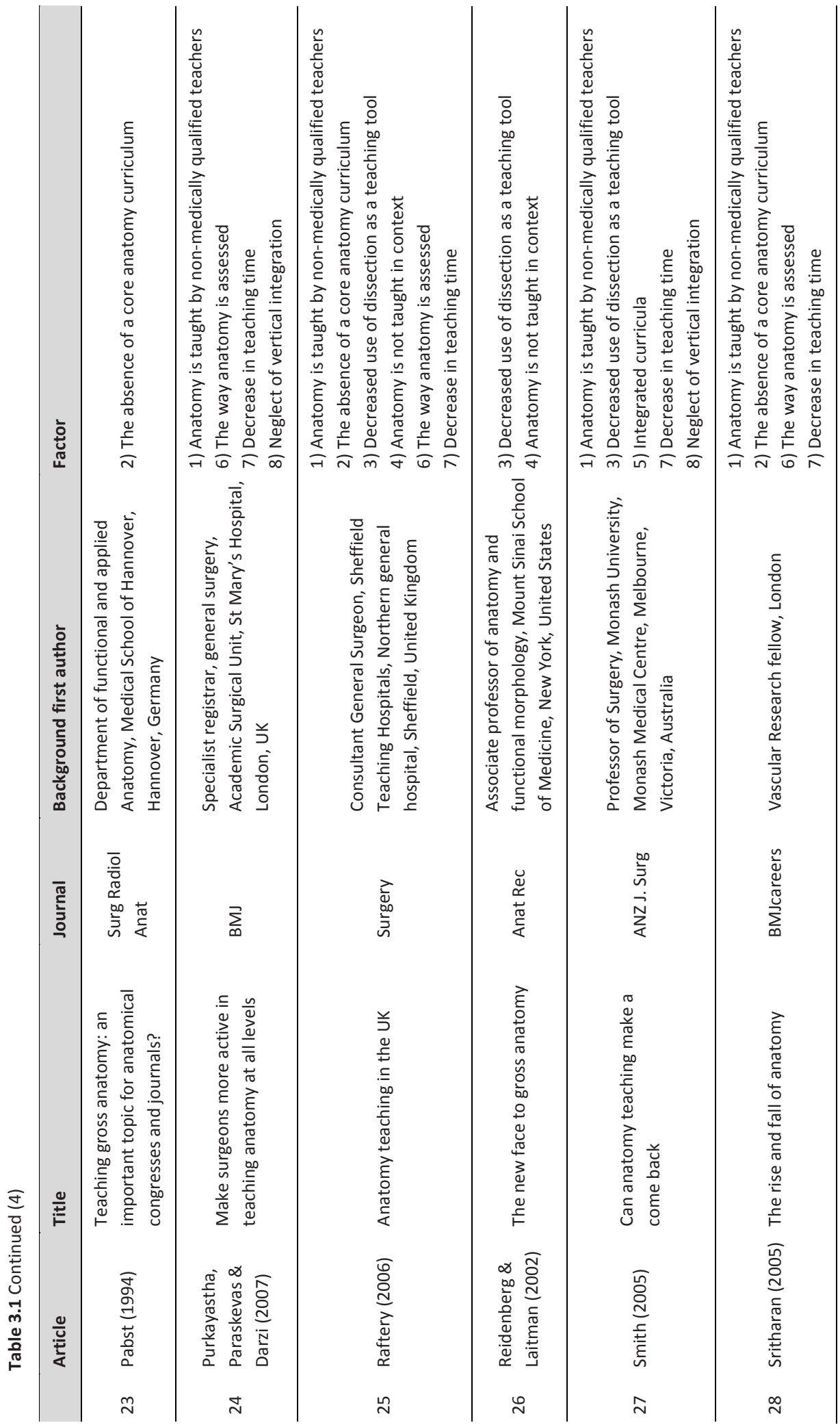




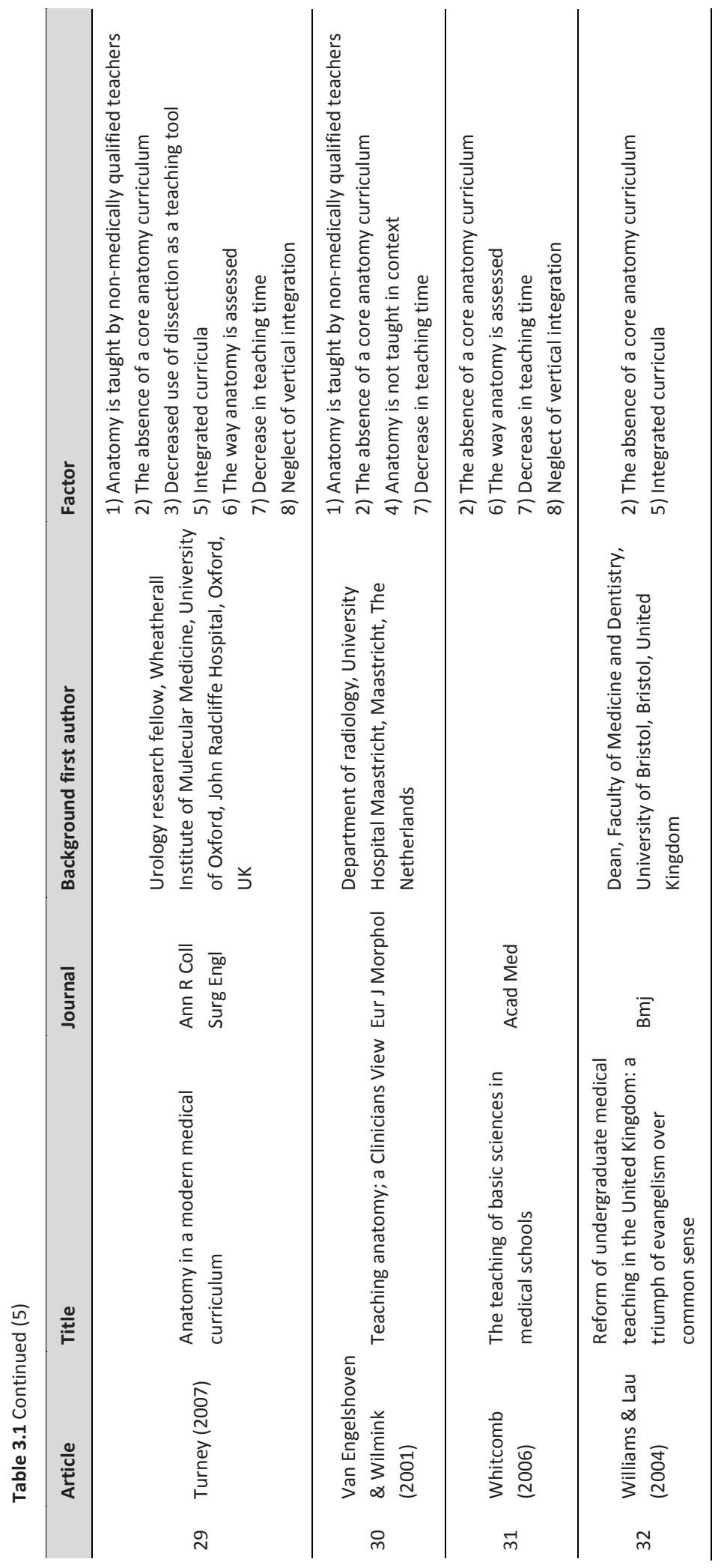




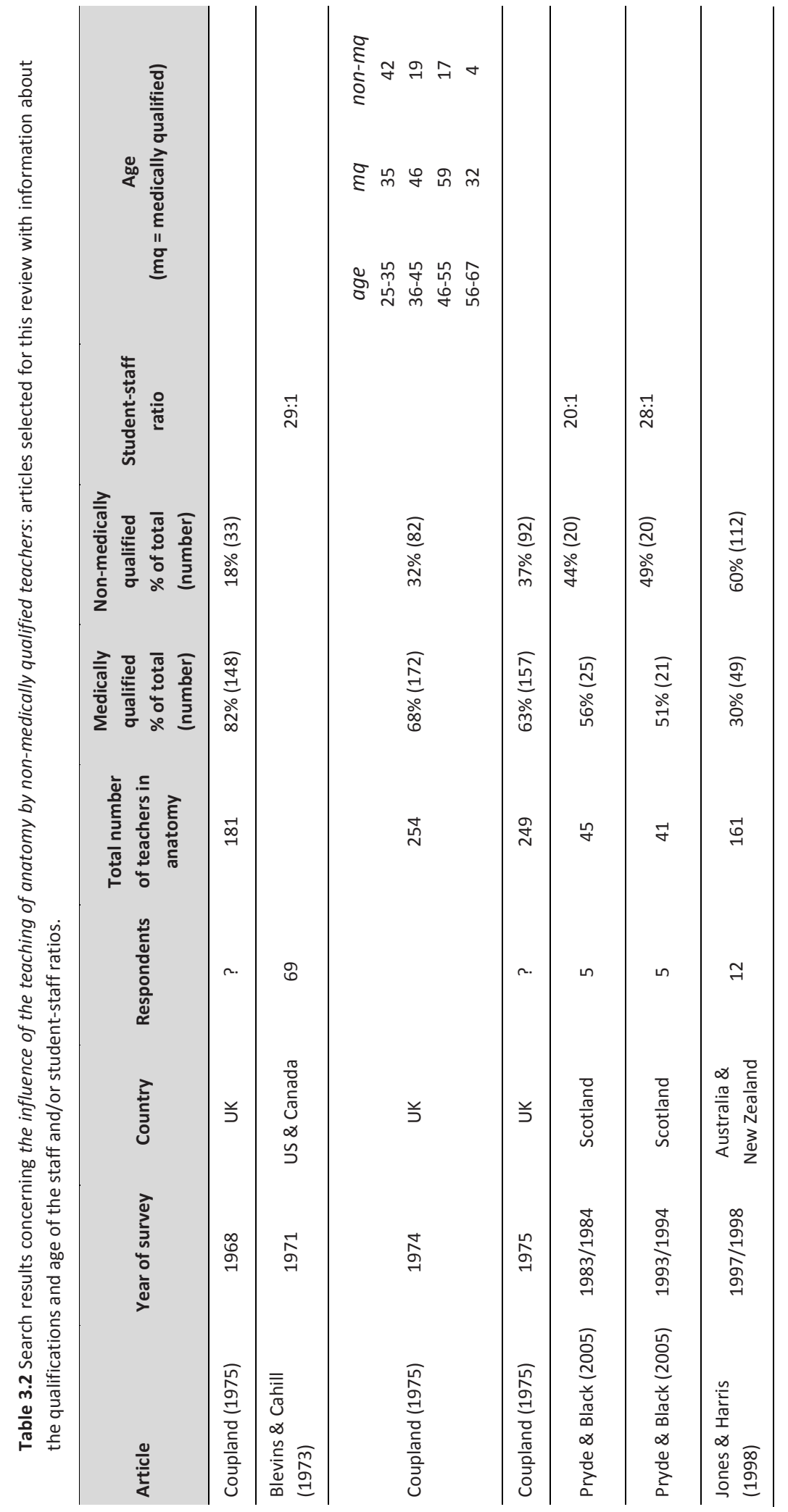




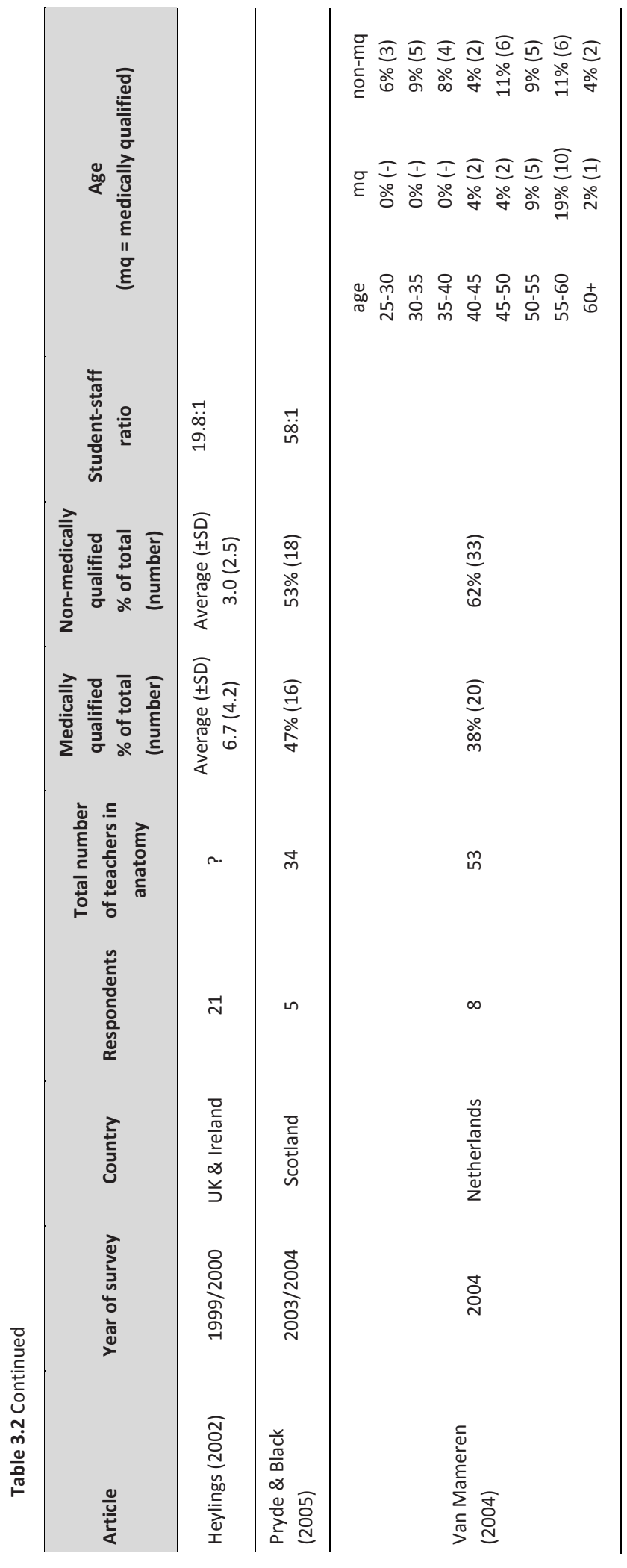




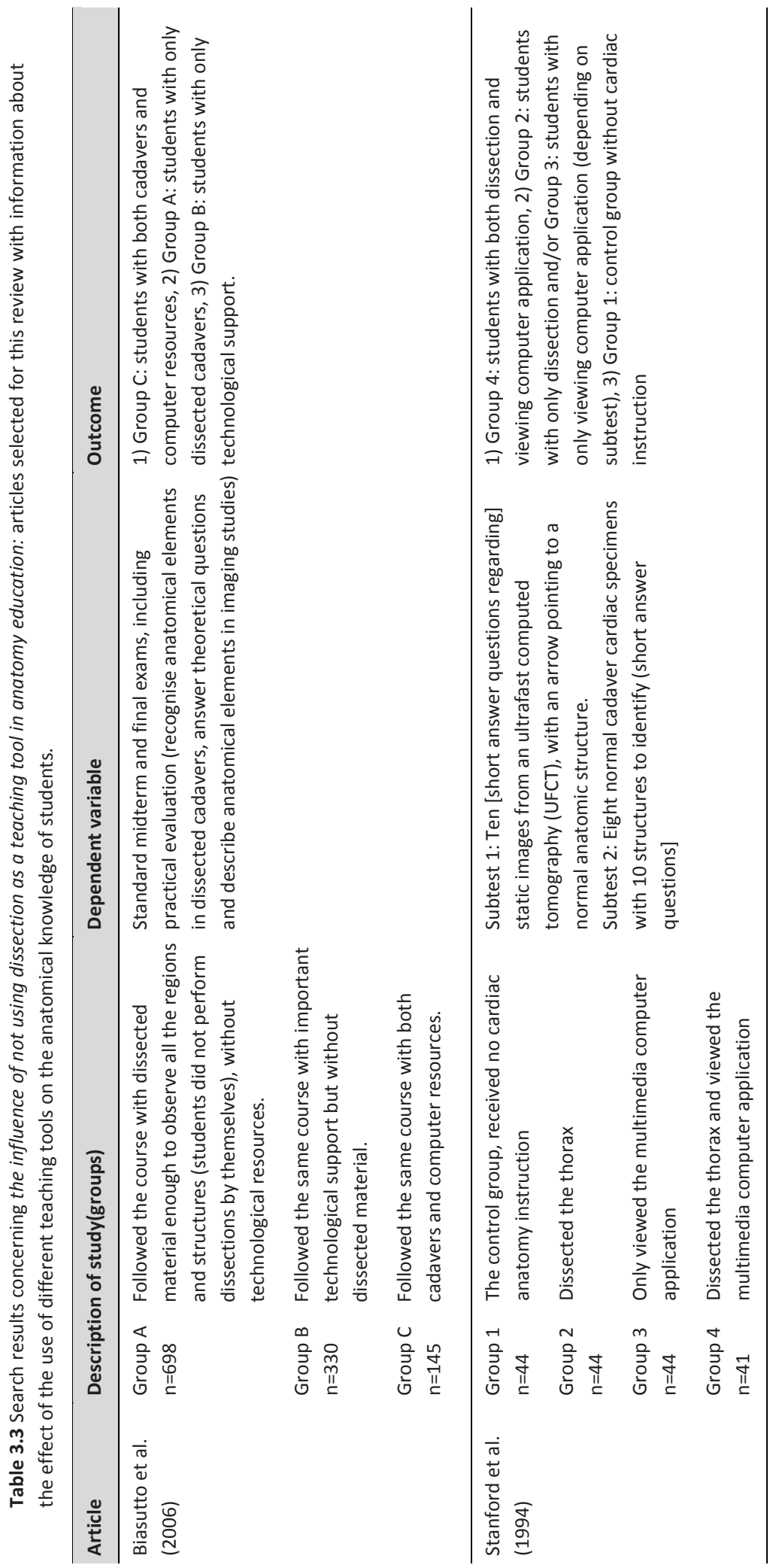




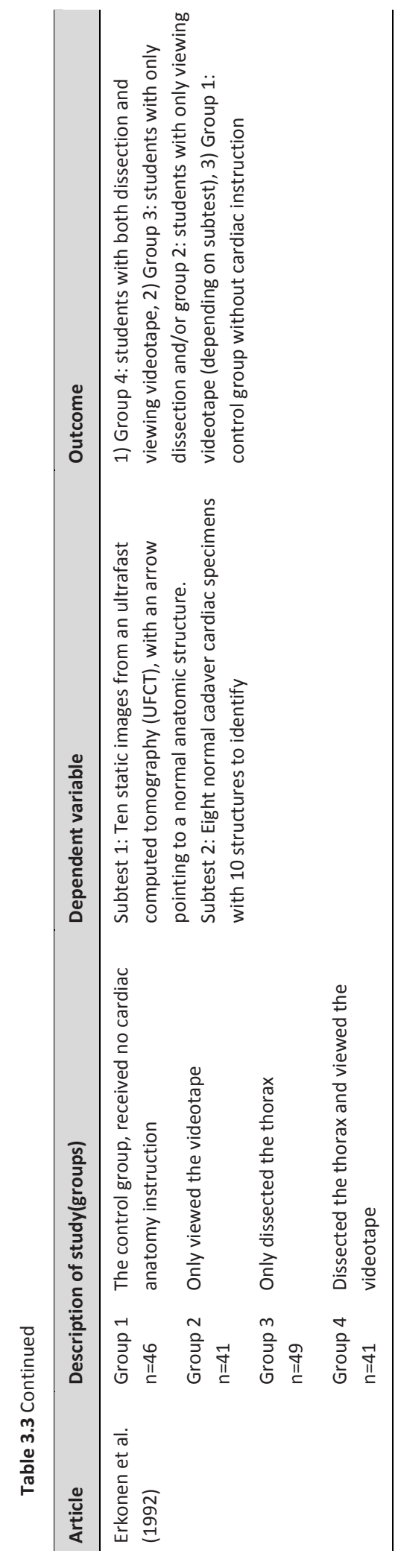




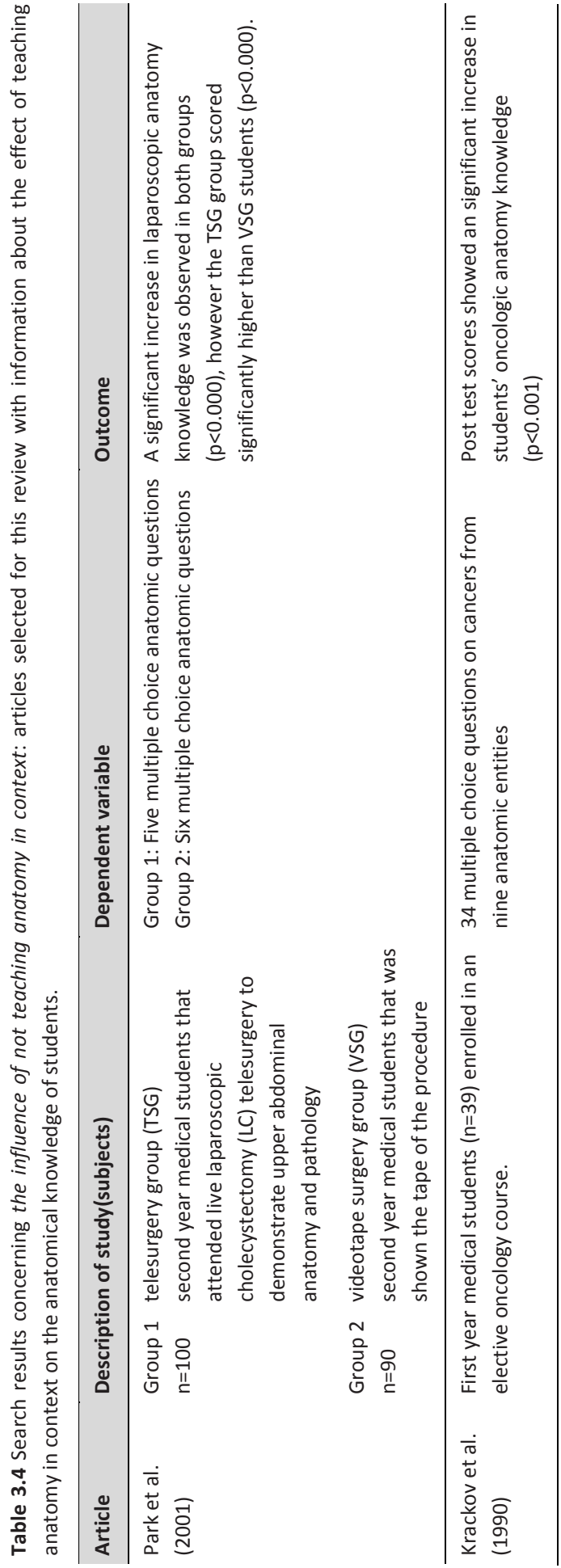




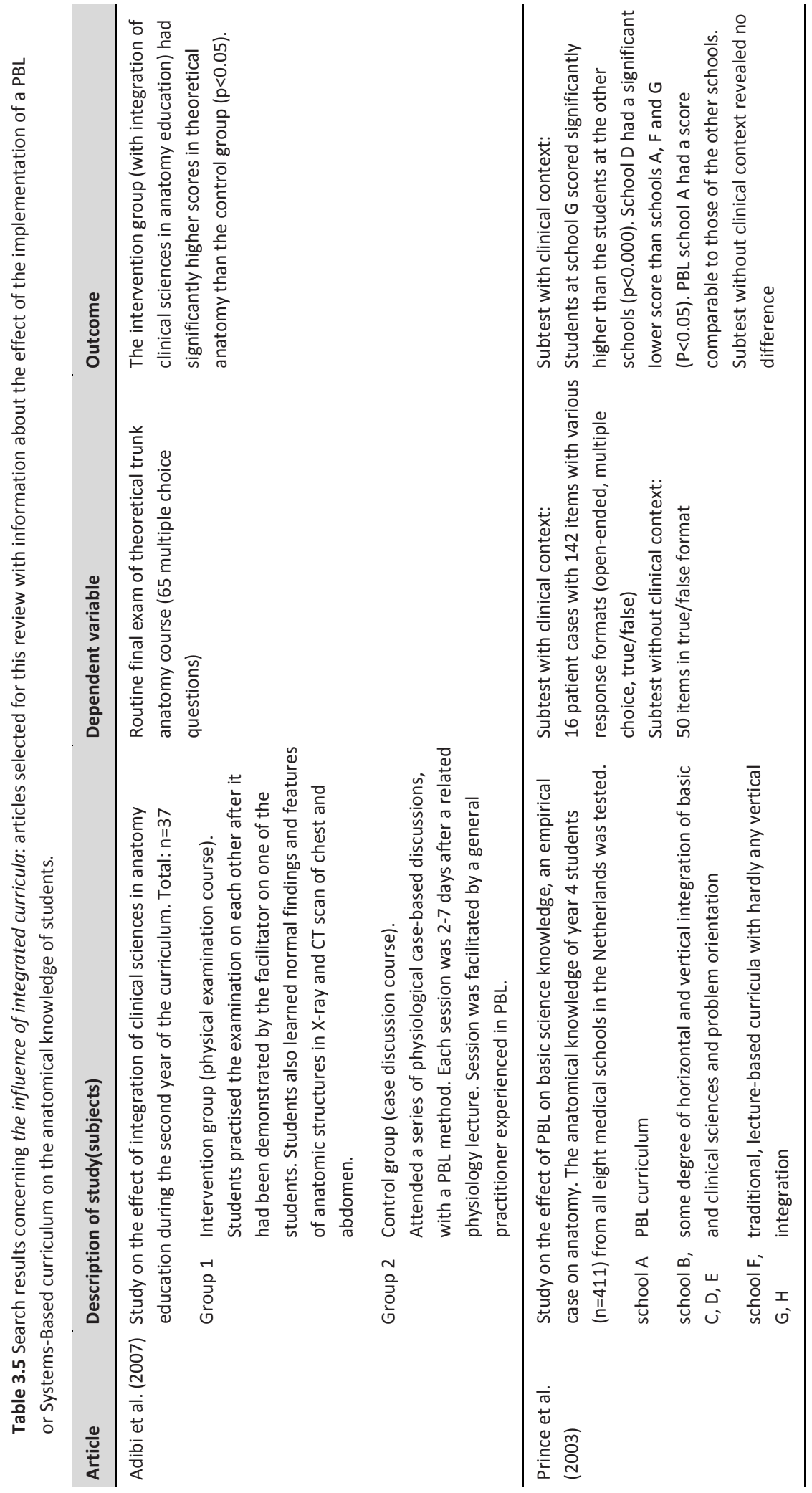




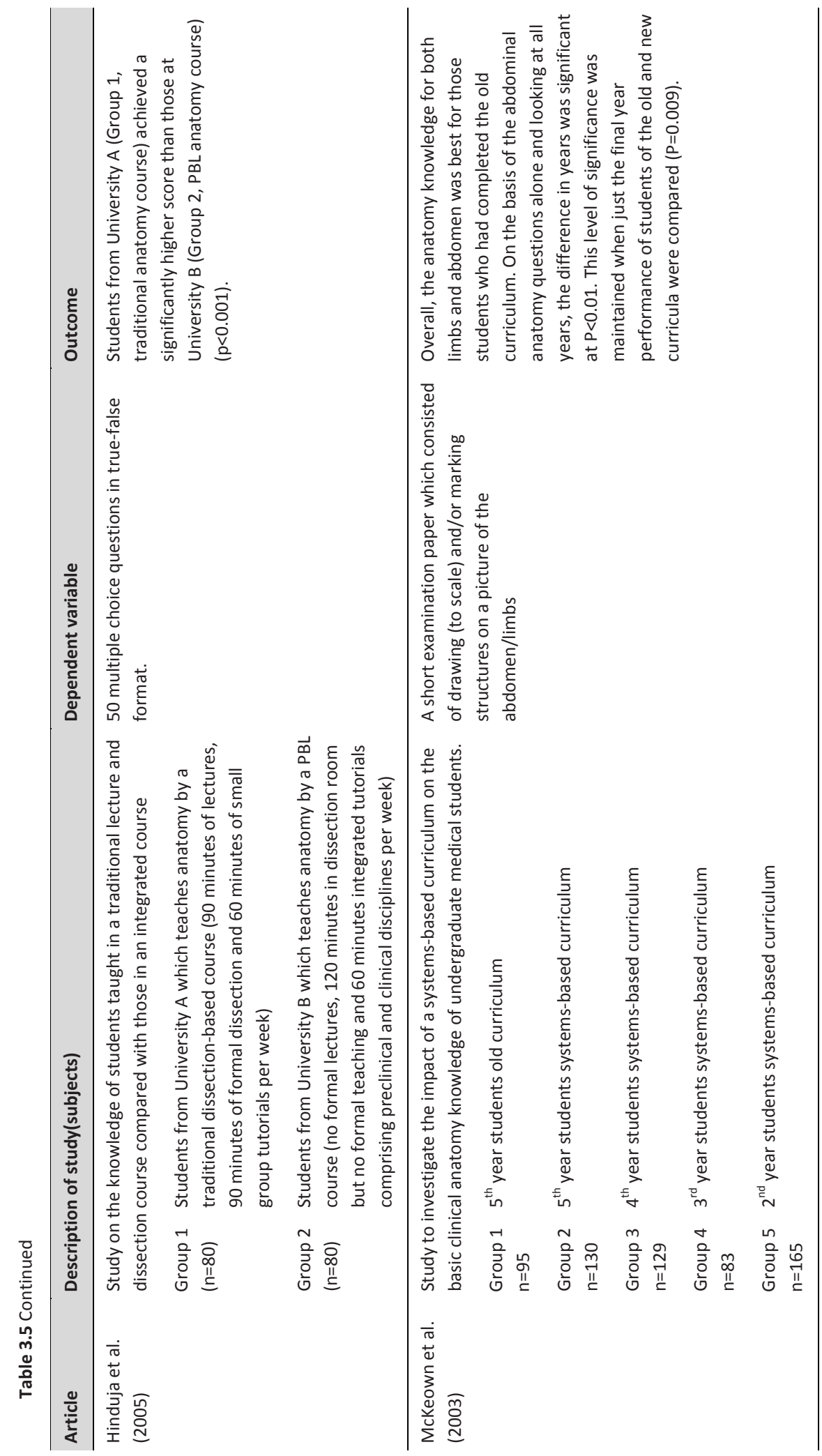




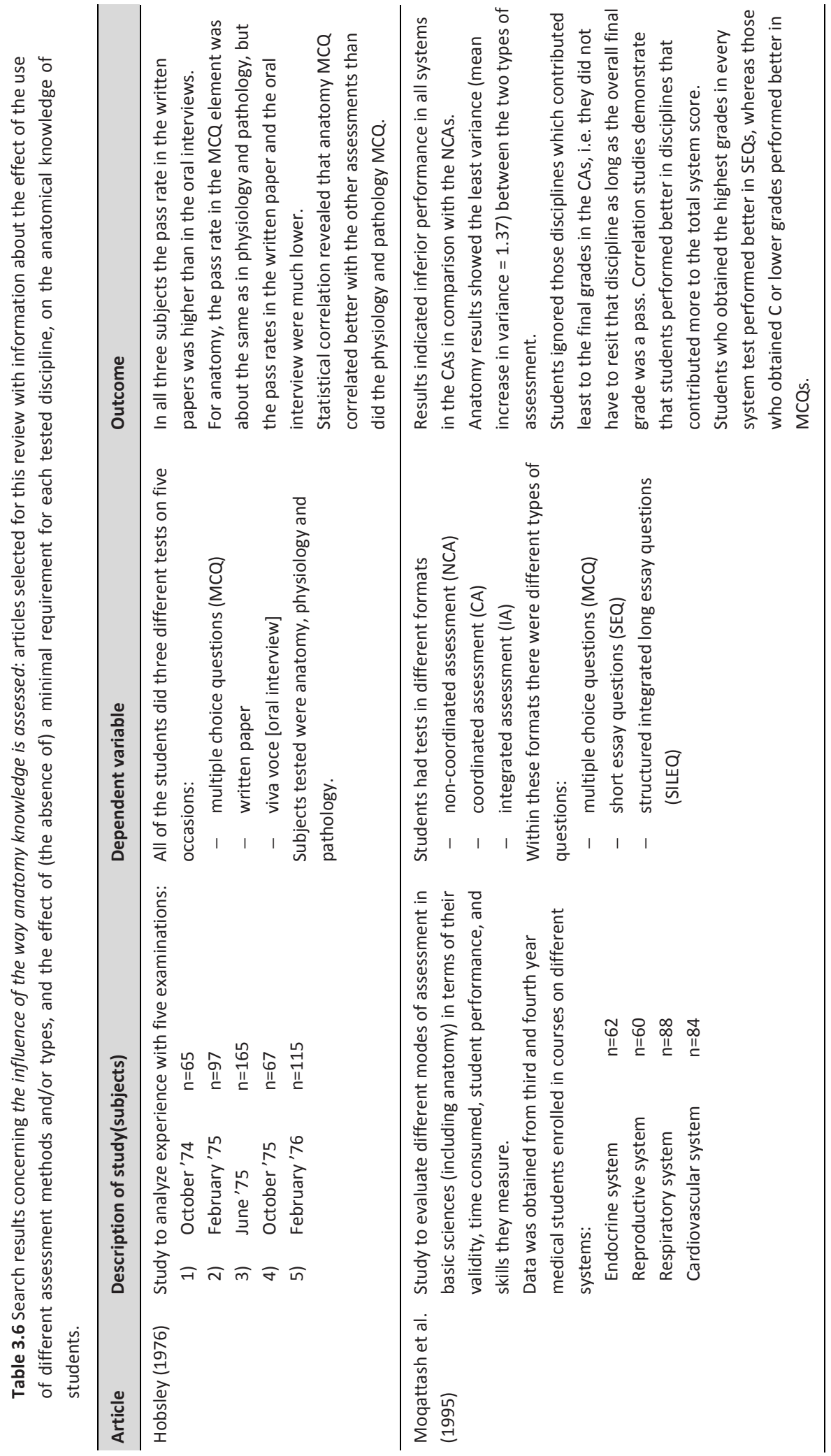




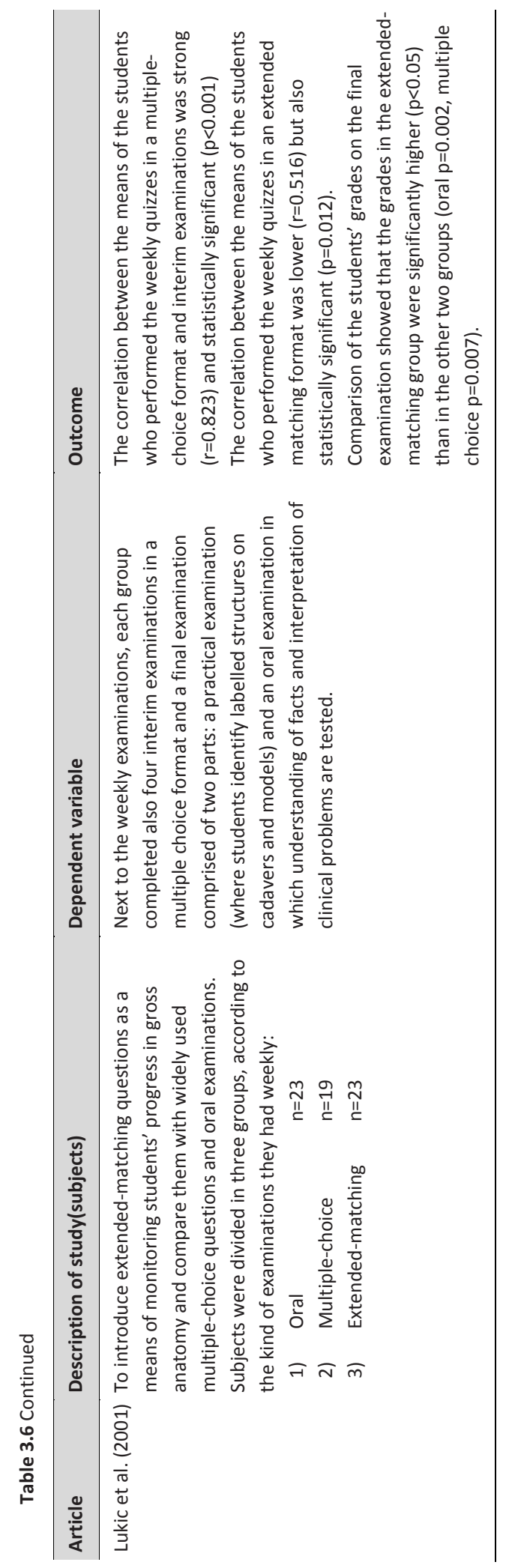




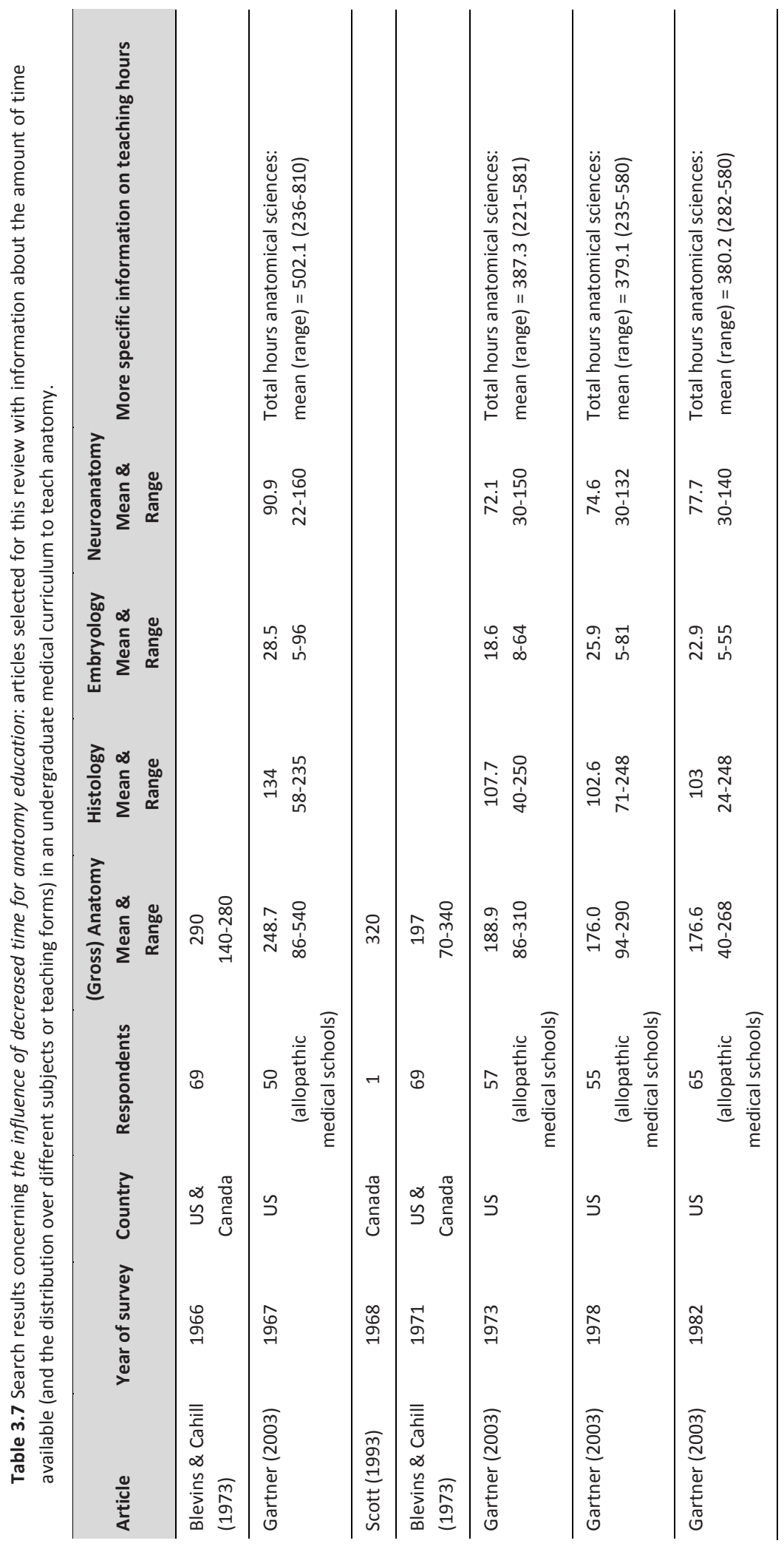




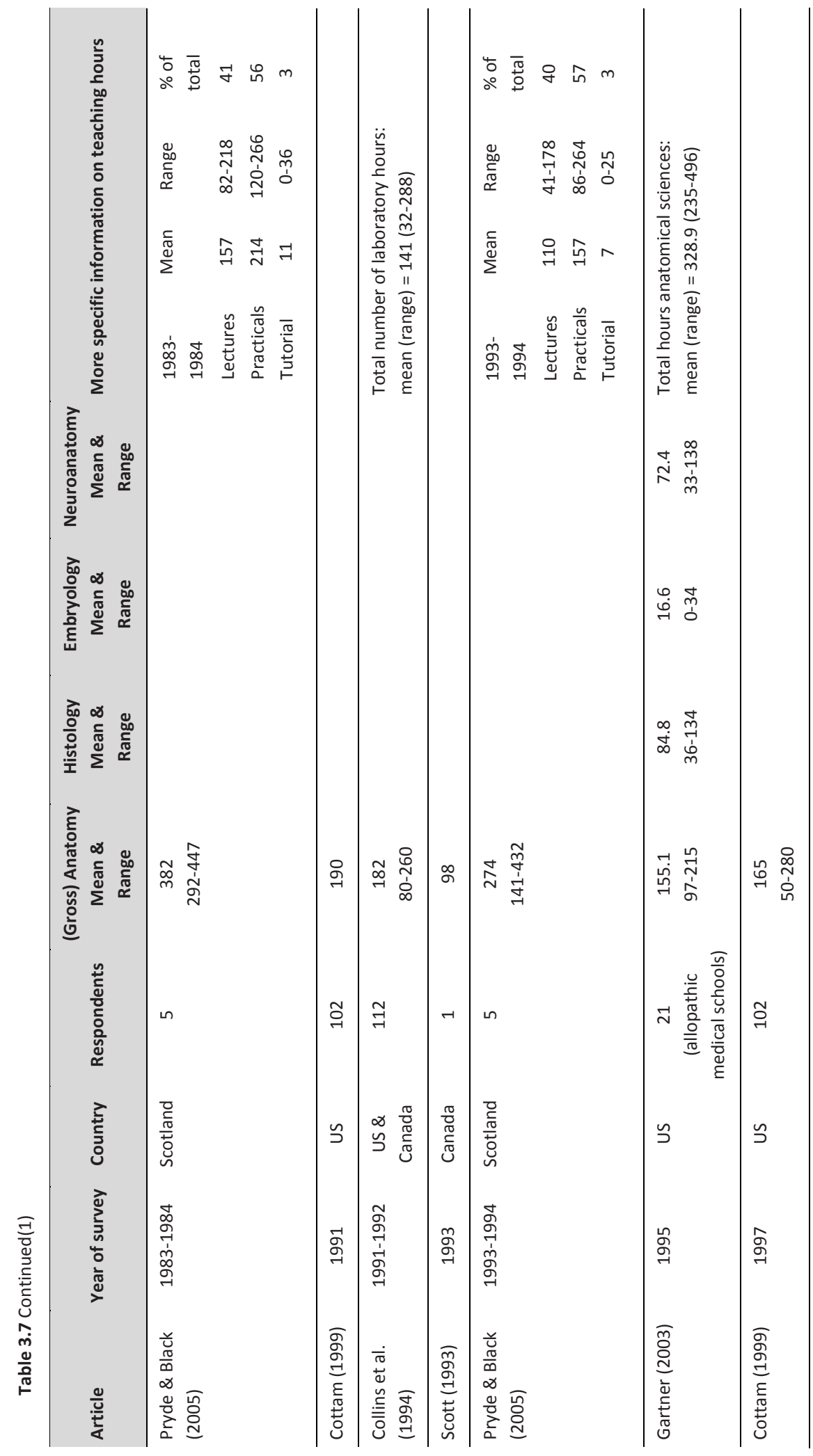




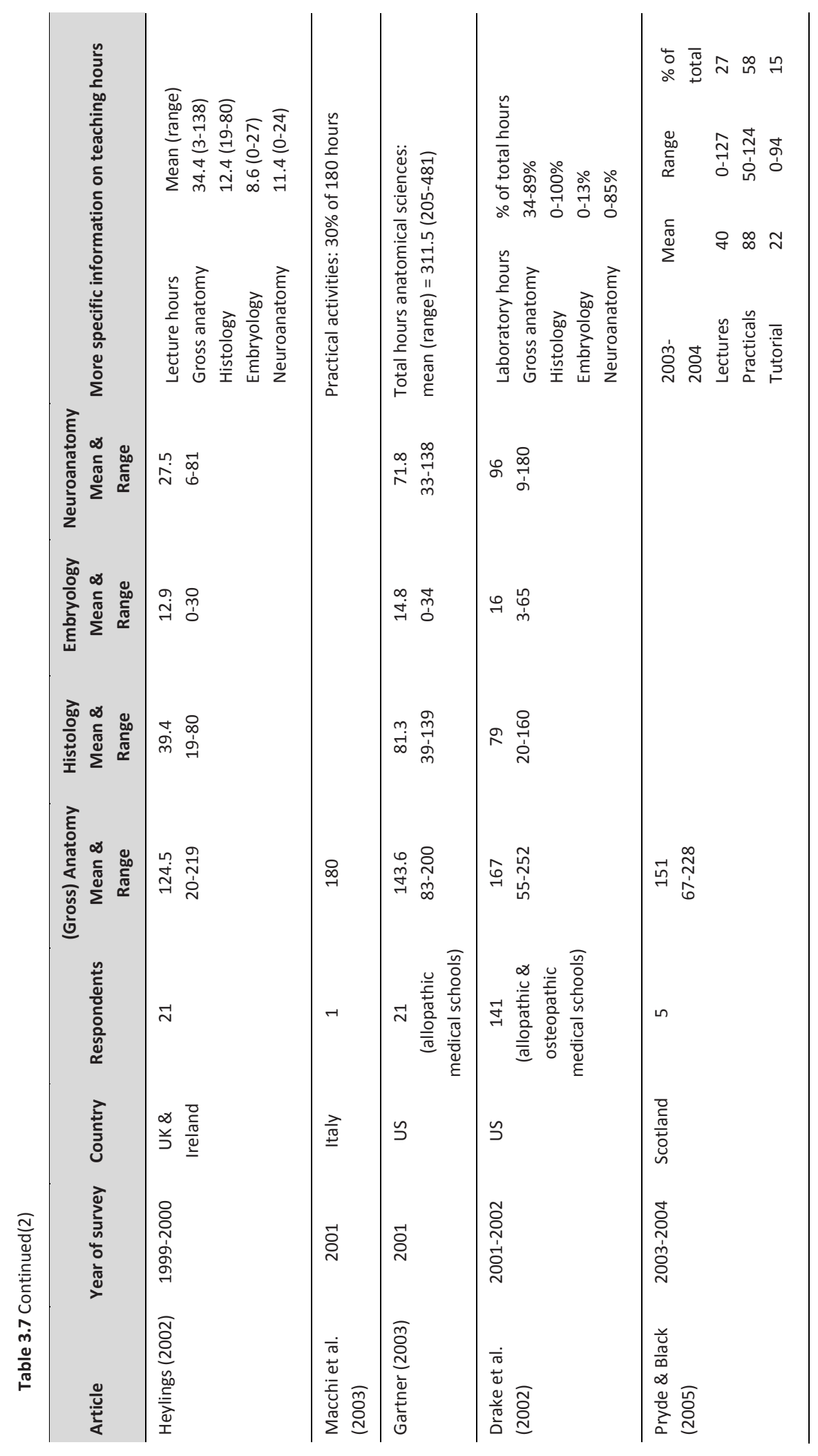




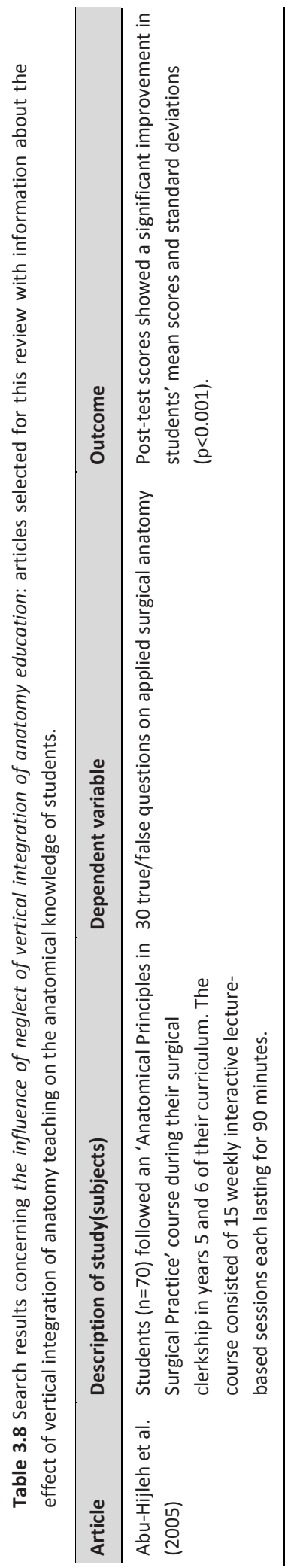





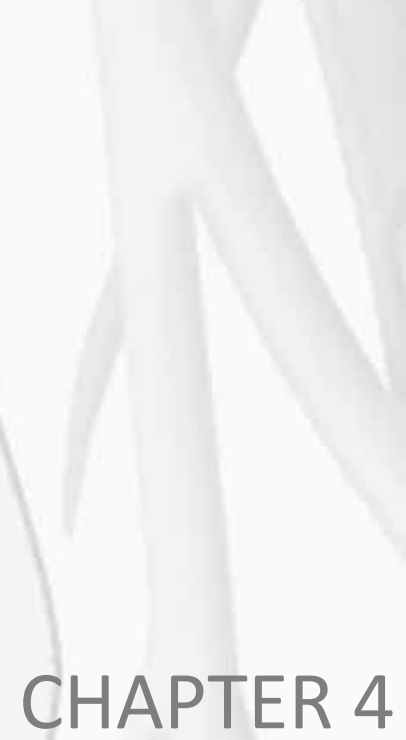

\section{Influences on anatomical knowledge.}

\section{The complete arguments}

\section{Published as:}

Bergman EM, Verheijen IWH, Scherpbier AJJA, Van der Vleuten CPM, De Bruin ABH (2014). Influences on anatomical knowledge. The complete arguments. Clinical Anatomy, 27(3): 296-303 


\section{ABSTRACT}

Eight factors are claimed to have a negative influence on anatomical knowledge of medical students: 1) teaching by non-medically qualified teachers, 2) the absence of a core anatomy curriculum, 3) decreased use of dissection as a teaching tool, 4) lack of teaching anatomy in context, 5) integrated curricula (problem-based learning or systems-based curricula), 6) inadequate assessment of anatomical knowledge, 7) decreased anatomy teaching time, and 8) neglect of vertical integration of anatomy teaching. A recent review revealed a lack of evidence underpinning any of the claims owing to the poor quality of papers, and recommendations were made for education and research on teaching in context and the implementation of vertical integration and of assessment strategies. In this article, we will describe the alleged factors fully, revealing additional recommendations for improving anatomy education by promoting recognition for teaching in institutions, by enhancing the professional recognition of anatomists through the implementation of a national postgraduate training program, and by encouraging anatomists to participate in educational research. 


\section{INTRODUCTION}

The role and position of the basic sciences in medical education are under debate (Norman 2000; Fincher et al. 2009; Norman 2012). Basic sciences are generally defined as the scientific foundations of clinical reasoning and medical practice (Kaufman et al. 2008); a firm foundation of basic science knowledge is considered indispensable for good clinical reasoning, and a sound knowledge of normal structure and function is deemed necessary for a proper understanding of abnormal structure and function (Swanson and Case 1997). The role of basic sciences in medical education is changing dramatically owing to shifts in educational concepts, for example, from monodisciplinary teaching to integrated learning and from a focus on facts and details to a focus on general principles, mechanisms and concepts (Bergman and de Goeij 2010).

\section{Influences on anatomical knowledge}

Although there is no empirical evidence that anatomical knowledge has declined among today's medical students, the claim is persistently emphasized in the literature by authors who attribute it to one or several of the following eight factors (table 4.1): 1) teaching by non-medically qualified teachers, 2) the absence of a core anatomy curriculum, 3) decreased use of dissection as a teaching tool, 4) lack of teaching anatomy in context, 5) integrated curricula (problem- based learning or systems-based curricula), 6) inadequate assessment of anatomical knowledge, 7) decreased anatomy teaching time, and 8) neglect of vertical integration of anatomy teaching. These factors were extracted from 32 articles (29 different first authors, nine of whom held their primary posts in anatomy departments (see Bergman et al. (2011)). In 2011, we published a study aimed at finding empirical evidence to verify the influences of the eight factors on medical students' anatomical knowledge. However, the quality of information within the existing literature was insufficient to support any of the claims (table 4.1). 


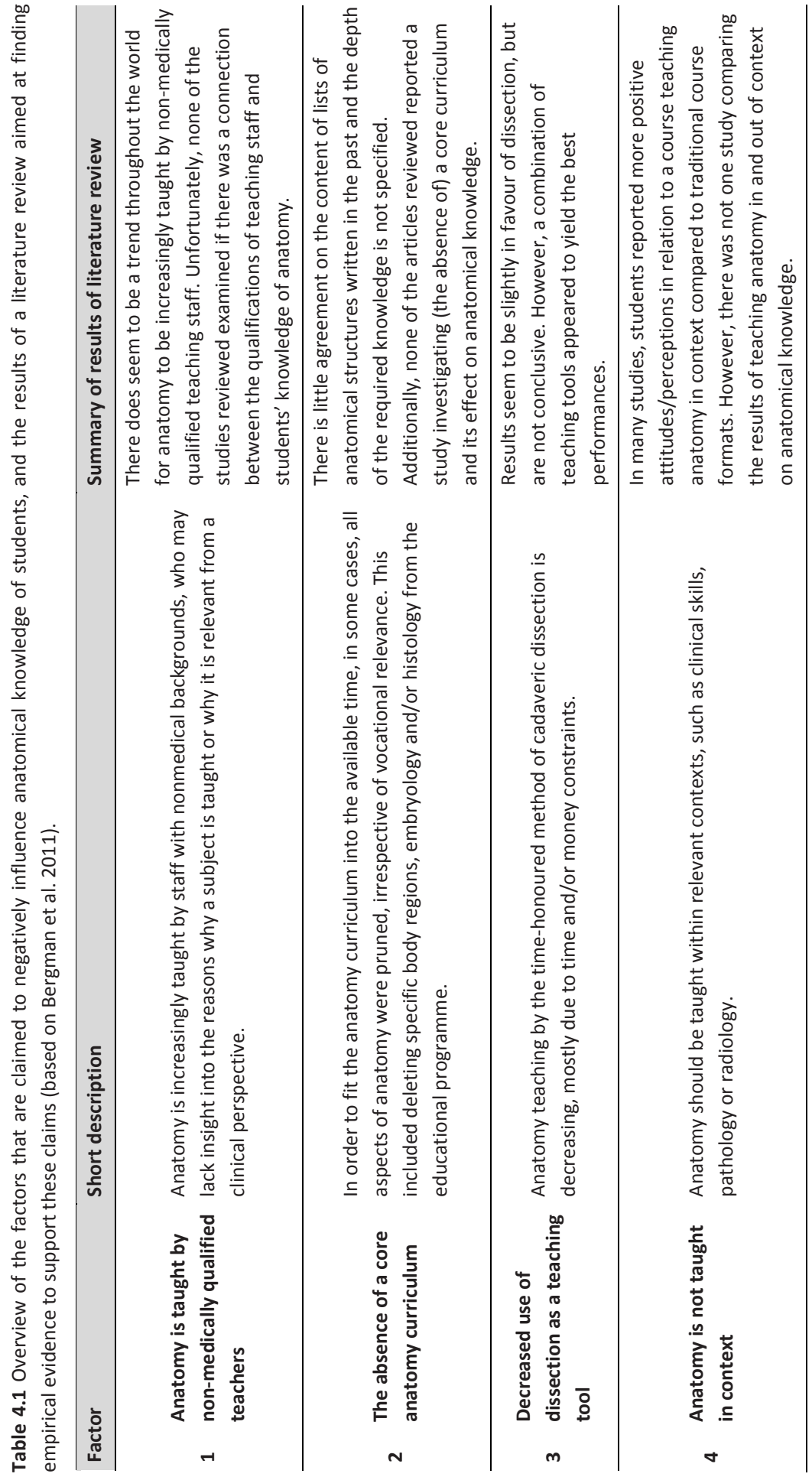




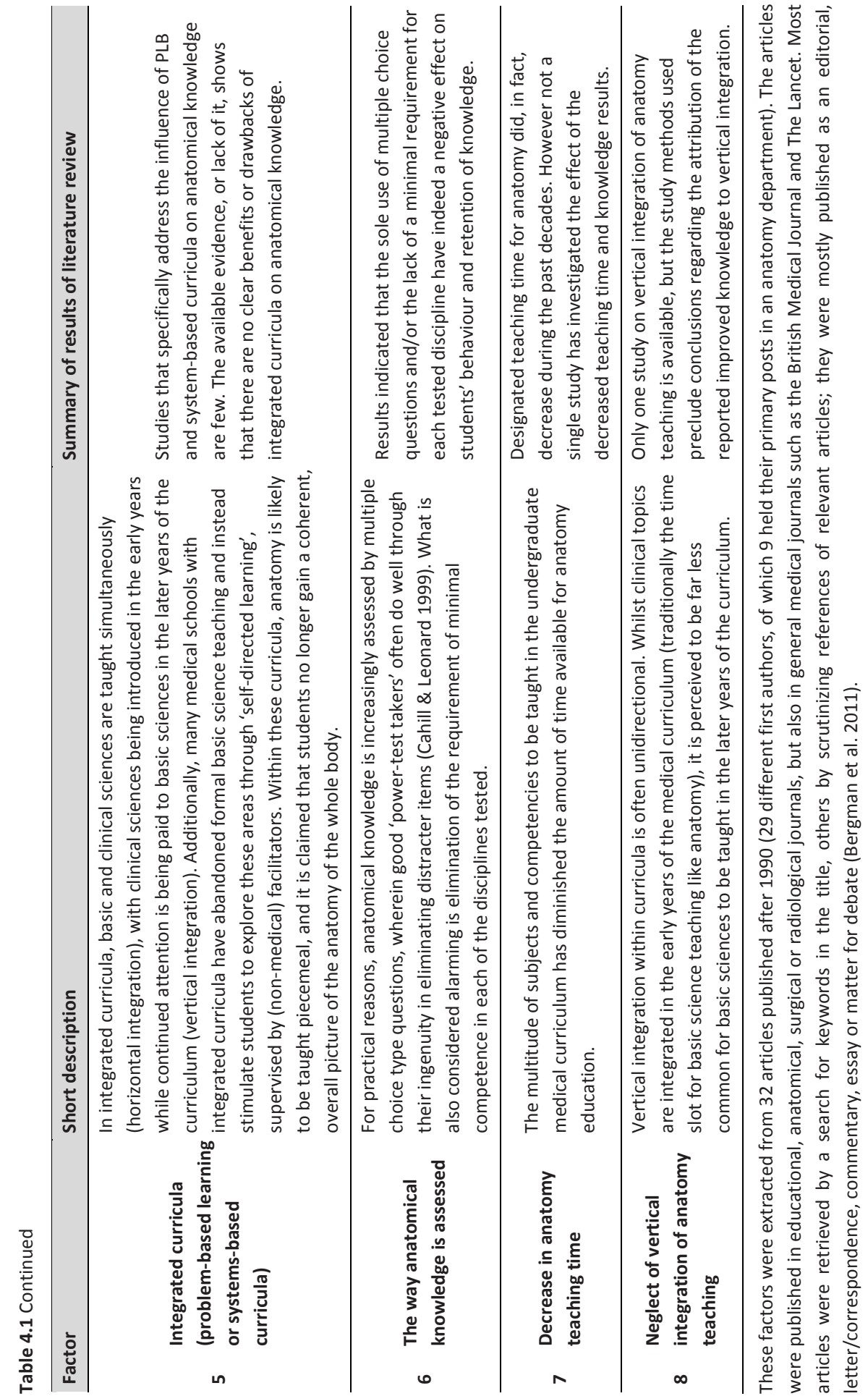


Obviously, these factors did not emerge out of the blue. Several authors have cited them as influential and have described their origins. So behind each factor there is a story. Our aim in writing this review is to share these stories with our readers. Since the stories are based on the perceptions and experiences narrated by the authors of the 32 papers we found in the literature, we share them mainly via quotations and anecdotes. When we speak of 'the authors', we refer to them, not to ourselves. We wish to emphasize that the authors of those papers are responsible for the stories and our narrating them in this review does not imply that we agree with them! However, in this review we want explore the stories fully, as we feel this could lead to important novel recommendations for further research and improvement of anatomy education. We feel there is a lesson in what those 29 authors are telling us, even if we cannot underpin their stories with empirical data (yet)!

\section{FACTOR 1: ANATOMY IS TAUGHT BY NONMEDICALLY QUALIFIED TEACHERS}

The authors feel that one explanation for the decline of anatomical knowledge is that it is becoming extremely rare for anatomy to be taught by dedicated, well-trained, medically qualified gross anatomists (Cahill and Leonard 1999; Older 2004). It is claimed that anatomy education is provided by faculty whose first interest is research and who look upon teaching as an annoyance, an unwelcome chore, rather than a key responsibility (Fraser 1991; Halasz 1999; Monkhouse and Farrell 1999). The authors argue that this should come as no surprise since faculty are usually recruited for research skills and potential for generating income (research grants), and not to meet teaching needs in particular areas (Cahill and Leonard 1999; Cahill et al. 2000).

Moreover, the authors state that faculty who are committed to teaching are subverted by the disproportionate importance placed on productivity in research, often measured by the number rather than the quality of research publications a department can list: the university mores of 'publish or perish' (Fraser 1991; Monkhouse and Farrell 1999). Teaching in both basic and clinical sciences is said to have low priority because, as an academic activity, it is valued less than research (Older 2004).

Another explanation given by the authors is that teachers who are medically qualified are first and foremost concerned with patient care and not with teaching. Even if they are interested in teaching, they are often restricted by workloads and pressures from a busy clinical service (Halasz 1999; Raftery 2006). In some countries, this problem is compounded by a distinctly unattractive salary structure deterring anyone with clinical qualifications from taking up teaching (Older 2004). 
Halasz (1999) argues that in no other type of professional school is almost half of the curriculum (i.e., the basic sciences) taught by faculty who do not practice the profession they teach. Since nonmedical anatomy teachers are said to have no notion why the subject is taught or why it is relevant from a clinical perspective, the decline in medically qualified anatomy teachers is viewed by the authors as a threat to students' mastery of anatomical knowledge (Monkhouse 1992; Pabst 1992; Monkhouse and Farrell 1999; Older 2004; Raftery 2006).

\section{FACTOR 2: THE ABSENCE OF A CORE ANATOMY CURRICULUM}

The authors indicate that the amount of time available for teaching anatomy has fallen during recent decades (see also factor 7 ) and, in some cases, attempts to fit anatomy within the allocated time have led to all aspects of anatomy (body regions, organ systems, or topics such as embryology) being pruned to a greater or lesser extent, notwithstanding their relevance for the medical profession (Monkhouse 1992; Cahill et al. 2000; Older 2004). The authors feel this directly affects the ability of future doctors to practice medicine safely. History-taking, inspection, palpation, percussion, auscultation, imaging, and surgery all require knowledge of how the body is constructed at the cell, tissue, and organ system levels. Looking up anatomical facts and pictures just before a procedure is no substitute for a rigorous knowledge of anatomy (Auer and McDonald 2003).

In stark contrast to the preceding arguments, clinicians frequently blame anatomists for teaching too many details and not what they define as the anatomical knowledge relevant to medical practice (such as how to provide high-quality care) (Pabst 1994; Whitcomb 2006). To explain this criticism, it is argued that the true purpose of undergraduate education has been forgotten: the product of undergraduate medical education is the student trained 'to become' a physician (Fraser 1991; Drake 1998; Whitcomb 2006).

The authors claim this problem has arisen because of the absence, or insufficient re-evaluating/re-orientation, of a (national) core anatomy curriculum (Monkhouse 1992; Halasz 1999; Older 2004; Raftery 2006). Such a core curriculum would cover topics of real clinical relevance and equip students with a good grasp of the relationship between structure and function (Pabst 1994; Raftery 2006). If it were in place, teachers (basic science and clinical) would know what their students were expected to learn and would be able to help them attain that knowledge (Bergman et al. 2011). 


\section{FACTOR 3: DECREASED USE OF DISSECTION AS A TEACHING TOOL}

Curricular reform is thought by the authors to have altered not only the amount of anatomical information imparted to medical students but also the format in which it is presented (Drake, 1999). The authors acknowledge that today's medical students are different. "The world of our students is multimodal and stimulus dependent. [...] the greater majority of average students can no longer solely respond to 'cut,' 'read' and 'listen'" [page 81, 82] (Reidenberg and Laitman 2002). Expensive anatomy rooms (whether or not for dissection) have been replaced by clinical skills laboratories and computer rooms (or revenue-generating research space) (Monkhouse and Farrell 1999; Cahill et al. 2000), but what the authors consider most worrying is the increasing decline of anatomy teaching by the time-honoured method of cadaveric dissection. They point out that anatomy is now taught via prosections (at best), problem-based tutorials, special study modules (student-selected components), computer-assisted instruction, and plastic models (at worst) (Raftery 2006). They think that the use of models, images, and audiovisuals fails to provide students with as much anatomical knowledge as comes from the investigative dissection of real tissue. But it is also acknowledged that there are very few substantive data to support this contention (Cahill et al. 2000; Reidenberg and Laitman 2002; Older 2004).

\section{FACTOR 4: ANATOMY IS NOT TAUGHT IN CONTEXT}

Anatomical knowledge among students can, in the opinion of the authors, be enhanced by extending anatomy education to surface anatomy, living (radiological) anatomy, and clinical skills. It is felt that anatomy should be presented in a context of physical examination of patients (e.g., stethoscope, abdominal palpation, peripheral pulses, testing of ligaments, muscle groups, and reflexes) and interpretation of images (e.g. X-rays, CT, MRI, ultrasound, and minimally invasive views through scopes) (Monkhouse 1992; Pabst 1992; Reidenberg and Laitman 2002; Older 2004; Raftery 2006). Reidenberg and Laitman (2002) even state that anatomy programs "must be at the forefront of integration of material and a home for interdisciplinary teaching and learning" [page 87], while Monkhouse (1992) argues that without such integration it is impossible to "see any grounds for the vocational necessity for medical students to study any anatomy" [page 834]. Additionally, the authors suggest that teaching in context can mean using anatomical knowledge to solve clinical problems: "unless students actively apply the concepts they are learning to understanding and explaining clinical problems, the knowledge will remain inert and will be soon forgotten" [page 402] (Norman 2007). 


\section{FACTOR 5: INTEGRATED CURRICULA (PROBLEM-BASED LEARNING OR SYSTEMS- BASED CURRICULA)}

Some medical schools today have largely abandoned the formal teaching of basic medical sciences, leaving students to explore these crucial areas through the problem based learning (PBL) approach alone (Williams and Lau 2004). The authors fear this will affect the students' anatomical knowledge in two ways.

First, the authors argue that in some places, self-directed learning has become a mere excuse for staff to abandon their responsibilities to students (Monkhouse and Farrell 1999). It is also felt that PBL can lead to competent teachers being replaced by facilitators (often anatomically untrained nonmedical scientists; see also factor 1 ), thereby depriving students of contact with inspirational and knowledgeable mentors, so they acquire less anatomical knowledge (Cahill et al. 2000; Williams and Lau 2004; Fasel et al. 2005). Second, the authors argue that PBL is an illogical and inefficient way to acquire basic scientific knowledge (Williams and Lau 2004) because it ignores the fact that the student must simply learn an accepted body of anatomical information; requiring students to gain this knowledge through curiosity and experiment is a waste of valuable time and resources (Monkhouse and Farrell 1999).

Monkhouse and Farrell (1999) further point to the danger that systems-based teaching can prevent students from gaining a coherent view of the anatomy of the whole body. In systems-based teaching, anatomy is likely to be taught in small segments with no regard to the whole organism, inevitably leaving students with only fragmented knowledge of the discipline. The authors consider it self-evident that doctors should have a sound working knowledge of human anatomy; at the very worst, they will not be disadvantaged by knowledge of the parts of the body, their relationships to another and to the body surface, and how they can be approached safely when intervention is necessary.

\section{FACTOR 6: THE WAY ANATOMICAL KNOWLEDGE IS ASSESSED}

The authors repeatedly state that anatomical knowledge is assessed inadequately, so it is poorly retained. It is felt that for reasons of practicality, questions on (anatomy) tests are increasingly of the multiple choice variety, in which good "power-test takers" often do well because of their expertise in eliminating distracter items (Cahill and Leonard 1999; Paalman 2000; Ellis 2002; Older 2004; Raftery 2006; Turney 2007). Furthermore, the authors fear the requirement for minimal competence in each of the disciplines tested is being eliminated (Ellis 2002; Raftery 2006; Purkayastha et al. 2007): "why should students learn gross anatomy anyway when there are only a few direct 
anatomy questions on the [USMLE] Step 1 Examination?" [page 221] (Cahill and Leonard 1999). "There should be a really tough examination in anatomy and this should be at a very early stage to be certain that candidates know their anatomy before they start practicing on patients" [page 2] (Raftery 2006).

\section{FACTOR 7: DECREASE IN ANATOMY TEACHING TIME}

The authors stated that the explosion of scientific knowledge during recent decades has made the amount of basic scientific information with potential relevance to medical practice too large for instructors to teach or for students to learn. The relevance of basic sciences to clinical medicine is said to be undergoing re-evaluation, inescapable in the face of reduced course hours and the shifting emphases of medical education (Drake 2002). It is argued that curricular revision to deal with this problem continues to challenge educators in the anatomical sciences at every level (Carmichael et al. 2002). Clearly, choices about which subjects to include in the anatomy curriculum had to be made, but the authors feel that these choices have led to the teaching of either too much or too little anatomy (see factor 2 ).

\section{FACTOR 8: NEGLECT OF VERTICAL INTEGRATION OF ANATOMY TEACHING}

Basic science teaching takes up a huge proportion of the preclinical curriculum (Norman 2007). Unfortunately, although vertical integration is said to help ensure that only clinically valuable basic science is taught (Monkhouse and Farrell 1999), the authors often experience it as unidirectional. While clinical topics are regularly integrated into the early years of medical curricula (traditionally the time slot for basic science teaching), it is much less common for basic sciences to be taught in later years (traditionally clinical teaching time) (McCrorie 2000). It is felt that this reform has led to reductions in both the time for (some claim reductions of more than $50 \%$ over 25 years) and the content of anatomy education (see also factors 2 and 7), the most drastic cut being in the laboratory parts of traditional teaching (Monkhouse 1992; Cahill et al. 2000; Older 2004). The authors state that undergraduate gross anatomy teaching is in decline worldwide, and it is feared that the pendulum could have swung too far, putting anatomy teaching in danger of disappearing completely from medical education (Fasel et al. 2005; Raftery 2006). So, neglect of vertical integration of anatomy teaching leads to a decline in gross anatomy teaching, which in turn leads to deficiencies in students' anatomical knowledge. To counteract this, the authors recommend that more anatomy should be integrated throughout the entire medical 
curriculum (content drawn from the biomedical sciences integrated into the later years of the curriculum) (Beaty 1990; Older 2004; Whitcomb 2006). It is stated that this will also adapt education to the fundamental idea from cognitive psychology that learning consists in the integration of new knowledge into existing knowledge (scaffolding); there is no need to teach everything all at once (Norman 2007). As Fitzgerald (1992) puts it: "[...] many clinically relevant points have to be omitted from the anatomy course owing to time constraints. The only way out of this dilemma (it seems to me) is by way of vertical integration, whereby clinicians pick up each anatomical ball in turn" [page 381].

\section{DISCUSSION AND RECOMMENDATIONS}

We have described the arguments of different authors that eight factors (listed in table 4.1) have contributed to the decline of anatomical knowledge among medical students. Our 2011 review revealed no empirical evidence to support these claims, and we recommended further research on the implementation of teaching in context, vertical integration, and assessment strategies (Bergman et al. 2011). The following additional recommendations arise from our extensive exploration during the present review of the stories behind the factors. The first and second recommendations increasing recognition for teaching and enhancing the professional recognition of anatomists - find support from other authors in the recent literature. The third recommendation is more innovative: to encourage anatomists to participate in educational research.

\section{Recognition for teaching}

If teaching received more recognition for its academic value, teachers would have more time and money to invest in the development and/or implementation of: their own anatomical and clinical knowledge and didactic skills (factor 1 ), a core anatomy curriculum (factor 2), different teaching methods (factor 3), teaching in context (factor 4 ), assessment strategies (factor 6), and vertical integration (factor 8).

Teaching (anatomy to) medical students is almost invariably combined with research activities for basic scientists or patient care duties (and research tasks) for clinicians (Ten Cate et al. 2011). Medical schools are urged to take their responsibility for preparing medical students to become doctors more seriously (Fraser 1991). A crucial but unfortunately poorly developed area in most medical schools is human resource management and the rewarding of teaching accomplishments (Bergman and de Goeij 2010). For academic staff, there is a strong emphasis on research targets, 
whereas teaching in both basic and clinical sciences is less valued as an academic activity and consequently receives low priority (Older 2004). Selection for rewards (promotions, space, endowed chairs, etc.) is almost exclusively based on the number of publications and grant funding, not on teaching and clinical competence (Cahill and Leonard 1999; Fasel et al. 2005).

Teaching needs to be valued, encouraged, and internalized into the culture of the department and institution (Ten Cate et al. 2011). Future developments and improvements in (anatomy) education can only be accomplished by rewarding excellent and enthusiastic teachers and educationalists willing to work to improve the quality of education in their institution (Bergman and de Goeij 2010). "Teachers should be trained; good teachers should be rewarded, as are productive researchers; and poor teachers should be counselled" [page 835] (Monkhouse 1992).

The failure to reward teaching accomplishments could in part be due to failure to recognize the complex skills necessary to succeed as a medical educator. The recent literature contains interesting publications on scholarship in education, focusing on demonstrating scholarship in teaching and other learning-related activities (in contrast to educational research, which can be assessed and rewarded using the same types of evidence as basic science or clinical research) (Turner et al. 2012). In the past, the main criteria for scholarly activities by which institutions evaluated individuals' academic progress were research, peer review of scientific results, and dissemination of new knowledge (Srinivasan et al. 2011; Turner et al. 2012). However, innovation, development, and changes in medical education have entailed a growing appreciation of the importance of the educational mission at a number of medical schools, besides their research and patient care missions (Pawlina and Drake 2010; Turner et al. 2012). In consequence, broader definitions of scholarship have emerged along with corresponding changes in the respective reward systems (Turner et al. 2012). Teaching can be a scholarly act, but even in many top academic institutions not all teaching is scholarly (Beckman and Cook 2007). Since a sustained record of scholarship is the foundation for advancement in academia, various initiatives to define criteria for evaluating scholarship in teaching have been published, in order to implement and assess teaching scholars' work (e.g. (Fincher et al. 2000; Whitcomb 2003; Moses et al. 2006; Simpson et al. 2007; Turner et al. 2012)). There seems to be agreement that scholarly teaching must transform and extend students' self-knowledge, be open to the public, be subjected to review, and be accessible for exchange with other educators (Beckman and Cook 2007). To engage in scholarship for teaching and learning seems a desirable step for anatomists to ensure that the educational product they deliver has quality and is valued by students, institutions, and professional communities (Srinivasan et al. 2011). It goes beyond the scope of this review to discuss 
the practicalities further, but we would recommend Fincher et al. (2000) and Simpson et al. (2007) as a start for further reading for anyone interested.

\section{Training to become an anatomist: enhancement of professional recognition}

If becoming an anatomist requires completion of an accredited training program, anatomists as a professional group will gain greater recognition. It is also highly likely that it will inspire a wider range of people to pursue careers in anatomy, especially those whose principal interest lies in teaching. It will also give anatomists a much more solid base for, and therefore improve the quality of, actions and decisions in management, education, and research.

Many countries lack a nationally endorsed training program in anatomy. In the Netherlands, for example, anyone who wishes can call themselves an anatomist. The title is generally used as soon as a position in an anatomy department is acquired. Similar situations exist in the UK, USA, Australia, and New Zealand. The fact remains that the job title 'anatomist' is not founded on an acknowledged professional qualification and consequently carries no regard/prestige or attractive salary structure. Moreover, in the present state of anatomy education, people with little experience of the subject often have to take action and make decisions in areas that are practically unknown to them.

However, in some countries, the title 'anatomist' is only awarded to those who have completed a rigorous training program. In Germany, for example, (veterinary) medical graduates can enter training programs in several institutions to become 'medical specialists in anatomy', similar to postgraduate training in surgery or gynaecology. For biomedical graduates, the German Anatomical Society offers a program to become a 'professional anatomist'. These programs cover knowledge of (radiological) anatomy, embryology, and histology, and also body donation and cadaver preservation. They offer skills training in cadaver dissection and histological fixation, cutting and colouring. Completion of training means a rise in salary and a better chance of a permanent position in an anatomy department. However, all the aforementioned training programs focus on participation in biomedical research, showing a general neglect of educational skills.

In the current literature, scant attention is paid to improving the prospects of teachers who wish to pursue a career in anatomy. Results from studies in India and Nigeria show that scarcity of job opportunities and of adequate research facilities make nonclinical teaching specialties such as anatomy far less attractive as career options than clinical specialties (Anand et al. 2004; Onakpoya et al. 2009). It is striking that Indian students interested in becoming anatomists expressed a wish for a formal course in teaching (Anand et al. 2004). 
We feel it would be wise for national anatomical associations, in consultation with the anatomy departments of their countries, to set up accredited training programs for anatomists. Such programs should be open to students with degrees in (bio)medical studies. Ideally, training should be part-time, with students holding a position in an anatomy department. Programs should at least focus on increasing students' anatomical knowledge, on skills in dissection and preservation of cadavers, and last but not least, on educational knowledge and skills. Training should also take into account that anatomists work together with medical and biomedical staff in both education and research. If desired, students should be able to train in anatomy while working toward a PhD in the biomedical or educational field.

When there is more recognition for teaching and for the profession of anatomist, anatomy departments will be unlikely to have to hire more faculty who are great researchers but regard teaching as a chore. Also, they will not have to rely on retired clinicians to take up those position as often happens at present, because job advertisements might then attract a significant number of suitable applicants.

\section{Participation in educational research}

We suggest that each anatomy department should appoint about two anatomy teachers (not educationalists!) who are willing (and enabled) to explore learning theories and principles, keep abreast of the educational literature, participate in/perform educational research, and attend (inter)national educational conferences. By these means, the development and/ or implementation of didactic skills, a core anatomy curriculum (factor 2), different teaching methods (factor 3), teaching in context (factor 4), assessment strategies (factor 6), and vertical integration (factor 8 ) can be informed by theory, based on evidence, and subjected to purposeful evaluation.

We want to stress that anatomists should engage in educational research, not that educationalists should take over anatomy education. Some anatomists already feel that ownership of the curriculum has been taken away (hijacked) from the teaching faculty to (or by) the curriculum committee. Subsequently, their decisions on 'what is being taught and how' are blamed for influencing the anatomical knowledge of medical students in a negative way.

In medical schools, the anatomy department is usually one of those with the highest teaching load. However, research interests within an anatomy department are more often biomedically than educationally directed. Also, owing to the background of staff and management in an anatomy department, a clear educational strategy is often absent. 
For some anatomy departments, teaching is their core business, their 'raison d'être', but unfortunately it is not uncommon for anatomy teachers to be frowned upon when they express interest in educational research. This is remarkable: it is self-evident that the regular duties of their counterparts in research and the clinic include reading the latest literature, being oriented toward the latest approaches, developments and theories, replacing existing habits with new ones when appropriate, and submitting their work to critical peer review (Van der Vleuten et al. 2000). In medicine, evidencebased practice is widely accepted and has been defined as "[...] the conscientious, explicit and judicious use of current best evidence in making decisions about the care of individual patients" [page 71] (Sackett et al. 1996). In sharp contrast, Best Evidence Medical Education, defined as "the implementation, by teachers in their practice, of methods and approaches to education based on the best evidence available" [page 242] (BEME-Group 2000), is very rarely implemented.

\section{CONCLUSIONS}

Despite the absence of empirical evidence, eight factors are often blamed for causing the decline in anatomical knowledge among today's medical students. Since there have been complaints about this decline for decades, we suggest that the perception that anatomical knowledge levels have fallen arises from a generation conflict (Bergman et al. 2011); however, further research is necessary to determine the truth.

Although there are different opinions regarding its scope, there is a general consensus that medical students definitely cannot do without anatomical knowledge, and consequently without anatomy education. Increasing recognition for teaching accomplishments within an institution, a national training program in anatomy, and dedicated time for anatomists within their departments to involve themselves in the science of teaching, learning, and educational research, could help to identify factors contributing to the acquisition, retention, and transfer of anatomical knowledge and increase the focus on how anatomy education can be made as effective as possible. 


\section{REFERENCES}

Anand M., Raibagkar C., Ghediya S. \& Singh P. (2004). Anatomy as a subject and career option in view of medical students in India. J Anat Soc India, 53(1): 10-14.

Auer R.N. \& McDonald D.S. (2003). Anatomy is still essential. Canadian Medical Association Journal, 168(7): 829.

Beaty H.N. (1990). Changes in medical education should not ignore the basic sciences. Academic Medicine, 65(11): 675-676.

Beckman T.J. \& Cook D.A. (2007). Developing scholarly projects in education: a primer for medical teachers. Med Teach, 29(2-3): 210-218.

BEME-Group (2000). Best Evidence Medical Education (BEME): Report of meeting 3-5 December 1999, London, UK Med Teach, 22(3): 242.

Bergman E. \& de Goeij A. (2010). Basic sciences in problem-based learning. In Van Berkel H., Scherpbier A., Hillen H. \& van der Vleuten C. (Eds.), Lessons from Problem-based Learning (pp. 57-65). Oxford: Oxford University Press.

Bergman E.M., Van Der Vleuten C.P. \& Scherpbier A.J. (2011). Why don't they know enough about anatomy? A narrative review. Med Teach, 33(5): 403-409.

Cahill D.R. \& Leonard R.J. (1999). Missteps and masquerade in American medical academe: clinical anatomists call for action. Clinical Anatomy, 12(3): 220-222.

Cahill D.R., Leonard R.J. \& Marks S.C., Jr. (2000). A comment on recent teaching of human anatomy in the United States. Surgical and Radiologic Anatomy, 22(2): 69-71.

Carmichael S.W., Haines D.E. \& Drake R.L. (2002). Education in the anatomical sciences: The common goals of societies. The Anatomical Record, 269(2): 67.

Drake R.L. (1998). Anatomy education in a changing medical curriculum. The Anatomical Record, 253(1): 2831.

Drake R.L. (2002). Meeting the challenge: the future of the anatomical sciences in medical school curricula. The Anatomical Record, 269(2): 68.

Ellis H. (2002). Medico-legal Litigation and its Links with Surgical Anatomy. Surgery, 20(8): i-ii.

Fasel J.H., Morel P. \& Gailloud P. (2005). A survival strategy for anatomy. Lancet, 365(9461): 754.

Fincher R.M., Simpson D.E., Mennin S.P., Rosenfeld G.C., Rothman A., McGrew M.C., Hansen P.A., Mazmanian P.E. \& Turnbull J.M. (2000). Scholarship in teaching: an imperative for the 21st century. Acad Med, 75(9): 887-894.

Fincher R.M., Wallach P.M. \& Richardson W.S. (2009). Basic science right, not basic science lite: medical education at a crossroad. [Review]. J Gen Intern Med, 24(11): 1255-1258.

Fitzgerald T. (1992). Undergraduate medical anatomy teaching. Journal of Anatomy, 181 (Pt 2): 381.

Fraser R.C. (1991). Undergraduate medical education: present state and future needs. British Medical Journal, 303(6793): 41-43.

Halasz N.A. (1999). We create and can remove the roadblocks to good basic science education. Academic Medicine, 74(1): 6-7.

Kaufman D.R., Yoskowitz N.A. \& Patel V.L. (2008). Clinical reasoning and biomedical knowledge: implications for teaching. In Higgs J., Jones M.A., Loftus S. \& Christensen N. (Eds.), Clinical reasoning in the health professions. Third edition. (pp. 137-149): Elsevier.

McCrorie P. (2000). The place of the basic sciences in medical curricula. Medical Education, 34(8): 594-595.

Monkhouse W.S. (1992). Anatomy and the medical school curriculum. Lancet, 340(8823): 834-835.

Monkhouse W.S. \& Farrell T.B. (1999). Tomorrow's doctors: today's mistakes? Clinical Anatomy, 12(2): 131134.

Moses A.S., Heestand D.E., Doyle L.L. \& O'Sullivan P.S. (2006). Impact of a teaching scholars program. Acad Med, 81(10 Suppl): S87-90. 
Norman G. (2000). The essential role of basic science in medical education: the perspective from psychology. Clin Invest Med, 23(1): 47-51.

Norman G. (2007). How basic is basic science? Advances in Health Sciences Education: Theory and Practice, 12(4): 401-403.

Norman G. (2012). The basic role of basic science. [Editorial

Introductory]. Adv Health Sci Educ Theory Pract, 17(4): 453-456.

Older J. (2004). Anatomy: a must for teaching the next generation. Surgeon, 2(2): 79-90.

Onakpoya O.H., Onakpoya U.U. \& Adereti G.E. (2009). The prospect of anatomy as a career choice among clinical year medical students in Nigeria. Ann Afr Med, 8(2): 90-94.

Paalman M.H. (2000). Why teach anatomy? Anatomists respond. The Anatomical Record, 261(1): 1-2.

Pabst R. (1992). Teaching of anatomy. Lancet, 340(8833): 1474.

Pabst R. (1994). Teaching gross anatomy: an important topic for anatomical congresses and journals? Surgical and Radiologic Anatomy, 16(1): 1-2.

Pawlina W. \& Drake R.L. (2010). Anatomical Sciences Education: a partner on the road to scholarship in teaching and learning. [Editorial]. Anat Sci Educ, 3(1): 1-2.

Purkayastha S., Paraskevas P. \& Darzi A. (2007). Make surgeons more active in teaching anatomy at all levels. British Medical Journal, 334(7585): 110.

Raftery A. (2006). Anatomy teaching in the UK. Surgery, 25(1): 1-2.

Reidenberg J.S. \& Laitman J.T. (2002). The new face of gross anatomy. The Anatomical Record, 269(2): 81-88.

Sackett D.L., Rosenberg W.M., Gray J.A., Haynes R.B. \& Richardson W.S. (1996). Evidence based medicine: what it is and what it isn't. BMJ, 312(7023): 71-72.

Simpson D., Fincher R.M., Hafler J.P., Irby D.M., Richards B.F., Rosenfeld G.C. \& Viggiano T.R. (2007). Advancing educators and education by defining the components and evidence associated with educational scholarship. [Research Support, Non-U.S. Gov't]. Med Educ, 41(10): 1002-1009.

Srinivasan M., Li S.T., Meyers F.J., Pratt D.D., Collins J.B., Braddock C., Skeff K.M., West D.C., Henderson M., Hales R.E. \& Hilty D.M. (2011). "Teaching as a Competency": competencies for medical educators. [Research Support, Non-U.S. Gov't

Review]. Acad Med, 86(10): 1211-1220.

Swanson D.B. \& Case S.M. (1997). Assessment in Basic Science Instruction: Directions for Practice and Research. Advances in Health Sciences Education, 2: 71-84.

Ten Cate T.J., Kusurkar R.A. \& Williams G.C. (2011). How self-determination theory can assist our understanding of the teaching and learning processes in medical education. AMEE guide No. 59. Med Teach, 33(12): 961-973.

Turner T., Palazzi D., Ward M. \& Lorin M. (2012). Transforming teaching into scholarship. [Research Support, Non-U.S. Gov't]. Clin Teach, 9(6): 363-367.

Turney B.W. (2007). Anatomy in a modern medical curriculum. Annals of the Royal College of Surgery of England, 89(2): 104-107.

Van der Vleuten C.P.M., Dolmans D.H.J.M. \& Scherpbier A.J.J.A. (2000). The need for evidence in education. Med Teach, 22(3): 246-250.

Whitcomb M.E. (2003). The medical school's faculty is its most important asset. [Editorial]. Acad Med, 78(2): 117-118.

Whitcomb M.E. (2006). The teaching of basic sciences in medical schools. Academic Medicine, 81(5): 413414.

Williams G. \& Lau A. (2004). Reform of undergraduate medical teaching in the United Kingdom: a triumph of evangelism over common sense. British Medical Journal, 329(7457): 92-94. 




\section{ABSTRACT}

\section{Background}

To get insight in how theoretical knowledge is transformed into clinical skills, important information may arise from mapping the development of anatomical knowledge during the undergraduate medical curriculum. If we want to gain a better understanding of teaching and learning in anatomy, it may be pertinent to move beyond the question of how and consider also the what, why and when of anatomy education.

\section{Methods}

A purposive sample of 78 medical students from the 2 nd, 3rd, 4th and 6th year of a $\mathrm{PBL}$ curriculum participated in 4 focus groups. Each group came together twice, and all meetings were recorded and transcribed verbatim. Data were analysed with template analysis using a phenomenographical approach.

\section{Results}

Five major topics emerged and are described covering the students' perceptions on their anatomy education and anatomical knowledge: 1) motivation to study anatomy, 2) the relevance of anatomical knowledge, 3) assessment of anatomical knowledge, 4) students' (in)security about their anatomical knowledge and 5) the use of anatomical knowledge in clinical practice.

\section{Conclusions}

Results indicated that a PBL approach in itself was not enough to ensure adequate learning of anatomy, and support the hypothesis that educational principles like timeon-task and repetition, have a stronger impact on students' perceived and actual anatomical knowledge than the educational approach underpinning a curriculum. For example, students state that repetitive studying of the subject increases retention of knowledge to a greater extent than stricter assessment, and teaching in context enhances motivation and transfer. Innovations in teaching and assessment, like spiral curriculum, teaching in context, teaching for transfer and assessment for learning (rewarding understanding and higher order cognitive skills), are required to improve anatomy education. 


\section{BACKGROUND}

For many clinical specialties, a good knowledge of anatomy is indispensable to ensure safe and efficient clinical practice (Fasel et al. 2005; Raftery 2006). Together with physiology and biochemistry, anatomy is one of the basic sciences that are to be taught in the medical curriculum (Bergman and de Goeij 2010). In Problem-based Learning (PBL) curricula, basic sciences are introduced simultaneously, so-called horizontal integration, and basic science instruction is integrated with clinical science instruction, so-called vertical integration (Dahle et al. 2002). In order to achieve this, basic and clinical sciences are not presented in separate courses but in integrated themes (Bergman and de Goeij 2010). PBL aims to promote active engagement of students in their own learning by stimulating constructive, self-directed, collaborative and contextual learning and by using (patient) problems as triggers of learning (Dolmans et al. 2005). Several meta-analyses have shown that PBL and traditional curricula do not differ in any way with regard to students' performance on tests of basic science and clinical knowledge (Vernon and Blake 1993; Colliver 2000; Newman 2003), and studies of students' basic science and anatomy knowledge have revealed neither benefits nor drawbacks of PBL curricula compared to traditional ones (Alleyne et al. 2002; Prince et al. 2003; Hinduja et al. 2005; Adibi et al. 2007). Nevertheless, it has been pointed out that there is a discrepancy between students' actual and perceived knowledge of basic sciences (Prince et al. 2003; Prince et al. 2005a; Prince et al. 2005b). A questionnaire among students in a PBL curriculum at the start of the clinical phase showed that only $18.5 \%$ thought their basic science knowledge was sufficient, with most deficiencies being perceived in pharmacology and anatomy (Prince et al. 2005a). Interestingly, students' views appeared to change with experience. When Prince et al. (2005b) asked anatomists, clinicians, beginning clerks and recent graduates to set a pass/fail standard for an anatomy test at the start of clinical training, the highest standard (failing 64\%) was set by the students, but the recent graduates were by far the most lenient judges (failing only $26 \%$ ), while clinicians and anatomists failed $58 \%$ and $42 \%$, respectively. The researchers suggested that the leniency of the recent graduates might be attributable to insight gained during clinical experience into the level of knowledge actually required in clinical practice and to their awareness of how much they had learned during the clerkships. It remains unclear, however, why, at the start of clinical training, students should feel so insecure about their knowledge and set such high standards for themselves.

It has been hypothesised that students' perceived and actual knowledge is less determined by the general educational approach of the curriculum than by educational strategies like time- on-task, repetition and teaching in context (Prince et al. 2003; Bergman et al. 2008). There is, however, no research evidence to support 
this, and a recent literature study seeking empirical evidence for factors affecting students' anatomical knowledge unfortunately failed to yield any meaningful conclusions due to the generally poor quality of studies (Bergman et al. 2011). Although quite varied, the current literature on anatomy education seems to focus on methods of teaching (Regan de Bere and Mattick 2010). An example is the ongoing debate about cadaver dissection as an educational tool (Aziz et al. 2002; Older 2004; Raftery 2006). Despite studies showing that a dissection course is not a uniform learning experience (Winkelmann 2007), that students do not always rate dissection as the most useful educational tool (Azer and Eizenberg 2007) and that they do not consider all aspects of anatomical education to be meaningful (Wilhelmsson et al. 2010), the debate has remained unresolved so far. However, perhaps we might learn from the debate that if we want to gain a better understanding of teaching and learning in anatomy, it may be pertinent to move beyond the question of how and consider also the what, why and when of anatomy education. In search of an answer to these questions, we explored the perceptions of students in a PBL curriculum regarding their anatomy education and knowledge.

\section{METHODS}

\section{Theoretical framework}

Expecting that the perceptions of students at different stages of the undergraduate curriculum would reflect a process of complex, unstable, non-linear change in medical education (Bunniss and Kelly 2010), we opted for a constructivist paradigm in designing the study. The constructivist paradigm is grounded in relativist ontology and subjectivist epistemology, which assume the existence of multiple and sometimes conflicting realities that are socially and experientially based, dependent on individuals (Illing 2007) and that different people experience the same world in different ways.

We analysed the data using a phenomenographical approach, aimed at describing, analysing and understanding: 1) experiences or perceptions of a phenomenon (anatomy) and 2) the different ways in which a phenomenon is perceived and understood (Marton 1981; Stenfors-Hayes et al. 2013). Because group processes were expected to stimulate students to explore and articulate their perceptions and push the boundaries of the discussion further than would be likely in one-on-one interviews (Willis et al. 2009), we gathered data in sessions of focus groups composed of students at different stages of the undergraduate curriculum. 


\section{Setting}

The study was conducted in the PBL curriculum of Maastricht University, the Netherlands (see Figure 5.1). At the time of this study, years 1 and 2 consist of six thematic units of approximately six weeks, with few real patient encounters. Paper cases are the starting point for learning in groups of around ten students and a tutor, and knowledge is assessed by 80-120 multiple choice questions in end-of-block tests. In the four systems-based clusters of year 3 , the paper cases are replaced by patient contacts in outpatient clinics (Diemers et al. 2008), and knowledge is assessed in oral exams and written essay questions. The anatomy of the thorax, abdomen, pelvis, musculoskeletal system and nervous system is taught in years 1 and 2, and revisited in year 3. In the first three years, anatomy is taught in tutorial groups, during lectures and in the dissection room with models, prosected cadavers and - for the musculoskeletal system - surface anatomy. Years 4 and 5 are devoted to clinical clerkships in twelve disciplines, with formal anatomy instruction being included in only the ophthalmology

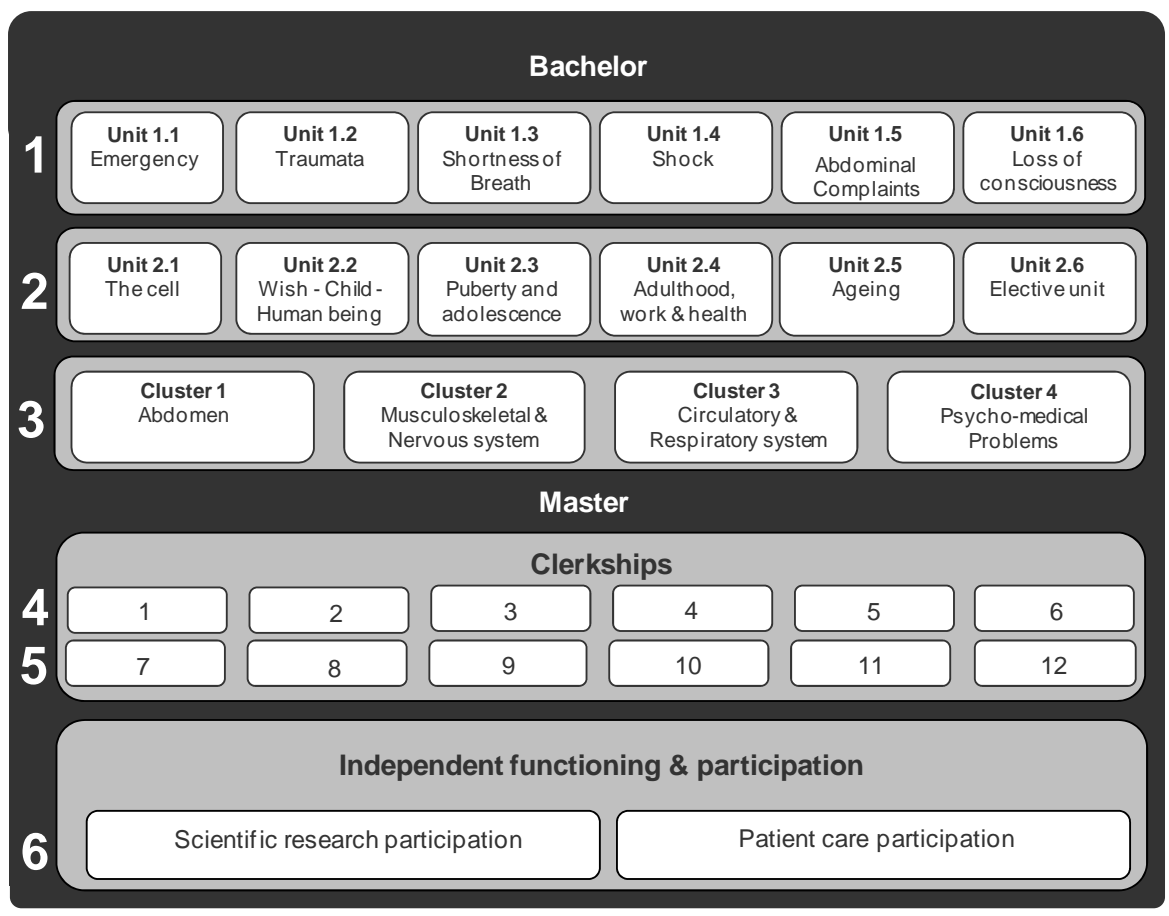

Figure 5.1 Curriculum map of the PBL curriculum of Maastricht University at time of this study. The first and second year are each divided in six thematic units, the third year is divided in four clusters. The fourth and fifth year are devoted to twelve different clerkships. Half of the sixth year is dedicated to participation in a research project, the other half is dedicated to in patient care (extensive clerkship). 
clerkship and ENT clerkship. In year 6 students undertake an eighteen-week research clerkship and an eighteen-week clinical clerkship with more independence and responsibility for patient care than in the preceding years. Throughout the curriculum, anatomy is also assessed in OSCE's in years 1, 2, 3 and 5 and four progress tests each year. For a detailed description of the curriculum see Van Berkel et al. (2010).

\section{Ethical approval}

Although the Dutch Ethical Review Board informed us that non-patient-related research was exempt from ethical review, we obtained written informed consent from all the participants.

\section{Participants}

To ensure a wide variety in clinical experience, medical students in years 2, 3, 4 and 6 were invited by email to participate in two focus groups. The students in year 2 had just finished year 1 , so they had had substantial anatomy education but no real patient encounters. The students in year 3 had just started and where on the brink of going into a series of real patient encounters. Year 4 and year 6 students would have had substantial real patient encounters. We selected students who would be able to attend both sessions, had completed at least half of the clerkship rotations, including the surgical clerkship (year 4) or all clerkships (year 6). The focus groups were scheduled to prevent interference with educational activities and clinical work. Participation was voluntary, sandwiches were available at sessions and students received a small fee for each hour of participation. The number and sizes of the focus groups were arranged to accommodate all volunteers. Participating students of the same year were randomly divided into two groups, in other words, the students from different years were not mixed in the groups.

A total of 78 students volunteered to participate (table 5.1). With a range of 1724 students from each year, and an average of 320 students per cohort, they represent about $6 \%$ of their population. Of the total number of participants, $75.6 \%$ was female, a slight overrepresentation compared to the actual figure of $60-70 \%$ per cohort. None of the volunteers were resit students. A T-test comparing Z-scores and percentile scores on progress tests only showed a significant difference in year 4 ( $p=0.037$, equal variances assumed) which turned out to be attributable to two students being in the top ten of their class. 
Table 5.1 Descriptives of focus group participants

\begin{tabular}{|c|c|c|c|c|c|c|c|}
\hline & & \multirow{2}{*}{$\begin{array}{l}\text { Focus group } \\
\text { number }\end{array}$} & \multirow{2}{*}{$\begin{array}{l}\text { Number of } \\
\text { participants }\end{array}$} & \multicolumn{2}{|l|}{ Age (years) } & \multicolumn{2}{|c|}{ Gender } \\
\hline & & & & Mean \pm SD & Range & Male & Female \\
\hline \multirow{4}{*}{$\begin{array}{l}\text { Junior } \\
\text { students }\end{array}$} & Year 2 & Group 1 & 12 & $19.5 \pm 1.0$ & $19-22$ & 2 & 10 \\
\hline & & Group 2 & 12 & $19.1 \pm 1.1$ & $18-22$ & 1 & 11 \\
\hline & & Group 3 & 10 & $20.3 \pm 0.9$ & $19-22$ & 3 & 7 \\
\hline & Year 3 & Group 4 & 9 & $20.2 \pm 0.4$ & $20-21$ & 4 & 5 \\
\hline \multirow{4}{*}{$\begin{array}{l}\text { Senior } \\
\text { students }\end{array}$} & Year 4 & Group 5 & 8 & $21.7 \pm 1.0$ & $21-23$ & 1 & 7 \\
\hline & & Group 6 & 9 & $24.2 \pm 4.0$ & $22-34$ & 5 & 4 \\
\hline & Year 6 & Group 7 & 10 & $24.3 \pm 1.6$ & $23-28$ & 1 & 9 \\
\hline & & Group 8 & 8 & $24.8 \pm 1.0$ & $23-26$ & 2 & 6 \\
\hline
\end{tabular}

\section{Procedure}

The two-hour focus group sessions were two weeks apart, so the total duration of the focus group sessions were a maximum of $2 \times 2$ hours. The objective of the second session was to elaborate on, or further clarify, statements or discussions that originated in the first session. Students received a written summary of the first session to stimulate elaboration and discussion in the second session. If we had felt that saturation was not reached after these $2 \times 2$ hours, we would have scheduled more session. However all groups did not even need the complete 2 hours of the second session to reach saturation and extra session where therefore not necessary. AS moderated the focus groups, guided by a topic list which was iteratively adjusted based on what emerged during the sessions. 


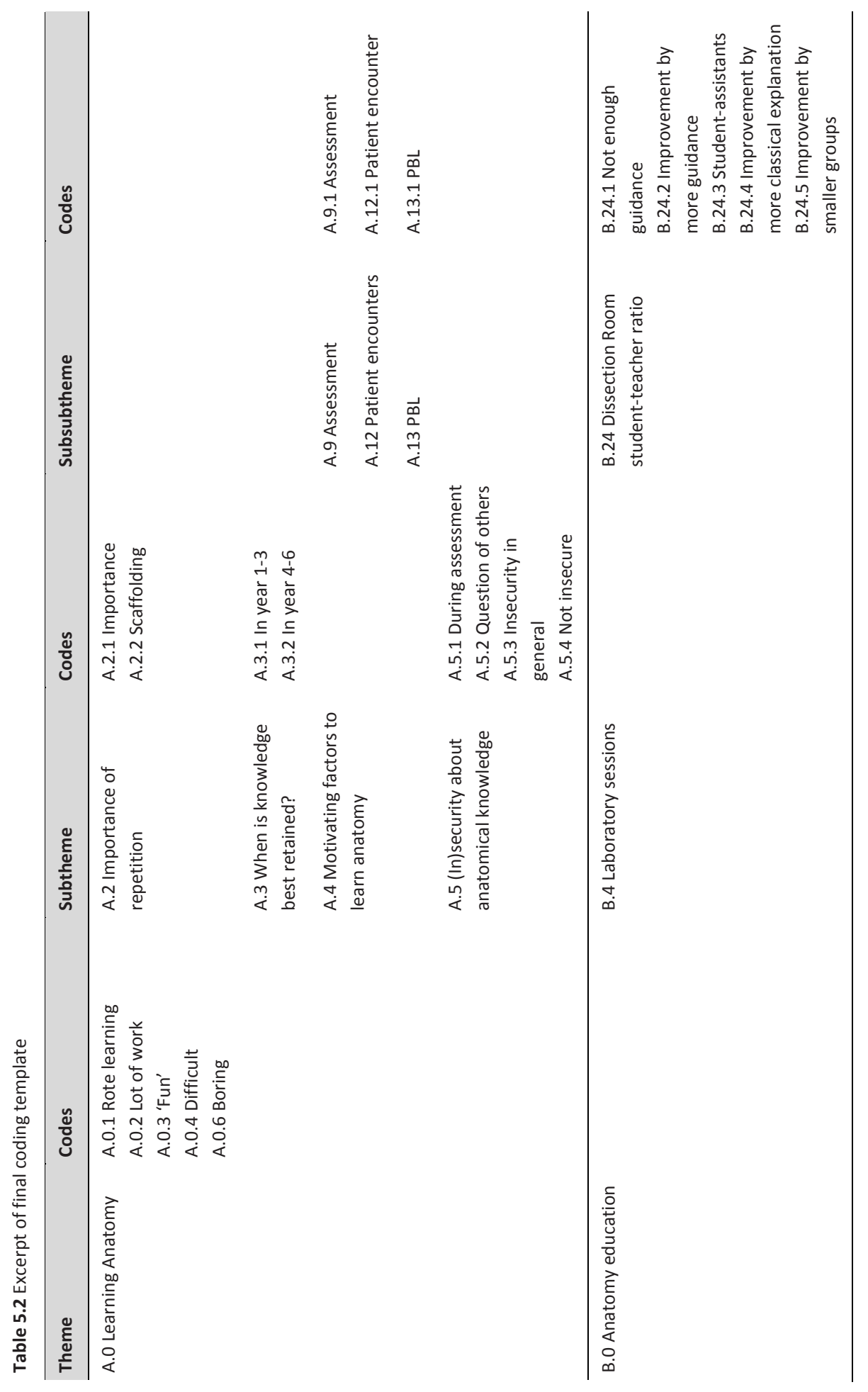




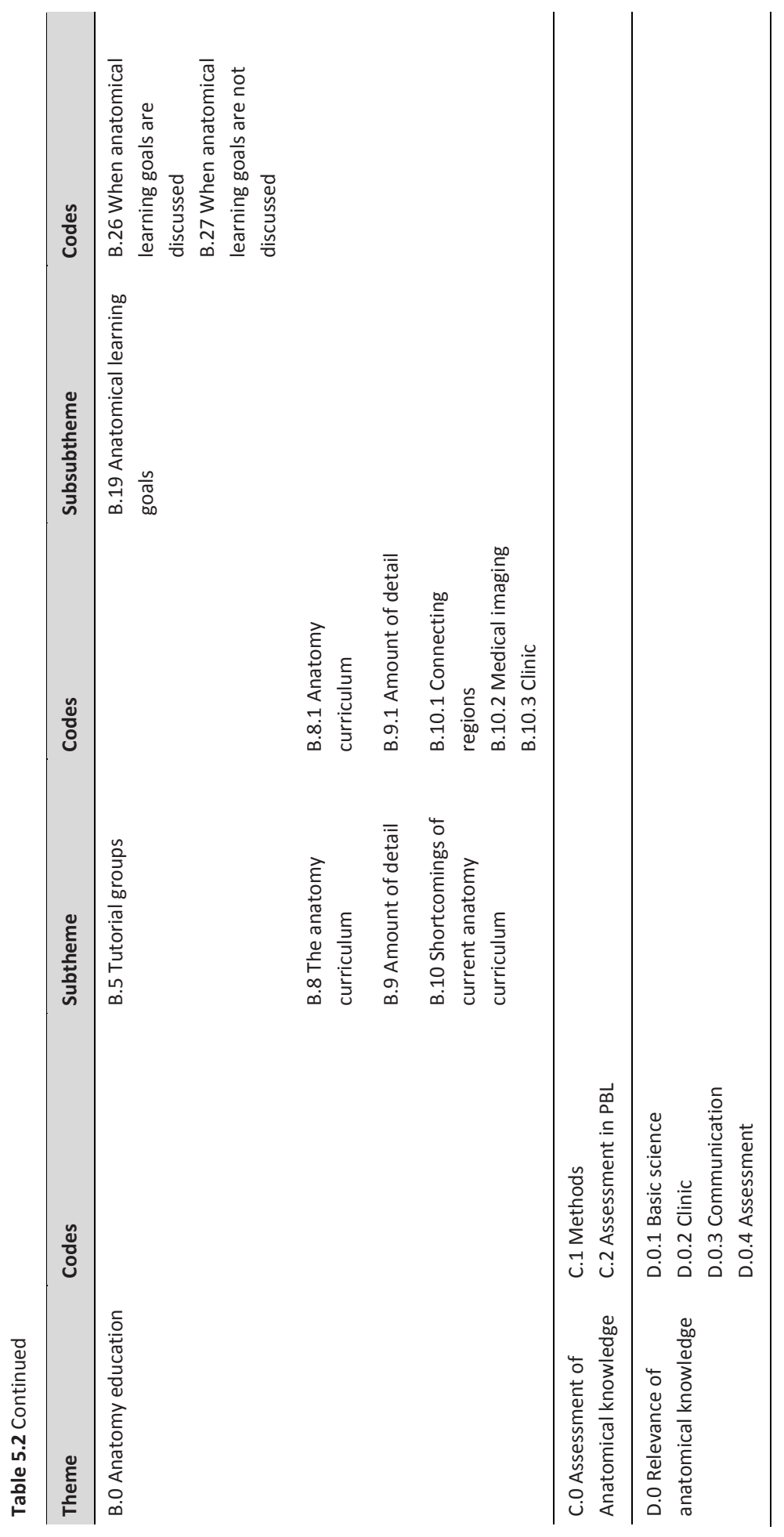




\section{Data analysis}

The discussions were audio-recorded and transcribed verbatim. The resulting sixteen transcripts were analysed using template analysis, described by King (2004) as a technique for organising (the relationships between) themes emerging during the analysis of (large sets of ) textual data, which is particularly effective for comparing the perspectives of different groups.

The transcripts were divided among three researchers (EB, AH and IV), who identified and entered themes and subthemes in individual templates, combining these, after discussion, into one general preliminary template. The researchers sometimes had different views on the division of (sub) themes, but these disagreements were resolved through discussion. Next, they created codes for each theme and subtheme reflecting students' relevant quotations, and entered these into the preliminary template after discussion. Careful reading and re-reading of the transcripts resulted in the final template (for an excerpt see table 5.2) that was used to code all the transcripts. ATLAS.ti 6.0 software (www.atlasti.com) was used for the analysis. Disagreements during coding were few, mainly concerning the attribution of multiple codes to one piece of text, and were discussed until consensus was reached. After the coding, the data were organised by themes to enable comparison amongst the groups. EB, AH and IV met several times to discuss and organise students' perceptions relating to the themes, focusing on emerging similarities and differences amongst the groups. To minimize bias in interpreting the data by EB and AH being anatomy teachers and IV being a student, frequent meetings were held with educationalists CV and AS to discuss the preliminary results.

\section{RESULTS}

Students' perceptions appeared to centre around five major topics: 1) motivation to study anatomy, 2) the relevance of anatomical knowledge, 3) assessment of anatomical knowledge, 4) students' (in)security about their anatomical knowledge and 5) the use of anatomical knowledge in clinical practice (for a summery, see table 5.3). The results for each topic are presented with illustrative quotes. For the sake of anonymity, the students are identified by unique codes ('student $6 d^{\prime}$ ' refers to 'student $d^{\prime}$ in group 6 (table 5.1)). When perceptions were similar, second-year and third-year students are referred to as junior students and fourth-year and sixth-year students as senior students. 
Table 5.3 Final main themes

\begin{tabular}{|c|}
\hline Motivation to study anatomy \\
\hline $\begin{array}{l}\text { Prime motivating factor to study anatomy is clinical exposure: preferably one-to-one (supervised) contact } \\
\text { with a real patient, but simulated patients also work well for junior students. PBL is not enough incentive } \\
\text { to study anatomy. Without putting anatomy education in context (bringing the patient to the dissection } \\
\text { room), learning anatomy is still perceived as boring and depending a lot on rote learning and self- } \\
\text { discipline. }\end{array}$ \\
\hline Relevance of anatomical knowledge \\
\hline $\begin{array}{l}\text { Perceived relevance of anatomy and perceived importance are not synonymous for most students. For } \\
\text { junior students relevance is strongly connected to the severity in which a subject assessed. Senior } \\
\text { students describe realisation of the relevance of anatomical knowledge only being reached after extensive } \\
\text { clinical exposure. }\end{array}$ \\
\hline Assessment of anatomical knowledge \\
\hline $\begin{array}{l}\text { While students suggest stricter assessment to acquire more anatomical knowledge, senior students } \\
\text { suggested that more repetition is necessary to promote knowledge retention. They furthermore } \\
\text { acknowledged that repetition also motivates them and increase possibilities of scaffolding. }\end{array}$ \\
\hline Students' (in)security about anatomical knowledge \\
\hline $\begin{array}{l}\text { The junior students are very insecure because they feel that they have not mastered everything in the } \\
\text { curriculum before their clerkships and expect to get into trouble during patient encounters because of } \\
\text { that. Senior students are able to put these feelings in perspective, understanding that these feelings were } \\
\text { only natural when students had not yet had any clinical experience. However, the question whether they } \\
\text { should master everything in the curriculum led to an unresolved considerable debate. }\end{array}$ \\
\hline Use of anatomical knowledge in clinical practice \\
\hline $\begin{array}{l}\text { As a clerk students did not encounter any real problems with not knowing all anatomical details. Senior } \\
\text { students specifically noted anatomy being taught by region as a specific shortcoming of PBL. They felt that } \\
\text { as a result, they did not form a clear coherent picture of the whole human body. This was especially felt } \\
\text { when knowledge of blood vessels or nerves was concerned, or when interpreting medical imaging. }\end{array}$ \\
\hline
\end{tabular}

\section{Motivation and stimulation}

There was a general feeling among junior students that anatomy was boring. They associated it with having to memorise vast amounts of factual knowledge, requiring more self-discipline than understanding. In marked contrast to the other basic sciences, physiology in particular, anatomy was perceived as learning the names of structures without any attention to how structures were related to clinical signs and symptoms. Senior students recollected this feeling from their earlier years.

"There is nothing to understand, it is just factual knowledge: what is this structure and what is that structure?" (student 1i, year 2). 
"[...] physiology, pharmacology and so on are strongly interrelated as regards mechanisms, [...] But anatomy, well it's just cramming. There is nothing to understand about anatomy." (student $3 b$, year 3 ).

The prime motivating factor to study anatomy was clinical exposure. For junior students this could be an encounter with a simulated patient, talking with a real patient in the small group or watching an operation from behind a window. But the strongest stimulus by far was one-to-one (supervised) contact with a real patient. Students were very much concerned not to lose face, and real patient encounters also appealed to their sense of responsibility and accountability.

"For, if you don't know the answer in a test, no-one will blame you. But if you have not prepared and you are facing a doctor, there comes a moment that you just feel rather stupid when you don't know the answer." (student $2 f$, year 2).

"A real patient is indeed more of an incentive, [...] this patient said to us "I want to ask you a question because I do not understand why the tingling is in these four fingers and not in the other one' [...]. We explained that it was because this nerve was only for those four fingers, but if you had not learnt that, you would really have been stuck for an answer." (student 3c, year 3).

It was generally agreed that PBL did not offer enough incentive to study anatomy. The paper cases did not stimulate students to learn about anatomy nor to see its relevance. The general opinion was that, for various reasons, it was common for groups to ignore the learning goals relating to anatomy, limiting their opportunities to practise the application of theoretical knowledge to clinical cases. Students suggested that anatomy instruction, both lectures and laboratory sessions, could be made more effective by providing context, for example by pointing to links with radiology or pathology. Students also asked for more guidance in laboratory sessions. To deal with potential staffing problems, they recommended the use of student assistants. It was not so much explanation they were after, although some of them would not mind, but coaching by an enthusiastic teacher with a good idea of their prior knowledge who asked questions and 'told stories' showing how anatomy could be useful in understanding and memorising pathological signs and symptoms. 


\section{Relevance versus importance}

There was general awareness among the students of the relevance of anatomy to numerous aspects of their future professional practice:

"You need it for diagnosis; you need it for physical examination. For handover to colleagues, for record keeping, for writing letters, in fact for understanding how certain processes work, why patients are ill and what should be done about it." (student 7i, year 6).

As for the junior students, despite their acknowledged awareness of the relevance of anatomy, their notion of relevance was not commensurate with the importance they accorded to anatomy. In other words, they did not give it priority over other studyrelated and personal activities. Perceived importance of a subject seems to be strongly connected to the severity in which it is assessed; the impact of the subject on assessment results. Perceived relevance of anatomy and perceived importance are not synonymous for these students, and stricter assessment is a frequently mentioned method as an incentive for them to study harder for anatomy (or any other subject).

The full realisation of the relevance of anatomy - its intrinsic value in medicine came only after extensive clinical experience:

"It was the same for me [insight] that in the clerkships I suddenly thought, hey, at this point it would have been really useful if I had studied a bit more" (student 8f, year 6).

"It is quite easy to survive [the first years] without anatomy [...]" "[...] but, [that] is a bad thing, because basically you need anatomy, it is just that when it is taught you don't realise that, or you don't want to [...]" (student $8 e$, student $8 b$, year 6).

Two educational experiences in particular had confronted the sixth-year students with the relevance of anatomy. The neurology clerkship was mentioned by many students:

"[...] I am doing neurology now and there you discover that every diagnosis, everything comes down to anatomy in the end and how things run and work, that is really awfully important." (student $7 g$, year 6).

The second experience was the senior clinical clerkship in year 6. Their increased independence and responsibility for patients meant that students had to rely on their own (anatomical) knowledge to a far greater extent than at any time before. 


\section{Assessment versus repetition}

A drawback of PBL, according to the students, was integrated assessment, which was particularly detrimental to their learning of anatomy, because it enabled them to pass tests without answering any anatomy question correctly. The strong association between assessment and the perceived importance of anatomy was underscored by students uniformly calling for a more stringent assessment process. A huge amount of focus group time was taken up by discussing ideas for minor adjustments and new methods of assessment. An interesting observation was made by senior students, who noted that, although a more stringent assessment procedure might make them study harder, it would not necessarily promote retention of anatomical knowledge. Retention was thought to benefit more from revisiting topics on more than two occasions in the course of the curriculum.

\section{"[...] for anatomy remains a subject [...] you really have to repeat, and I mean, for you can study it very thoroughly once and teaching may have been good and it may be assessed, but I think you are bound to forget it after a year, [...] you really should look at it again after a year then it will stick in your mind much better [...]" (student 6b, year 4).}

Both junior and senior students suggested that anatomical topics should be presented with less detail the first time. Junior students arrived at this suggestion by observing that having to memorise a long list of structures was such a daunting task that it was more likely to demotivate them than to encourage them to study:

"Well, as I see it all the time, those arteries, those names and those nerves. I just feel like no, I will never be able to remember all of that. And then I don't even begin to study." (student 3 h, year 3 ).

The senior students suggested that the amount of detail should increase with each repetition of a topic. They felt that currently anatomy education was using a 'one shot approach', presenting anatomy topics with all the major and minor structures (the latter being 'the details') in one long session. It was suggested that multiple shorter sessions, preferably spread over (more than) the first three years of the curriculum, would be more effective. The first session might cover the major structures ('the basics') with more detail being added in subsequent sessions. Students argued that in this way they would learn less per session, but would likely remember more eventually. It was also argued that they would be more motivated to study the same topic again when, on revisiting it, they found they already knew something about it. 
"Repetition is really a stimulus. Oh, I already know that, oh but not that." (student $5 \mathrm{~g}$, year 4).

\section{Insufficiency and insecurity}

The vast majority of junior and senior students alike believed that their anatomical knowledge was deficient. They had mastered the broad outlines, but not all the important details. As a result, junior students anticipated problems in the clerkships, based on the assumption that the details were important since they were included in the curriculum. This perceived lack of knowledge made them feel uncertain, and students came up with a variety of ideas for how they might remedy their deficiencies in the future.

Senior students remembered these feelings of uncertainty, but were now able to put them into perspective, understanding that these feelings were only natural when students had not yet had any clinical experience.

"I've had different phases, at first I really thought my knowledge is really awful, also for anatomy, and now I am gradually getting to the stage of well perhaps it may be alright after all [...]" (students 7a, year 6).

"Yes, for I also sort of think well it will be alright, [...] yes after all I am only a student [...], I mean we should not be thinking that we are all doctors already, and aim so high, that doesn't make things better" (student 5b, year 4).

The students seemed to be in two minds, however. On the one hand, they were aware that the physicians (residents) they worked with did not know everything about anatomy (just a lot about their own specialty), which reassured them that they did not have to know everything. On the other hand, however, they felt that, since they were training to become a medical doctor and not a specialist, they should have a sound general knowledge of anatomy. This was an issue of considerable debate among the senior students, which remained unresolved.

\section{Anatomical knowledge in practice}

Obviously, the senior students were the only ones who were able to comment on the application of anatomical knowledge in clinical practice. In their experience, less than detailed knowledge did not cause major problems: 
"It is not as if in the clerkships I have messed up completely, not at all, but what I find is that you notice, well things are not going quite as smoothly as they should." (student 5c, year 4).

When discussing the generally felt need for more basic science knowledge, students frequently referred to neuroanatomy or structures extending across body regions, like nerves and blood vessels:

"[...] blood vessels and nerves. These are really the most important things you should see in their entirety [...]" "Yes, you would see them run into the foot, but you had no idea where they had branched off" (student 5c \& student $5 b$, year 4$)$.

According to the students, a specific shortcoming of PBL was that anatomy was taught by region, sometimes with months between different regions. As a result, they did not form a clear coherent picture of the human body. Even some of the junior students identified this problem and its clinical consequences:

"And I just thought it strange, you start with the ankle and then, I don't even remember the order in which we did it, but you really moved from one place to the other [...]" (student 7c, year 6).

"One time on a scan you saw something down in the lung and then it turned out to be the stomach coming through the diaphragm. And I would never have thought of that, because to me thorax and abdomen are just two totally unrelated things." (student $1 f$, year 2 ).

Students also mentioned problems applying theoretical knowledge in the clinical context, such as memorising, retrieving and then using knowledge of the musculoskeletal system when examining and diagnosing a patient or interpreting $X$ rays, CT scans or MRIs:

"[...] what we need in clinic for there they say, yes just take a look at that scan. And then I think like, well, what is the abnormality here, yes I see a shadow there, wow, yes no that is a, that is just an artery, yes sorry, that is ..." (student 6d, year 4). 


\section{DISCUSSION}

Mapping the development of anatomical knowledge over the continuum of medical training may yield valuable information about how theoretical basic science knowledge transforms into clinically applicable skills and practices (Wilhelmsson et al. 2010). The results of the present study indicate that at different stages of a PBL curriculum students have different perceptions of anatomy education and anatomical knowledge. We will discuss the results in light of the literature to arrive at implications for several areas of anatomy instruction.

\section{Motivation}

Students' general awareness of the relevance of anatomy is consistent with results reported by Moxham \& Plaisant (2007). For junior students, however, relevance appeared to be dissociated from the importance of anatomy in terms of study effort: they needed assessment as an incentive to make them study. Assessment driving learning is a well known phenomenon in education (Larsen et al. 2008; Schuwirth and Van der Vleuten 2011). An interesting perception was voiced by senior students who argued that stricter assessment might have motivated them to study harder, but would not necessarily lead to better retention of knowledge.

Test-directed studying can be regarded as a sign of external motivation. Strong internal motivation, according to the students, arose from contact with real patients. The introduction of such encounters in the preclinical phase of a PBL curriculum has been described extensively (e.g. Dammers et al. (2001) Diemers et al. (2007) and Diemers et al. (Diemers et al. 2008)). A study by Takkunnen et al. (2011) showed that the introduction of a real patient in a preclinical first-year anatomy curriculum, in addition to paper cases, did enhance motivation, understanding of learning objectives and confidence for future patient encounters, but failed to improve learning outcomes (scores on the course exam). As the implementation and integration of real patient contacts in medical curricula is too complicated to be embarked upon lightly (Diemers et al. 2007), further research should investigate how real patient contacts can have a positive impact on learning outcomes.

In their Self-Determination Theory (SDT), Ryan \& Deci (2000) described a continuum of extrinsic motivation, ranging from impoverished forms of motivation to more active, agentic states. They suggested that students could be stimulated to attain a more active state of extrinsic motivation by fostering a feeling of competence within students. According to SDT, students are more likely to adopt an extrinsic goal as their own goal, when they are offered optimal challenges and given relevant feedback. This mechanism appears to resonate with remarks of the students in the focus groups that 
they would be more motivated to study a topic when it was presented iteratively, because they would recognise the topic and feel they already understood some of it. SDT seems to be a promising area of research in relation to anatomy instruction.

\section{Spiral curriculum, from concept to complex}

Repetition with increasing detail as advocated by the students to enhance retention of knowledge appears to be in alignment with the characteristics of a spiral curriculum (Harden and Stamper 1999): "A spiral curriculum is one in which there is an iterative revisiting of topics, subjects or themes throughout the course. A spiral curriculum is not simply the repetition of a topic taught. It requires also the deepening of it, with each successive encounter building on the previous one" [page 141]. Studies have confirmed that a spiral curriculum can be motivating because it activates and reinforces prior knowledge and stimulates a more advanced level of application and integration of knowledge and consequently increases expertise and feelings of competence (Harden and Stamper 1999; Mattick and Knight 2007). In a spiral curriculum, knowledge is presented in a logical sequence from simple to complex. In the study of Smith \& Mathias (2010), students also reported that the amount of anatomy they needed to learn to be daunting. Controlled introduction of knowledge in the first loop of the spiral prevents students from being overwhelmed by details, one of the barriers to learning mentioned in the focus groups.

Furthermore, teaching anatomical concepts (Eizenberg 1988; Louw et al. 2010) may facilitate a controlled introduction and thus promote learning. This could be done by starting with the basic principles of general similarities between anatomical structures, such as arteries, anastomoses, muscle, bone, joint, ligament, tendon, aponeurosis, glands and plexus. In the first loop, for example, the ligament (a structure of connective tissue, attached to two different bones, preventing unwanted movement between bones, poorly vascularised and therefore slow to heal) might be introduced with some normal examples and some anatomical variations (also normal CT, X-ray etc.). This approach could enable students to build a structural framework for analysing information, e.g. details of names, locations, connections and relations of ligaments. A potential benefit of this approach may be that, in contrast to establishing a list of anatomical structures to be memorised by students (Bergman et al. 2011), creating a list and descriptions of anatomical concepts may be less likely to give rise to problems. McMaster University in Canada has introduced the concept-based COMPASS curriculum, emphasising underlying concepts and with logical sequencing of concepts and body systems (Neville and Norman 2007). However, to test the feasibility of identifying and using anatomical concepts and their functionality as a guideline for curriculum development, further research is needed. 
Despite the attractiveness of the idea of a spiral curriculum, one may wonder how detailed anatomy instruction needs to be. Norman (2010) has suggested that most medical specialists who rarely get to see inside the body may well get by with the simplified schematics in textbooks, or may even be advantaged by such an approach.

\section{Understanding, meaning and teaching in context}

Our students were not the only ones to point to substantial differences between instruction in anatomy and in other biomedical sciences. In a study by Mattick \& Knight (2007), students suggested that anatomy was unique in that it represents a huge set of facts, codified in a specialised language and therefore demanded different learning strategies. We would suggest that because of the nature of anatomy, learning anatomy requires reliance on both surface and deep learning approaches. Memorising information is generally referred to as a surface approach to learning, in contrast to a deep approach, characterised by efforts to understand information by seeking a structure within the material and manipulating the information to make sense of it in relation to what is known of the subject matter (Pandey and Zimitat 2007). Wilhelmsson et al. (2010) describe anatomy as having a dual identity: "On the one hand, a substantial amount of detailed knowledge of anatomical structures is to be learned. On the other hand, a more whole-directed understanding of complex threedimensional relationships between different parts of the body is needed" [page 162]. Because of anatomy's complex vocabulary, it has been hypothesised that a deep approach to anatomy learning needs to build on a preliminary stage of rote learning, which is difficult to distinguish from a surface approach (Entwistle and Ramsden 1983; Smith et al. 2014). The students in our study, however, perceived and described memorisation of details as an endpoint of learning rather than a stage in a process leading to understanding. Several other studies have reported similar findings (Miller et al. 2002; Mattick and Knight 2007; Pandey and Zimitat 2007). It has even been reported that a surface approach to learning, finding anatomy learning daunting and not seeing the point of learning anatomy are associated (Smith and Mathias 2010). One way to change students' perceptions might be to adopt a strategy of assessment for learning, as opposed to assessment of learning, steering and fostering the learning of students and rewarding understanding and higher order cognitive skills (Pandey and Zimitat 2007; Schuwirth and Van der Vleuten 2011).

Students appear to try and understand anatomy by giving meaning to what is learnt (Wilhelmsson et al. 2010). 'To give meaning' entails moving beyond labelling structures towards studying anatomy as an integrated whole. Contextualization of anatomy education, aimed at understanding relationships between anatomy and clinical manifestations (signs and symptoms) may make anatomy more meaningful. 
Furthermore it may increase their awareness of the relevance of and increase motivation to study anatomy. Considering that paper cases in tutorial groups were not perceived as effective in inducing students to study anatomy, we propose translating the PBL principle of contextual learning to anatomy education. A good example of such a strategy has been described by Scott (1994), who created a case-based anatomy course for second-year medical students.

Students in this study specifically asked for help from teachers in achieving deeper learning, integration and application of knowledge. A similar view was expressed by Regan de Bere \& Mattick (2010): "learning anatomy for clinical practice may well benefit from a subtle shift [from self-directed learning] to 'directed self-learning'. [. .] not suggesting [...] that students should be spoon-fed, rather that self study should be guided by experts in the subjects of both anatomy and medicine" [page 582]. Such a shift would require teachers to carefully consider the content and delivery of laboratory sessions and lectures.

\section{Uncertainty}

The results show that students feel very uncertain about their anatomical knowledge, especially at the start of clinical training. Their perceptions suggest that they are uncertain because they feel that their failure to master all the knowledge presented in the preclinical phase will get them into trouble during their clerkships: most importantly by losing face in front of physicians, fellow students and especially patients. Light (1979) posited that uncertainty surrounding knowledge is one of five sources of uncertainty for medical students. Fox (2000) described three types of uncertainty, including inability to judge whether problems encountered are due to lack of knowledge or other reasons. That our results also suggest that that senior students were able to handle uncertainty better than junior students could be a direct consequence of their clinical experience when their knowledge grows with subsequent training and they are increasingly exposed to, and learn, the main ways in which many physicians handle uncertainty (Light 1979; Fox 2000). These findings may also explain why recent graduates were more lenient than students in setting the required level of anatomical knowledge for beginning clerks (Prince et al. 2005b).

Although it is one of the aims of PBL to ease the transition from preclinical to clinical learning, the results suggest that PBL was not successful in reducing students' uncertainty and anxiety about their lack of basic science knowledge. It has been suggested that uncertainty can be mitigated by special training in which students are told that uncertainty is a normal part of medical training and practice and shown ways to deal with it (for example Kitto et al. (2004)). 


\section{Transfer of knowledge}

Students indicated that it was difficult for them to apply the knowledge gained in the preclinical phase in clinical practice, for example in examining patients or interpreting a CT scan. Research has shown that anatomy and surgical teaching staff recognise, but have no formal educational strategy to overcome, this problem of transfer (Bolander Laksov et al. 2008), that is, using a concept learnt in one context to solve a problem in a different context. It has been proposed that transfer should be the main focus of basic science education, although achieving retention is not unimportant as students need to remember information in order to be able to transfer it (Custers 2010; Custers and Ten Cate 2011). Strategies suggested by Norman (2009) to enhance transfer, such as embedding a concept in a problem, encouraging active learning and mixed and distributed practice, would fit very well into a spiral PBL curriculum. A longitudinal experiment on the effectiveness of new methods for learning neuroanatomy described by Chariker et al. (2011) is a good example of the type of further research that is needed to elucidate ways to attain (the combination of) learning, transfer and retention of anatomical knowledge.

\section{CONCLUSIONS}

The results of this study appear to support the hypothesis that educational principles have a stronger impact on students' perceived and actual anatomical knowledge than the educational approach underpinning a curriculum. Students' perceptions indicated that a PBL approach in itself appears to be not enough to ensure adequate learning of anatomy. Change and innovation in teaching and assessment are required to improve anatomy education. A spiral curriculum, an increased focus on understanding of subject matter, contextualised instruction and strategies to enhance transfer all seem to hold promise for increasing students' motivation, awareness of relevance, (retention of) knowledge and feelings of competence with regard to the learning of anatomy.

\section{Acknowledgements}

The authors would like to thank all students who participated in the focus groups for their input. The authors would also like to thank Jules Huijnen and Ida Smailbegovic for their help in transcribing the focus groups, and Mereke Gorsira for editing the final version of the manuscript. 


\section{REFERENCES}

Adibi I., Hasani N., Ashoorioun V., Sadrearhami S. \& Monajemi A.R. (2007). Integrating physical examination and trunk anatomy; a new course for second year medical students. Med Teach, 29(9): 975-977.

Alleyne T., Shirley A., Bennett C., Addae J., Walrond E., West S. \& Pinto Pereira L. (2002). Problem-based compared with traditional methods at the Faculty of Medical Sciences, University of the West Indies: a model study. Med Teach, 24(3): 273-279.

Azer S.A. \& Eizenberg N. (2007). Do we need dissection in an integrated problem-based learning medical course? Perceptions of first- and second-year students. Surg Radiol Anat, 29(2): 173-180.

Aziz M.A., McKenzie J.C., Wilson J.S., Cowie R.J., Ayeni S.A. \& Dunn B.K. (2002). The human cadaver in the age of biomedical informatics. Anat Rec, 269(1): 20-32.

Bergman E. \& de Goeij A. (2010). Basic sciences in problem-based learning. In Van Berkel H., Scherpbier A., Hillen H. \& van der Vleuten C. (Eds.), Lessons from Problem-based Learning (pp. 57-65). Oxford: Oxford University Press.

Bergman E.M., Prince K.J., Drukker J., van der Vleuten C.P. \& Scherpbier A.J. (2008). How much anatomy is enough? Anat Sci Educ, 1(4): 184-188.

Bergman E.M., Van Der Vleuten C.P. \& Scherpbier A.J. (2011). Why don't they know enough about anatomy? A narrative review. Med Teach, 33(5): 403-409.

Bolander Laksov K., Lonka K. \& Josephson A. (2008). How do medical teachers address the problem of transfer? Adv Health Sci Educ Theory Pract, 13(3): 345-360.

Bunniss S. \& Kelly D.R. (2010). Research paradigms in medical education research. Medical Education, 44(4): 358-366.

Chariker J.H., Naaz F. \& Pani J.R. (2011). Computer-Based Learning of Neuroanatomy: A Longitudinal Study of Learning, Transfer, and Retention. Journal of Educational Psychology, 103(1): 19-31.

Colliver J.A. (2000). Effectiveness of problem-based learning curricula: research and theory. Acad Med, 75(3): 259-266.

Custers E.J. (2010). Long-term retention of basic science knowledge: a review study. Adv Health Sci Educ, 15(1): 109-128.

Custers E.J. \& Ten Cate O.T. (2011). Very long-term retention of basic science knowledge in doctors after graduation. Med Educ, 45(4): 422-430.

Dahle L.O., Brynhildsen J., Behrbohm Fallsberg M., Rundquist I. \& Hammar M. (2002). Pros and cons of vertical integration between clinical medicine and basic science within a problem-based undergraduate medical curriculum: examples and experiences from Linkoping, Sweden. Med Teach, 24(3): 280-285.

Dammers J., Spencer J. \& Thomas M. (2001). Using real patients in problem-based learning: students' comments on the value of using real, as opposed to paper cases, in a problem-based learning module in general practice. Med Educ, 35(1): 27-34.

Diemers A.D., Dolmans D.H., Van Santen M., Van Luijk S.J., Janssen-Noordman A.M. \& Scherpbier A.J. (2007). Students' perceptions of early patient encounters in a PBL curriculum: a first evaluation of the Maastricht experience. Med Teach, 29(2-3): 135-142.

Diemers A.D., Dolmans D.H.J.M., Verwijnen G.M., Heineman E. \& Scherpbier A.J.J.A. (2008). Students' opinions about the effects of preclinical patient contacts on their learning. Adv Health Sci Educ 13: 633-647.

Dolmans D.H., De Grave W., Wolfhagen I.H. \& van der Vleuten C.P. (2005). Problem-based learning: future challenges for educational practice and research. Med Educ, 39(7): 732-741.

Eizenberg N. (1988). Approaches to Learning Anatomy: Developing a Programme for Preclinical Medical Students. In Ramsden P. (Ed.), Improving Learning, New Perspectives. London: Kogan Page Ltd.

Entwistle N.J. \& Ramsden P. (1983). Understanding student learning. London: Croom-Helm. 
Fasel J.H., Morel P. \& Gailloud P. (2005). A survival strategy for anatomy. Lancet, 365(9461): 754.

Fox R.C. (2000). Medical Uncertainty Revisited. In Albrecht G.L., Fitzpatrick R. \& Scrimshaw S.C. (Eds.), Handbook of Social Studies in Health and Medicine (pp. 409-425). London: Sage.

Harden R.M. \& Stamper N. (1999). What is a spiral curriculum? Med Teach, 21(2): 141-143.

Hinduja K., Samuel R. \& Mitchell S. (2005). Problem-based learning: is anatomy a casualty? Surgeon, 3(2): 8487.

Illing J. (2007). Thinking about research: frameworks, ethics and scholarship. Edinburgh: ASME.

King N. (2004). Using Templates in the Thematic Analysis of Text. In Cassell C. \& Symon G. (Eds.), Essential Guide to Qualitative Methods in Organizational Research. London: Sage.

Kitto S., Chestsers J., Villanueva E. \& Fox J. (2004). Normalising uncertainty in undergraduate clinical transition seminars. Focus on Health Professional Education: A Multi-Disciplinary Journal, 6(1): 37-51.

Larsen D.P., Butler A.C. \& Roediger H.L., 3rd (2008). Test-enhanced learning in medical education. Med Educ, 42(10): 959-966.

Light D., Jr. (1979). Uncertainty and control in professional training. J Health Soc Behav, 20(4): 310-322.

Louw G., Eizenberg N. \& Carmichael S.W. (2010). Guide 41: The Place of Anatomy in Medical Education. . Dundee, UK: Association for Medical Education in Europe (AMEE).

Marton F. (1981). Phenomenography - describing conceptions of the world around us. Instructional Science, 10: $177-200$.

Mattick K. \& Knight L. (2007). High-quality learning: harder to achieve than we think? Med Educ, 41(7): 638644.

Miller S.A., Perrotti W., Silverthorn D.U., Dalley A.F. \& Rarey K.E. (2002). From college to clinic: reasoning over memorization is key for understanding anatomy. Anat Rec, 269(2): 69-80.

Moxham B.J. \& Plaisant O. (2007). Perception of medical students towards the clinical relevance of anatomy. Clin Anat, 20(5): 560-564.

Neville A.J. \& Norman G.R. (2007). PBL in the undergraduate MD program at McMaster University: three iterations in three decades. Acad Med, 82(4): 370-374.

Newman M. (2003). A pilot systematic review and meta-analysis on the effectiveness of problem based learning. Newcastle: Learning \& Teaching Subject Network for Medicine, Dentistry and Veterinary Medicine.

Norman G. (2009). Teaching basic science to optimize transfer. Med Teach, 31(9): 807-811.

Norman G. (2010). Anatomical mysteries. Adv Health Sci Educ Theory Pract, 15(2): 149-151.

Older J. (2004). Anatomy: a must for teaching the next generation. Surgeon, 2(2): 79-90.

Pandey P. \& Zimitat C. (2007). Medical students' learning of anatomy: memorisation, understanding and visualisation. Med Educ, 41(1): 7-14.

Prince K.J., Boshuizen H.P., van der Vleuten C.P. \& Scherpbier A.J. (2005a). Students' opinions about their preparation for clinical practice. Med Educ, 39(7): 704-712.

Prince K.J., Scherpbier A.J., van Mameren H., Drukker J. \& van der Vleuten C.P. (2005b). Do students have sufficient knowledge of clinical anatomy? Med Educ, 39(3): 326-332.

Prince K.J., van Mameren H., Hylkema N., Drukker J., Scherpbier A.J. \& van der Vleuten C.P. (2003). Does problem-based learning lead to deficiencies in basic science knowledge? An empirical case on anatomy. Med Educ, 37(1): 15-21.

Raftery A. (2006). Anatomy teaching in the UK. Surgery, 25(1): 1-2.

Regan de Bere S. \& Mattick K. (2010). From anatomical 'competence' to complex capability. The views and experiences of UK tutors on how we should teach anatomy to medical students. Adv Health Sci Educ Theory Pract, 15(4): 573-585.

Ryan R.M. \& Deci E.L. (2000). Intrinsic and Extrinsic Motivations: Classic Definitions and New Directions. Contemp Educ Psychol, 25(1): 54-67.

Schuwirth L.W. \& Van der Vleuten C.P. (2011). Programmatic assessment: From assessment of learning to assessment for learning. Med Teach, 33(6): 478-485. 
Scott T.M. (1994). A case-based anatomy course. Med Educ, 28(1): 68-73.

Smith C.F., Martinez-Alvarez C. \& McHanwell S. (2014). The context of learning anatomy: does it make a difference? J Anat, 224(3): 270-278.

Smith C.F. \& Mathias H.S. (2010). Medical students' approaches to learning anatomy: students' experiences and relations to the learning environment. Clin Anat, 23(1): 106-114.

Stenfors-Hayes T., Hult H. \& Dahlgren M.A. (2013). A phenomenographic approach to research in medical education. Med Educ, 47(3): 261-270.

Takkunen M., Turpeinen H., Viisanen H., Wigren H.K., Aarnio M. \& Pitkaniemi J. (2011). Introduction of real patients into problem-based learning in preclinical first-year anatomy curriculum. Med Teach, 33(10): 854-856.

Van Berkel H., Scherpbier A.J.J.A., Hillen H. \& Vleuten C.P.M.v.d. (Eds.). (2010). Lessons from Problem-based Learning. Oxford: Oxford University Press.

Vernon D.T. \& Blake R.L. (1993). Does problem-based learning work? A meta-analysis of evaluative research. Acad Med, 68(7): 550-563.

Wilhelmsson N., Dahlgren L.O., Hult H., Scheja M., Lonka K. \& Josephson A. (2010). The anatomy of learning anatomy. Adv Health Sci Educ Theory Pract, 15(2): 153-165.

Willis K., Green J., Daly J., Williamson L. \& Bandyopadhyay M. (2009). Perils and possibilities: achieving best evidence from focus groups in public health research. Aust N Z J Public Health, 33(2): 131-136.

Winkelmann A. (2007). Anatomical dissection as a teaching method in medical school: a review of the evidence. Med Educ, 41(1): 15-22. 


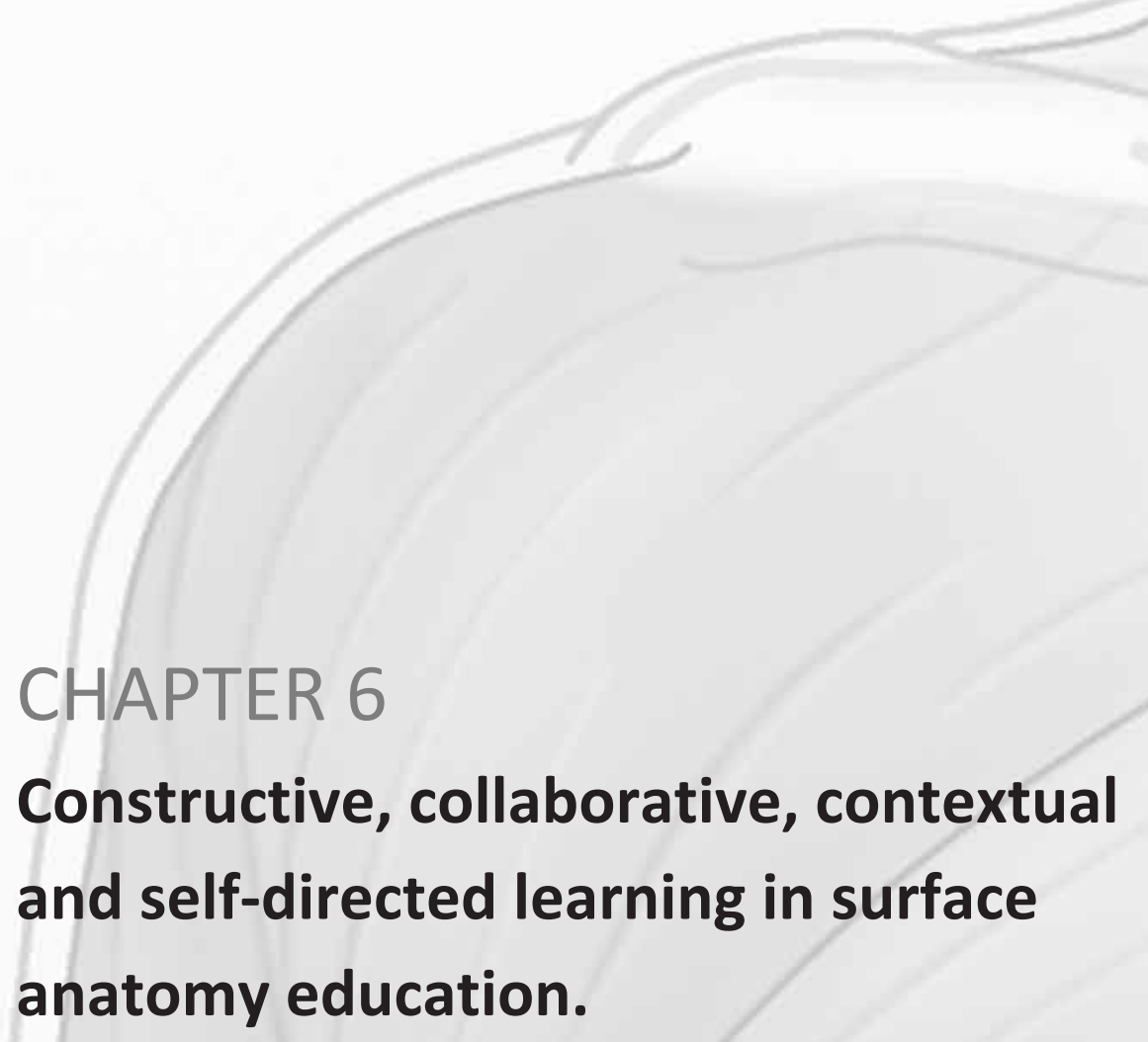




\section{ABSTRACT}

Anatomy education often consists of a combination of lectures and laboratory sessions, the latter frequently including surface anatomy. Studying surface anatomy enables students to elaborate on their knowledge of the cadaver's static anatomy by enabling the visualization of structures, especially those of the musculoskeletal system, move and function in a living human being. A recent development in teaching methods for surface anatomy is body painting, which several studies suggest increases both student motivation and knowledge acquisition. This article focuses on a teaching approach and is a translational contribution to existing literature. In line with best evidence medical education, the aim of this article is twofold: to briefly inform teachers about constructivist learning theory and elaborate on the principles of constructive, collaborative, contextual, and self-directed learning; and to provide teachers with an example of how to implement these learning principles to change the approach to teaching surface anatomy. Student evaluations of this new approach demonstrate that the application of these learning principles leads to higher student satisfaction. However, research suggests that even better results could be achieved by further adjustments in the application of contextual and self-directed learning principles. Successful implementation and guidance of peer physical examination is crucial for the described approach, but research shows that other options, like using life models, seem to work equally well. Future research on surface anatomy should focus on increasing the students' ability to apply anatomical knowledge and defining the setting in which certain teaching methods and approaches have a positive effect. 


\section{INTRODUCTION}

In subjects like anatomy, biochemistry, pharmacology, radiology, and pathology, a great deal of information is provided to students during laboratory sessions. Laboratory sessions usually give students the opportunity to directly obtain information from teachers and materials that are available during session time, present knowledge in a 'hands-on' environment, and enable students to combine knowledge acquisition while practicing a variety of relevant skills.

\section{Surface anatomy education}

In most medical schools, anatomy education consists of a combination of lectures and laboratory sessions in a variety of formats, including living anatomy sessions. Most physicians encounter the body as living anatomy, as opposed to the cadaveric anatomy encountered in the dissection room (Griksaitis et al. 2012). Living anatomy can be studied in several ways. Surface anatomy is a part of living anatomy, which usually includes peer-physical examination. In addition, living anatomy can also be studied by students via medical imaging, like ultrasound (Griksaitis et al. 2012).

Surface anatomy was not introduced into anatomy education until well into the 1940s (McLachlan and Patten 2006). The first studies of the use of live models in anatomy education were published more than 20 years later (Barrows et al. 1968; Stillman et al. 1978). Nowadays, surface anatomy is promoted as one of the most important modalities contributing to an optimal learning content of anatomy education (Sugand et al. 2010). Studying surface anatomy provides an elaboration on the static anatomy of the cadaver by enabling students to see phenotypical structures, particularly those of the musculoskeletal system, move and function in a living human being. Surface anatomy includes inspection and palpation (sometimes aided by percussion and/or auscultation) of structures that lie beneath the skin. "Living anatomy focuses attention on the differences between individuals and on variations within the same individual, including variations outside the norm and those that become manifest under different conditions" [page 75] (Leonard et al. 1996). Furthermore, surface anatomy sessions enable students to familiarize themselves with important surface landmarks and to observe, examine, and interact with a living person (Collins 2008). Many believe that this is important, since doctors examining a patient should have a clear mental picture of what is lying below his/her examining fingers (Ellis 2001). In some institutions, surface anatomy is therefore thought to be of vital importance for education, sometimes even more important than teaching anatomy with cadavers (Monkhouse 1992). 
A recent development within surface anatomy education is body painting. The concept of painting on a live model was described by Cody (1995), but Op Den Akker et al. (2002) were the first to introduce body painting as a teaching tool. In body painting sessions, hypo-allergenic, water-based body paint is used by students to paint anatomical structures and/ or concepts (e.g. dermatomes) on their peers under supervision by anatomy staff (Op Den Akker et al. 2002; McMenamin 2008; Finn 2010; Finn and McLachlan 2010; Finn et al. 2011). To run a successful body painting session, it is advisable to provide instruction sheets with a detailed protocol, listing structures and how to paint them (Finn 2010). One of the arguments for introducing body painting was that the 'traditional' method using cosmetic pencils resulted in complex one-colour drawings of intersecting lines, which were unattractive, had little meaning and were difficult for students to interpret (Op Den Akker et al. 2002; McMenamin 2008). A recent study by Finn et al. (2011) however, unexpectedly showed that there was no difference in short-term and long-term retention of knowledge between students who used bright colours to block paint viscera and students who painted only black outlines of the viscera. This finding was attributed to a type II statistical error or to the influence of time-on-task. It makes one wonder, however, whether the learning gains of students from newly developed body painting sessions may also be attributable to other factors.

\section{Best evidence medical education: learning theories and learning principles in practice}

Being a professional teacher requires more than being an expert in a content area; it also requires awareness, familiarity, use (and perhaps even production) of educational theory and empirical evidence. However, teaching is often dominated by intuition (personal experiences and beliefs) and traditional values (dogmas), which could be labelled 'opinion based teaching'. Empirical evidence has shown that opinion based teaching has often misguided teachers (Harden et al. 1999; 2000; Van der Vleuten et al. 2000).

Best evidence medical education (BEME) is defined as "the implementation, by teachers in their practice, of methods and approaches to education based on the best evidence available" [page 71] (Harden et al. 2000). The emphasis in BEME is on the user, not only on a committee, institutional or national level, but also on the individual teacher who must translate research into practice when making decisions about his/her own teaching (BEME-Group 2000). If one considers a continuum with $100 \%$ opinion-based teaching at one end of the spectrum, (where no useful evidence is available), and $100 \%$ evidence-based education at the other (where decisions can be taken on the basis of detailed evidence), BEME suggests that teachers make decisions 
about their teaching practice on the best evidence that is available at whichever point they find themselves on the continuum (Harden et al. 1999; 2000).

It is shown that evidence could play a major role in making teaching decisions particularly in the area of medical education. While it is difficult to generate good evidence for medical education practices, it seems even harder to translate this evidence into improving the quality of practice and outcomes (Van der Vleuten et al. 2000; Wolf 2000). Although there is an abundance of information available about the potential contributions of learning theories, as well as on the pressing problems faced by those dealing with practical learning issues, there are few reports of learning theories being put to use to solve practical learning problems (Ertmer and Newby 1993). In other words, there is a gap between educational researchers and users of educational research (Harden et al. 1999; 2000).

One well-known and established learning theory is constructivism, which views learning metaphorically as a building process in which individuals or social communities actively construct their own knowledge. Problem-based learning (PBL) is based on this theory. In the early 1990s and 2000s, several reviews of studies on the implementation of PBL at a curriculum level were published. These include Norman and Schmidt (1992), Albanese and Mitchell (1993), Vernon and Blake (1993), Colliver (2000), Dochy et al. (2003), and Newman (2003). All of the reviews showed that PBL had a positive effect on students' satisfaction, ability to apply knowledge, and/or ability in clinical problem solving. However, no significant differences were found in conventional measurements of the accumulation of factual knowledge, or else presented mixed results, with some studies reporting increased benefits of PBL and others of conventional curricula (Mamede et al. 2006).

The constructivist learning theory rejects the idea of learners as passive recipients of knowledge (Tynjälä 1999). This becomes even more evident when one takes a closer look at the four learning principles underpinning PBL: constructive, collaborative, contextual, and self-directed learning. These principles (from Dolmans et al. (2005)) are described in the first column of Table 1. In brief, they state that learning should be an interactive process, which takes place within a context and is regulated by the learners themselves. While complete curricula are increasingly being restructured in accordance with modern learning theories like constructivism, teachers often struggle to translate theories to their teaching methods, and thus rely on traditional teachercentred instruction, especially during laboratory sessions. While every teacher has probably heard of problem-based learning, many will not have heard of the four learning principles underpinning it, let alone having ever wondered if and how they could apply these principles to their own teaching. While these learning principles come forth from a constructivist theory and PBL approach, they can to a large extent also be implemented in more conventional curricula. 
In line with BEME, the purpose of this article is to make a translational contribution by showing teachers how educational evidence can be brought into educational practice. This study will show teachers how the principles of constructive, collaborative, contextual, and self-directed learning can be implemented in the practice of laboratory teaching, illustrated by the development of a student manual for a new instructional format for surface anatomy that is currently used at Maastricht University. This will be done by describing the problems of the conventional format and how the application of constructivist learning principles in designing the new format helped to overcome those problems. Furthermore, the results of the student evaluation of the new format will be discussed, as well as the lessons learned with regard to surface anatomy education.

\section{METHODS}

In the Netherlands, most students enter medical school immediately from high school at the age of approximately 18 years. Maastricht University Medical School delivers a $\mathrm{PBL}$ curriculum. An important part of learning in PBL takes place in small tutorial groups, where students are confronted with a description of a problem that requires explanation. The group formulates learning objectives for aspects of the problem that they are unable to explain and students undertake individual self-study activities to collect information about the learning objectives. They report their findings to the group, which then discusses the information and integrates it to explain the problem.

Surface anatomy sessions have been a part of the self-study activities in the Maastricht anatomy curriculum since the start of the medical school. For both the conventional format and the new format, the general planning of the surface anatomy sessions were the same: they are scheduled between macroscopic anatomy sessions in the dissection room and physical examination training at the Skills Laboratory. In the current curriculum, surface anatomy is only taught for regions of the musculoskeletal system. These sessions are mainly scheduled in the second year (shoulder, back, hip, and knee), with the ankle/foot in the first year and elbow/wrist/ hand in the third year. A surface anatomy session takes two hours, with a maximum of 30 students and one teacher per session. The same session is taught 12 times to accommodate all 360 students of one cohort.

\section{Problems with the conventional format and aims for the new format}

It was decided to develop new educational materials to replace the existing surface anatomy books because it was felt these had some important limitations. They either 
used the rather traditional systematic approach (in which all bones are palpated first, then the joints, then ligaments, muscles, nerves, and blood vessels) or they did not connect structure and function (the palpation of a muscle and the description of its function over the joints would be pages apart). Furthermore, they lacked clinical context as well as clear instructions to students on how to position themselves and/or their 'subject' to improve visualization and/or palpation of deeper lying structures.

Next, the new format was aimed at being less sensitive to variations in teachers' knowledge and experience. This meant that the new materials had to include some kind of protocol to facilitate the reproduction of the same learning experience for each group of students in the series of surface anatomy sessions. The new materials were also designed to serve as a reference book for students after the sessions, so that they could review the materials during their later studies. Lastly, the conventional format mainly consisted of a teacher showing the students how to go about the activity while at the same time providing information. In the present format, focus was placed on stimulating student involvement and activity, thereby reducing teacher involvement. This goal encouraged the application of the four PBL learning principles to these surface anatomy sessions.

\section{Application of the learning principles}

The new format is based on what was called a 'student manual' or 'work sheet' (figure 6.1). The anatomists wrote a draft manual, which was discussed with other experts (skills teachers, general physicians, and/or orthopedic surgeons). The manual contains instructions, assignments, and questions about body regions. In congruence with the recommendation of Finn (2010), symbols were inserted in the margins of the manual to make the purpose of the adjacent text clear at a glance. The first column of table 6.1 contains the definition of each learning principle as described by Dolmans et al. (2005). The other two columns show an overview of how each individual principle was applied along with some explicit examples, as discussed below.

\section{- Constructive learning principle}

To stimulate the use of prior knowledge and elaboration of new knowledge, questions were inserted in the manual, signposted by a question mark, and a designated space was provided where students could write down the answer, as shown in figure 6.1 and the first row of table 6.1. Students at Maastricht University can find everything they need for their studies (block books, schedules, announcements, assignments, etc.), including the new manual, in a virtual learning environment utilizing the commercially available curriculum management system 'Blackboard' (Blackboard, Inc., Washington, DC). Students must download the manual from the virtual learning environment, print it, prepare the home 
assignments, and bring the manual to the anatomy session. The questions that students are expected to prepare at home have an answer space that is signposted by a house symbol (figure 6.1).

\section{- Collaborative learning principle}

During the surface anatomy sessions, students work in mostly mixed gender subgroups of three or four. One student is the 'subject' (student model) and the others are the 'examiners'. The roles rotate with every new anatomical region. In the ankle/foot manual, for example, the regions are as follows: 1) leg, 2) ankle, and 3) foot. Input of fellow students is indispensable to complete most of the assignments, signposted by a hand symbol in the manual, as can be seen in figures 6.1 and 6.2 and the second row of table 6.1. One anatomy teacher is present to answer questions, demonstrate techniques, help with assignments, and/or give further explanations.

\section{- Contextual learning principle}

Effort was made to provide the students with clear instructions on how to do the assignments. To extend the instructions beyond mere drawing (as for example in Op Den Akker et al. (2002)), the structural and functional relationships of structures were combined wherever possible. Careful attention was also paid to introduce or elaborate on most of the structures by putting them within the context of physical examination or common pathologies, as can be seen in figure 6.2 and the third row of table 6.1.

\section{- Self-directed learning principle}

It was quite difficult to capture the essence of this learning principle in the manual, as a manual usually dictates what has to be done, which is in contrast to the principle of students directing their own learning. The principle of selfdirected learning is visible in the context in which the manual and the sessions are presented. Attendance of surface anatomy sessions is not compulsory and, if students feel they can acquire the same knowledge in a different way, they are free to do so. Furthermore, out of the sessions offered during the self-study phase, students can sign up for the one that best suits their schedule (fourth row of table 6.1). Students can also use the manual to repeat the exercises for themselves at another place and/or time. 


\section{I - Assignments \& questions lower leg region}

BONES \& JOINTS

1. All group members should undress their lower legs and feet. Stand opposite each other. Inspect the lower legs, ankles and feet. For instance, look at the shape of the calves, ankles, toes, the skin (colour, hairs, scars) and other aspects that strike you. Compare the left and right side per person and compare the group members.

2. Ask the subject to sit on the short end of an examination table with the legs hanging over the edge. One of the two bones in the lower leg is the tibia. Palpate the anterior border of the tibia. Mark the border with a cosmetic pencil.

3. Palpate the medial surface of the tibia and circle it carefully with a cosmetic pencil.

4. The tibia ends distally in the medial malleolus. Mark this with a cross.

5. ? Find the tibia and fibula in the skeleton or in a book. Describe the location of the fibula compared to the tibia.

造

6. The proximal head of the fibula will be examined in detail during the practical training about the anatomy of the knee. Still, we also palpate the head in this training, because it helps you to get an idea of the length and location of the fibula. The head can be palpated on the lateral side (backside) of the lower leg, just beneath the knee fold. Mark the head with a cross.

7. The fibula ends distally in the lateral malleolus, mark it with a cross.

8. Now indicate the location of the fibula with a dotted line.

Some people break their fibula and continue to walk on it without noticing any real symptoms (except for some vague pain complaints) ...

9. Which (two) muscles make it hard to palpate the fibula? Which parts of the fibula can be easily palpated?

\section{MUSCLES \& TENDONS}

10. There is no functional difference between the two muscles of item 9. Therefore, the muscle bellies of these two muscles can only be palpated as one structure (approximately halfway the lower leg, on the lateral side). To feel this, place the foot in plantar flexion and ask the subject to perform eversion (against resistance). Instruct the person to subsequently tense and release alternately.

Figure 6.1 An example of one page in a student manual (work sheet). It shows the assignments, signposted with the 'hand' symbol, and the questions, signposted with the 'question mark' symbol. Furthermore the designated spaces to write the answers to the questions can be seen, and one question that should be prepared by students at home before coming to the session, signposted with the 'house' symbol. 


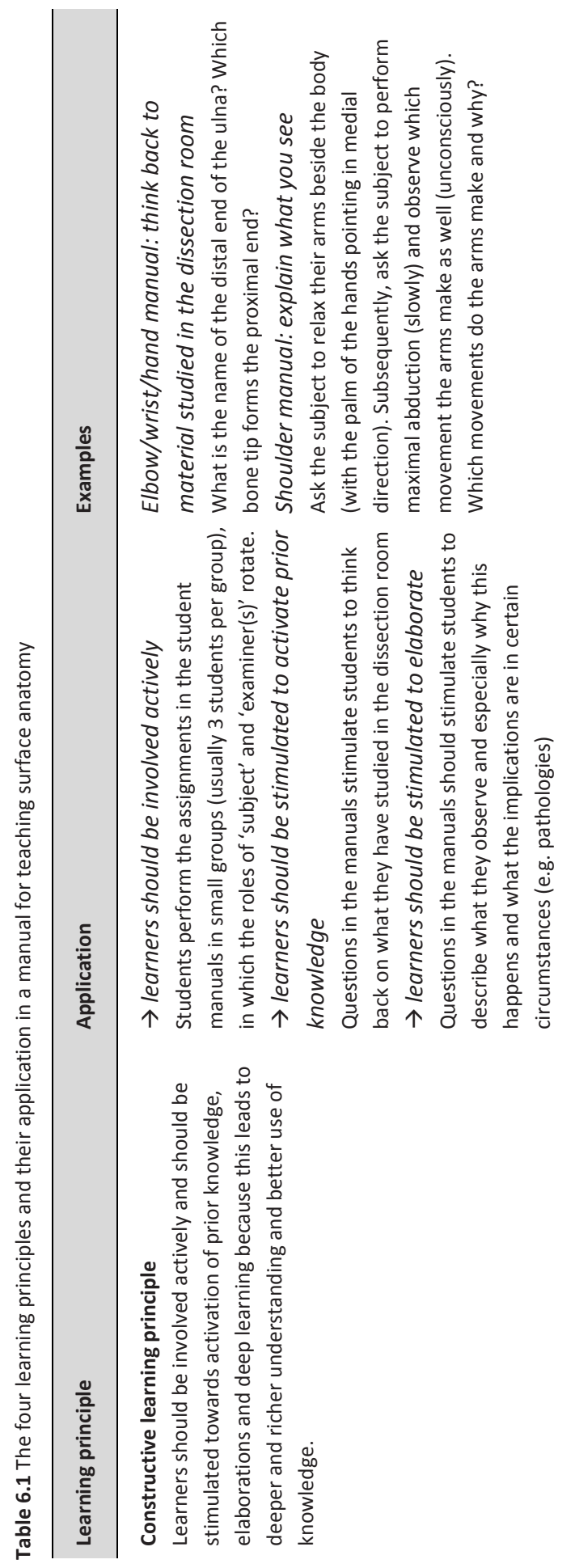

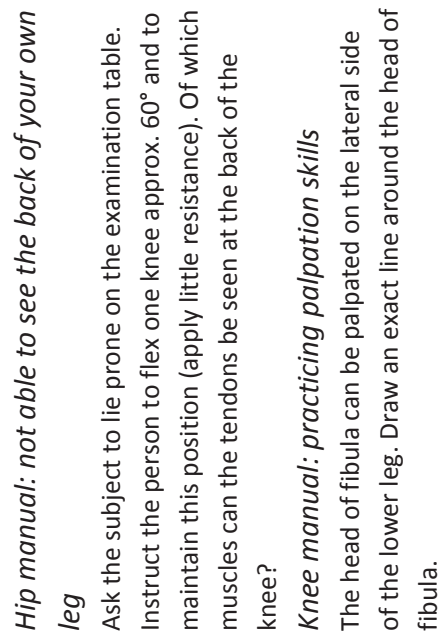

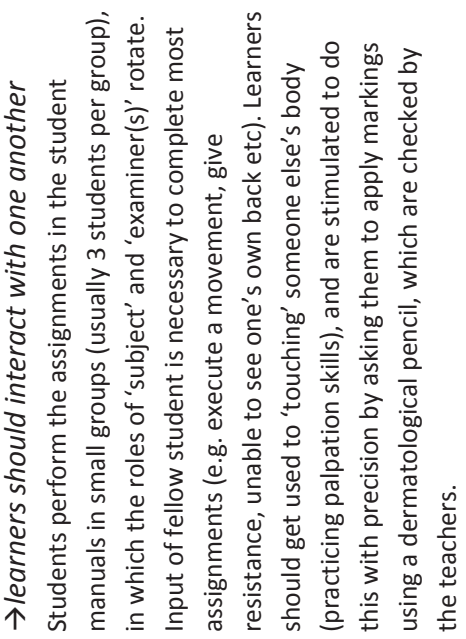

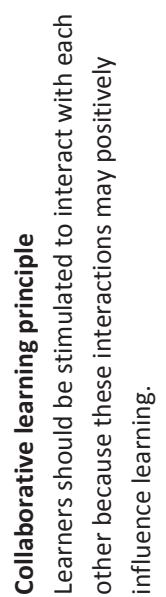




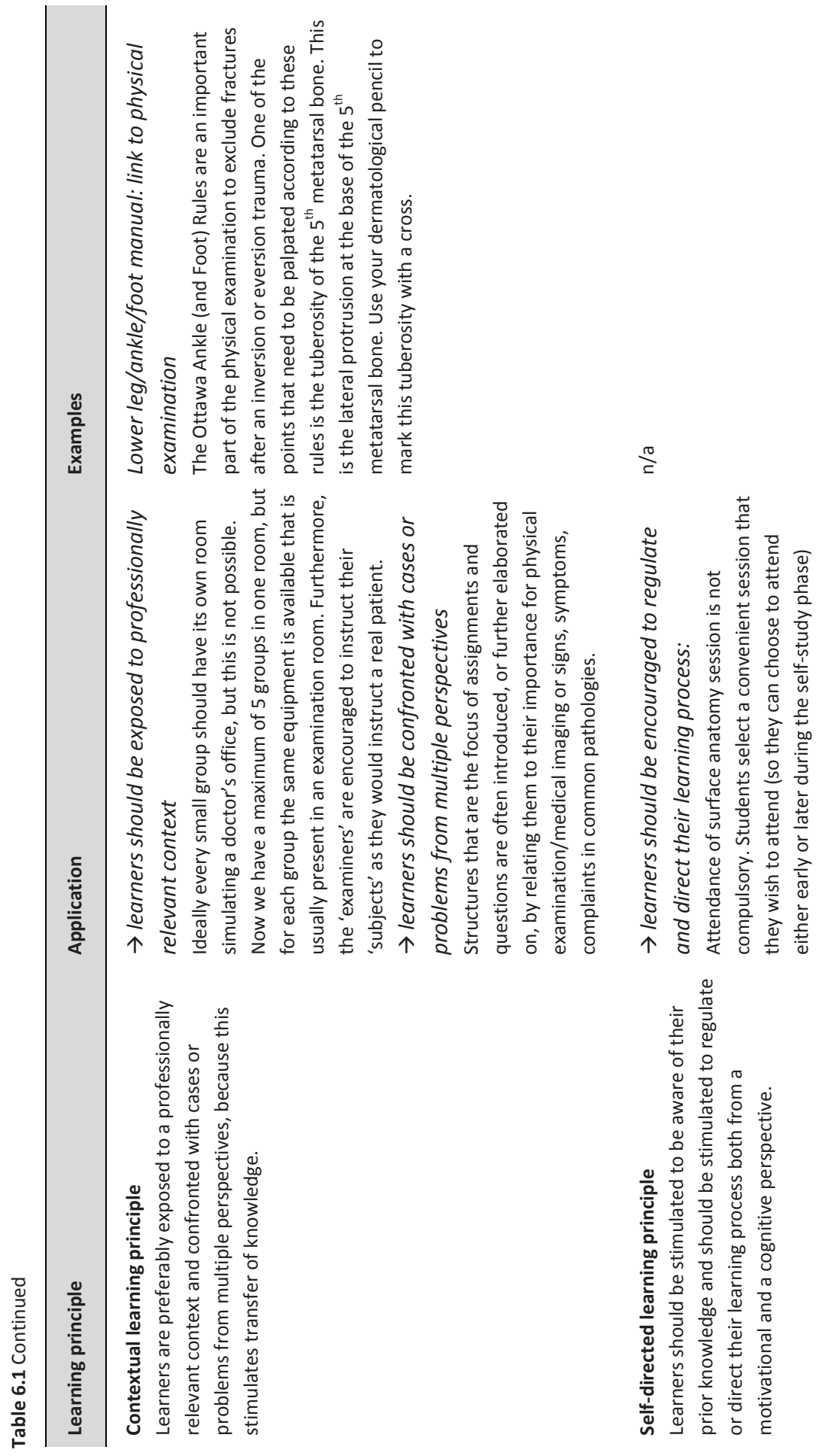




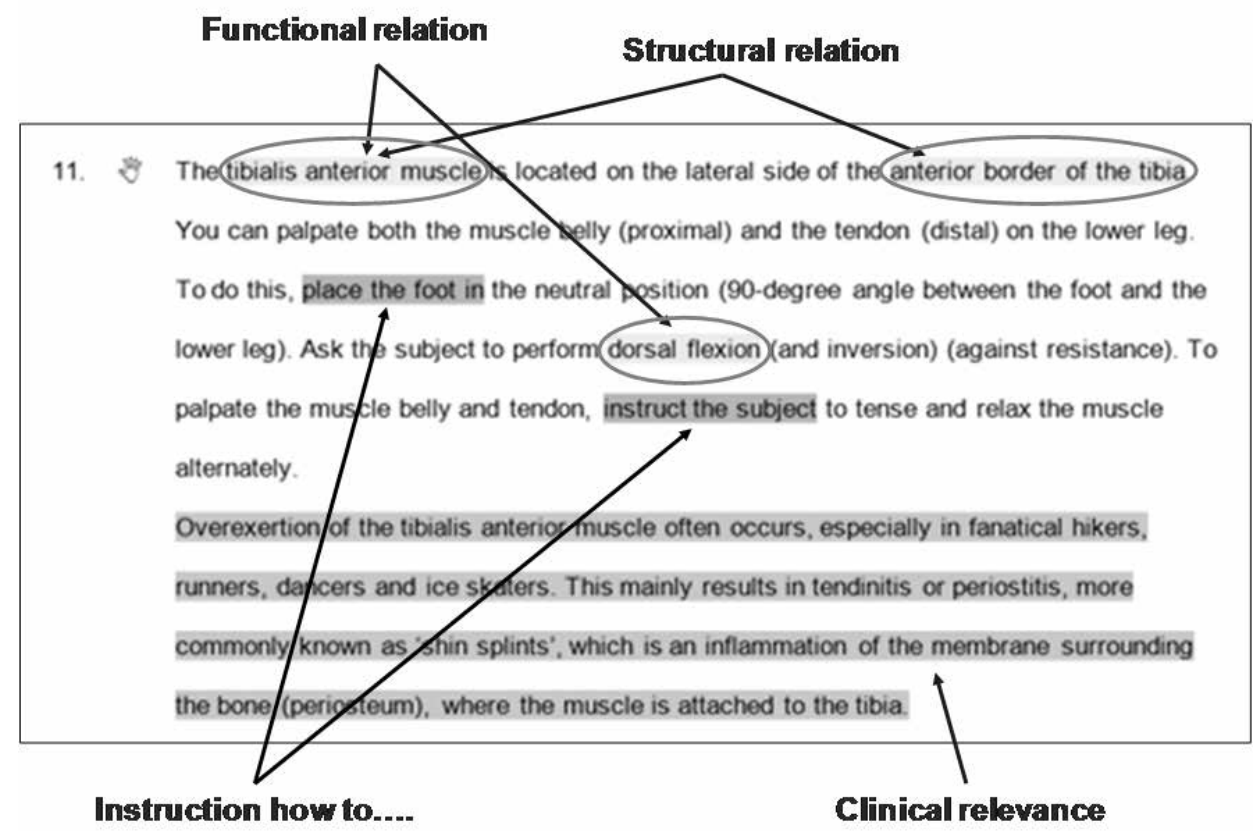

Figure 6.2 An example of an assignment within the student manual, in which the structural and functional relations, and clinical relevance of a structure are combined, together with instructions how to palpate this structure.

\section{Evaluating surface anatomy education}

To evaluate the manual and to contrast the new to the old format, a questionnaire was administered to third year students who were present at the surface anatomy session about the elbow/wrist/hand region. Because these students had attended surface anatomy sessions about other regions in the conventional format a year earlier, they were able to compare the conventional

The questionnaire was anonymous and consisted of 30 items: questions with a five-point Likert scale response format ( 1 = absolutely not useful; 5 = very useful) and open-ended questions. There were five general questions, eight questions concerning the old format, and 17 questions concerning the new format. Open questions were included to enable students to comment on their answers. It was hoped that this would provide more insight into students' reasons for their responses on five-point Likert scale questions. The students completed the questionnaire directly after they had finished their surface anatomy session. 


\section{Ethical approval}

Although the Dutch Ethical Review Board informed the authors that non-patientrelated research was exempt from ethical review, informed consent was obtained from all the participants.

\section{RESULTS}

A total of 206 completed forms were received. The majority of the students (>90\%) had attended at least three surface anatomy sessions in previous years. They were very positive about the added value of surface anatomy sessions in general (regardless of the format). Various reasons were mentioned, including the ability to study anatomy from a different perspective (living anatomy), the possibility of revising anatomical knowledge, and the link to clinical practice and physical examination.

"You know what the structures feel like 'in real life' and how to find them in a patient. It is a link between anatomy [in the dissection room] and the Skillslab" (student 12). "Here I am better able to learn about the muscles and their functions" (student 30).

Peer examination was considered very useful by most students (mean \pm SD $=3.88 \pm$ 0.75 ), because they felt they learned with/from one another and therefore achieved better knowledge/understanding. Furthermore, they could inspect common varieties between each other, and it added valuable extra opportunities to practice their palpating skills.

"You learn to recognize variation and you can help each other to identify specific points or structures" (student 52).

The results showed that the students were reasonably satisfied with the conventional teaching format of surface anatomy: demonstration by a teacher (which was the main teaching method in this format) was highly appreciated ( $4.20 \pm 0.72)$ and the included movement analysis was useful (3.75 \pm 0.76$)$, because it enabled students to check/correct their own findings, to see how things should be done, to receive extra explanation/information and to repeat the information once more.

However, major drawbacks of the demonstrations were also mentioned. The most frequent complaint about the sessions in the old format was that students were unable to see large parts of the demonstration: either their fellow students or the teacher were blocking their view (see figure 6.3A). Furthermore, students found they 
had too little time and opportunity to write down the information given by the teacher. When they were writing, they missed part of the demonstration. If they took short notes, the notes turned out to be not clear when they wanted to study them at a later moment. As a result, students had limited possibilities for further study or for looking back and elaborating on what they had learned. This problem was experienced most strongly by students who were not completely familiar with the region at the time of the surface anatomy session.

"I could not see it that well and things went too fast to take notes or to process [the information]" (student 30).

Students were highly satisfied with the teaching of surface anatomy in the new format. The students rated the new format as very informative $(4.39 \pm 0.58)$, with most of them indicating that working in small groups made them more active (figure 6.3B). The manual served as a guideline, structured their work better or gave them a better overview during the session.

"You go through the structures in a systematic way, and you receive instructions on how to execute specific manoeuvres" (student 191).

A very interesting response that was expressed several times was that students appreciated the possibility to work at their own pace.

"Nice to practice on each other in a directed manner through assignments at your own pace [...]" (student 173).

Seven students preferred the conventional format and fourteen students indicated they had no preference either way. Of the seven students who preferred the conventional format, two elaborated on their choice by explaining that they felt the conventional format gave them either a better grip on the material or worked more efficiently. Of the fourteen students who gave no preference, the majority that completed the open question commented that they would like to see a combination of the two formats.

"Actually you could combine the two. It is nice to get an explanation and it is nice to be active yourself" (student 195).

In response to the question to give tips or comments to improve teaching, three reactions occurred most frequently: 1 ) that the instructors should give students the answers to the questions, 2) that the manual should include even more clinical 
relevance, and 3) that not all plenary explanations (demonstrations) should have been eliminated. Of the 199 students who completed the question about which format they preferred, 178 (89.4\%) opted for the new format.

"There is much more structure and therefore more completeness" (student 176). "You can repeat everything for yourself again" (student 192). "You learn more by doing it yourself" (student 200).

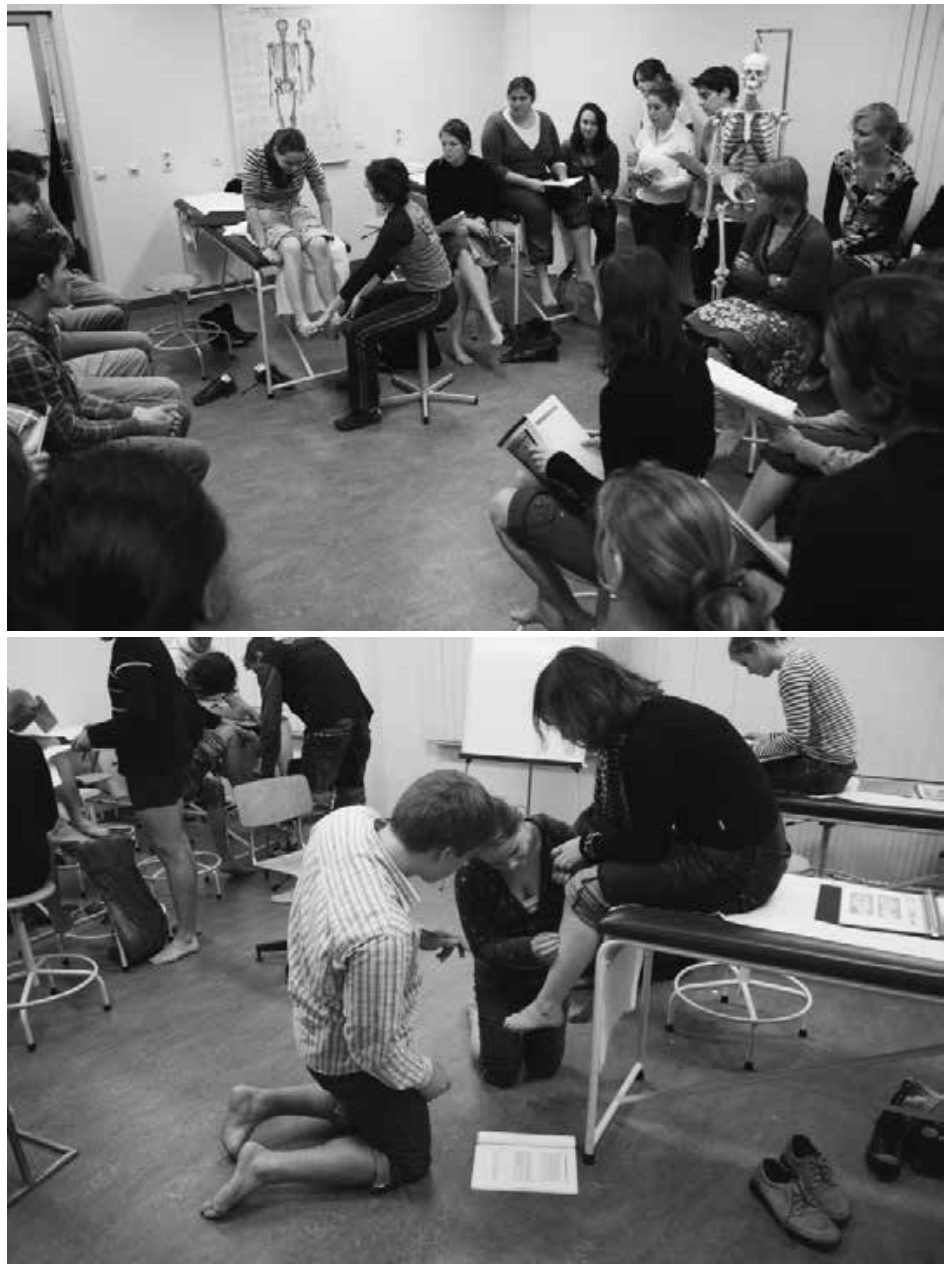

Figure 6.3 Students during the conventional format (Picture A, above) and the new format (Picture B, below). In picture $A$, it can be seen that the view of some of the students is blocked by the teacher. Furthermore, students can be seen trying to take notes or looking up the discussed structures in a book, and as a result missing part of the demonstration. In picture B, students can be seen working in small groups, rotating the roles of 'subject' and 'examiner', identifying structures using the assignments in the student manuals (work sheets) and an atlas and using cosmetic pencils to indicate certain structures on each other. 


\section{DISCUSSION}

The results of this study show that students' first experiences with the new teaching format were predominantly positive. Students regarded surface anatomy as a valuable teaching method, especially for the musculoskeletal system. It gives students a chance to study the anatomy of a living person, and at the same time repeat and/or elaborate on anatomical knowledge they gained in the dissection room. This is consistent with results of Lujan et al. (2006) in which students indicated a preference towards different modes of information presentation (multimodal learning). Furthermore, students stated that surface anatomy creates a link between factual knowledge and clinical practice (pathology and/or physical examination skills). This is in agreement with a study by Aggarwal et al. (2006) in which students reported that they enjoyed the surface anatomy sessions and understood their importance.

Although teachers' evaluations were not formally sought, the teachers were positive about the new format as well. They found that it enabled them to provide more individual guidance to student subgroups. Instead of demonstrating the information to the whole group, they could help small groups or individuals with specific problems with assignments or questions. Teachers also noticed improved comparability between sessions and across teachers.

\section{Application of the learning principles}

Application of the constructive, collaborative, and contextual learning principles to the instruction manual proved to be relatively easy. This success is confirmed by statements from students that with the new format, they were more actively involved, they enjoyed (and learned from) working together and they acknowledged the clinical relevance of the material. Applying the self-directed learning principle was more difficult, mostly due to constraints in time, venue, and financial resources. However, students referred to an improvement in self-directed learning when they stated that it increased the opportunity to work at their own pace, the opportunity to take the manual with them to repeat the exercises again later, and the option to write down notes in the document, thus creating a personalized reference book. A very recent study of Findlater et al. (2012) shows that it is worth pursuing the goal of increased self-directed learning, as their research shows that their switch from a primarily didactic method to supported self-directed learning of anatomy resulted in a significant improvement in anatomy examination scores over a period of 5 years.

The principle of contextual learning warrants a little more elaboration. Ever since the classic 'on land and underwater' study of Godden and Baddeley (1975), it is believed that a positive effect on both learning and recall is elicited when the context 
in which something is learned is the same as in which it is retrieved. The contexts that are commonly used in anatomy teaching can be roughly divided into four categories: 1) clinical skills (physical examination), 2) pathology (e.g., cancer, neurological diseases, and musculoskeletal disorders), 3) radiology (e.g., interpreting X-rays, CT scans, and ultrasound images) and 4) surgical procedures (e.g., appendectomy or endoscopic/laparoscopic procedures). However, a review of literature published up to 2007 yielded not one study comparing the results of teaching anatomy within and out of context on student's knowledge (Bergman et al. 2011). Interestingly, results in a later publication of Finn et al. (2010) showed that students examined in the same context as they were taught, in this case represented by either wearing scrubs or their own clothes, recalled significantly more information five weeks after teaching. Although the effect size of these teaching interventions was small (and other factors may have a bigger effect on recall), it is a significant result, as wearing the same clothing would seem intuitively trivial. Other studies however, showed that creating a context that actually facilitates learning, retention, and transfer of knowledge is not as straightforward as is often thought (Koens et al. 2003; Koens et al. 2005). To reach those goals, creating a context may have to go much further than a written contextual introduction or elaboration of anatomical structures (e.g., illustrating their importance in physical examination or common pathologies) as described for the discussed student manual. Currently, the possibilities of teaching anatomy in context are not fully understood, and further research is therefore necessary.

\section{Making use of peer physical examination}

The new format is based on students examining their peers. Students' willingness to be a subject in situations of this kind has mostly been studied in relation to physical examination (Wearn et al. 2008; Rees et al. 2009; McLachlan et al. 2010). Being a subject has been reported to be embarrassing and even detrimental to learning, which in some cases has led to large groups of up to fifteen students crowding around one subject (Aggarwal et al. 2006). The approach outlined in the present report uses, on average, one subject for every two students. To a large extent, this can be attributed to the set-up of the format and the strict supervision by teachers, but it may also be due to the fact that the surface anatomy sessions cover only the musculoskeletal system. In the future, it may be interesting to see if this format is also valuable for teaching the surface anatomy of other regions as well. The literature shows that students are less willing to engage in peer physical examination when it concerns the chest, abdominal, and pelvic regions (Rees et al. 2009). However, engaging in peer physical examination helps students to feel comfortable with and develop a professional attitude towards therapeutically touching unclothed bodies (Chinnah et 
al. 2011), as well as to appreciate what it feels like to have to undress and undergo a physical examination (Metcalf et al. 1982; Rees et al. 2004). As surface anatomy sessions contribute to the learning of anatomical knowledge and skills of inspection/visualization and palpation, as well as to the general professional development of students, the authors feel that peer examination is a key aspect of medical education, although caution is recommended when it comes to peer examination of 'socially sensitive areas' (female breasts, anal region, inguinal region, and genitalia) (Metcalf et al. 1982).

\section{Body painting during surface anatomy sessions}

Finn (2010) suggested that inexpensive versions of eyeliner and lip pencils from makeup stores could be used in surface anatomy sessions instead of body paint, especially for drawing fine structures. With literature showing that there are no differences in short-term and long-term retention of knowledge between students who block painted and students who only drew the outlines of viscera (Finn et al. 2011), it was opted to use cosmetic pencils of different colours for surface anatomy sessions. These products are easy to apply and remove when used to mark outlines, cause less staining of clothes, and are readily available in a range of colours.

The authors feel it is highly possible that the reported positive effects of the introduction of body painting on students' perceptions of surface anatomy sessions (Op Den Akker et al. 2002; McMenamin 2008; Finn and McLachlan 2010) may also be due to accompanying factors that are equally or more important but currently underexposed, such as the stricter reliance on small-group learning and/or the rewriting of session goal(s) and/or the student instructions. In the present example, the use of multicoloured pencils and the rotation of the roles of examiner and subject solved the problem of surface anatomy sessions that resulted in (student) models with complex, meaningless drawings of intersecting lines on their bodies.

\section{LESSONS LEARNED}

The first drafts of the student manuals are now under revision. The length and difficulty of some questions and assignments need to be adjusted. Increased application of the learning principles is also being pursued. For the contextual and constructive learning principle, it would be beneficial to add even more links to pathologies or physical examination when a certain structure is discussed. A future goal is also to include pictures, drawings, and/or schemes in the manuals, as the manuals now only contain written text. For example, a picture of the skeleton could be included and students could be asked to draw (a) certain muscle(s) on it. Another 
possibility could be to include a picture of a patient with certain pathology (e.g., a winged scapula) and ask students to describe the possible cause (e.g., paralyzed serratus anterior muscle due to long thoracic nerve damage).

Another adjustment that needs to be made is to reintroduce some plenary demonstration and/or explanation. Students' comments have indicated that it is possible the pendulum has swung too far, going from almost all plenary demonstration to no plenary demonstration at all. Just like lectures within a PBL curriculum, short plenary demonstrations during a surface anatomy session could allow teachers "to give introductory or wrap-up overviews in areas where there might be anticipated difficulty for students facing such concepts for the first time" [page 374] (Neville and Norman 2007). Three examples of these areas can be 1) the function of the gastrocnemius muscle as an example of biarticular muscles, 2) attribution of individual anatomical variations related to thoracic outlet syndrome, or 3 ) the explanation of the mechanisms causing Duchenne or Trendelenburg gait in patients.

Some global changes have taken place within anatomy education in general over the past decade(s), which resulted in an abundance of publications. In the past, the main methods of teaching were lectures and dissection of cadavers by students, focused primarily on gaining anatomical knowledge. Nowadays, there is an increased use of prosections, a greater reliance on computer technology (e.g. digital anatomical atlases), and more dependence on small group learning (either in problem-based or other formats) (Older 2004; Raftery 2006; Louw et al. 2009). Furthermore, additional learning objectives have been integrated in anatomy education, e.g. professionalism, manual dexterity, teamwork, ethics, patient care, and 'dealing with death' (Marks et al. 1997; Aziz et al. 2002; Rizzolo 2002; Gregory et al. 2009).

Surface (living) anatomy education did not get a lot of specific attention, even though it is regarded as a very important addition to anatomy education (Monkhouse 1992; Ellis 2001). However, next to the implementation of body painting discussed in the introduction, a few promising initiatives within surface anatomy education have been described in the last decade. The study of Patten (2007) illustrates the use of a computer with software that allows the students to simultaneously view 2D and 3D anatomical images during surface anatomy sessions. Most interesting however, is that the same software is used to project 3D reconstructions of structures on the surface of a living body itself (e.g. from a student or assistant). Combined with palpation, this can provide a way to help students to develop an appropriate mental representation of spatial relationships of the body. Collett et al. (2009) explored the role of living models in surface anatomy classes. The study revealed that the models, next to being available for students to examine, can act as active participants in class: offering students guidance on anatomical content, giving students individual feedback on their communication and examination skills, reinforcing the humanity and individuality of 
the body, sharing their past medical histories and experiences, and providing feedback to the staff on class performance. Kotzé et al. (2012) introduced full body digital X-ray images during dissection classes to stimulate more engagement with surface anatomy. They also had students draw both the normal and actual positions of organs on a laminated image provided. Azer (2012) assessed YouTube videos for learning surface anatomy. Unfortunately, the search revealed that only a very small percentage of videos (15 out of a total of 235 , mainly covering the musculoskeletal regions) provided relevant and useful surface anatomy information.

All the mentioned examples show that there are many interesting new methods available for teaching surface anatomy. Unfortunately, they are all single studies and not all of them have shown outcome measurements on perception, knowledge, and/or skills gained among students, so further research is necessary.

\section{CONCLUSIONS}

In conclusion, the results show that teaching surface anatomy according to the constructive, collaborative, contextual, and self-directed learning principles leads to higher student satisfaction compared to more traditional methods of teaching surface anatomy. This was expected, as students are also more satisfied with a PBL curriculum based on these four learning principles compared to a traditional curriculum (Norman and Schmidt 1992; Albanese and Mitchell 1993; Vernon and Blake 1993; Colliver 2000; Dochy et al. 2003; Newman 2003).

Furthermore, this article also shows teachers how best evidence medical education can be put into practice. The extensive description of the application of the learning principles in a new method for teaching surface anatomy is a translational contribution to existing literature; it shows teachers an example of how to implement the best evidence available to improve the quality of their own methods and approaches.

The results also indicate that students feel that they learn more from the new format. Therefore, future research on whether teaching surface anatomy in this new format increases students' ability to apply anatomical knowledge is worth pursuing. In addition, it might be interesting to define the context in which teaching based on the four learning principles (as an example of an educational intervention) has a positive effect. The context is made up of different variables, such as the target audience, group size, subject matter, prior knowledge, motivation of the students, behaviour of the teacher etc. Each of these variables may have a greater or lesser influence on the outcomes of the educational intervention, but at this moment it is not clear how and why. As Norman and Schmidt (2000) put it, "the advantage of a real environment is [...] 
that it is so rich with other variables that we must capture these effects to truly understand the complexity of learning interactions" [page 726]. Clarification studies should improve the ability to predict which instructional methods will enhance educational efforts and, therefore, advance the understanding of medical education (Cook et al. 2008). In agreement with Norman and Schmidt (2000), the authors recommend further studies of the application of learning principles on surface anatomy teaching which seek "to understand the complexities of the application setting through examining the interplay of multiple variables" [page 726].

\section{Acknowledgments}

The authors would like to thank Renée Stalmeijer from the Department of Educational Development and Research of Maastricht University for her help in developing the questionnaire; and Roger Troost and Peter Freens of the Skills Laboratory of Maastricht University for their help in developing the student manuals. They also thank Rogier Trompert and Herman Popeijus for creating the figures and Mereke Gorsira for editing the final version of the manuscript. Last but not least they would like to thank our students for their cooperation and giving permission to publish the photos taken during their surface anatomy sessions. 


\section{REFERENCES}

Aggarwal R., Brough H. \& Ellis H. (2006). Medical student participation in surface anatomy classes. Clin Anat, 19(7): 627-631

Albanese M.A. \& Mitchell S. (1993). Problem-based learning: A review of literature on its outcomes and implementation issues. Acad Med, 68(1): 52-81

Azer S.A. (2012). Can "YouTube" help students in learning surface anatomy? Surg Radiol Anat.

Aziz M.A., McKenzie J.C., Wilson J.S., Cowie R.J., Ayeni S.A. \& Dunn B.K. (2002). The human cadaver in the age of biomedical informatics. Anat Rec, 269(1): 20-32.

Barrows H.S., Patek P.R. \& Abrahamson S. (1968). Introduction of the living human body in freshman gross anatomy. Br J Med Educ, 2(1): 33-35.

BEME-Group (2000). Best Evidence Medical Education (BEME): Report of meeting 3-5 December 1999, London, UK Med Teach, 22(3): 242.

Bergman E.M., van der Vleuten C.P. \& Scherpbier A.J. (2011). Why don't they know enough about anatomy? A narrative review. Med Teach, 33(5): 403-409.

Chinnah T.I., de Bere S.R. \& Collett T. (2011). Students' views on the impact of peer physical examination and palpation as a pedagogic tool for teaching and learning living human anatomy. Med Teach, 33(1): e2736.

Cody J. (1995). Painting anatomy on anatomy. J Biocommun, 22(2): 14-17.

Collett T., Kirvell D., Nakorn A. \& McLachlan J.C. (2009). The role of living models in the teaching of surface anatomy: Some experiences from a UK medical school. Med Teach, 31(3): e90-96.

Collins J.P. (2008). Modern approaches to teaching and learning anatomy. BMJ, 337: a1310.

Colliver J.A. (2000). Effectiveness of problem-based learning curricula: Research and theory. Acad Med, 75(3): 259-266.

Cook D.A., Bordage G. \& Schmidt H.G. (2008). Description, justification and clarification: A framework for classifying the purposes of research in medical education. Med Educ, 42(2): 128-133.

Dochy F., Segers M., Bossche P.V. \& Gijbels D. (2003). Effects of problem-based learning: A meta-analysis. Learn Instruct, 13(5): 533-568.

Dolmans D.H., De Grave W., Wolfhagen I.H. \& van der Vleuten C.P. (2005). Problem-based learning: Future challenges for educational practice and research. Med Educ, 39(7): 732-741.

Ellis H. (2001). Teaching in the dissecting room. Clin Anat, 14(2): 149-151.

Ertmer P.A. \& Newby T.J. (1993). Behaviorism, cognitivism, constructivism: Comparing critical features form an instructional design perspective. Performance Improvement Quarterly, 6(4): 50-72.

Findlater G., Kristmundsdottir F., Parson S. \& Gillingwater T. (2012). Development of a supported selfdirected learning approach for anatomy education. Anatomical Sciences Education, Epub ahead of print, DOI 10.1002/ase.1255.

Finn G.M. (2010). Twelve tips for running a successful body painting teaching session. Med Teach, 32(11): 887-890.

Finn G.M. \& McLachlan J.C. (2010). A qualitative study of student responses to body painting. Anat Sci Educ, 3(1): 33-38.

Finn G.M., Patten D. \& McLachlan J.C. (2010). The impact of wearing scrubs on contextual learning. Med Teach, 32(5): 381-384.

Finn G.M., White P.M. \& Abdelbagi I. (2011). The impact of color and role on retention of knowledge: a body-painting study within undergraduate medicine. Anat Sci Educ, 4(6): 311-317.

Godden D. \& Baddeley A. (1975). Context-dependent memory in two natural environments: On land and underwater. Brit J Psychol, 66: 325-331.

Gregory J.K., Lachman N., Camp C.L., Chen L.P. \& Pawlina W. (2009). Restructuring a basic science course for core competencies: an example from anatomy teaching. Med Teach, 31(9): 855-861. 
Griksaitis M.J., Sawdon M.A. \& Finn G.M. (2012). Ultrasound and cadaveric prosections as methods for teaching cardiac anatomy: A comparative study. Anat Sci Educ, 5(1): 20-26.

Harden R., Grant J., Buckley G. \& Hart I. (1999). BEME guide no. 1: Best Evidence Medical Education. Med Teach, 21(6): 553-562.

Harden R., Group B., Buckley G. \& Hart I. (2000). Best Evidence Medical Education. Adv Health Sci Educ 5: $71-$ 90.

Koens F., Mann K.V., Custers E.J. \& Ten Cate O.T. (2005). Analysing the concept of context in medical education. Med Educ, 39(12): 1243-1249.

Koens F., Ten Cate O.T. \& Custers E.J. (2003). Context-dependent memory in a meaningful environment for medical education: in the classroom and at the bedside. Adv Health Sci Educ Theory Pract, 8(2): 155165.

Kotze S.H., Mole C.G. \& Greyling L.M. (2012). The translucent cadaver: An evaluation of the use of full body digital x-ray images and drawings in surface anatomy education. Anat Sci Educ.

Leonard R., Acland R., Agur A., Blevins C., Cahill D., Collins J., Dalley A., Dolph J., Hagedoorn J., Hoos P., Jones D., Mathers L., McFee R., Mennin S., Negulesco J., Nelson M., Olson T., Page D., Pawlina W., Petterborg L., Price J., Spielman J. \& Younoszai R. (1996). A clinical anatomy curriculum for the medical student of the 21st century: gross anatomy. Clin Anat, 9(2): 71-99.

Louw G., Eizenberg N. \& Carmichael S.W. (2009). The place of anatomy in medical education: AMEE Guide no 41. Med Teach, 31(5): 373-386.

Lujan H.L. \& DiCarlo S.E. (2006). First-year medical students prefer multiple learning styles. Adv Physiol Educ, 30(1): 13-16.

Mamede S., Schmidt H.G. \& Norman G.R. (2006). Innovations in problem-based learning: What can we learn from recent studies? Adv Health Sci Educ Theory Pract, 11(4): 403-422.

Marks S.C., Jr., Bertman S.L. \& Penney J.C. (1997). Human anatomy: a foundation for education about death and dying in medicine. Clin Anat, 10(2): 118-122.

McLachlan J.C. \& Patten D. (2006). Anatomy teaching: Ghosts of the past, present and future. Medical Education, 40(3): 243-253.

McLachlan J.C., White P., Donnelly L. \& Patten D. (2010). Student attitudes to peer physical examination: A qualitative study of changes in expressed willingness to participate. Med Teach, 32(2): e101-e105.

McMenamin P.G. (2008). Body painting as a tool in clinical anatomy teaching. Anat Sci Educ, 1(4): 139-144.

Metcalf N.F., Prentice E.D., Metcalf W.K. \& Stinson W.W. (1982). Peer group models in examination instruction as an integral part of medical gross anatomy. J Med Educ, 57(8): 641-644.

Monkhouse W.S. (1992). Anatomy and the medical school curriculum. Lancet, 340(8823): 834-835.

Neville A.J. \& Norman G.R. (2007). PBL in the undergraduate MD program at McMaster University: Three iterations in three decades. Acad Med, 82(4): 370-374.

Newman M. (2003). A pilot systematic review and meta-analysis on the effectiveness of problem based learning. Newcastle Learning \& Teaching Subject Network for Medicine, Dentistry and Veterinary Medicine.

Norman G.R. \& Schmidt H.G. (1992). The psychological basis of problem-based learning: A review of the evidence. Acad Med, 67(9): 557-565.

Norman G.R. \& Schmidt H.G. (2000). Effectiveness of problem-based learning curricula: Theory, practice and paper darts. Med Educ, 34(9): 721-728.

Older J. (2004). Anatomy: a must for teaching the next generation. Surgeon, 2(2): 79-90.

Op Den Akker J.W., Bohnen A., Oudegeest W.J. \& Hillen B. (2002). Giving color to a new curriculum: bodypaint as a tool in medical education. Clin Anat, 15(5): 356-362.

Patten D. (2007). What lies beneath: the use of three-dimensional projection in living anatomy teaching. The Clinical Teacher, 4: 10-14.

Raftery A. (2006). Anatomy teaching in the UK. Surgery, 25(1): 1-2. 
Rees C.E., Bradley P. \& McLachlan J.C. (2004). Exploring medical students' attitudes towards peer physical examination. Med Teach, 26(1): 86-88.

Rees C.E., Wearn A.M., Vnuk A.K. \& Sato T.J. (2009). Medical students' attitudes towards peer physical examination: Findings from an international cross-sectional and longitudinal study. Adv Health Sci Educ Theory Pract, 14(1): 103-121.

Rizzolo L.J. (2002). Human dissection: an approach to interweaving the traditional and humanistic goals of medical education. Anat Rec, 269(6): 242-248.

Stillman P.L., Ruggill J.S. \& Sabers D.L. (1978). The use of live models in the teaching of gross anatomy. Med Educ, 12(2): 114-116.

Sugand K., Abrahams P. \& Khurana A. (2010). The anatomy of anatomy: a review for its modernization. Anat Sci Educ, 3(2): 83-93.

Tynjälä P. (1999). Towards expert knowledge? A comparison between a constructivist and a traditional learning environment in the university. International Journal of Educational Research, 31: 357-442.

Van der Vleuten C.P.M., Dolmans D.H.J.M. \& Scherpbier A.J.J.A. (2000). The need for evidence in education. Med Teach, 22(3): 246-250.

Vernon D.T. \& Blake R.L. (1993). Does problem-based learning work? A meta-analysis of evaluative research. Acad Med, 68(7): 550-563.

Wearn A.M., Rees C.E., Bradley P. \& Vnuk A.K. (2008). Understanding student concerns about peer physical examination using an activity theory framework. Med Educ, 42(12): 1218-1226.

Wolf F. (2000). Lessons to be learned from evidence-based medicine: Practice and promise of evidencebased medicine and evidence-based education. Med Teach, 22(3): 251-259. 


\section{CHAPTER 7}

\section{Effects of learning content in context on knowledge acquisition and recall.}

A pretest-posttest control group design. 


\section{ABSTRACT}

It is generally assumed that learning in context increases performance. This study investigates the relationship between the characteristics of a paper-patient context (relevance and familiarity), the mechanisms through which the cognitive dimension of context could improve learning (activation of prior knowledge, elaboration and increasing retrieval cues), and test performance. A total of 145 medical students completed a pretest of 40 questions, of which half were with a patient vignette. One week later, they studied musculoskeletal anatomy in the dissection room without a paper-patient context (control group) or with (ir)relevant-(un)familiar context (experimental groups), and afterwards completed a cognitive load scale. Following a short delay, the students completed a posttest. Surprisingly, our results show that students who studied in context did not perform better than students who studied without context. This finding may be explained by an interaction of the participants' expertise level, the nature of anatomical knowledge and students' approaches to learning. A relevant-familiar context only reduced the negative effect of learning the content in context. Our results suggest discouraging the introduction of an uncommon disease to illustrate a basic science concept. Higher scores on germane cognitive load predict higher performance. Interestingly, students performed significantly better on the questions with context in both tests, possibly due to a 'framing effect'. Since studies focusing on the physical and affective dimensions of context have also failed to find a positive influence of learning in a clinically relevant context, further research seems necessary to refine our theories around the role of context in learning. 


\section{INTRODUCTION}

The theory of Transfer-Appropriate Processing (Morris et al. 1977) states that performance is determined by (the relationship between) the context in which the content is learned, and the context in which the content is later retrieved. The impact of context is of particular interest in medical education, since students generally learn basic science knowledge in the medical school and apply it in the clinical workplace (Wilkerson et al. 2009; Finn et al. 2010). It is generally assumed that learning in context will increase performance in knowledge acquisition, recall and transfer (Norman 2007; Mann et al. 2011). However, studies with a sound research design determining the effect of teaching in context on performance are scarce (Bergman et al. 2011). Furthermore, teaching in context does not always seem to be beneficial. For example, the results of Böckers et al (2013) showed no significant differences in performance on oral and written examination results between students enrolled in a course with direct practical application of anatomical knowledge within a surgical context and students enrolled in a regular gross anatomy course. Paper-patient cases (patient vignettes) are used as a context to learn e.g. diagnostic skills (Nendaz et al. 2000) and professional behavior (Bernabeo et al. 2013). This study aims to contribute to the literature on learning in context by investigating whether and how a paper-patient used as context in basic science education can influence the acquisition and recall of knowledge. Leading up to our research questions, and as explanation for our research design, we will first discuss how context within medical education is defined, and then describe the possible influence of a paper-patient context on learning and retrieval.

\section{DIMENSIONS OF CONTEXT}

In medical education, 'context' is often conceptualized as the relationship between the basic sciences, clinical sciences and clinical practice (Koens et al. 2005). Koens et al (2005) developed a model with three 'dimensions of context' (see figure 7.1): the physical dimension, the affective (commitment) dimension and the cognitive (semantic) dimension.

The physical dimension refers to the physical surroundings in which the content, the new knowledge to be learned, is presented to the learner. Extensive research on the physical dimension (for a review see Smith and Vela (2001)), has pointed towards a 'same-context advantage', explained by the idea that cues present in the environment during learning are encoded in the memory along with the content. When these cues reappear in the environment in which the content is recalled, they facilitate retrieval of the content (Koens et al. 2005). The affective dimension focuses on the influence of 


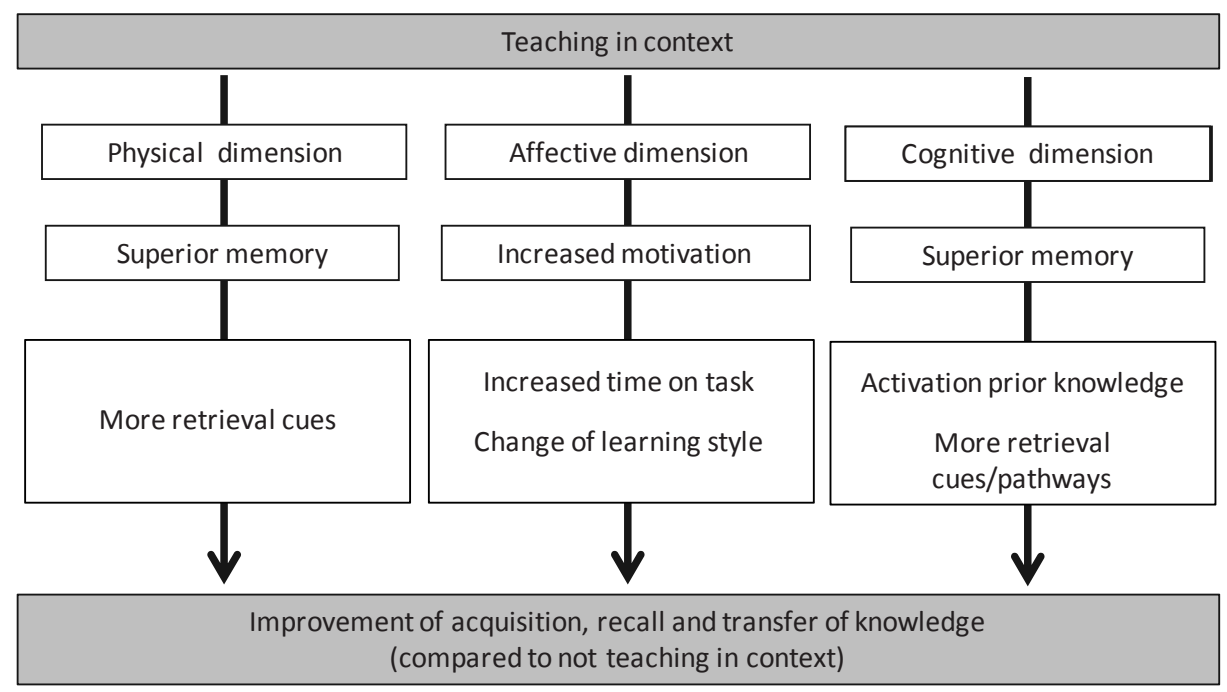

Figure 7.1 Dimensions of context model (adapted from Koens et al. (2005)).

context on the learner's willingness to invest effort in (motivation for) the learning task. The affective dimension is stated to manifest itself in two ways: increased 'time on task' and/or a shift in learning style from superficial to more deep learning. Both can lead to an increase in the acquisition, understanding and retention of knowledge (Koens et al. 2005).

Providing a paper-patient case as a context to learn basic science knowledge (as is for example done in problem-based learning (Dolmans and Schmidt 1994; Dolmans et al. 2005)), is thought to facilitate transfer: using knowledge acquired in one context to solve a new problem in another context (Norman 2009). It further appeals to the mechanisms through which the cognitive dimension of context should improve learning and retrieval: activation of prior knowledge, elaboration and storage of retrieval cues. However before further explanation about these mechanisms can be given, it is important to describe how the learned content is thought to be stored in one's memory.

\section{CHARACTERISTICS OF CONTEXT AND SEMANTIC NETWORKS}

Information is thought to be stored in one's memory by the creation of knowledge structures called semantic networks. Semantic networks consist of one or more propositions, which are described as statements that contain information parts (concepts, facts, experiences) and their meaningful interrelations or 'links' (Schmidt 
1993; Regehr and Norman 1996). Knowledge is thought to be retrieved through activation of a semantic network (Regehr and Norman 1996), and the structure of a semantic network influences its accessibility (Schmidt 1993; Kalyuga et al. 2003; Kalyuga 2009). Semantic networks are idiosyncratic: they reflect a person's experiences, views and ideas and therefore no two persons have exactly the same knowledge about a certain topic (Schmidt 1993; Novak 2002). The quality of a semantic network, i.e. the detail, amount, accuracy and organization of propositions, may be influenced by presenting the content in context. In addition, specific characteristics of that context, here defined as familiarity and relevance, may influence the quality of a semantic network even further.

\section{Influence of the familiarity of the context}

Familiarity of the context, i.e. the extent to which the students are familiar with the disease of the paper-patient, may influence the activation of prior knowledge. Schmidt (1993) states that "the prior knowledge people have regarding a subject is the most important determinant of the nature and amount of new information that can be processed" [page 424]. However, the mere availability of relevant prior knowledge is not sufficient: prior knowledge needs to be activated before links between prior knowledge and new information can be made (Schmidt 1993). The paper-patient context may stimulate prior knowledge activation on the part of the learner by triggering the retrieval of information about the content a student already has, which would not happen if the content was presented without context. This improves the acquisition of the new content: creation of a more extensive semantic network and thus 'superior memory'. Choosing a presumably familiar context, i.e. a paper-patient with a common disease, may increase the chance of the presence and activation of an appropriate semantic network in students, and subsequently may improve learning further.

\section{Influence of the relevance of context}

Relevance of the context, i.e. the extent to which the disease of the paper-patient is associated with content to be learned, may influence the amount of retrieval cues and/or retrieval pathways. Similar as the encoding of environmental cues that explains the same-context advantage of the physical dimension, cues of the paper-patient context may be stored along with the content as information parts in the propositions of a semantic network. As each proposition can be a means to recall all the other knowledge stored in a semantic network, learning in a paper-patient context can consequently facilitate retrieval of the content by increasing retrieval cues. 
Furthermore, the paper-patient context can increase the amount of retrieval pathways, as it may stimulate elaboration. Elaboration means that the learner expands on the relation between two information parts, either from prior knowledge, new content and/or context, by generating meaningful connections and thus integrates new information within an existing semantic network (Wittrock 1992; Schmidt 1993; Kalyuga 2009). The paper-patient context gives more information parts to expand on during elaboration, and therefore possibly gives the opportunity to create more links between information parts and thus enrich a students' semantic network (Blankenstein et al. 2013). To increase the retrieval cues and/or retrieval pathways, the given context, i.e. the disease of the paper-patient, should be relevant to the content to be learned; otherwise the creation of propositions will be limited as making meaningful interrelations between prior knowledge, content and context is hindered.

Although the interaction between the characteristics of context and the mechanisms through which the cognitive dimension of context should improve learning as described above may seem obvious, they are theoretical. There is no empirical evidence to support these hypotheses.

\section{CONTEXT AND COGNITIVE LOAD}

It is possible that learning in context is not always beneficial because it increases cognitive load. The central tenet of cognitive load theory is that human cognitive architecture - and especially the limitations of working memory - should be taken into account when designing instruction (Durning et al. 2012). Working memory has a limited capacity of seven plus or minus two elements (or chunks) of information when merely holding information (Miller 1956) and even fewer (circa four) when processing information (Cowan 2001). Working memory load, or cognitive load, is therefore determined by the number of information elements that need to be processed simultaneously within a certain amount of time (Barrouillet et al. 2007). Proper measurement of the different types of cognitive load can help us understand why the effectiveness and efficiency of learning environments may differ as a function of instructional formats and learner characteristics.

When processing (complex) information, three types of cognitive load may be imposed on the person processing the information: task complexity and the person's prior knowledge of the subject determine the intrinsic cognitive load, instructional features that are not beneficial for learning contribute to extraneous cognitive load, and instructional features that are beneficial for learning contribute to germane cognitive load (Merrienboer and Sweller 2010). Recently, a ten-item instrument was developed that yielded a three-factor solution consistent with cognitive load theory 
(Leppink et al. 2013; Leppink et al. 2014). An advantage of learning in context is expected when the learning task imposes an optimum of intrinsic cognitive load and a minimum of extraneous cognitive load. While an optimum intrinsic cognitive load stimulates students to engage in germane cognitive load activities, minimizing extraneous cognitive load avoids that students refrain from germane cognitive load activity either because they experience cognitive overload or because this engagement would require more cognitive effort than they are willing to invest in learning.

For the last three decades it has been advocated that medical education should be integrated, or in other words, its content should be presented in a for the medical profession relevant context. Next to reducing the 'shock of practice' (Prince et al. 2000) and helping to focus on the clinically relevant aspects of the basic sciences (Clough et al. 2004), teaching in context is said to contribute to knowledge acquisition and retrieval as described above. This study aims to contribute to the literature on teaching in context by investigating whether and how a paper-patient used as a context during learning of a basic science can influence acquisition and recall of knowledge. Following the literature and theories described above we generated four hypotheses:

H1 Learning with a paper-patient context leads to better performance than learning without context

H2 A relevant paper-patient context leads to better performance than irrelevant context

H3 A familiar paper-patient context leads to better performance than unfamiliar context

H4 Higher scores on germane cognitive load predicts high performance

\section{METHODS}

Ethical approval for this study was obtained from the Dutch Association of Medical Education (NVMO) ethical review board.

\section{Setting}

This study was conducted at the Radboud University Medical Centre Nijmegen. The university's medical curriculum is a 6-year problem-oriented, student-centered and (horizontally and vertically) integrated curriculum. In the Netherlands, students enter medical school at the age of around 18 years. 


\section{Participants and experimental design}

To investigate the effect of the characteristics of context, i.e. relevance and familiarity, on knowledge acquisition and recall, a total of 145 first-year (bachelor) medical students (see table 7.1 for descriptives) were allocated randomly to either of five experimental treatment conditions: 1) the control group taught without context, and the experimental groups respectively being taught with 2) relevant-familiar, 3) relevant-unfamiliar, 4) irrelevant-familiar, and 5) irrelevant-unfamiliar context.

The flowchart of the experiment, including the timeframe in which it was conducted, is depicted in figure 7.2. About a week before participating in the experimental condition they had been assigned to, all students completed the pre-test. One hour after treatment, all students completed the post-test. Both pre-test and post-test consisted of 40 extended matching questions about the four musculoskeletal regions that were studied in the learning task (10 questions each). Half of the questions were with and half of the questions were without context. Students did not receive feedback on their test performance.

The students also completed a questionnaire assessing the participants' familiarity with the context provided in the learning task. Students could indicate their familiarity with the diseases on which the patient cases (the context) in the learning task was based. The options were: 0 for 'I have never heard of this disease', and then a

Table 7.1 Descriptives of participants

\begin{tabular}{ll}
\hline Variable & Results \\
\hline Age & $\begin{array}{l}\text { Average 19,2 years } \\
\text { Range 17.5-23.6 years }\end{array}$ \\
\hline Gender & 112 female \\
& 33 male \\
\hline Nationality & 138 Dutch, 3 German, 1 Yugoslav \\
& 1 Iraqi, 1 Turkish, 1 Bulgarian \\
Relevant previous education & $\begin{array}{l}15 \\
\text { (4 Biology, } 4 \text { Biomedical sciences/technology, } 1 \text { Technical Medicine, } 1 \\
\text { Psychology, } 1 \text { Health sciences, 1 Pharmacology, 3 other) } \\
\text { All students quit their other education upon acceptance into medical } \\
\text { school }\end{array}$ \\
\hline
\end{tabular}


Day 1

Day 2

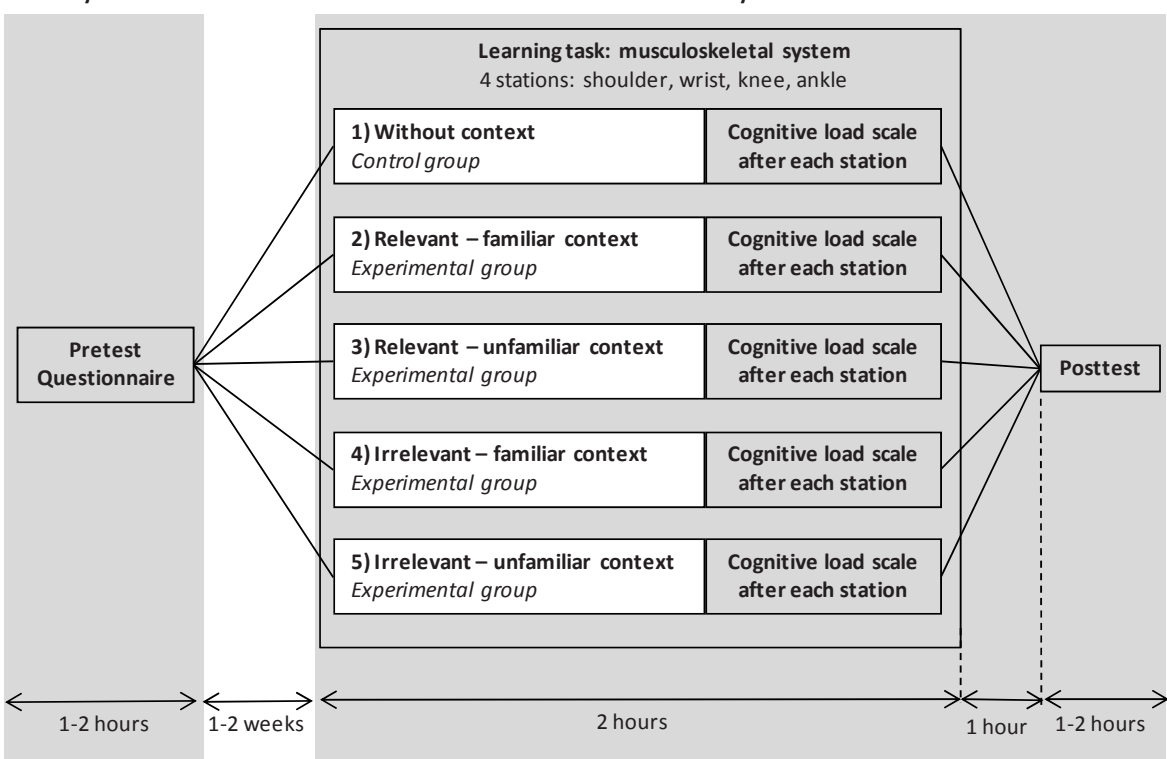

Figure 7.2 Experimental design. On day 1, students completed a pretest assessing their knowledge about musculoskeletal anatomy and a questionnaire assessing their familiarity with the diseases used in the paperpatient context. On day 2, students completed a learning task in the dissection room rotating through four different stations. After each station they completed a cognitive load scale. One hour after treatment, all students completed the post-test.

5 point Likert scale with 1 being 'I have little knowledge of this disease' until 5 being 'I have a lot of knowledge of this disease'.

The learning task of the experiment focused on the musculoskeletal system, which was scheduled to be taught in the regular curriculum directly after this study. This setup was purposefully chosen to stimulate students to participate in the experiment. Furthermore, the participants received a dinner on day 2 and a small financial fee after finishing all parts of the study.

\section{Procedure}

The learning task was a voluntary, extra-curricular, 2 hour structured learning session in the dissection room (Kooloos et al. 2012), with students rotating through 4 different stations focusing on different musculoskeletal regions: shoulder, wrist, knee and ankle (see figure 7.3). The order in which the students rotated through the stations during the learning task was counterbalanced. A manual was written containing the paperpatient case followed by questions and assignments around relevant structures (bones, muscles, ligaments etc.) of the regions. At each station, students had 25 minutes to study the content using the provided prosected cadavers and skeletal 
material. The remaining time was dedicated to explaining the process at the beginning of the session, and time between each station for completion of the cognitive load scale developed by Leppink et al. $(2013 ; 2014)$ and tailored to the domain of anatomy (see appendix 1), and rotation of the students.
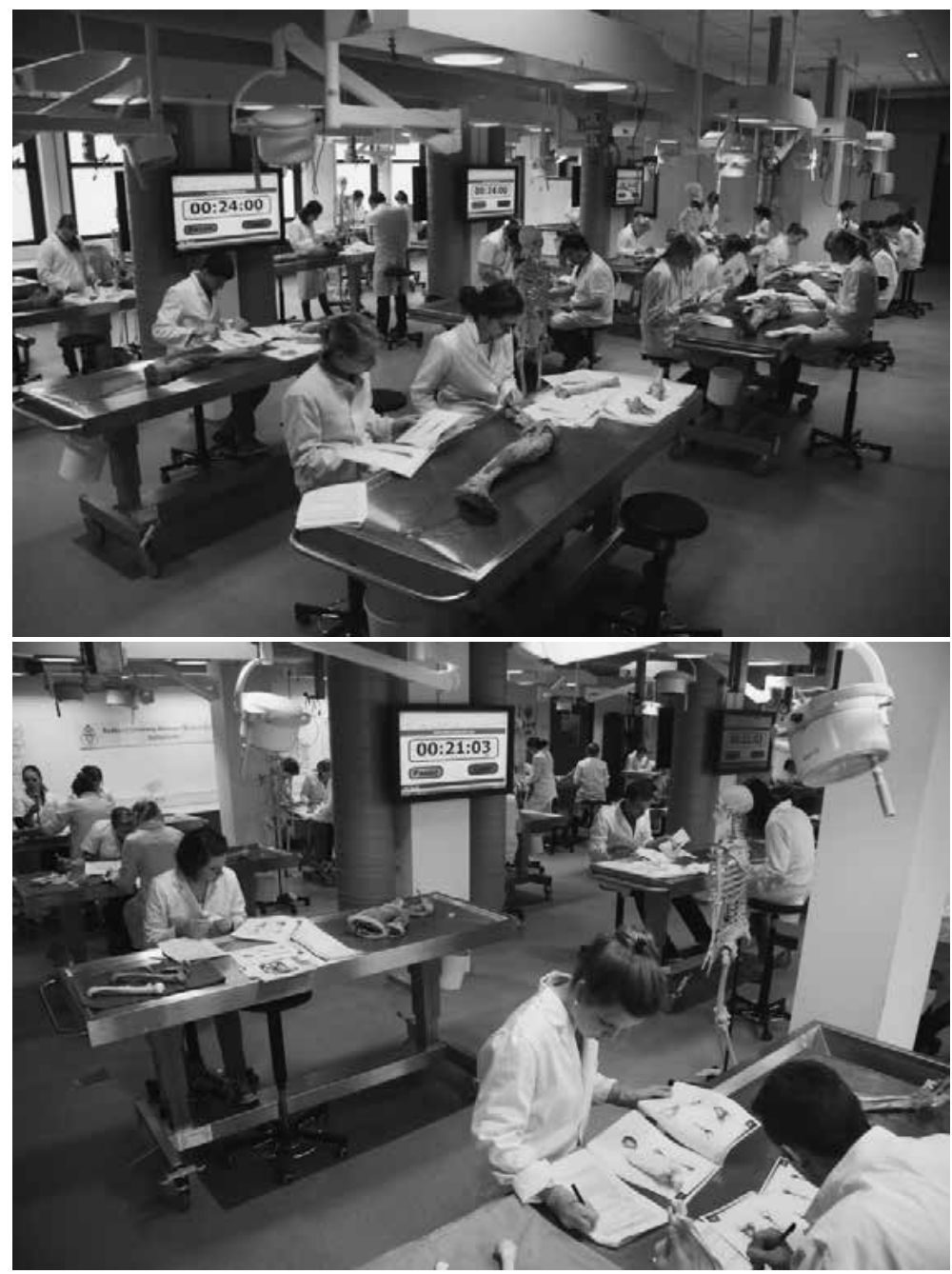

Figure 7.3. Students are studying four musculoskeletal regions (shoulder, wrist, knee, ankle) in the dissection room using skeletal material, prosected parts of cadavers, copies of pages of an anatomical atlas and textbook, and a manual especially written for the experiment containing the context ((ir)relevant and (un)familiar patient case) and the to-be-learned anatomical content. 
The context provided consisted of patient case vignettes. The relevant context focused on the patients with a musculoskeletal problem and the irrelevant context on patients with problems of the nervous system. Familiar context was context with which we thought the students were more able to identify with, as they were common pathologies. Unfamiliar context were pathologies that we thought students would have almost never heard off. See table 7.2 for an overview of the learning tasks and the provided context in each group.

\section{Influence of fellow students, teachers \& study material}

To limit the influence of fellow students, by for example sharing knowledge or explaining to each other, students worked individually and were not allowed speaking with each other, which was monitored by supervisors. There were no teachers available to explain the studied information. As many modern anatomy textbooks include clinical context that may interfere with the purposes of the context of the experiment, we provided the students with copied pages of the Sobotta Atlas of Human Anatomy (Putz and Pabst 2009) and Clinically Oriented Anatomy (Moore et al. 2010) that only contained anatomical information.

Table 7.2 Overview of the learning tasks and the provided (ir)relevant and (un)familiar context

\begin{tabular}{|c|c|c|c|c|c|}
\hline $\begin{array}{l}\text { Learning } \\
\text { task }\end{array}$ & $\begin{array}{l}\text { Group } 1 \\
\text { No context }\end{array}$ & $\begin{array}{l}\text { Group } 2 \\
\text { Relevant- } \\
\text { familiar } \\
\text { context }\end{array}$ & $\begin{array}{l}\text { Group } 3 \\
\text { Relevant- } \\
\text { unfamiliar context }\end{array}$ & $\begin{array}{l}\text { Group } 4 \\
\text { Irrelevant- } \\
\text { familiar context }\end{array}$ & $\begin{array}{l}\text { Group } 5 \\
\text { Irrelevant-unfamiliar } \\
\text { context }\end{array}$ \\
\hline Shoulder & Not applicable & $\begin{array}{l}\text { Dislocated } \\
\text { shoulder }\end{array}$ & $\begin{array}{l}\text { Impingement of } \\
\text { supraspinatus } \\
\text { muscle }\end{array}$ & $\begin{array}{l}\text { Parkinson's } \\
\text { disease }\end{array}$ & $\begin{array}{l}\text { Hallevorden-Spatz } \\
\text { disease }\end{array}$ \\
\hline Wrist & Not applicable & $\begin{array}{l}\text { Carpal tunnel } \\
\text { syndrome }\end{array}$ & Trigger finger & $\begin{array}{l}\text { Multiple } \\
\text { Sclerosis }\end{array}$ & Huntington's Disease \\
\hline Knee & Not applicable & $\begin{array}{l}\text { Ruptured knee } \\
\text { ligaments }\end{array}$ & $\begin{array}{l}\text { Patellofemoral } \\
\text { pain syndrome }\end{array}$ & $\begin{array}{l}\text { Alzheimer's } \\
\text { disease }\end{array}$ & Möbius syndrome \\
\hline Ankle & Not applicable & Sprained ankle & $\begin{array}{l}\text { Anterior } \\
\text { compartment } \\
\text { syndrome }\end{array}$ & Meningitis & $\begin{array}{l}\text { Von Recklinghausen } \\
\text { disease } \\
\text { (neurofibromatosis) }\end{array}$ \\
\hline
\end{tabular}

The students completed a questionnaire assessing the participants' familiarity with the context provided in the learning task to ascertain the chosen context were indeed (un)familiar to the students. There was a significant difference between the familiar and unfamiliar context (see results section). 


\section{Data analysis}

Analysis of covariance (ANCOVA) was performed with posttest score (i.e., sum score of 0-40) as response variable. Relevance (i.e., relevant vs. irrelevant) and familiarity (i.e., familiar vs. unfamiliar) were included as dummy variables to test the hypotheses that learning with a paper-patient context leads to better performance than learning without context' (H1), 'relevant context leads to better performance than irrelevant context' (H2) and 'familiar context leads to better performance than unfamiliar context' (H3). The germane load score averaged over the four stations and was included to test the hypothesis that 'higher scores on the germane load scale predict higher performance' (H4). Pretest score (i.e. sum score of 0-40) was included as covariate to maximize statistical power through reduction of unexplained variance in posttest score. Mean centering was applied to germane load and pretest, so that the intercept reflects the expected performance in the control condition (i.e., irrelevant, unfamiliar, and no context) for average germane load and average pretest performance.

\section{RESULTS}

\section{Familiarity of context}

The results of the students' familiarity with the context showed an average score for the presumably familiar diseases of 2.11 (sd 0.69) for the musculoskeletal and 2.50 (sd $0.67)$ for the neurological subjects. The average score for the presumably unfamiliar diseases were 0.16 (sd 0.32) for the musculoskeletal and 0.33 (sd 0.26) for the neurological subjects. There was a significant difference between the familiar and unfamiliar context $(p<.001)$. Showing that students were indeed much more familiar with the diseases used in the patient cases in the 'familiar context groups'. This increases the chance that these familiar contexts indeed activated prior knowledge in students, which was the aim.

\section{Context and performance}

Cronbach's $\alpha$ was 0.58 for the pretest and 0.76 for the post-test. A plausible explanation for the somewhat lower internal consistency of the pretest is a restrictionof-range effect in knowledge prior to the experiment; the contents covered in the experiment had not yet been offered in the students' curriculum at that point in time.

Table 7.3 presents the results of the ANCOVA for performance as response variable. No multicollinearity problems were encountered, tolerance values varied 
Table 7.3 ANCOVA for performance to test H1-H4.

\begin{tabular}{lllllll}
\hline Effect & $B(\mathrm{SE})$ & $B$ & $B(\mathrm{SE})$ & $p$-value & \multicolumn{2}{c}{$95 \%$ confidence interval } \\
\cline { 5 - 7 } & & & & & Lower & Upper \\
\hline Intercept & $20.015(0.768)$ & & 26.061 & $<0.001$ & 18.497 & 21.534 \\
\hline Context $^{1}$ & $-3.803(1.027)$ & -0.301 & -3.704 & $<0.001$ & -5.834 & -1.773 \\
\hline Relevant $^{2}$ & $0.942(0.784)$ & 0.091 & 1.201 & 0.232 & -0.608 & 2.492 \\
\hline Familiar $^{3}$ & $1.769(0.789)$ & 0.169 & 2.244 & 0.026 & 0.210 & 3.329 \\
\hline Germane load $^{4}$ & $1.018(0.354)$ & 0.196 & 2.874 & 0.005 & 0.318 & 1.719 \\
\hline Pretest $^{4}$ & $0.830(0.113)$ & 0.507 & 7.333 & $<0.001$ & 0.606 & 1.054 \\
\hline
\end{tabular}

${ }^{1}$ context (1) vs. no context (0); ${ }^{2}$ relevant (1) vs. irrelevant (0); ${ }^{3}$ familiar (1) vs. unfamiliar $(0) ;{ }^{4}$ mean centered

from 0.683 for context to 0.966 for germane load. Against expectations, the hypothesis that 'learning with a paper-patient context leads to better performance than learning without context' (H1) could not be confirmed. Results even show an opposite effect. The hypothesis that 'relevant context leads to better performance than irrelevant context' (H2) is not supported convincingly, and the standardized beta indicates a small effect (in the expected direction) at best. As expected, 'familiar context leads to better performance than unfamiliar context' (H3). The standardized betas $(B)$ indicate that the effect of familiarity is in the range of small $(0.10)$ to medium (0.25) (Lipsey and Wilson 2001).

In both the pre- and posttest, participants scored significantly better on the test questions with context than on test questions without context $(p<.001)$, see table 7.4. The treatment condition did not influence students' performance on test questions with and without context.

Table 7.4 Average scores and standard deviation for test questions with and without context.

\begin{tabular}{llll}
\hline & $k$ & Pre-test & Post-test \\
\hline Questions with context & 20 & $5.04( \pm 1.95)$ & $9.50( \pm 2.74)$ \\
\hline Questions without context & 20 & $2.91( \pm 1.48)^{*}$ & $8.61( \pm 3.01)^{*}$ \\
\hline
\end{tabular}

$* p<0.001$ 


\section{Context and cognitive load}

The germane cognitive load score is an average of the germane cognitive load scores measured after each station in the learning task. In the original paper by Leppink and colleagues (2013), the germane cognitive load score was the average of four items. In the current study, one of the four items had a considerably, but explainable (see appendix 1), lower item-total correlation, lowering the internal consistency of the scale (Cronbach's $\alpha$ of the original four-item scale ranged from 0.50 to 0.66 ). Therefore, the average of the remaining three items was taken as germane cognitive load score in the current study (Cronbach's $\alpha$ of this revised scale ranged from 0.77 to 0.84 ).

The absence of context, or the presence of (ir)relevant-(un)familiar context does not influence the scores on the three cognitive load subscales. Nonetheless, 'higher scores on the germane load scale predict higher performance' (H4) as expected, see Table 3. The standardized betas $(B)$ indicate that the effect of germane load is in the range of small (0.10) to medium (0.25) (Lipsey and Wilson 2001).

\section{DISCUSSION}

\section{INFLUENCE OF CONTEXT ON PERFORMANCE}

Our results show that students who studied the anatomical content with (a paperpatient) context did not perform better (and in some cases even worse) than students who studied the content without context. This finding may potentially be explained by an interaction of the expertise level of the participants, the nature of anatomical knowledge and approaches to learning by students.

It is generally known that one of the most important factors affecting learning is what a learner already knows, or in other words, a learners' prior knowledge is the most important pre-requisite for learning (Schmidt 1993; Kalyuga and Renkl 2010; Ormrod 2012). The expertise level regarding anatomy of the musculoskeletal system of the complete group of participants was low, being first year medical students who had not studied this region before entering in this study (average score on pretest was 8.1 points out of 40); this low expertise level may have influenced their approach to learning during the learning task.

Our understanding of how students approach learning is informed by the research of Marton and Säljö (1976a, 1976b), whose results showed that students' approaches to study could be divided into two categories: surface and deep. A surface approach to learning is associated with an intention to memorize information (facts) in isolation and recite them back in examinations. It invites routine memorization, 'rote-learning' 
or 'mechanical repetition', of facts and lists, often aided by the use of mnemonics. A deep approach to learning is characterized by a motivation to understand the topic. Students using a deep approach try to make the information meaningful. While learning, students try to make connections between facts and with previous knowledge, seek structure within the material, search for principles and integrate facts across domains (Pandey and Zimitat 2007; Smith and Mathias 2010; Ward 2011; Böckers et al. 2013). Students with a higher expertise level (more prior knowledge) have more ideas to which they can relate new information and so can more easily engage in such processes as meaningful learning and elaboration (Ormrod 2012). Therefore it is possible that the participants of this study used a surface approach to learning during the learning task. Furthermore, anatomy is a discipline with its own language to describe the organization and structures of the body (Pandey and Zimitat 2007). Students have described this large amount of vocabulary and facts as daunting (Mattick and Knight 2007; Bergman et al. 2013). It has also been previously reported that, in sciences, where there is a complex vocabulary associated with learning, a deep approach may require a preliminary stage of rote learning that is difficult to distinguish from a surface approach (Entwistle and Ramsden 1983). Rote learning in this instance might be an example of an intention to understand, even though memorizing jargon or symbols is part of the learning process (Laurillard 1984). It is likely that the students spent the learning task rote-learning the names of the structures (surface approach), and did not engage in a deep approach by for example trying to understand how the anatomical content could explain signs and symptoms described in the paper-patient case of each station. Theoretically, the (characteristics of the) context in which content is learned may only have a positive effect on performance when students attempt a deep approach to learning. And with respect to anatomy, taking a deep approach to learning may only be possible when students have mastered a certain level of 'anatomical vocabulary' and thus have a higher expertise level. Our results even suggest that providing context while students are in a surface learning phase may work counterproductive. If both expertise level of students and the nature of anatomical knowledge indeed lead to a necessary primary stage of surface learning, and context may only influence learning while taking a deep approach, this may have a significant impact on the way the content is taught. Further research should therefore investigate these interactions.

\section{INFLUENCE OF PRIOR KNOWLEDGE, RELEVANCE AND FAMILIARITY ON PERFORMANCE}

Even though the expertise level of the group of participants as a whole was low, the prior knowledge within the group varied (ranging between 3 and 19 points out of 40 
on the pretest). The results show that scores on the pretest had a great effect on performance in the posttest, which seems to confirm the statement that a learners' prior knowledge is the most important pre-requisite for learning (Schmidt 1993; Kalyuga and Renkl 2010; Ormrod 2012). There was no interaction between the scores on the pre-test and the group in which the student performed the learning task. This indicates that there was no expertise-reversal effect: students with more prior knowledge of one of the musculoskeletal subjects did not benefit less by the content being presented in context than students with less prior knowledge.

The characteristics of the context had a small positive effect in the expected direction. Results of this study suggest that having a relevant-familiar context reduces the possible negative impact of being provided with a context. In an educational setting, a situation in which students encounter an irrelevant context is improbable. However, it is not unusual for teachers to introduce an uncommon disease to illustrate some basic science concept or principle. The results of this study seem to indicate that choosing a disease with which the students are most likely familiar is preferable above diseases with which they are unfamiliar. A semantic network needs to be activated before meaningful connections between the prior knowledge in that network and the new information in the content and context can be made (Schmidt 1993). It is plausible that a familiar context (disease) will activate a much larger semantic network (more prior knowledge) about a subject than an unfamiliar context, because students will be better able to relate information in the context to what they already know. Since the present study is the first to investigate the relationship between the characteristics of a context (relevance and familiarity), the mechanisms through which the cognitive dimension of context is said to improve learning (activation of prior knowledge, increasing retrieval cues/pathways), and test performance (increased acquisition and recall of knowledge), more research is necessary to further investigate and explain our findings.

\section{Limits of the study}

Some aspects of the experimental design might have influenced the results discussed above. First, all groups were given the same amount of time during the learning task to study the content. The students in the 'without context' treatment condition did not have a patient case to read through, so they could invest all the available time on studying the content. It is possible that this increased 'time on task' contributed to a better than expected performance on the post-test. It was debated to give students in the without context condition a completely different text to read (for example a fairytale). However "it is important to note that the context includes all features of the environment at the time of learning, not simply those judged by some external 
criterion to be, in some way, important or relevant to the material learned" [page 559] (Norman and Schmidt 1992), and we therefore opted for a complete without context condition. Furthermore, a patient case had on average 364 words, which takes such a short time to read we assume that there is a limited impact on time on task.

A further limitation of this study could be that students only studied the content in context, but did not apply the learned content to context. For example, an X-ray was included in the patient case about the dislocated shoulder, but students were not asked to identify the bones (e.g. scapula, humerus, clavicle) and/or bone markings (e.g. acromion, coracoid process, greater tubercle) which they studied in the to-be-learned content.

A total of 158 students completed the pretest, but 145 students participated in the learning task and completed the posttest. Analysis showed that the majority students that have withdrawn emanated from group 4 and that their pretest scores were lower than average. Subsequently, only students who scored above average studied the content in the irrelevant-familiar context and completed the posttest. Therefore a limitation of the study is that the effect of relevance could now be slightly underestimated and the effect of familiarity slightly overestimated.

The last limitation is that the results would have had more power if it was possible to calculate interactions. However the experimental design could not reach a full 3way factorial $(2 \times 2 \times 2)$ design, as it proved difficult to come up with a solution on how to create a learning task 'without (ir)relevant and (un)familiar context', or in other words how to manipulate the relevance and familiarity of the context when the context is absent. A full $2 \times 2 \times 2$ design would also offer the possibility of comparing groups with the same amount of participants, instead of the comparison of the control condition to all other conditions as done in this study.

\section{INFLUENCE OF CONTEXT ON COGNITIVE LOAD AND KNOWLEDGE RETRIEVAL}

As predicted, the results showed that higher scores on the germane load scale, indicating that the student found the instructional features beneficial for learning, predict higher performance. However, one might expect that students with an irrelevant context would score significantly higher on the extraneous cognitive load scale, as irrelevant context could be seen as instructional features that are not beneficial for learning. An explanation could be the manifestation of a 'nonsense effect': students avoided engagement with the context because the patient case did not make sense to them in combination with the content that needed to be learned. Consequently, the instructional features of the irrelevant context would not have added to the students (extraneous) cognitive load. 
Taking into account the theory of Transfer-Appropriate Processing, half of the test questions were formulated with context (patient vignette) and half of the test questions were formulated without context. Interestingly, the results show that students performed significantly better on the questions with context, not only in the posttest but already in the pretest! Whether the students studied the content with or without context did not influence performance on the different test questions. This contradicts the findings of Prince et al. (2003), who showed that student taught in a clinical context performed better on a subtest with clinical context. The 40 test questions, 10 of each of the 4 musculoskeletal region, were presented in a mixed order. However, the option lists from which they had to pick an answer would contain all the muscles, bone (markings) or ligaments of all regions. Context may have had a 'framing effect': psychological research has shown that the way a question is 'framed' (the words used) influences how people answer the question (Gong et al. 2013). In this study, the context within the question may stimulate activation of an appropriate semantic network and therefore increase the chance students' pick the correct answer out of the option list. The results make it tentative to state that context aids retrieval (or improve correct guessing) of (anatomical) knowledge for (first year medical) students, but not the acquisition of knowledge as much as expected. However, the study design does not allow any conclusions to be drawn in this direction and it may be interesting to pursue these effects in further studies. Especially since results of a study investigating the difference between short case and factual knowledge questions in problem-solving assessment has shown that placing the questions in a realistic context has a considerable effect on the type of cognitive operations (thinking processes) which take place (Schuwirth et al. 2001).

\section{EFFECT OF LEARNING CONTENT IN CONTEXT}

The relationship between context and learning is much more complex than originally expected. The study of Koens et al. (2003), which focused on the physical dimensions of context, the study of Böckers et al (2013), which focused more on the affective dimension of context, and the present study focusing on the cognitive dimension of context all failed to find a significant positive influence of learning in a clinically relevant context. Our results suggest that relevance and familiarity of a paper-patient case positively influence the contribution of the cognitive dimension of context on increased acquisition and recall of knowledge. However, an interaction with expertise level and approaches to learning may exist. Experiments should systematically vary prior knowledge, familiarity, learning approach and cognitive load and search for consistent interactions. We may subsequently refine our theories around the role of context in learning. 


\section{Acknowledgements}

We would like to thank all students for their participation in this study. Furthermore we would like to thank our colleagues and student-assistants for their help in organizing and executing the learning sessions in the dissection room. 


\section{REFERENCES}

Barrouillet P., Bernardin S., Portrat S., Vergauwe E. \& Camos V. (2007). Time and cognitive load in working memory. Journal of Experimental Psychology: Learning, Memory and Cognition, 33: 570-585.

Bergman E.M., de Bruin A.B., Herrler A., Verheijen I.W., Scherpbier A.J. \& van der Vleuten C.P. (2013). Students' perceptions of anatomy across the undergraduate problem-based learning medical curriculum: a phenomenographical study. BMC Med Educ, 13(1): 152.

Bergman E.M., Van Der Vleuten C.P. \& Scherpbier A.J. (2011). Why don't they know enough about anatomy? A narrative review. Med Teach.

Bernabeo E.C., Holmboe E.S., Ross K., Chesluk B. \& Ginsburg S. (2013). The utility of vignettes to stimulate reflection on professionalism: theory and practice. Adv Health Sci Educ Theory Pract, 18(3): 463-484.

Blankenstein F.M.v., Dolmans D.H., Van der Vleuten C.P. \& Schmidt H.G. (2013). Elaboration during problembased group discussion: effects on recall for high and low ability students. Adv Health Sci Educ Theory Pract, 18(4): 659-672.

Böckers A., Mayer C. \& Böckers T.M. (2013). Does learning in clinical context in anatomical sciences improve examination results, learning motivation, or learning orientation? Anat Sci Educ.

Clough R.W., Shea S.L., Hamilton W.R., Estavillo J.A., Rupp G., Browning R.A. \& Lal S. (2004). Weaving basic and social sciences into a case-based, clinically oriented medical curriculum: one school's approach. Acad Med, 79(11): 1073-1083.

Cowan N. (2001). The magical number 4 in short-term memory: a reconsideration of mental storage capacity. Behavioral and Brain Sciences, 24: 152-153.

Dolmans D.H., De Grave W., Wolfhagen I.H. \& van der Vleuten C.P. (2005). Problem-based learning: future challenges for educational practice and research. Med Educ, 39(7): 732-741.

Dolmans D.H. \& Schmidt H.G. (1994). What drives the student in problem-based learning? Med Educ, 28(5): 372-380.

Durning S.J., Artino A.R., Boulet J.R., Dorrance K., van der Vleuten C. \& Schuwirth L. (2012). The impact of selected contextual factors on experts' clinical reasoning performance (does context impact clinical reasoning performance in experts?). Adv Health Sci Educ Theory Pract, 17(1): 65-79.

Entwistle N. \& Ramsden P. (1983). Understanding Student Learning. New York, NY, USA: Croom Helm Ltd.

Finn G.M., Patten D. \& McLachlan J.C. (2010). The impact of wearing scrubs on contextual learning. Med Teach, 32(5): 381-384.

Gong J., Zhang Y., Yang Z., Huang Y., Feng J. \& Zhang W. (2013). The framing effect in medical decisionmaking: a review of the literature. Psychology, Health \& Medicine, 18(6): 645-653.

Kalyuga S. (2009). Knowledge elaboration: a cognitive load perspective. Learning and Instruction, 19: 402410.

Kalyuga S., Ayres P., Chandler P. \& Sweller J. (2003). The expertise reversal effect. Educational Psychologist, 38: 23-31.

Kalyuga S. \& Renkl A. (2010). Expertise reversal effect and its instructional implications: introducation to the special issue. Instr Sci, 38: 209-215.

Koens F., Mann K.V., Custers E.J. \& Ten Cate O.T. (2005). Analysing the concept of context in medical education. Med Educ, 39(12): 1243-1249.

Koens F., Ten Cate O.T. \& Custers E.J. (2003). Context-dependent memory in a meaningful environment for medical education: in the classroom and at the bedside. Adv Health Sci Educ Theory Pract, 8(2): 155165.

Kooloos J.G., de Waal Malefijt M.C., Ruiter D.J. \& Vorstenbosch M.A. (2012). Loosely-guided, self-directed learning versus strictly-guided, station-based learning in gross anatomy laboratory sessions. Anat Sci Educ, 5(6): 340-346. 
Laurillard D. (1984). Learning formal representations through multimedia. In Marton F. (Ed.), The Experience of Learning (pp. 172-183). Edinburgh: Scottish Academic Press.

Leppink J., Paas F., Van der Vleuten C.P., Van Gog T. \& Van Merrienboer J.J. (2013). Development of an instrument for measuring different types of cognitive load. Behav Res Methods.

Leppink J., Paas F., Van Gog T., van der Vleuten C.P.M. \& van Merrienboer J.J.G. (2014). Effects of pairs of problems and examples on task performance and different types of cognitive load. Learning and Instruction, 30: 32-43.

Lipsey M.W. \& Wilson D.B. (2001). Practical meta-analysis. London: Sage.

Mann K., Dornan T. \& Teunissen P.W. (2011). Perspectives on learning. In Dornan T., Mann K., Scherpbier A. \& Spencer J. (Eds.), Medical Education: Theory and Practice (pp. 17-38). London: Elsevier Ltd. .

Marton F. \& Säljö R. (1976a). On qualitative differences in learning. I. Outcome and process. Br J Educ Psychol, 46: 4-11.

Marton F. \& Säljö R. (1976b). On qualitative differences in learning. II. Outcome as a function of the learner's conception of the task. Br J Educ Psychol, 46: 115-127.

Mattick K. \& Knight L. (2007). High-quality learning: harder to achieve than we think? Med Educ, 41(7): 638644.

Merrienboer J.J.v. \& Sweller J. (2010). Cognitive load theory in health professional education: design principles and strategies. [Review]. Med Educ, 44(1): 85-93.

Miller G. (1956). The magical number seven, plus or minus two: some limits on our capacity for processing information. The Psychological Review, 63: 81-97.

Moore K., Dalley A. \& Agur A. (2010). Clinically Oriented Anatomy, 6th edition. Baltimore, MD, USA: Wolters Kluwer, Lippincott Williams \& Wilkins.

Morris C.D., Bransford J.D. \& Franks J.J. (1977). Levels of processing versus transfer appropriate processing. Journal of Verbal Learning and Verbal Behavior, 16(5): 519-533.

Nendaz M.R., Raetzo M.A., Junod A.F. \& Vu N.V. (2000). Teaching Diagnostic Skills: Clinical Vignettes or Chief Complaints? Adv Health Sci Educ Theory Pract, 5(1): 3-10.

Norman G. (2007). How basic is basic science? Adv Health Sci Educ Theory Pract, 12(4): 401-403.

Norman G. (2009). Teaching basic science to optimize transfer. Med Teach, 31(9): 807-811.

Norman G. \& Schmidt H.G. (1992). The psychological basis of problem-based learning: a review of the evidence. Acad Med, 67(9): 557-565.

Novak J. (2002). Meaningful learning: the essential factor for conceptual change in limited or inappropriate propositional hierarchies leading to empowerment of learners. Science Education, 86(4): 548-571.

Ormrod J.E. (2012). Human Learning, Sixth Edition. Upper Saddle River, New Jersey, USA: Pearson Education, Inc.

Pandey P. \& Zimitat C. (2007). Medical students' learning of anatomy: memorisation, understanding and visualisation. Med Educ, 41(1): 7-14.

Prince K.J., Van De Wiel M., Scherpbier A.J., Can Der Vleuten C.P. \& Boshuizen H.P. (2000). A Qualitative Analysis of the Transition from Theory to Practice in Undergraduate Training in a PBL-Medical School. Adv Health Sci Educ Theory Pract, 5(2): 105-116.

Prince K.J., van Mameren H., Hylkema N., Drukker J., Scherpbier A.J. \& van der Vleuten C.P. (2003). Does problem-based learning lead to deficiencies in basic science knowledge? An empirical case on anatomy. Med Educ, 37(1): 15-21.

Putz R. \& Pabst R. (2009). Sobotta Atlas of Human Anatomy, 14th edition, Latin Nomenclature. Münich, Germany: Elsevier Urban \& Fischer.

Regehr G. \& Norman G.R. (1996). Issues in cognitive psychology: implications for professional education. Acad Med, 71(9): 988-1001.

Schmidt H. (1993). Foundations of problem based learning: some explanatory notes. Med Educ, 27: $422-432$.

Schuwirth L.W., Verheggen M.M., van der Vleuten C.P., Boshuizen H.P. \& Dinant G.J. (2001). Do short cases elicit different thinking processes than factual knowledge questions do? Med Educ, 35(4): 348-356. 
Smith C.F. \& Mathias H.S. (2010). Medical students' approaches to learning anatomy: students' experiences and relations to the learning environment. Clin Anat, 23(1): 106-114.

Smith S.M. \& Vela E. (2001). Environmental context-dependent memory: a review and meta-analysis. Psychon Bull Rev, 8(2): 203-220.

Ward P.J. (2011). First year medical students' approaches to study and their outcomes in a gross anatomy course. Clin Anat, 24(1): 120-127.

Wilkerson L., Stevens C.M. \& Krasne S. (2009). No content without context: integrating basic, clinical, and social sciences in a pre-clerkship curriculum. Med Teach, 31(9): 812-821.

Wittrock M. (1992). Generative learning processess of the brain. Educational Psychologist, 27(4): 531-541. 


\section{APPENDIX 1}

The cognitive load questionnaire of Leppink et al. (tailored to the domain of anatomy education)

All of the following 10 questions refer to the task (the station) that you just finished. Please take your time to read each of the questions carefully and respond to each of the questions on the presented scale from 0 to 10 , in which ' 0 ' indicates not at all the case and ' 10 ' indicates completely the case.

(I.) The images and prosections in this station were very complex.

$\begin{array}{lllllllllll}0 & 1 & 2 & 3 & 4 & 5 & 6 & 7 & 8 & 9 & 10\end{array}$

(II.) The anatomy covered in this station was very complex.

$\begin{array}{lllllllllll}0 & 1 & 2 & 3 & 4 & 5 & 6 & 7 & 8 & 9 & 10\end{array}$

(III.) In this station, very complex terms were mentioned.

$\begin{array}{lllllllllll}0 & 1 & 2 & 3 & 4 & 5 & 6 & 7 & 8 & 9 & 10\end{array}$

(IV.) The explanations and instructions in this station were very unclear.

$$
\begin{array}{llllllllll}
0 & 1 & 2 & 3 & 4 & 5 & 6 & 7 & 8 & 9
\end{array}
$$

(V.) The explanations and instructions in this station were full of unclear language.

$\begin{array}{lllllllllll}0 & 1 & 2 & 3 & 4 & 5 & 6 & 7 & 8 & 9 & 10\end{array}$

(VI.) The explanations and instructions in this station were, in terms of learning, very ineffective.

$\begin{array}{lllllllllll}0 & 1 & 2 & 3 & 4 & 5 & 6 & 7 & 8 & 9 & 10\end{array}$

(VII.) This station really improved my understanding of the anatomy that was covered.
12
3
45
$\begin{array}{lll}6 & 7 & 8\end{array}$
9

(VIII.) This station really improved my understanding of the diseases that were covered.
0
$\begin{array}{lll}1 & 2 & 3\end{array}$
45
$\begin{array}{lll}6 & 7 & 8\end{array}$
10

(IX.) This station really improved my knowledge of the terms that were mentioned.

$$
\begin{array}{llllllllll}
0 & 1 & 2 & 3 & 4 & 5 & 6 & 7 & 8 & 9
\end{array}
$$

(X.) This station really improved my knowledge and understanding of anatomy in general.
0
1
23
34
45
5
$6 \quad 7 \quad 8$

For calculation of germane load, item VIII was excluded. That this item lowered the internal consistency of the scale is not surprising considering the fact that within the patient cases, only the signs and symptoms of a disease were described, added with short information on diagnosis and treatment. The pathophysiology of a disease was not extensively explained, which could consequently not have led to a great improvement of the understanding of the disease itself. 

CHAPTER 8

General discussion 


\section{BACKGROUND}

Anatomical knowledge is thought, together with knowledge of the other basic sciences, to be essential for good clinical practice. However, changes in medical education such as the integration of additional knowledge and skills in the curriculum, shortening of the curriculum, modern educational approaches and teaching methods have given rise to concern about the level of basic science knowledge attained by graduating medical students, particularly in anatomy. Whether or not there is a decline in knowledge is left undisputed in this thesis. Although extensive anatomy education is no longer self-evident, the general consensus is that medical students definitely cannot do without basic science knowledge, and thus time granted in the medical curriculum needs to be used as effectively as possible. Therefore, the main research question of this thesis is: How can anatomy education be optimised? 


\section{THE WHY, WHAT, WHEN, WHERE, WHO AND HOW OF ANATOMY EDUCATION}

This discussion contains the main findings and conclusions of this thesis. As it turns out, there is not one answer to the question how anatomy education can be optimised. The answer depends on one's responses to the why, what, when, were, who and how of anatomy education. In order to formulate this thesis' response to these questions, the main findings and conclusions are related to, and combined with, other literature. Each paragraph will be followed by recommendations for future research and practical implications. Although much of the information presented below mainly focuses on anatomy, it also concerns all the other basic sciences. This discussion ends by informing the reader about the strengths and limitations of this thesis and a personal afterthought.

\section{WHY ARE WE TEACHING ANATOMY?}

Although the wording may differ, students, clinicians, anatomists and educationalists will probably answer the 'why' question similarly: anatomy (and the other basic sciences) is taught because it is pertinent for students' future professional practice. Studies have shown that students' who learn causal mechanisms using basic science information have a more coherent understanding of, and are better in reconstructing and recalling the relation between, clinical features and disease (Woods et al. 2005; 2006). Furthermore, knowledge of underlying causal mechanisms can aid student memory for diagnostic categories (Woods et al. 2007a). Last but not least, basic science knowledge seems to play a critical role in the diagnosis of challenging clinical problems (Woods et al. 2007b).

An essential finding reported in Chapter 5 of this thesis is that even though students acknowledge the relevance of anatomical knowledge, this does not automatically mean they are stimulated or motivated to study anatomy. The perceived importance of a subject, and thus the time and effort that students invest in studying the subject seems to be strongly connected to the impact of the subject on assessment results. Assessment driving learning is a well-known phenomenon in education (Larsen et al. 2008; Schuwirth and Van der Vleuten 2011). If you were to ask a student in the medical library why (s)he is studying so hard, you will more often be told the exact time left before their next exam than an elaborate answer on how learning the subject contributes to their wish to become a great physician. Although in theory students learn for future practice, what and how they learn in practice is driven by the "hidden curriculum'. The 'hidden curriculum' is described as: "processes, pressures and constraints which fall outside [...] the formal curriculum, and which are often 
unarticulated or unexplored" [page 770] (Lempp and Seale 2004). If we are teaching students anatomy to be able to explain patients' symptoms, detect abnormalities in an $\mathrm{X}$-ray, interpret signs during a physical examination, then why are the questions in assessments mostly of the 'name this structure' format? In my opinion, assessment should be more tailored to what we want students to learn.

\section{Suggestions for further research}

The studies of Woods et al. (2005; 2006; 2007a, 2007b) mentioned above have shown the importance of basic science knowledge for diagnostic reasoning. Vorstenbosch et al. (2014) have shown that junior doctors actively use (the visual representation of) their anatomical knowledge when performing a consultation with a patient with a complex shoulder complaint. Further research should continue to carry out these types of experiments. Information on how and when physicians use anatomical (basic science) knowledge throughout their career (from novice to expert) is needed in order to inform curriculum design for undergraduate and postgraduate education.

\section{Implications for educational practice}

This thesis has shown that although the vocabulary of anatomy may require an initial stage of rote-learning the names of structures (Chapter 7), teachers should be aware that students are not perceiving the achievement of this goal as an endpoint of their learning (Chapter 5). Knowing the terminology may be defined as the anatomical competence of a novice, yet is only necessary for communication for experts. Teachers should keep on showing students the relevance of anatomical knowledge, and provide them with multiple opportunities to experience how signs and symptoms can be explained by anatomical knowledge. This can be aided by the implementation of an assessment for learning programme. Assessment for learning is "an approach in which the assessment process is inextricably embedded within the educational process, which is maximally information-rich, and which serves to steer and foster the learning of each individual student to the maximum of his/her ability" [page 478] (Schuwirth and Van der Vleuten 2011). When assessment focuses on the use of anatomical knowledge in a clinical setting, the 'assessment drives learning phenomenon' ensures that students see this goals as an endpoint of their learning as well.

\section{WHAT ANATOMICAL KNOWLEDGE SHOULD BE TAUGHT?}

"There clearly are basic science topics for which an in-depth understanding is required for effective patient care. There are also basic science topics for which students need 
only understand general concept and principles sufficiently well that they can read about scientific advances and incorporate them into their clinical practice when appropriate. One difficulty in developing the medical school curriculum is deciding which topics fall in each category" [page 73] (Swanson and Case 1997). This thesis showed that there is little agreement among authors on the content of lists of anatomical structures and many differences in judgment on the depth and (active) knowledge between basic scientists and clinicians (Chapter 2). As teachers, we should be aware that the purpose of undergraduate medical education is not to produce anatomists (or physiologists, biochemists, statisticians, molecular biologists, etc.), but to create a student trained to become a physician (Fraser 1991; Drake 1998; Whitcomb 2006).

Norman (2010) has suggested that most medical specialists who rarely get to see inside the body may well get by with the simplified schematics in textbooks, and may even benefit from such an approach. The results of a study by Schauber et al. (2013), who used a structural equation model to analyse the temporal relationship between biomedical and clinical knowledge as measured in a progress test, have even shown that high levels of biomedical knowledge at the start of clinical training is negatively related to the acquisition of clinical knowledge. However, these findings may have been influenced by individual differences in the motivational or cognitive characteristics of students, processes of interference during learning and/or inappropriate transfer (Schauber et al. 2013).

Research in this thesis has shown that people have been complaining about the decline of anatomical knowledge for decades. It also suggests that the perception that anatomical knowledge levels have fallen arises from a generation conflict (Chapter 3 ). However, this provides no answers to how detailed anatomy instruction should be. This thesis showed that being instructed to memorise a list of structures was perceived as such a daunting task that students were more likely to be demotivated than encouraged to study anatomy (Chapter 5). Do students need to learn the names of the foot bones when it is highly likely they will end up as a cardiologist? The difficulty in this discussion is that we will never know for sure what a students' specialism will become when we are teaching anatomy in the undergraduate curriculum. As a solution, Chapter 5 of this thesis suggests the initial teaching of anatomical concepts. Anatomical concepts are descriptions of general similarities between anatomical structures (for example, a ligament in the musculoskeletal system is a structure of connective tissue, attached to two different bones, preventing unwanted movement between bones and is poorly vascularised and therefore slow to heal). This approach could enable students to build a structural framework for analysing information (e.g. details of names, locations, connections and relations of structures) and facilitate controlled introduction of information, thus promoting learning. 


\section{Suggestions for further research}

This thesis suggests the teaching of anatomical concepts as described above. Louw et al. (2009) have suggested something similar when they distinguish between the teaching of 'general' and 'specific' anatomy. General anatomy "should be the anatomy that all health science students receive as their initial learning experience" and is described as "the foundation for 'specific anatomy' in the clinical setting", and as "the glue that holds the components of specific anatomy together" [page 377] (Louw et al. 2009). Fortunately, Louw et al. (2009) have formulated a set of specific objectives that could be taught as 'general anatomy'. Whether the teaching of anatomical concepts or general anatomy will indeed results in "students [being] equipped with the necessary intellectual tools to then master subject matter at any time in their training and career" as suggested, is an interesting subject to study in future research.

\section{Implications for educational practice}

For the practical implications, the question of 'what anatomical knowledge should be taught' is extended by the phrase 'when teachers meet their students face-to-face'. In a more traditional curriculum, valuable contact hours are often spent by students listening to multiple lectures in which the lecturer summarises what (s)he believes to be the core course content (Fyrenius et al. 2005). As also shown in this thesis (Chapter 5), "students are thought to be able to read and learn information on their own, but need instructors as coaches to stimulate and challenge their thinking, guide them in solving problems and encourage their learning and application of the material" [page 236] (McLaughlin et al. 2014). In recent years, our digitally-oriented world has facilitated the possibility for a 'flipped classroom' (Prober and Khan 2013). In their selfstudy time, students may learn the required knowledge by viewing short web-based lectures, in preparation for face-to-face sessions. Next, they practice applying this knowledge in interactive sessions facilitated by expert teachers. This does not mean lectures will become obsolete, but basic science teachers are recommended to use lectures for different aims (Fyrenius et al. 2005; van Berkel and Schmidt 2005): 1) to introduce students to a new topic and organise their study effort, 2) to explain particularly difficult concepts or problems, or to address frequently occurring misconceptions and 3) to place the material in a context and the content into a broader perspective (i.e. its place in the curriculum and how it prepares the students for professional practice). 


\section{WHEN SHOULD ANATOMY EDUCATION BE INCLUDED IN THE MEDICAL CURRICULUM?}

The general consensus is that medical students definitely cannot do without anatomical knowledge, and it seems highly unlikely that students will ever not be taught anatomy in their first year of medical school. The question is when anatomy should be taught during and after its first introduction in the curriculum.

Modern curricula strive to teach the basic sciences simultaneously and in an interrelated manner, so-called horizontal integration, and integrated with the clinical sciences, so-called vertical integration (Dahle et al. 2002). However, this thesis has shown that the vertical integration is often perceived as unidirectional. While clinical topics are regularly integrated into the early years of medical curricula (traditionally the time slot for basic science teaching), this thesis reported that the students' anatomical knowledge might be negatively influenced by it being much less common for basic sciences to be taught in later years (traditionally clinical teaching time) (Chapter 3). Improving vertical integration, and thus the teaching of the basic sciences in the later years, will stimulate the development of a spiral curriculum. "A spiral curriculum is one in which there is an iterative revisiting of topics, subjects or themes throughout the course. A spiral curriculum is not simply the repetition of a topic taught. It requires also the deepening of it, with each successive encounter building on the previous one" [page 38] (Harden and Stamper 1999). Chapter 5 showed that students asked for such a curriculum when they suggested repeating initially learned anatomical knowledge with increased detail.

Implementing a spiral curriculum has two advantages. First, a spiral curriculum increases the possibility of repetition, or spaced education. Spaced education means that information is spaced out and repeated over time; compared to bolus education in which the information is taught all at once (massed distribution) (Kerfoot et al. 2007). A crucial finding reported in Chapter 5 of this thesis is that students regard repetition, and not stricter assessment, as essential for the retention of knowledge. Spaced education has shown to improve students' retention of clinical knowledge (Kerfoot et al. 2007). Furthermore, studies have confirmed that a spiral curriculum can be motivating because it activates and reinforces prior knowledge (Harden and Stamper 1999; Mattick and Knight 2007). Interestingly, research has shown that repeated retrieval, which involves the practice of retrieving information from memory, improves retention of knowledge better than repeated study (Larsen et al. 2009).

A second advantage is that a spiral curriculum stimulates a more advanced level of application and integration of knowledge and consequently increases expertise and feelings of competence (Harden and Stamper 1999; Mattick and Knight 2007). In other words: a spiral curriculum promotes (instructional) scaffolding. Scaffolding helps 
students acquire knowledge and skills by changing complex and difficult tasks in such a way that these tasks are accessible, manageable and within the students' current abilities (Hmelo-Silver 2007). In a spiral curriculum, knowledge is presented in a logical sequence from simple to complex. This thesis reports students suggesting that the major structures ('the basics') should be covered the first time an anatomical topics is presented, with more detail (the minor structures) being added with each repetition of the topic (Chapter 5). Being able to acquire knowledge one bit at a time increases students' feelings of competence, and acquiring knowledge through repetition increases expertise. Teachers play a significant role in scaffolding as they guide students in the learning process through e.g. coaching, task structuring, offering tools (Hmelo-Silver 2007). This spiral line can be continued in postgraduate education.

\section{Suggestions for further research}

It is important that further research focuses on the optimal planning for repetition. For example, the literature discriminates between active learning, which is more studentcentred and self-directed, and passive learning, which is more teacher centred. We know that when students are taught information for the very first time, active learning leads to better performance than passive learning (Minhas et al. 2012). However, it is unknown whether active learning also leads to better performance when it is used in the repetition of knowledge, or whether more passive learning methods might work equally well. Furthermore, it is unknown whether repeated retrieval is more of an advantage for the repetition of basic science knowledge than repeated study.

\section{Implications for educational practice}

This thesis aims to stimulate institutions to design a spiralling curriculum, with an equal vertical integration of basic and clinical sciences and application of the constructive learning principle. As a result, anatomy could be taught throughout the undergraduate medical curriculum. However, (anatomy) teachers are warned not to let curriculum integration lead to course disintegration (Bolender et al. 2013). Especially in multidisciplinary integration, when blocks or modules are arranged by theme or disease, the important process of scaffolding knowledge should not be overlooked.

\section{WHERE SHOULD ANATOMY EDUCATION TAKE PLACE?}

In the past, anatomy has always been taught in lecture halls and the dissection room. Exposure to cadavers and dissection by students themselves was generally seen as essential to anatomy learning. With the introduction of curricula that were not 
discipline based (such as problem-based or systems based), the use of prosected cadaveric specimens was introduced and some of the teaching of anatomy was moved to e.g. tutorial groups. A new medical school in Great Britain decided not to use cadaveric material at all (McLachlan et al. 2004), which revitalised the ongoing debate about cadaver dissection as an educational tool (Aziz et al. 2002; Older 2004; Raftery 2006). Despite studies showing that a dissection course is not a uniform learning experience (Winkelmann et al. 2007), that students do not always rate dissection as the most useful educational tool (Azer and Eizenberg 2007) and that they do not consider all aspects of anatomical education to be meaningful (Wilhelmsson et al. 2010), the debate has remained unresolved so far. Advocates of the use of dissection in medical education frequently mention its additional benefits for other learning objectives besides anatomical knowledge, such as professionalism, manual dexterity, teamwork, self- and peer-evaluation and ethics (Aziz et al. 2002; Rizzolo 2002; Gregory et al. 2009). However, exploring other options is not that farfetched when considering the space, time and money required to maintain a dissection room, and the problems many medical schools around the world encounter when trying to obtain enough cadavers.

Chapter 3 of this thesis reported studies that do not show any clear preferences for learning from either cadaveric dissection or prosected cadavers. Furthermore, when dissection is compared to other teaching methods, a combination of methods seems ideal for stimulating the transfer of knowledge. The study described in Chapter 7 of this thesis seems to indicate that anatomy education in the dissection room may be the most useful in the second of three steps of learning anatomy. Students could learn the vocabulary of anatomy (i.e. the names of the structures) through a (webbased) lecture or computer aided instruction. The dissection room might be the best opportunity to understand 3D relationships of structures (until 3D software and glasses become mainstream), which would be the second step. The third step, discussing how anatomical knowledge can be used to explain signs and symptoms, can probably be done in settings like tutorial groups.

\section{Suggestions for further research}

This thesis has shown that the dissection room is not always the best place to learn anatomical knowledge. Therefore, it is important to investigate what and how students learn from dissection and other teaching methods, in order to provide teachers with information on which they can base their choices. 


\section{Implications for educational practice}

There is much literature on how anatomy can be taught in a problem-based learning approach. In Chapter 5 this thesis reported that, for various reasons, it was common for groups to ignore the learning goals relating to anatomy. When an anatomical learning objective is discussed in a tutorial group, students often adopt a 'been there, done that' attitude. Everybody has attended the lectures and dissection room sessions, so they tend to move to the next learning objective if nobody has a specific question. If tutors let this happen, they severely limit the opportunities for students to practice the application of theoretical knowledge to clinical cases. Possible ways to discuss anatomical objectives are to have students draw on the whiteboard, interpret X-rays or MR scans, and bring skeletal material/plastinated specimens or low-tech models to tutorial groups. Last but not least, students can be asked what aspects of the patient problem can be explained with the knowledge they gained.

\section{WHO SHOULD BE RESPONSIBLE FOR ANATOMY EDUCATION?}

This thesis showed the existence of a substantial amount of literature that reports concerns about anatomy being taught by non-medically trained staff (Chapter 4). The conclusion was that it is probably best to have a 'competent non-specialist' teaching: a person who knows what is broadly important. The adjective competent seems to be the operative word here. Results show that students are not after a 'textbook-style' transfer of information when they ask for more guidance during dissection room sessions (Chapter 5). They seek coaching by an enthusiastic teacher with a good idea of their prior knowledge who asks questions and 'tells stories' showing how anatomy could be useful in understanding and memorising signs and symptoms. So based on the assumption that students' knowledge is strongly influenced by 'who teaches', qualifications may be relevant but not necessarily decisive for the quality of 'Individual teachers' enthusiasm for teaching and didactic abilities may carry much more weight than their professional medical background.

For some anatomy departments, teaching is their core business, their 'raison d'être'. Unfortunately, anecdotes have shown that it is not uncommon for anatomy teachers to be frowned upon when they express an interest in educational research. This is remarkable: it is self-evident that the regular duties of their counterparts in research and the clinic include reading the latest literature, being oriented toward the latest approaches, developments and theories, replacing existing habits with new ones when appropriate, and submitting their work to critical peer review (Van der Vleuten et al. 2000). Being a professional teacher requires more than being an expert in a 
content area; it also requires awareness, familiarity, use (and perhaps even production) of educational theory and empirical evidence. However, teaching is often dominated by intuition (personal experiences and beliefs) and traditional values (dogmas), which could be labelled as 'opinion-based teaching'. Empirical evidence has shown that opinion-based teaching has often misguided teachers (Harden et al. 1999; Harden et al. 2000; Van der Vleuten et al. 2000).

\section{Suggestions for further research}

This thesis has shown that the number of students per teacher has more than doubled in the past 30 years (Chapter 3), possibly negatively influencing students' anatomical knowledge. Students themselves recognise potential staffing problems, and suggest the use of student assistants (Chapter 5). Furthermore, the use of the collaborative learning promotes students' feeling that they are achieving better knowledge/understanding of the subject (Chapter 6). Therefore, teachers are advised to increase the use of peer-teaching in anatomy education. An interesting endeavour would be to see whether simultaneous initial learning for junior students and repetition sessions for senior students benefits both groups.

\section{Implications for educational practice}

Institutions are urged to define criteria for evaluating scholarship to ensure that the educational products delivered by their teachers have are based on the best evidence available and are valued by students, institutions and professional communities. The recent literature contains interesting publications on scholarship in education (e.g. Fincher et al. (2000), Simpson et al. (2007) and Turner et al (2012)) on which a special committee compiled by each institution could base their efforts when implementing scholarship in teaching. Recognising the complex skills necessary to succeed as a medical educator could lead to rewards for teaching accomplishments and academic advancement of teachers.

\section{HOW SHOULD ANATOMY BE TAUGHT?}

If there is a take home message from this thesis, it is that there is no single teaching method that can function as an answer for how anatomy should be taught. It does not matter whether you as a teacher use cadaveric dissection, prosected cadavers, videos, holograms, e-learning modules, models or textbooks; it is not about the method you are using, but about how you are using it. 
One of the most important findings of this thesis, described in Chapter 2 and confirmed by students in Chapter 5 , is that the application of educational principles in anatomy education is much more important than the educational approach underpinning a curriculum. Strategies such as increasing 'time on task', creating occasions for repetition and scaffolding (constructive learning), including opportunities for interaction between learners (collaborative learning) and placing learning in a context (contextual learning) are crucial when it comes to knowledge acquisition and retention. Fortunately, these learning principles can be applied independently from any teaching method. The findings confirm the view that the circumstances in which teaching methods are utilised is imperative.

How should the method of teaching and its employment be decided upon? In medicine, evidence-based practice is widely accepted and has been defined as "[...] the conscientious, explicit and judicious use of current best evidence in making decisions about the care of individual patients" (Sackett et al. 1996). In sharp contrast, Best Evidence Medical Education, defined as "the implementation, by teachers in their practice, of methods and approaches to education based on the best evidence available" (BEME-Group 2000), is very rarely implemented. The method of teaching anatomy should be based more on educational theory than on personal preferences or time-honoured methods. As stated in the paragraph above, but important to repeat here again, empirical evidence has shown that opinion-based teaching has often misguided teachers (Harden et al. 1999; Harden et al. 2000; Van der Vleuten et al. 2000).

An important finding reported in Chapter 3 of this thesis is that a combination of teaching tools appears to yield the best student performance. This relates to the notion of 'transfer': using knowledge acquired in one context to solve a problem in a different context (Norman 2009). Studies that are reported in this thesis have, for example, shown that anatomical knowledge learned with cadavers is not transferred when students are asked to identify the same structures on a CT, or that anatomical knowledge learned with an e-learning module is not transferred when students are asked to identify the same structures on a cadaver (Chapter 3). "Nevertheless, teachers can adopt a number of strategies to facilitate transfer. These include strategies to improve the understanding of the concept at time of initial presentation, use of multiple example problems to identify common deep structures, and use of mixed practice with multiple examples to focus on identifying when a concept applies" [page 810] (Norman 2009).

The effect of a teaching method is often connected to the guidance students receive during their learning. This thesis reports studies that sate that the self-directed learning principle underpinning certain educational approaches has a negative effect on anatomical knowledge of students (Chapter 4). It is said that it deprives students of 
contact with inspirational and knowledgeable teachers, and that requiring students to gain anatomical information through curiosity and experiment is a waste of valuable time and resources (Monkhouse and Farrell 1999). The results of this thesis also show that students do ask for guidance during their learning, as described in the previous paragraph, either from teachers or student-assistants (Chapter 5). Important clues about guidance can be extracted from the four-component instructional design (4C-ID) model (Van Merrienboer et al. 2003; Kirschner and Van Merrienboer 2008). Although designed for training complex skills, many aspects can be employed in teaching elaborate knowledge. The 4C-ID model describes a blueprint in which each major learning task starts with one or more smaller learning tasks with a high level of support and guidance. As students proceed to the next learning tasks, support and guidance gradually diminishes until they are no longer needed. Because insufficient or excessive support can hamper a learning process, it is critical to determine the right type and amount of support (teaching methods) and guidance (presence and input of a teacher) and to fade at the appropriate time and rate (Van Merrienboer et al. 2003; Kirschner and Van Merrienboer 2008).

Last but certainly not least, there is the issue of teaching in context. It is generally assumed that learning in context will increase performance in knowledge acquisition, recall and transfer (Norman 2007; Mann et al. 2011). However, Chapter 3 of this thesis showed that there are very few studies with a sound research design that determine the effect of teaching in context on performance. Students have also indicated that teaching in context may increase their awareness of the relevance of anatomy, and increase their motivation to study the subject. Perhaps an even more important finding in this thesis is that students who studied anatomical knowledge in a paperpatient context did not perform better, and in some cases performed even worse, than students who studied the same content without context (Chapter 7). Future evidence will hopefully tell us how to best employ teaching in context (and not that we were misguided), because intuitively teaching in context would be preferable above teaching without context. This intuitive feeling is evoked because of the why. Anatomy (and the other basic sciences) are taught because it is pertinent for students' future professional practice. Whether it is through the 'two worlds hypothesis', described by Patel et al. (1989), or the 'knowledge encapsulation theory', described by Boshuizen and Schmidt (1992), basic science knowledge has to transform into clinically applicable skills and practices. Awareness of this goal should continually be on the forefront of everybody's mind. 


\section{Suggestions for further research}

Further research should investigate how basic sciences can be taught for transfer. In his article, Norman (2009) describes some critical elements for each phase of (concept) learning, such as 'the use of analogy' for initial concept learning (phase 1), 'active contrast versus no contrast' for phase 2 in which examples of the concept are given, and 'blocked versus mixed practice' when problems are practised in phase 3 . At first glance, however, not all elements seem to be easily applicable to all basic sciences. Future studies could focus on if and how these critical elements can be shaped in anatomy education.

In addition, teaching in context is an important topic for further investigation. Questions have risen about the effect of context on learning of novices and more advanced students, and on learning different subjects (Chapter 7). Furthermore, one may wonder how much context is necessary to facilitate transfer. Last but not least, it is unknown what characteristics a given context should have to improve learning, and what effect context has on cognitive processes during assessment.

\section{Implications for educational practice}

Teachers are urged to critically review their education, ascertain the available evidence on teaching methods and become familiar with cognitive and sociocultural views on learning. Teachers need to seek opportunities for the implementation of the learning principles as described in this thesis. Furthermore, it is important that student guidance takes on the form of 'directed self-learning' with the introduction of each new subject (e.g. by having students follow a manual during laboratory sessions), and more 'self-directed learning' as student expertise in the subject increases.

\section{STRENGTHS AND LIMITATIONS}

The first strength is that this thesis consists of a wide variety of research methodologies, both in the quantitative and qualitative domain. Not only did this extensive range aid in reviewing and analysing the problem of optimising anatomy education from different angles, it also gave us a diverse experience that will serve as a strong base for future research endeavours. Furthermore, this thesis started out with a very broad approach to the question, first identifying all the factors that might influence the anatomical knowledge of students, and then gradually narrowing down to a certain focus. It assisted in finding novel empirical evidence to inform the optimisation of anatomy education. It furthermore ensured that the choice to 
manipulate teaching in context in the last study was thoroughly founded on results of the previous studies. An often heard complaint is that there is a gap between educational researchers and the users of educational research (teachers) (Harden et al. 1999; 2000). Being both an anatomy teacher and an educational researcher, my practical experience has informed research and research has informed practice throughout the composition of this thesis, and will continue to do so.

A possible limitation is the fact that most studies were conducted at one institute, Maastricht University, which has a specific educational setting. The results of the research should be tested in different settings to determine to what extent they can be generalised across different contexts. Furthermore, some results were derived from the participants' perceptions. Although they account for very rich data, they present a 'filtered' picture of reality as they are affected by the individuals' experiences and beliefs. Using different participants or research designs can further strengthen and triangulate these findings.

\section{PERSONAL AFTERTHOUGHT}

The title of this thesis is 'dissecting anatomy education in the medical curriculum'. At the end of this thesis, I feel I have only lifted the skin and can see the first hints of what lies beneath. I could have extended the sections about suggestions for further research and implications for practice with many more issues. As a sort of conclusion section, I would like to share the following.

It is incredibly important that educational principles are applied in teaching and learning, and I am convinced that any (group of) teacher(s) can do so, independent of teaching methods and the institutions educational approach. I thoroughly believe education should be informed by the best evidence available, and teachers should be rewarded when they practise accordingly. I would like to encourage the conduction of clarification studies (see Cook et al. (2008)) aimed at the prediction of which instructional methods will enhance educational efforts in what contexts. The introduction of this thesis started with a citation from the 'Flexner report', and I would like to end this discussion with one as well:

"undergraduate instruction will be throughout explicitly conscious of its professional end and aim. [...]. An active apperceptive relation must be established and maintained between laboratory and clinical experience. [...] There is no cement like interest, no stimulus like the hint of a coming practical application."

Abraham Flexner (1910) page 59 


\section{REFERENCES}

Azer S.A. \& Eizenberg N. (2007). Do we need dissection in an integrated problem-based learning medical course? Perceptions of first- and second-year students. Surg Radiol Anat, 29(2): 173-180.

Aziz M.A., McKenzie J.C., Wilson J.S., Cowie R.J., Ayeni S.A. \& Dunn B.K. (2002). The human cadaver in the age of biomedical informatics. Anat Rec, 269(1): 20-32.

BEME-Group (2000). Best Evidence Medical Education (BEME): Report of meeting 3-5 December 1999, London, UK Med Teach, 22(3): 242.

Bolender D.L., Ettarh R., Jerrett D.P. \& Laherty R.F. (2013). Curriculum integration = course disintegration: what does this mean for anatomy? Anat Sci Educ, 6(3): 205-208.

Boshuizen H. \& Schmidt H. (1992). On the role of biomedical knowledge in clinical reasoning by experts, intermediates and novices. Cogn. Sci., 16: 153-184.

Cook D.A., Bordage G. \& Schmidt H.G. (2008). Description, justification and clarification: a framework for classifying the purposes of research in medical education. Med Educ, 42(2): 128-133.

Dahle L.O., Brynhildsen J., Behrbohm Fallsberg M., Rundquist I. \& Hammar M. (2002). Pros and cons of vertical integration between clinical medicine and basic science within a problem-based undergraduate medical curriculum: examples and experiences from Linkoping, Sweden. Med Teach, 24(3): 280-285.

Drake R.L. (1998). Anatomy education in a changing medical curriculum. Anat Rec, 253(1): 28-31.

Fincher R.M., Simpson D.E., Mennin S.P., Rosenfeld G.C., Rothman A., McGrew M.C., Hansen P.A., Mazmanian P.E. \& Turnbull J.M. (2000). Scholarship in teaching: an imperative for the 21st century. Acad Med, 75(9): 887-894.

Flexner A. (1910). Medical Education in the United States and Canada: A Report to the Carnegie Foundation for the Advancement of Teaching. Bulletin No. 4. Retrieved from http://www.carnegiefoundation.org/elibrary November 2013

Fraser R.C. (1991). Undergraduate medical education: present state and future needs. British Medical Journal, 303(6793): 41-43.

Fyrenius A., Bergdahl B. \& Silen C. (2005). Lectures in problem-based learning--why, when and how? An example of interactive lecturing that stimulates meaningful learning. Med Teach, 27(1): 61-65.

Gregory J.K., Lachman N., Camp C.L., Chen L.P. \& Pawlina W. (2009). Restructuring a basic science course for core competencies: an example from anatomy teaching. Med Teach, 31(9): 855-861.

Harden R., Grant J., Buckley G. \& Hart I. (1999). BEME guide no. 1: Best Evidence Medical Education. Med Teach, 21(6): 553-562.

Harden R., Group B., Buckley G. \& Hart I. (2000). Best Evidence Medical Education. Adv Health Sci Educ 5: 7190.

Harden R.M. \& Stamper N. (1999). What is a spiral curriculum? Med Teach, 21(2): 141-143.

Hmelo-Silver C.D., RE; Chinn, CA (2007). Scaffolding and Achievement in Problem-Based and Inquiry Learning: A Response to Kirschner, Sweller, and Clark (2006). Educational Psychologist, 42(2): 99-107.

Kerfoot B.P., DeWolf W.C., Masser B.A., Church P.A. \& Federman D.D. (2007). Spaced education improves the retention of clinical knowledge by medical students: a randomised controlled trial. Med Educ, 41(1): 23-31.

Kirschner P.A. \& Van Merrienboer J.J.G. (2008). Ten steps to complex learning: A new approach to instruction and instructional design. In Good T.L. (Ed.), 21st century education. A reference handbook (pp. 244-253). Thousand Oaks, CA: Sage Publications.

Larsen D.P., Butler A.C. \& Roediger H.L., 3rd (2008). Test-enhanced learning in medical education. Med Educ, 42(10): 959-966.

Larsen D.P., Butler A.C. \& Roediger H.L., 3rd (2009). Repeated testing improves long-term retention relative to repeated study: a randomised controlled trial. Med Educ, 43(12): 1174-1181. 
Lempp H. \& Seale C. (2004). The hidden curriculum in undergraduate medical education: qualitative study of medical students' perceptions of teaching. BMJ, 329(7469): 770-773.

Louw G., Eizenberg N. \& Carmichael S.W. (2009). The place of anatomy in medical education: AMEE Guide no 41. Med Teach, 31(5): 373-386.

Mann K., Dornan T. \& Teunissen P.W. (2011). Perspectives on learning. In Dornan T., Mann K., Scherpbier A. \& Spencer J. (Eds.), Medical Education: Theory and Practice (pp. 17-38). London: Elsevier Ltd. .

Mattick K. \& Knight L. (2007). High-quality learning: harder to achieve than we think? Med Educ, 41(7): 638644.

McLachlan J.C., Bligh J., Bradley P. \& Searle J. (2004). Teaching anatomy without cadavers. Med Educ, 38(4): 418-424.

McLaughlin J.E., Roth M.T., Glatt D.M., Gharkholonarehe N., Davidson C.A., Griffin L.M., Esserman D.A. \& Mumper R.J. (2014). The flipped classroom: a course redesign to foster learning and engagement in a health professions school. Acad Med, 89(2): 236-243.

Minhas P.S., Ghosh A. \& Swanzy L. (2012). The effects of passive and active learning on student preference and performance in an undergraduate basic science course. Anat Sci Educ, 5(4): 200-207.

Monkhouse W.S. \& Farrell T.B. (1999). Tomorrow's doctors: today's mistakes? Clin Anat, 12(2): 131-134.

Norman G. (2007). How basic is basic science? Adv Health Sci Educ Theory Pract, 12(4): 401-403.

Norman G. (2009). Teaching basic science to optimize transfer. Med Teach, 31(9): 807-811.

Norman G. (2010). Anatomical mysteries. Adv Health Sci Educ Theory Pract, 15(2): 149-151.

Older J. (2004). Anatomy: a must for teaching the next generation. Surgeon, 2(2): 79-90.

Patel V.L.E., D.A.; Groen, G.J. (1989). Reconciling Basic Science and Clinical Reasoning. Teaching and Learning in Medicine, 1(3): 116-121.

Prober C.G. \& Khan S. (2013). Medical education reimagined: a call to action. Acad Med, 88(10): 1407-1410.

Raftery A. (2006). Anatomy teaching in the UK. Surgery, 25(1): 1-2.

Rizzolo L.J. (2002). Human dissection: an approach to interweaving the traditional and humanistic goals of medical education. Anat Rec, 269(6): 242-248.

Sackett D.L., Rosenberg W.M., Gray J.A., Haynes R.B. \& Richardson W.S. (1996). Evidence based medicine: what it is and what it isn't. BMJ, 312(7023): 71-72.

Schauber S.K., Hecht M., Nouns Z.M. \& Dettmer S. (2013). On the role of biomedical knowledge in the acquisition of clinical knowledge. Med Educ, 47(12): 1223-1235.

Schuwirth L.W. \& Van der Vleuten C.P. (2011). Programmatic assessment: From assessment of learning to assessment for learning. Med Teach, 33(6): 478-485.

Simpson D., Fincher R.M., Hafler J.P., Irby D.M., Richards B.F., Rosenfeld G.C. \& Viggiano T.R. (2007). Advancing educators and education by defining the components and evidence associated with educational scholarship. [Research Support, Non-U.S. Gov't]. Med Educ, 41(10): 1002-1009.

Swanson D.B. \& Case S.M. (1997). Assessment in Basic Science Instruction: Directions for Practice and Research. Advances in Health Sciences Education, 2: 71-84.

Turner T., Palazzi D., Ward M. \& Lorin M. (2012). Transforming teaching into scholarship. [Research Support, Non-U.S. Gov't]. Clin Teach, 9(6): 363-367.

van Berkel H. \& Schmidt H. (2005). On the additional value of lectures in a problem-based curriculum. Educ Health (Abingdon), 18(1): 45-61.

Van der Vleuten C.P.M., Dolmans D.H.J.M. \& Scherpbier A.J.J.A. (2000). The need for evidence in education. Med Teach, 22(3): 246-250.

Van Merrienboer J.J.G., Kirschner P.A. \& Kester L. (2003). Taking the load off a learner's mind: instructional design for complex learning. Educational Psychologist, 38(1): 5-13.

Vorstenbosch M., Kooloos J., Bolhuis S. \& Laan R. (2014). An investigation of anatomical competence in junior doctors. In Vorstenbosch M. (Ed.), The nature of anatomical competence in medicine and medical education (Thesis) (pp. 101-116). Nijmegen. 


\section{Chapter 8 - General discussion}

Whitcomb M.E. (2006). The teaching of basic sciences in medical schools. Academic Medicine, 81(5): 413414.

Wilhelmsson N., Dahlgren L.O., Hult H., Scheja M., Lonka K. \& Josephson A. (2010). The anatomy of learning anatomy. Adv Health Sci Educ Theory Pract, 15(2): 153-165.

Winkelmann A., Hendrix S. \& Kiessling C. (2007). What do students actually do during a dissection course? First steps towards understanding a complex learning experience. Acad Med, 82(10): 989-995.

Woods N.N., Brooks L.R. \& Norman G.R. (2005). The value of basic science in clinical diagnosis: creating coherence among signs and symptoms. Med Educ, 39(1): 107-112.

Woods N.N., Brooks L.R. \& Norman G.R. (2007a). It all make sense: biomedical knowledge, causal connections and memory in the novice diagnostician. Adv Health Sci Educ Theory Pract, 12(4): 405415.

Woods N.N., Brooks L.R. \& Norman G.R. (2007b). The role of biomedical knowledge in diagnosis of difficult clinical cases. Adv Health Sci Educ Theory Pract, 12(4): 417-426.

Woods N.N., Howey E.H., Brooks L.R. \& Norman G.R. (2006). Speed kills? Speed, accuracy, encapsulations and causal understanding. Med Educ, 40(10): 973-979. 
Summary 
Summary 
This thesis is focused on anatomy education within the undergraduate medical curriculum. Specifically a medical curriculum with the duration of 6 years, upon which students enter after the completion of high school around the age of 18.

Chapter 1 provides the background of this thesis. Anatomical knowledge is thought, together with knowledge of the other basic sciences, to be essential for good clinical practice. However, changes in medical education such as the integration of additional knowledge and skills in the curriculum, shortening of the curriculum, educational approaches and teaching methods have given rise to concern about the level of basic science knowledge attained by graduating medical students; particularly in anatomy. Whether or not there is a decline in knowledge is left undisputed in this thesis. Although extensive anatomy education is not self-evident anymore, the general consensus is that medical students definitely cannot do without basic science knowledge, and thus time granted in the medical curriculum needs to be used as effectively as possible. The main research question is how can anatomy education be optimised?

In order to identify the factors that influence anatomical knowledge, a broad research strategy was taken for studies 2 to 5 by exploring the opinions of clinicians and anatomists in the literature and students in group discussion.

The first study, described in chapter 2, reviewed several studies investigating the knowledge of anatomy of students in eight Dutch medical schools. Results showed that students uniformly perceive deficiencies in their anatomical knowledge at the start of their clinical training, and that their actual knowledge of anatomy is not related to the school's didactic approach. Test failure rates based on absolute standards set by different groups of experts were indicative of unsatisfactory levels of anatomical knowledge, although standards differed markedly between the groups of experts. We found potential clues that other factors are affecting students' anatomical knowledge, such as time on task, repetition and teaching in context.

The abovementioned clues made us want to identify possible other factors that are persistently blamed for negatively influencing anatomical knowledge of students as mentioned in existing literature. Eight factors were extracted from 32 articles published after 1990. The articles were published in educational, anatomical, surgical or radiological journals, but also in general medical journals such as the British Medical Journal and The Lancet. Most articles were retrieved by a search for keywords in the title, others by scrutinizing references of relevant articles; they were mostly published as an editorial, letter/correspondence, commentary, essay or matter for debate. The factors are: 1 ) teaching of anatomy by non-medically qualified teachers, 2 ) the absence 
of a core anatomy curriculum, 3) decreased use of dissection as a teaching tool, 4) lack of teaching anatomy in context, 5) integrated curricula, 6) inadequate assessment of anatomical knowledge, 7) decreased anatomy teaching time and 8) neglect of vertical integration of anatomy teaching.

A literature study, described in chapter 3, was performed to find empirical evidence for the influence of these factors. The results showed a lack of sufficient quantity and quality of information to support any of the claims convincingly. There does seem to be a trend throughout the world for anatomy to be increasingly taught by non-medically qualified teaching staff. Unfortunately, none of the studies reviewed examined the possible connection between the qualifications of teaching staff and students' knowledge of anatomy. There is little agreement on the content of lists of anatomical structures written in the past and the depth of the required knowledge is not specified. Additionally, none of the articles reviewed reported a study investigating (the absence of) a core curriculum and its effect on anatomical knowledge. Results seem to be slightly in favor of dissection, but are not conclusive. However, a combination of teaching tools appeared to yield the best performances. In many studies, students reported more positive attitudes/perceptions in relation to a course teaching anatomy in context than to traditional course formats. However, no study compared the effects on anatomical knowledge of teaching anatomy in and out of context. Studies that specifically address the influence of problem-based learning and system-based curricula on anatomical knowledge are few. The available evidence, or lack of it, shows that there are no clear benefits or drawbacks of integrated curricula for anatomical knowledge. Results indicated that the sole use of multiple choice questions and/or the lack of a minimal requirement for each tested discipline indeed have a negative effect on students' behavior and retention of knowledge. Designated teaching time for anatomy has, in fact, decreased during recent decades. However, no study has investigated the effect of the decreased teaching time on the knowledge attained. Only one study on vertical integration of anatomy teaching is available, but the study methods used preclude conclusions regarding the attribution of the reported improvement in knowledge to vertical integration.

Obviously, the eight factors did not emerge out of the blue. Several authors have cited them as influential and have described their origins. So behind each factor there is a story. The aim for the review in chapter $\mathbf{4}$ was to explore the stories fully and share them with the readers, as we felt this would lead to important novel recommendations for further research and improvement of anatomy education. There was a lesson in what those authors are telling us; even their stories cannot be underpinned with empirical data (yet)! Results led to additional recommendations for improving anatomy education by promoting recognition for teaching in institutions, enhancing 
the professional recognition of anatomists and encouraging anatomists to participate in educational research.

Studies discussed in chapter 2 have shown that students are probably even more severe in the judgment of their anatomical knowledge than anatomists and clinicians, and may therefore have strong opinions concerning factors influencing that knowledge. In the subsequent study described in chapter $\mathbf{5}$, medical students were invited to give their perceptions on anatomy education and anatomical knowledge. A purposive sample of 78 medical students from the $2 \mathrm{nd}, 3 \mathrm{rd}$, 4th and 6 th year of a PBL curriculum participated in 4 focus groups. Each group came together twice, and all meetings were recorded and transcribed verbatim. Data were analyzed with template analysis using a phenomenographical approach, which is aimed at describing, analyzing and understanding: 1) experiences or perceptions of a phenomenon (anatomy) and 2) the different ways in which a phenomenon is perceived and understood. Results indicate that a problem-based learning approach in itself was not enough to ensure adequate learning of anatomy, and support the hypothesis that educational principles have a stronger impact on students' knowledge than the educational approach underpinning a curriculum. Students state for example that repetitive studying of the subject increases retention of knowledge to a greater extent than stricter assessment, and teaching in context enhances motivation and transfer. Further research to improve anatomy education is suggested to focus on introducing a spiral curriculum, teaching in context, teaching for transfer and assessment for learning.

With the information gathered in the studies mentioned above, the research strategy narrowed down as we had a clearer idea on ways to improve anatomy education. In chapters 6 and 7 of this thesis, the manipulation of one or more factors in an experimental design in order to investigate their influence on the perceived and actual anatomical knowledge of students is discussed.

Precursory studies of this thesis had revealed that the application of learning principles could positively influence the perceived anatomical knowledge of students. In basic science education, a great deal of information is provided to students during laboratory sessions. In line with Best Evidence Medical Education (BEME), the aim for the study described in chapter 6 was twofold: to briefly inform teachers about the constructivist learning theory and elaborate on the principles of constructive, collaborative, contextual and self-directed learning; and to provide teachers with an example of how to implement these learning principles in surface anatomy education. The design of the new more student-centered teaching format is described, with much attention to the creation of a so called 'student manual'. To evaluate the manual and to contrast the new to the conventional, more teacher centered format, a 
questionnaire with both Likert scale items and open-ended questions was administered to third year medical students able to compare the conventional and the new format. Results show that the application of the learning principles leads to higher student satisfaction. Students stated that they thought they were achieving more and better understanding of anatomical knowledge with this new format. Even more improvement could be reached by making even more use of the contextual and selfdirected learning principle. Future research on surface anatomy should focus on increasing the students' ability to apply anatomical knowledge and defining the setting in which certain teaching methods and approaches have a positive effect.

One factor was consistently mentioned as influential on anatomical knowledge, and kept appearing as a possible focus for further research in the prior studies: teaching in context. The impact of context is of particular interest since students generally learn basic science knowledge in the medical school and apply it in the clinic. The last study of this thesis described in chapter $\mathbf{7}$ therefore investigated the impact of a paper-patient case as a context to learn anatomical knowledge. Giving paper patientcases as a context to learn basic science knowledge is thought to facilitate transfer: using knowledge acquired in one context to solve a new problem in another context. It further appeals to the mechanisms through which the cognitive dimension of context should improve learning and retrieval: activation of prior knowledge, elaboration and storage of retrieval cues. Information is thought to be stored in one's memory by the creation of knowledge structures called semantic networks. In this study, familiarity of the context, i.e. the extent to which the students are familiar with the disease of the paper-patient, was thought to influence the activation of a semantic network containing prior knowledge. Relevance of the context, i.e. the extent to which the disease of the paper-patient is associated with content to be learned, was thought to influence the amount of retrieval cues and/or retrieval pathways created in a semantic network. A total of 145 medical students completed a pretest of 40 questions, of which half were with a patient vignette. One week later, they studied musculoskeletal anatomy in the dissection room without a paper-patient context (control group) or with (ir)relevant-(un)familiar context (experimental groups), and afterwards completed a cognitive load scale. Following a short delay, the students completed a posttest. Surprisingly, results showed that students who studied the anatomical content with context did not perform better than students who studied the content without context, and that having a relevant-familiar context only reduced the possible negative impact of being provided with a context. This finding may be explained by an interaction of the expertise level of the participants, the nature of anatomical knowledge and (deep or surface) approaches to learning by students. Furthermore, the results make it tentative to state that context aids retrieval of (anatomical) knowledge for (first year medical) students, but not the acquisition of knowledge as much as 
expected. However, the study design did not allow any conclusions to be drawn in these directions.

Chapter 8 states that the main research question, how can anatomy education be optimised, does not have one clear answer, yet depends on one's responses to the why, what, when, where, who and how of anatomy education. Therefore, this thesis' answers to those questions are given in this last chapter, by relating the main findings and conclusions of chapters 2 to 7 to, and combining them with, other literature.

Why are we teaching anatomy? Although opinions may differ as to its scope, anatomy is taught because it is pertinent for the students' future professional practice. An essential finding reported in this thesis is that even though students acknowledge the relevance of anatomical knowledge, this does not automatically mean it is perceived as an important subject in terms of study effort. Students may be learning for future practice in theory, what and how they learn in practice is driven by the 'hidden curriculum' such as what assessments require of them to pass.

What anatomical knowledge should be taught? As a teacher we should be aware that the purpose of undergraduate medical education is to create a student trained to become a physician. Students need to be provided with a strong knowledge base upon which they can build during their livelong learning. Instead of developing long lists of structures, this thesis suggests the initial teaching of anatomical concepts.

When should anatomy education be included in the medical curriculum? This thesis suggests that anatomy should be taught through a spiraling curriculum, starting at the early years of medical school and extending all the way into specialist training. A spiral curriculum increases the possibility of repetition of previously learned knowledge, which is reported in this thesis as a key feature for retention of knowledge. With each loop a more advanced level of application and integration of knowledge can be attained, giving ample opportunity to employ scaffolding and thus increase expertise and feelings of competence.

Where should anatomy education take place? Whether the best place to teach anatomy is the dissection room depends on what is taught to whom. Whereas the dissection room might be best for studying 3D relationships of structures, learning the anatomical vocabulary or how to use anatomical knowledge during clinical reasoning can probably be done in other settings.

Who should be responsible for anatomy education? Qualifications may be relevant but not necessarily decisive for the quality of teaching. This thesis suggests the teacher to be a competent professional not only in the content but also in relationship to educational theory and empirical evidence.

How should anatomy be taught? The take home message of this thesis is that it is not about the method you are using, but about how you are using it. Teaching should 
be based more on educational theory than on personal preferences or time-honored methods. This thesis shows that a combination of teaching methods seems best to promote transfer. It is further important to administer an appropriate amount of guidance for students during their learning. Last but not least, we should never lose sight of the reason why anatomy is taught... 
Samenvatting

(Summary in Dutch) 
Samenvatting 
Dit proefschrift gaat over het anatomieonderwijs* binnen de basisopleiding geneeskunde $^{1}$. Deze opleiding bestaat uit een 6 jarig curriculum* waar studenten na voltooiing van de middelbare school, als ze ongeveer 18 jaar oud zijn, aan kunnen beginnen.

Hoofdstuk 1 is de algemene introductie en bevat de achtergrond die aanleiding gaf tot het uitvoeren van het onderzoek beschreven in dit proefschrift. Van anatomische kennis wordt gedacht dat het, samen met kennis van de andere basisvakken*, essentieel is voor een goede uitvoering van de werkzaamheden als arts. In de afgelopen decennia hebben er diverse veranderingen in de basisopleiding geneeskunde plaatsgevonden, zoals het uitbreiden van het curriculum met nieuwe kennis en extra vaardigheden, het verkorten van andere delen van het curriculum en het veranderen van de didactische benadering* en lesmethoden. Deze veranderingen hebben aanleiding gegeven tot bezorgdheid over het niveau van kennis van afstuderende geneeskundestudenten, in het bijzonder de kennis van de anatomie. Er worden in dit proefschrift echter geen uitlatingen gedaan of er inderdaad sprake is van een daling van de kennis van studenten. Hoewel uitgebreid anatomieonderwijs tegenwoordig niet meer vanzelfsprekend is, is de algemene consensus dat de geneeskundestudenten zeker niet zonder deze kennis kunnen. De beschikbare tijd binnen het geneeskundecurriculum moet dus zo efficiënt mogelijk gebruikt worden. De centrale onderzoeksvraag is daarom: hoe kan het anatomieonderwijs geoptimaliseerd worden?

Om de factoren die de anatomische kennis van studenten kunnen beïnvloeden te bepalen, werd voor studies 2 tot en met 5 een brede onderzoeksstrategie gehanteerd. Er werd in de bestaande literatuur naar de overtuigingen van artsen en anatomen* gezocht en er zijn groepsdiscussies met geneeskundestudenten gehouden.

De eerste studie van dit proefschrift, beschreven in hoofdstuk $\mathbf{2}$, is een review* van verschillende studies waarin de anatomische kennis van studenten in de acht Nederlandse geneeskundefaculteiten onderzocht werd. Resultaten toonden aan dat alle studenten vinden dat hun anatomische kennis te kort schiet op het moment dat zij aan hun coschappen* beginnen en dat de daadwerkelijke kennis* van studenten niet gerelateerd is aan de didactische benadering van de universiteit. De zak-slaag grenzen die werden gesteld door verschillende artsen, anatomen en de studenten zelf duiden op een onbevredigend niveau van anatomische kennis van studenten, maar de gehanteerde grenzen verschilden aanzienlijk. Er werden aanwijzingen gevonden dat factoren als de hoeveelheid tijd die er aan een taak besteed wordt, het al of niet

\footnotetext{
${ }^{1}$ Termen gevolgd door een * worden toegelicht in de verklarende woordenlijst achter deze samenvatting
} 
herhalen van reeds aangeleerde kennis en het geven van onderwijs in context* van invloed zijn op de anatomische kennis van studenten.

De bovengenoemde aanwijzingen zorgden ervoor dat we alle factoren waar in de literatuur van gezegd wordt dat ze de anatomische kennis van studenten negatief beïnvloeden wilden bepalen. Er werden in totaal acht factoren geïdentificeerd uit 32 artikelen. Deze artikelen werden gepubliceerd na 1990 in onderwijskundige, anatomische, chirurgische of radiologische tijdschriften, maar ook in meer algemene medische tijdschriften zoals The British Medical Journal en The Lancet. De meeste artikelen werden gevonden door te zoeken naar trefwoorden in de titel. Anderen vonden we door het nazoeken van de referenties* van relevante artikelen. Ze werden meestal gepubliceerd als een redactioneel artikel, brief, commentaar, essay of discussiepunt. De acht geïdentificeerde factoren die de anatomische kennis van studenten negatief zouden beïnvloeden zijn: 1) het geven van anatomieonderwijs door niet-medisch gekwalificeerde docenten, 2) het ontbreken van een standaard anatomiecurriculum, 3) dalen van het gebruik van dissectie* als onderwijsmethode, 4) gebrek aan het geven van anatomieonderwijs in context, 5) de implementatie van geïntegreerde curricula*, 6) een slechte manier van toetsen van anatomische kennis, 7) de verminderde tijd voor anatomieonderwijs en 8) de verwaarlozing van verticale integratie* van het anatomieonderwijs.

Om empirisch bewijs* voor de invloed van deze factoren te vinden, werd er een literatuurstudie* uitgevoerd. Deze wordt beschreven in hoofdstuk 3. De resultaten tonen te weinig kwantiteit en kwaliteit van beschikbare studies om zelfs maar één van de beweringen te ondersteunen. Over de hele wereld is een trend waarneembaar dat anatomie steeds vaker onderwezen wordt door niet-medisch gekwalificeerd docenten, maar er is geen enkele studie die de invloed hiervan op de anatomische kennis van studenten onderzoekt. $\mathrm{Er}$ is weinig overeenstemming tussen diverse partijen die getracht hebben om lijsten van anatomische structuren* op te stellen die als standaard anatomiecurriculum kunnen dienen. Verder geeft geen van deze lijsten aan wat de diepgang* van de benodigde kennis moet zijn. Ook hierover zijn geen studies te vinden die het effect van de aan- of afwezigheid van een vastgesteld curriculum op de anatomische kennis van studenten beoordelen. De resultaten van de studies die er zijn lijken enigszins in het voordeel van dissectie uit te vallen, al zijn ze niet overtuigend. Een combinatie van leermiddelen bleek de beste leerprestaties in studenten te leveren. In veel studies rapporteren studenten een positievere houding als anatomie in context wordt onderwezen in vergelijking met meer traditioneel onderwijs*. Echter, geen enkele studie heeft het effect van onderwijs in context en zonder context op de anatomische kennis van studenten vergeleken. Er zijn slechts weinig studies die specifiek ingaan op de invloed van geïntegreerde curricula, zoals probleem-gestuurd onderwijs* of curricula gebaseerd op de systemen van het menselijk lichaam*. Het 
beschikbare bewijs, of het gebrek daaraan, laat zien dat er geen duidelijke voor- of nadelen van geïntegreerde curricula zijn voor anatomische kennis. De resultaten laten wel zien dat het exclusieve gebruik van meerkeuze vragen* en/of het ontbreken van een minimale vereiste* voor elke geteste discipline binnen een samengestelde toets* inderdaad een negatief effect hebben op het leergedrag en het behoud van kennis van de studenten. In de literatuur is inderdaad bewijs te vinden dat de onderwijstijd voor anatomie de afgelopen decennia gedaald is. $\mathrm{Er}$ is echter geen enkel onderzoek dat het effect van de verminderde onderwijstijd op de kennis van studenten bestudeerde. Er was slechts één studie over de verticale integratie van anatomieonderwijs beschikbaar, maar deze studie gebruikte een inadequate onderzoeksmethode waardoor het niet zeker is dat de gerapporteerde verbetering van kennis van studenten daadwerkelijk komt door de verticale integratie.

Uiteraard komen deze acht factoren niet uit de lucht vallen. Verschillende auteurs hebben ze benoemd als invloedrijk en hun oorsprong beschreven. Achter elke factor zit dus een verhaal. Het doel van de review in hoofdstuk 4 was om deze verhalen volledig te verkennen en te delen met de lezers, omdat we vonden dat dit zou leiden tot belangrijke nieuwe aanbevelingen voor verder onderzoek en verbetering van het anatomieonderwijs. Er zit een les in wat deze auteurs ons vertellen, zelfs als hun verhalen (nog) niet ondersteund kunnen worden met empirisch bewijs! De resultaten van de review hebben geleid tot aanvullende aanbevelingen voor het verbeteren van het anatomieonderwijs door erkenning van onderwijsprestatie door universiteiten, door het verbeteren van de professionele erkenning van anatomen, en door anatomen aan te moedigen om deel te nemen aan onderwijskundig onderzoek.

Uit de studies die besproken zijn in hoofdstuk 2 is gebleken dat studenten nog strenger zijn over hun eigen anatomische kennis dan anatomen en artsen en ze hebben waarschijnlijk ook zeer sterke opvattingen over de factoren die van invloed zijn op die kennis. In de studie beschreven in hoofdstuk 5, werden geneeskundestudenten uitgenodigd om hun percepties* over anatomieonderwijs en anatomische kennis met ons te delen. Een steekproef van 78 geneeskundestudenten uit het $2^{\mathrm{e}}, 3^{\mathrm{e}}, 4^{\mathrm{e}}$ en $6^{\mathrm{e}}$ studiejaar van een probleem-gestuurd curriculum hebben deelgenomen aan 4 focusgroepen*. Elke groep kwam twee keer bij elkaar; alle discussies werden opgenomen en letterlijk uitgetypt. Deze teksten werden vervolgens geanalyseerd met behulp van een template analyse* via een fenomenografische benadering*. Deze benadering is gericht op het beschrijven, analyseren en begrijpen van 1) ervaringen met of ideeën over een fenomeen (anatomie) en 2) de verschillende manieren waarop dit fenomeen wordt waargenomen en begrepen. De resultaten laten zien dat het baseren van een curriculum op probleem-gestuurd leren niet genoeg is om het goed leren van anatomische kennis voldoende te waarborgen. Verder ondersteunen de resultaten de hypothese dat leerprincipes* een sterkere invloed hebben op de kennis 
van studenten dan de didactische benadering van een curriculum. Studenten geven bijvoorbeeld aan dat het leerprincipe van herhaald bestuderen van een onderwerp volgens hen leidt tot een langer behoud van reeds geleerde kennis dan strenger toetsen. Verder zeggen de studenten dat het geven van het anatomieonderwijs in context de motivatie voor leren en de transfer* van hun kennis vergroot. Uit deze studie blijkt dat verder onderzoek naar het verbeteren van anatomieonderwijs zich zou kunnen concentreren op de invoering van een spiraliserend curriculum*, het geven van onderwijs in context, het geven van dusdanig onderwijs dat transfer van kennis wordt bevorderd en het afnemen van toetsen die het leren van studenten op een andere manier stuurt (bijvoorbeeld door vragen te stellen die studenten alleen kunnen beantwoorden als ze diepgaand leren* toepassen).

Met de informatie uit de bovengenoemde studies is een duidelijk beeld ontstaan van manieren waarop het anatomieonderwijs verbeterd kan worden, en kon de onderzoeksstrategie voor de rest van het proefschrift worden versmald. De hoofdstukken 6 en 7 van dit proefschrift beschrijven studies waarin één of meer factoren in een experiment* gemanipuleerd werden om hun invloed op de gepercipieerde* en daadwerkelijke* anatomische kennis van studenten te onderzoeken.

In de voorgaande studies van dit proefschrift is gebleken dat de toepassing van leerprincipes een positieve invloed kan hebben op de gepercipieerde anatomische kennis van studenten. Tijdens het onderwijs in de basisvakken wordt een groot deel van de informatie tijdens practica aan de studenten verstrekt. In overeenstemming met het principe van Best Evidence Medical Education (BEME)*, is het doel van de studie beschreven in hoofdstuk 6 tweeledig: ten eerste om docenten te informeren over de constructivistische leertheorie* en de principes van constructief*, samenwerkend*, contextueel* en zelfgestuurd* leren en ten tweede om docenten een voorbeeld te geven hoe deze principes toegepast kunnen worden in het onderwijzen van anatomie in vivo*. Het ontwerp van de nieuwe, meer student-gerichte, onderwijsvorm wordt beschreven, waarbij veel aandacht wordt besteed aan de samenstelling van een handleiding voor de studenten. De nieuwe onderwijsvorm werd vergeleken met een meer traditionele, docent-gecentreerde, onderwijsvorm. Om deze vergelijking mogelijk te maken vulden derdejaars geneeskundestudenten een vragenlijst in met betrekking tot zowel de oude als de nieuwe onderwijsvorm. Deze vragenlijst bestond uit zowel Likertschaal* als open vragen*. De resultaten tonen aan dat de toepassing van de vier leerprincipes leidt tot een hogere tevredenheid van studenten. Studenten verklaarden dat zij dachten met de nieuwe onderwijsvorm een beter begrip van de anatomische kennis te bereiken. Nog meer verbetering kan bereikt worden door nog beter gebruik te maken van het contextuele en zelfgestuurde leerprincipe. Toekomstig 
onderzoek naar onderwijs van anatomie in vivo zou zich kunnen richten op het vergroten van het vermogen van studenten om hun kennis toe te kunnen passen in de praktijk, en het definiëren van de omstandigheden waarin bepaalde lesmethodes en didactische benaderingen een positief effect hebben.

Eén factor werd constant genoemd als invloedrijk op anatomische kennis, en bleef verschijnen als mogelijke focus voor verder onderzoek in eerdere studies: het geven van onderwijs in context. De impact van de context is van bijzonder belang in de geneeskundeopleiding omdat studenten over het algemeen de kennis van de basisvakken leren op de universiteit en moeten toepassen in de kliniek. De laatste studie van dit proefschrift, beschreven in hoofdstuk 7, onderzocht daarom het effect van het gebruik van een patiëntencasus* als context op het leren van anatomische kennis. Men denkt dat het aanbieden van een patiëntencasus als een context om de basisvakken te leren de transfer van deze kennis vergemakkelijkt. Verder doet het een beroep op de mechanismen waarop de cognitieve dimensie van context* het aanleren en ophalen van kennis moet verbeteren: het activeren van voorkennis en het opslaan van retrieval cues*. Er wordt gedacht dat informatie in het geheugen wordt opgeslagen door het creëren van kennisstructuren, zogenaamde semantische netwerken*. Bekendheid met de context* zou de activatie van semantische netwerken met voorkennis kunnen beïnvloeden. Relevantie van de context* zou de hoeveelheid retrieval cues in een semantisch netwerk kunnen beïnvloeden. In totaal 145 geneeskundestudenten voltooiden een pretest* van 40 vragen, waarvan de helft een patiëntenvignet* bevatte. Een week later bestudeerden deze studenten op de snijzaal* de anatomie van het bewegingsapparaat* zonder een patiëntencasus als context (controlegroep*), met relevante of irrelevante context en met bekende of onbekende context (experimentele groepen*). Hierna vulden zij een vragenlijst in om hun cognitieve belasting* tijdens het leren te meten. Na een korte pauze voltooiden alle studenten een posttest*. Tot onze grote verrassing bleken studenten die de inhoudelijke anatomische kennis met de patiëntencasus als context hadden bestudeerd het niet beter te doen dan studenten die de inhoud zonder context hadden bestudeerd. Alleen een context die zowel relevante als bekend is verminderde de mogelijke negatieve gevolgen van het leren in context. Deze resultaten zouden verklaard kunnen worden door een interactie tussen het deskundigheidsniveau van de studenten, de aard* van de anatomische kennis en de diepgaande* of oppervlakkige* benadering van het leren door studenten. De resultaten maken het verder verleidelijk om te beweren dat context (eerstejaar geneeskunde)studenten dus niet zoveel helpt bij het verwerven van kennis, maar wel in ruime mate bijdraagt aan het ophalen van (anatomische) kennis. Echter, door de opzet van de studie mogen er geen conclusies in deze richting worden getrokken. 
Hoofdstuk $\mathbf{8}$ is de algemene discussie van dit proefschrift. Dit hoofdstuk licht toe dat er geen eenduidig antwoord is op de centrale onderzoeksvraag hoe anatomieonderwijs geoptimaliseerd kan worden, maar dat dit afhangt van iemands reacties op het waarom, wat, wanneer, waar, wie en hoe van anatomieonderwijs. De antwoorden van dit proefschrift op deze vragen worden behandeld in dit laatste hoofdstuk. Dit wordt gedaan door de belangrijkste resultaten en conclusies van hoofdstuk 2 tot en met 7 te relateren aan, en combineren met, andere literatuur.

Waarom geven we anatomieonderwijs? Hoewel de meningen kunnen verschillen over de omvang, is iedereen het erover eens dat de reden dat anatomie wordt onderwezen is omdat het relevant is voor de toekomstige beroepspraktijk van de geneeskundestudent. Een essentiële bevinding in dit proefschrift is dat, hoewel studenten het belang van anatomische kennis erkennen, dit niet automatisch hoeft te betekenen dat ze het ook een belangrijk onderwerp vinden om veel studie-inspanning voor te leveren. Studenten leren in theorie voor hun toekomst, maar in de praktijk wordt hun leren gestuurd door het 'verborgen curriculum*', zoals wat ze moeten kennen om te slagen voor een toets.

Wat voor anatomische kennis moeten we onderwijzen? Docenten moeten zich ervan bewust blijven dat het doel van de basisopleiding geneeskunde is om een student te creëren die kan worden opgeleid tot arts. Studenten moeten worden voorzien van een goede basiskennis waarop ze tijdens hun verdere professionele leven kunnen blijven voortbouwen. In plaats van het ontwikkelen van lange lijsten met anatomische structuren stelt dit proefschrift voor om het onderwijs te beginnen met het aanleren van anatomische concepten*.

Wanneer moet anatomie onderwezen worden binnen het geneeskundecurriculum? Dit proefschrift suggereert dat anatomie moet worden aangeleerd door middel van een spiraliserend curriculum, te beginnen in de eerste jaren van de geneeskunde studie en helemaal doorlopend tot in de opleiding tot specialist*. Een spiraliserend curriculum verhoogt de kans op herhaling van eerder geleerde kennis. In dit proefschrift wordt dat beschreven als essentieel voor het behoud van deze kennis. Met elke lus van de spiraal kan de toepassing en integratie van kennis een hoger niveau bereiken, omdat er veel mogelijkheid bestaat om uit te bouwen op reeds bestaande kennis. Hierdoor kunnen gevoelens van deskundigheid en bekwaamheid worden verhoogd.

Waar moet het anatomieonderwijs plaats vinden? Of de snijzaal de beste plek is om anatomie te leren hangt af van wat er wordt onderwezen en aan wie. Hoewel de snijzaal de beste plek lijkt om de driedimensionale relaties van structuren te bestuderen, zou het leren van de anatomische woordenschat* of hoe anatomische kennis gebruikt kan worden tijdens het klinisch redeneren* waarschijnlijk ook plaats kunnen vinden in een andere omgeving. 
Wie zou er verantwoordelijk moeten zijn voor het anatomieonderwijs? De kwalificaties (geneeskundeopleiding, goede anatomische kennis) van een docent zijn relevant, maar niet noodzakelijkerwijs bepalend voor de kwaliteit van het onderwijs. Dit proefschrift stelt dat de docent een competente professional moet zijn, niet alleen wat betreft de inhoud, maar ook in relatie tot onderwijskundige theorieën* en empirisch bewijs.

Hoe moet anatomie onderwezen worden? De belangrijkste boodschap van dit proefschrift is dat het niet gaat om de methode die wordt gebruikt, maar over de manier waarop de methode wordt gebruikt. Onderwijs zou meer gebaseerd moeten worden op onderwijskundige theorieën en minder op persoonlijke voorkeur en traditionele methodes. Dit proefschrift toont aan dat een combinatie van onderwijsmethodes het beste lijkt om transfer van kennis te bevorderen. Het is verder belangrijk dat studenten de juiste hoeveelheid begeleiding krijgen tijdens hun gehele leerproces. En als laatste maar daarom niet het minst belangrijk, we moeten nooit uit het oog verliezen waarom anatomie onderwezen wordt... 



\section{VERKLARENDE WOORDENLIJST}

\section{Aard anatomische kennis}

Als studenten beginnen met anatomieonderwijs, dan leren ze eerst de namen van een groot deel van de structuren waaruit het menselijk lichaam is opgebouwd. In Nederland wordt hiervoor, net als in de meeste andere niet-Engelstalige landen, de Terminologia Anatomica, ook wel het 'anatomenlatijn', gebruikt. Dit betekent dat de studenten als het ware een hele nieuwe taal moeten leren die is gebaseerd op het Latijn. Met de aard van anatomische kennis wordt dus bedoeld dat de studenten zich eerst een hele nieuwe woordenschat moeten eigen maken voordat deze kennis kunnen toepassen (net als dat je van een buitenlandse taal eerst enkele woorden moet leren voordat je ergens de weg kan vragen).

\section{Anatomen}

Medewerkers van een afdeling anatomie die onder andere verantwoordelijk zijn voor het geven van anatomieonderwijs.

\section{Anatomie(onderwijs)}

Anatomie is de leer van de bouw van het menselijk lichaam. Bij anatomieonderwijs wordt de studenten dus geleerd uit welke onderdelen het menselijk lichaam bestaat, hoe deze delen eruit zien, waar deze delen zich ten opzichte van elkaar bevinden en hoe de delen functioneel aan elkaar gerelateerd zijn.

\section{Anatomie in vivo}

Anatomie in vivo wordt door een populair leerboek ook wel omschreven als 'het ontleden van een lichaam met het oog en de hand, door de gesloten huid heen'. Bij anatomie in vivo onderwijs bestuderen studenten de anatomie aan de hand van een levend lichaam van een andere persoon (meestal een medestudent). Hierbij wordt bijvoorbeeld onderzocht welke delen van het skelet gemakkelijk te voelen zijn, wat er gebeurt als bepaalde spieren worden aangespannen of wordt bepaald waar buikorganen ongeveer zouden moeten liggen.

\section{Anatomische concepten}

Anatomische concepten zijn beschrijvingen van algemene overeenkomsten tussen verschillende anatomische structuren (bijvoorbeeld een ligament in het bewegingsapparaat is een structuur van bindweefsel, gehecht aan twee verschillende botten, voorkomt ongewilde beweging tussen deze botten en is slecht gevasculariseerd en geneest daardoor langzaam). Het initieel aanleren van anatomische concepten zou studenten in staat kunnen stellen om een kader op te bouwen voor het analyseren van binnenkomende informatie (bijvoorbeeld gegevens van namen, locaties, verbindingen en relaties van structuren). Verder zou het de gecontroleerde introductie van informatie vergemakkelijken, waardoor het leren wordt bevorderd. [zie ook anatomische structuren]

\section{Anatomische structuren}

Anatomische structuren zijn de 'bouwstenen' waaruit het menselijk lichaam bestaat, zoals de verschillende organen, botten en spieren.

\section{Anatomische woordenschat}

[Zie aard anatomische kennis]

\section{Basisopleiding geneeskunde}

De huidige geneeskundestudenten in Nederland doorlopen allemaal een basisopleiding van 6 jaar. $\mathrm{Na}$ afronding hiervan zijn ze dan ook 'basisarts'. Deze studenten kunnen vervolgens aan de slag als anios (assistent-niet-in-opleiding-tot-specialist, voorheen agnio, assistent-geneeskundigeniet-in-opleiding) op een afdeling in het ziekenhuis. Mochten ze echter de wens hebben om zich verder te ontwikkelen tot bijvoorbeeld huisarts, orthopeed, chirurg, internist, oncoloog, uroloog etc. dan moeten ze een vervolgopleiding van 4 tot 6 jaar afronden. Gedurende deze specialisatie worden de studenten aios (arts-inopleiding-tot-specialist) genoemd. $A(n)$ ios worden ook wel 'zaalartsen' genoemd.

\section{Basisvakken}

Van oudsher worden de disciplines anatomie, fysiologie en biochemie de basisvakken genoemd. Bij een meer hedendaagse brede definitie van de basisvakken behoren naast anatomie, fysiologie en biochemie (minimaal) ook de disciplines epidemiologie, statistiek, microbiologie, farmacologie, moleculaire biologie, celbiologie, immunologie, pathologie, psychologie, sociologie en ethiek. Naast 
basisvakken bevat een curriculum ook klinische vakken zoals chirurgie, radiologie, orthopedie en oncologie. [zie ook geïntegreerd curriculum]

\section{Bekendheid van de context}

Bekendheid van de context geeft de mate aan waarin de studenten bekend/vertrouwd zijn met (al kennis heeft van) de context. Bijvoorbeeld: een student met een demente oma weet meer van dementie dan een student zonder demente oma. [Engels: familiarity]

\section{Best Evidence Medical Education (BEME)}

Best Evidence Medical Education (BEME; beste bewijs medisch onderwijs) wordt gedefinieerd als 'de uitvoering, door docenten in hun praktijk, van onderwijsmethoden en onderwijsbenaderingen op basis van het beste beschikbare bewijs'.

\section{Bewegingsapparaat}

Het bewegingsapparaat is het (orgaan)systeem waarmee de mens zich kan voortbewegen; hieronder vallen het skelet, de gewrichten en de spieren. [zie ook systemen van het menselijk lichaam]

\section{Cognitieve belasting}

Bij de cognitieve belasting gaat het erom in hoeverre het uitvoeren van een taak aandacht en concentratie van iemand vraagt. Dit kan beïnvloed worden door de instructies die gegeven worden om een taak uit te voeren. Bij het geven van onderwijs in context is het van belang dat de taak door de context niet belastender wordt voor de student en in sommige gevallen hopelijk zelfs minder belastend. [Engels: cognitive load] [zie ook onderwijs in context]

\section{Cognitieve dimensie van context}

Er bestaat een model over context waarin wordt gesteld dat context drie dimensies heeft: 1) de fysieke dimensie verwijst naar de werkelijke omgeving (bv een klaslokaal) waarin de kennis die geleerd moet worden aan de studenten wordt gepresenteerd, 2) de affectieve dimensie richt zich op de motivatie van studenten om de kennis te leren, 3) de cognitieve dimensie gaat over hoe de kennis die de student al heeft en de kennis die hij/zij moet leren aan elkaar gerelateerd zijn.

\section{Constructief leerprincipe}

Het constructief leerprincipe stelt dat studenten actief betrokken moeten worden bij het leren, en gestimuleerd moeten worden om hun voorkennis te activeren, te elaboreren (betekenis geven aan nieuwe informatie) en diep te leren, omdat dit leidt tot een dieper en rijker begrip en beter gebruik van de kennis. [zie ook diepgaand leren]

\section{Constructivistische leertheorie}

Het constructivisme gaat ervan uit dat het verwerven van kennis en vaardigheden niet zozeer het gevolg is van een directe overdracht van kennis door de docent, maar eerder het resultaat van denkactiviteiten van de studenten zelf. De studenten leren door de nieuwe informatie te verbinden aan datgene wat ze al weten. Kennis komt tot stand door interpretaties van informatie. Omdat interpretatie afhankelijk is van de voorkennis en associaties van de studenten, is deze per definitie subjectief van aard. Door de kennis te spiegelen aan de kennis van anderen, wordt deze niet alleen verrijkt, maar krijgt de lerende ook meer inzicht in hoe goed hij/zij de kennis beheerst. Het constructivisme gaat uit van de volgende definitie van leren: Leren is een constructief, cumulatief, zelfsturend, doelgericht, gesitueerd, coöperatief en individueel verschillend proces van kennisverwerving, betekenisgeving en vaardigheidsontwikkeling. [zie ook constructief leerprincipe, collaboratief leerprincipe, samenwerkend leerprincipe en zelfsturend leerprincipe]

\section{Context}

[Zie onderwijs in context]

\section{Contextueel leerprincipe}

Het contextueel leerprincipe stelt dat studenten bij voorkeur moeten worden blootgesteld aan een professioneel relevante context en een casus of probleem vanuit meerdere perspectieven moeten bestuderen, omdat dit transfer van kennis stimuleert. [zie ook transfer]

\section{Controlegroep}

Bij een (onderwijskundig) experiment worden minimaal twee verschillende groepen vergeleken. De ene groep wordt behandeld (krijgt onderwijs) volgens een nieuw bedachte methode(n), de experimentele groep(en). De andere groep krijgt een alternatieve behandeling waarmee de nieuw bedachte methode vergeleken wordt, bijvoorbeeld de al bestaande behandeling (onderwijsmethode), de controlegroep. 


\section{Coschappen}

In de laatste jaren van de basisopleiding geneeskunde lopen studenten meerdere stages, de coschappen, bij bijvoorbeeld verschillende afdelingen in het ziekenhuis, een verpleegtehuis, een revalidatiecentrum en bij de huisarts. De studenten worden dan coassistenten genoemd. De duur van de coschappen is ongeveer drie jaar (inclusief een wetenschappelijke stage), waarbij ze leren om zelfstandig patiëntenzorg te verlenen.

\section{Curriculum}

Een curriculum is een onderwijsprogramma; het samenhangend geheel van studieonderdelen die samen een opleiding vormen. In Nederland duurt het curriculum van de basisopleiding geneeskunde 6 jaar, maar bijvoorbeeld in de Verenigde Staten is het ook mogelijk om aan het eind van een 3 jarig curriculum bij een andere biomedische opleiding een 4 jarig geneeskundecurriculum te volgen.

\section{Daadwerkelijke kennis}

Daadwerkelijke kennis is de kennis die studenten echt bezitten (ook wel feitelijke of actuele kennis genoemd). Deze kennis kan bijvoorbeeld worden aangetoond met een toets.

\section{Didactische benadering}

De didactische benadering is de praktische invulling van de achterliggende onderwijskundige theorieën waarop een curriculum gebaseerd is. Probleem-gestuurd leren is bijvoorbeeld een didactische aanpak gebaseerd op de constructivistische leertheorie. [zie ook onderwijskundige theorieën, curriculum, geïntegreerde curricula, probleem-gestuurd leren en constructivistitsche leertheorie]

\section{Diepgaand leren}

Diepgaand leren wordt gekenmerkt door een motivatie om het onderwerp te begrijpen. Studenten die diepgaand leren proberen de kennis die geleerd moet worden betekenisvol te maken. Tijdens het leren proberen de studenten om verbindingen tussen de nieuwe kennis en hun voorkennis te maken, ze zoeken structuur in de kennis, ze zoeken naar algemene principes en proberen de kennis van verschillende domeinen te integreren. Dit staat in contrast met oppervlakkig leren. [zie ook oppervlakkig leren]

\section{Diepgang van anatomiekennis}

Bij de diepgang van anatomiekennis gaat het om de vraag wat studenten precies moeten weten van anatomische structuren. Neem bijvoorbeeld voor het onderwerp 'spieren'. Hoeven studenten in het basiscuriculum geneeskunde dan alleen te weten waar een spier globaal ligt en wat hij doet of is het ook noodzakelijk dat hij/zij exact weet waar op welk bot deze spier vast zit en welke nevenfuncties deze spier nog meer heeft? [zie ook anatomische structuren]

\section{Dissectie}

Dissectie is het, door de studenten zelf, ontleden van een menselijk stoffelijk overschot (lichaam) dat door de overledene beschikbaar is gesteld aan de wetenschap.

\section{Empirisch bewijs}

Empirisch bewijs wordt gevormd door bevindingen die gebaseerd zijn op reële directe waarneming, bijvoorbeeld omdat ze proefondervindelijk zijn vastgelegd.

\section{Experiment}

Bij een experiment wordt nagegaan of wat er in theorie wordt verwacht, ook echt in de praktijk gebeurt. In een experiment manipuleert de onderzoeker een variabele, onder meer door met experimentele en controlegroepen te werken, om daarna de uitkomst te bestuderen en met de theorie te vergelijken. [zie ook controle groep]

\section{Experimentele groep}

[Zie controlegroep]

\section{Fenomenografische benadering}

Deze benadering is gericht op het beschrijven, analyseren en begrijpen van 1) ervaringen met of ideeën over een fenomeen (in het geval van deze studie 'anatomie') en 2) de verschillende manieren waarop dit fenomeen wordt waargenomen en begrepen. In fenomenografie ligt bij de uitkomst de focus op de variatie in ervaringen van een bepaald fenomeen. Dit in contrast met een fenomenologische analyse. Hierbij is het doel om de essentie (datgene wat voor iedereen hetzelfde is) van de beleving van een bepaald fenomeen te beschrijven.

\section{Focusgroepen}

Een verzameling van een kleine groep individuen (meestal tussen de 5 en 12), die een groepsdiscussie houden over een specifiek onderwerp onder leiding van een moderator. De 
moderator zorgt ervoor dat alle vragen van de onderzoeker beantwoord worden, maar ook dat het proces goed verloopt door bijvoorbeeld iedereen bij het gesprek te betrekken. Focusgroepen worden meestal opgenomen, waarna de discussie wordt uitgetypt om deze vervolgens te kunnen analyseren. [zie ook template analyse]

\section{Geïntegreerd curriculum}

Een geïntegreerd curriculum wordt gezien als de tegenhanger van een traditioneel curriculum. Een traditioneel curriculum richt zich de eerste jaren op de basisvakken en de daaropvolgende jaren op de klinische vakken en vaardigheidstraining. Elk basisvak heeft hier zijn eigen cursus en deze cursussen worden na elkaar gegeven. Bij geïntegreerde curricula worden de basisvakken gelijktijdig met elkaar verweven onderwezen, wat horizontale integratie wordt genoemd. Verder worden de klinische vakken al geïntroduceerd in de vroege jaren van het curriculum, geïntegreerd met de basisvakken, en vice versa, wat verticale integratie wordt genoemd [zie ook basisvakken, curriculum en traditioneel onderwijs]

\section{Gepercipieerde kennis}

De gepercipieerde kennis bestaat uit de denkbeelden die studenten over hun eigen anatomische kennis hebben. [zie ook perceptie]

\section{Klinisch redeneren}

Klinisch redeneren bestaat uit 'het nadenken over het professioneel handelen in de praktijk'. Het is een gestructureerde gedachtengang met als doel om de zorgvraag en de zorgbehoefte (het probleem) van een bepaalde patiënt systematisch te verwoorden, te analyseren en op te lossen.

\section{Leerprincipes}

Leerprincipes worden ook wel aangeduid als 'de wetten van het leren' en zijn toepasbaar op elk leerproces. Deze principes zijn tijdens jarenlang onderwijskundig onderzoek ontdekt, toegepast, getest en bewezen in praktische situaties. Leerprincipes bieden extra inzicht in hoe mensen het meest effectief leren. [zie ook constructief leerprincipe, contextueel leerprincipe, samenwerkend leerprincipe en zelfgestuurd leerprincipe]

\section{Likertschaal vragen}

Een vragenlijst bevat meestal een Likertschaal als het de bedoeling is om moeilijk te kwantificeren gegevens toch in een cijfer uit te drukken. Veel gebruikte zijn de 5- en 7-punts Likertschaal waarbij diegene die het antwoord geeft wordt gevraagd om een getal te kiezen tussen de extremen van het antwoordmodel die mate van instemming met, of afwijzing van, de uitspraak aangeven. Bijvoorbeeld: "Ik vind de verklarende woordenlijst bij de Nederlandse samenvatting van dit proefschrift een nuttige toevoeging".

Volledig mee $\begin{array}{llllllll}1 & 2 & 3 & 4 & 5 & 6 & 7 & \text { Volledig mee }\end{array}$

oneens

eens

\section{Literatuurstudie}

Een literatuurstudie houdt in dat er een poging wordt gedaan om een onderzoeksvraag te beantwoorden door de wetenschappelijke literatuur die betrekking heeft op het onderwerp op systematische wijze te doorzoeken en samen te vatten.

\section{Meerkeuze vragen}

Een meerkeuzevraag is een vraag waarbij uit een beperkt aantal antwoorden het juiste antwoord gekozen moet worden. Bijvoorbeeld: welk orgaan zorgt ervoor dat het bloed door ons lichaam gepompt wordt? A) hart, B) hersenen, C) lever, D) longen.

\section{Minimale vereiste}

Bij een samengestelde toets kan ervoor gekozen worden om studenten te laten slagen als ze bijvoorbeeld 70 van de 100 vragen correct hebben beantwoord. Studenten kunnen er dan echter voor kiezen om één of twee onderwerpen binnen deze toets niet te leren en de anderen beter. Als er een minimale vereiste wordt gesteld, dan betekent het dat de studenten van elk onderwerp dat binnen de samengestelde toets aan bod komt bijvoorbeeld 7 van de 10 vragen goed moet hebben. Hierdoor is het voor de studenten niet meer mogelijk om een bepaald onderwerp niet of nauwelijks te bestuderen, omdat dat de kans van slagen verkleint. [zie ook samengestelde toets]

\section{Onderwijs in context}

Bij het geven van onderwijs in context wordt de kennis die geleerd moet worden gekoppeld aan een toekomstige professioneel relevante situatie. In het geval van anatomie kan het bijvoorbeeld 
zijn dat er een patiënt wordt besproken met aan aandoening aan de knie, zodat studenten inzien waarom ze kennis moeten vergaren over de kniebanden en meniscus (context als introductie). Het kan ook zijn dat studenten te horen krijgen dat ze straks een patiënt met een schouderklacht moeten onderzoeken, en daarom kennis moeten vergaren over de anatomie van het schoudergewricht (context als toepassing).

\section{Onderwijskundige theorie}

Wetenschappelijke onderbouwde ideeën over manieren waarop het onderwijs het beste vormgegeven kan worden.

\section{Open vragen}

Een open vraag is een vraag waarbij minimaal één complete zin als antwoord gegeven moet worden. Dit in tegenstelling tot een kortantwoord vraag, waarbij het antwoord uit bijvoorbeeld één term kan bestaan.

\section{Opleiding tot specialist}

[Zie basisopleiding geneeskunde]

\section{Oppervlakkig leren}

Een oppervlakkige benadering van leren wordt geassocieerd met de bedoeling om informatie (feiten) geïsoleerd te onthouden om het letterlijk te kunnen reproduceren tijdens een toets. Het nodigt uit tot het routinematig memoriseren, 'stampen' of 'mechanisch herhalen', van feiten en lijsten, vaak geholpen door het gebruik van ezelsbruggetjes. Dit in contrast met diepgaand leren. [zie ook diepgaand leren]

\section{Patiëntencasus}

Een patiëntencasus is een tekst waarin het verhaal van een patiënt beschreven wordt. Hierin staat bijvoorbeeld de klachten die de patiënt heeft, hoe de diagnose van de ziekte van de patiënt is gesteld, hoe de patiënt aan de ziekte komt, waarmee de patiënt behandeld wordt etc.

\section{Patiëntenvignet}

Lijkt op een patiëntencasus maar is meestal korter omdat het maar een deel van de informatie bevat. [zie ook patiëntencasus]

\section{Perceptie}

Gedachtengang, waarneming, denkbeeld; de manier waarop iemand iets ervaart en beoordeelt.

\section{Posttest}

[Zie pretest]

\section{Pretest}

Een pretest is een toets. Deze toets is vaak een onderdeel van een experiment waarbij verschillende groepen verschillende behandelingen ondergaan (bijvoorbeeld verschillende groepen eerstejaars studenten die allemaal op een andere manier onderwijs krijgen). Na het experiment wordt dan een vergelijkbare toets afgenomen, de posttest, waarvan de uitslagen met de pretest worden vergeleken om zo te kijken welke behandeling het beste werkt.

\section{Probleem-gestuurd onderwijs}

Bij probleem-gestuurd onderwijs is het leren van studenten georganiseerd rond problemen (patiëntencasussen). Onderwijsgroepen, bestaande uit een kleine groep studenten (bijvoorbeeld 10 studenten) en hun tutor (begeleider) komen regelmatig (bijvoorbeeld twee keer per week) bij elkaar om een probleem te bespreken. Deze problemen bestaan uit een beschrijving van een of meerdere verschijnselen die de studenten met hun voorkennis proberen uit te leggen in termen van onderliggende (biomedische of psychosociale) processen. Tijdens deze discussie ontdekken studenten wat ze al weten en wat ze nog niet weten. Vervolgens worden er leerdoelen geformuleerd waarop ze antwoorden zoeken tijdens de zelfstudiefase. Tijdens deze fase maken ze gebruik van de door de universiteit aangereikte middelen (colleges, practica, vaardigheidstraining, etc.) en/of bestuderen ze relevante literatuur. De eerste bijeenkomst met de onderwijsgroep helpt studenten met het bepalen van zowel de richting als de omvang van de te ondernemen zelfstudie. Tijdens het eerste deel van de volgende bijeenkomst met de onderwijsgroep bespreken de studenten hun antwoorden op de leerdoelen en verwerven op die manier een dieper inzicht met betrekking tot het probleem. Daarna krijgen ze een volgend probleem voorgelegd en begint de cyclus opnieuw. [zie ook patiëntencasus]

\section{Referenties}

Een referentie is een verwijzing. Als je tijdens het schrijven van een wetenschappelijk artikel een bewering doet, dan verwijs je naar auteurs die (een deel van) deze informatie hebben beschreven om je bewering te ondersteunen. Aan het eind van het artikel volgt dan een lijst 
met de complete verwijzingen, zodat lezers deze informatie zelf na kunnen zoeken indien ze daar behoefte aan hebben.

\section{Relevantie van de context}

De relevantie van de context geeft de mate aan waarin de context (in dit geval de ziekte in de patiëntencasus) aansluit op de inhoudelijke kennis die geleerd moet worden.

\section{Retrieval cues}

Letterlijk vertaald zijn retrieval cues 'ophaalaanwijzingen'. Een praktisch voorbeeld van hoe retrieval cues werken is de moeite die je kunt hebben om de naam van een collega te herinneren wanneer je hem/haar tegenkomt in de supermarkt. Cues die aanwezig zijn op het werk (bijvoorbeeld de kleur van het tapijt, plaatsing van de bureaus) helpen om toegang te krijgen tot de informatie die is opgeslagen in je geheugen (de namen van collega's). Deze cues zijn afwezig in de supermarkt, waardoor het moeilijker is om daar de naam op te halen.

\section{Review}

Een review is een (kritische) beschrijving van relevante, wetenschappelijke literatuur.

\section{Samengestelde toets}

In een samengestelde toets wordt de kennis van meerdere onderwerpen tegelijkertijd getoetst.

\section{Samenwerkend leerprincipe}

Het samenwerkend leerprincipe stelt dat studenten moeten worden gestimuleerd om met elkaar samen te werken, omdat deze interacties een positieve invloed kunnen hebben op het leren.

\section{Semantische netwerken}

Semantische netwerken zijn netwerken die relaties tussen begrippen weergeven. Semantische netwerken bestaan uit één of meer proposities. Proposities bevatten begrippen (concepten, feiten, ervaringen) en hun onderlinge betekenisvolle verbanden. Semantische netwerken worden vaak weergegeven als spinnenwebachtige figuren van cirkels die verbonden zijn met lijnen. De cirkels bevatten de begrippen en de draden zijn de verbanden tussen de begrippen.Bijvoorbeeld: de duim (begrip) is onderdeel van (verband) de hand (begrip)

\section{Snijzaal}

De snijzaal is een speciale ruimte van de afdeling anatomie waar de ontleding van de menselijke stoffelijke overschotten (lichamen) plaats vindt. Deze lichamen zijn door de overledenen beschikbaar gesteld aan de wetenschap. Daarnaast kunnen studenten in deze ruimte ook reeds ontlede lichamen en/of lichaamsdelen bestuderen om de anatomie te leren.

\section{Spiraliserend curriculum}

Een spiraliserend curriculum is een curriculum waarbij onderwerpen en thema's steeds opnieuw herhaald worden. Tevens vereist elke herhaling uitbreiding en/of verdieping van het onderwerp, waarbij elke nieuw herhalingsmoment voorbouwt op het vorige. [zie ook curriculum]

\section{Systemen van het menselijk lichaam}

Het menselijk lichaam bestaat uit systemen opgebouwd uit organen die gezamenlijk een bepaalde functie uitvoeren. Voorbeelden zijn:

Cardiovasculair systeem: hart en bloedvaten voor de bloedsomloop.

Ademhalingsstelsel, luchtpijp en longen voor het opnemen van zuurstof en afgeven van koolstofdioxide.

Spijsverteringssysteem: maag, darmen, lever, galblaas, alvleesklier voor verwerking van voedsel.

Immuunsysteem: zwezerik en lymfoïde organen ter verdediging tegen bacteriën en virussen.

Voortplantingsstelsel, geslachtsorganen voor het krijgen van kinderen.

Bewegingsapparaat: skelet, gewrichten en spieren om te kunnen voortbewegen.

Zenuwstelsel: hersenen, ruggenmerg en zenuwen voor het aansturen van het lichaam en informatieverwerking.

\section{Template analyse}

Template analyse is een techniek voor het organiseren van (de relatie tussen) thema's die verschijnen tijdens de analyse van een grote hoeveelheid tekst. Deze vorm van analyse is bijzonder effectief als het doel is om perspectieven van verschillende groepen te vergelijken. Met template analyse kunnen thema's op een hiërarchische manier getoond worden, bijvoorbeeld in de vorm van een tabel (de meest linker kolom geeft de grotere, oppervlakkige thema's aan, en hoe verder naar rechts in de tabel hoe groter de analysediepte, en dus hoe kleiner de thema's worden). Een voordeel van template analyse is dat je 
voorafgaand aan het analyseproces al thema's, waarvan je al weet dat deze in de tekst naar voren zullen komen (omdat de moderator er bijvoorbeeld tijdens de focusgroepen naar heeft gevraagd) mag specificeren. [zie ook focusgroepen]

\section{Traditioneel onderwijs}

In traditionele curricula richten de eerste jaren zich op de basisvakken en de daaropvolgende jaren op de klinische vakken en vaardigheidstraining. Leren wordt gezien als een accumulatie van kennis. Goede kennis van de basisvakken wordt beschouwd als een absolute vereiste voor het klinisch redeneren, en kennis van de normale structuur en functie wordt noodzakelijk geacht om de abnormale structuur en functie te begrijpen. Dit fundament van basiskennis is geconcentreerd in een 'preklinische fase', van meestal drie tot vier jaar. Elk basisvak wordt gepresenteerd in een geïsoleerde cursus, die strikt afdeling gebaseerd is en er is weinig of geen integratie tussen disciplines. Cursussen bestaan voornamelijk uit docent gecentreerde kennisoverdracht tijdens lezingen en practica. $\mathrm{Er}$ is weinig bewuste instructie in de toepassing van de basisvakken tijdens klinisch redeneren en er is beperkte interactie tussen studenten en patiënten. Basisvaardigheden, zoals het afnemen van een anamnese, communicatie met patiënten en het uitvoeren van een gestructureerd lichamelijk onderzoek worden gedoceerd aan het begin van de coschappen of zelfs helemaal niet. [zie ook basisvakken, curriculum, geïntegreerde curricula, klinisch redeneren]

\section{Transfer}

Het gebruiken van kennis die werd verworven in de ene context om een nieuw probleem in een andere context op te lossen. (Bijvoorbeeld anatomiekennis geleerd op de snijzaal in de universiteit gebruiken om als huisarts tijdens een lichamelijk onderzoek een pijnlijke schouder van een patiënt te onderzoeken.

\section{Verborgen curriculum}

Het verborgen curriculum wordt beschreven als 'processen, spanningen en beperkingen die buiten het formele curriculum vallen en vaak onuitgesproken zijn, of niet zijn nagegaan. Het zijn de neveneffecten van een opleiding of de 'lessen die worden geleerd, maar niet openlijk zo zijn bedoeld'. Vaak betreft dit normen, waarden en overtuigingen, maar het kunnen ook bepaalde gedragingen zijn. Het verborgen curriculum kan juist een positief of een negatief effect hebben. Bijvoorbeeld: het doel van anatomieonderwijs is het kunnen toepassen van de kennis in de praktijk (het bereiken van transfer), maar bij toetsing worden de studenten vaak alleen maar gevraagd om de juiste naam aan verschillende structuren te geven. [Engels: hidden curriculum] [zie ook curriculum en transfer]

\section{Verticale integratie}

[Zie geïntegreerd curriculum]

\section{Zelfgestuurd leerprincipe}

Het zelfgestuurd leerprincipe stelt dat studenten gestimuleerd moeten worden om zich bewust te zijn van hun voorkennis en om hun leerproces te reguleren en dirigeren, vanuit zowel een motivationeel als cognitief perspectief. 



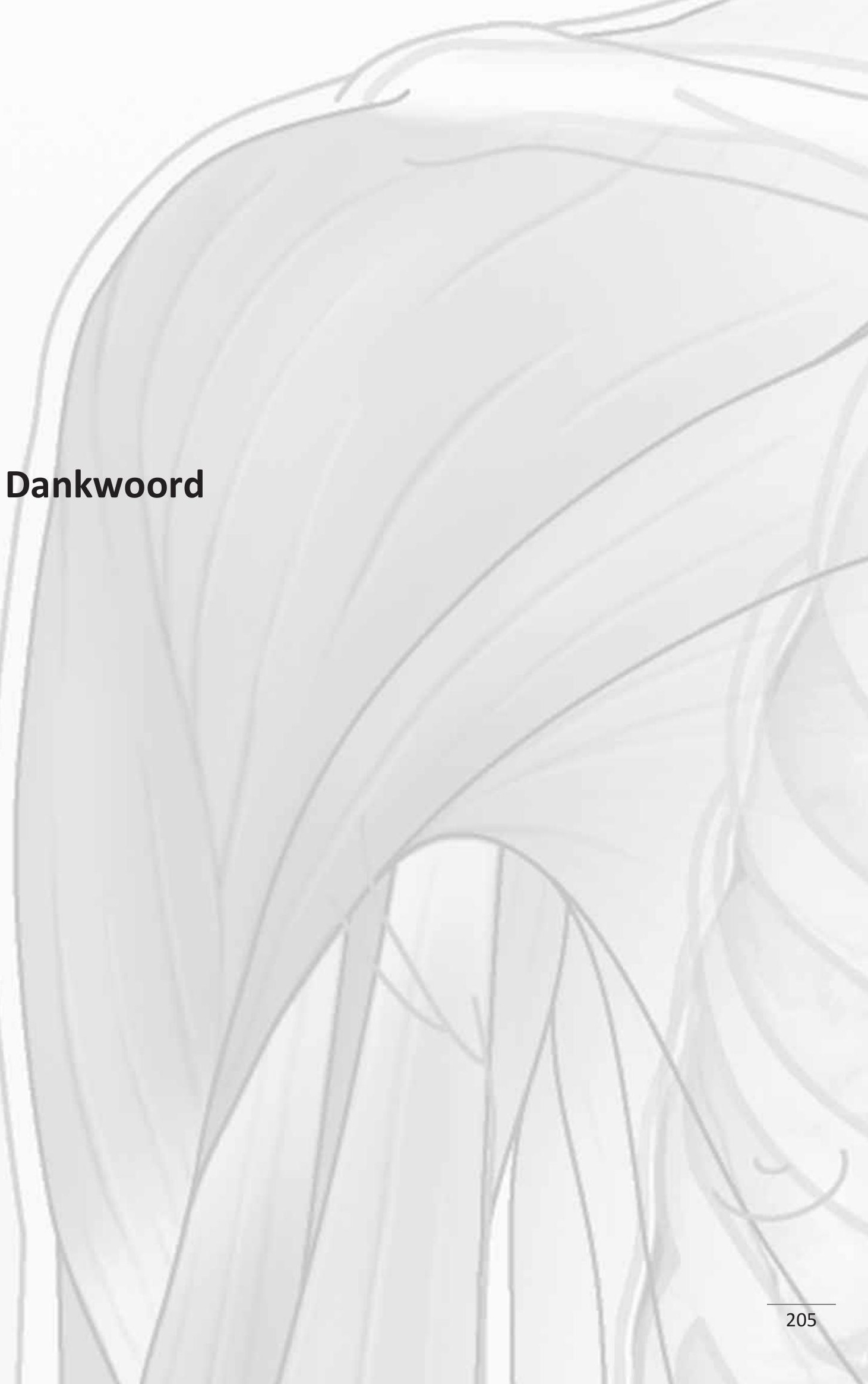


Dankwoord 
Wat is een dankwoord schrijven moeilijk! Maar hier is ie dan, en veel te lang. Ik hoop dat jullie het mij kunnen vergeven als ik in clichés verval of toch nog personen vergeten ben...

Heren C\&A, het was een enorm voorrecht onder jullie te mogen promoveren, van jullie te leren en van jullie netwerk gebruik te mogen maken. Ondanks dat we elkaar door drukke agenda's niet vaak face-to-face zagen, was dit altijd op korte termijn mogelijk als het echt noodzakelijk was. Wat ik zeer waardeer is jullie enorm snelle reacties op mijn emailtjes, want ookal waren ze soms kort (met "ok A" won ik het wedstrijdje 'wieheeft-het-kortste-mailtje-van-Albert-ontvangen' onder promovendi), ze gaven altijd antwoord op mijn vraag en ik kon weer vooruit. Albert Scherpbier, vanaf het begin toonde je constant vertrouwen in mijn kunnen. Dit heeft mij enorm gemotiveerd om de stap naar deze andere onderzoeksdiscipline te maken. Cees van der Vleuten, naast de voortgang van mijn onderzoek was je ook altijd geïnteresseerd in mijn persoonlijke wel en wee. Ik ben heel blij dat ik ook na het afronden van mijn proefschrift met je mag blijven samenwerken.

Toen de plannen voor mijn studies echt serieuse vormen aannamen ging $\mathrm{jij}$, Anique de Bruin, als co-promoter deel uitmaken van mijn team. Het is goed om iemand in je team te hebben die open staat voor de kleine vragen, en kritisch de rode pen hanteerd. Ik hoop ook in de toekomst van je ervaring als onderzoekster, en als moeder, gebruik te mogen blijven maken.

Het begon natuurlijk allemaal toen ik ging werken op de afdeling Anatomie en Embryologie van de Universiteit Maastricht. Henk van Mameren, Jaap van der Wal, Frans Thors, Arno Lataster, Andreas Herrler, Ulrike von Rango en Thomas Verlinden, ik heb waanzinnig veel inhoudelijke anatomische informatie van jullie geleerd, en ook welke stijl van onderwijsgeven (niet) bij mij past. Ook bedankt, samen met Paul van Dijk, Els Terwindt, Roy Cloots, Chiel de Thije, Tine Comhair, Sonja Garcia en alle stagaires, voor de heerlijk humoristische koffie- en lunchpauzes. Deze gezamelijke momenten schepten een band tussen alle medewerkers op de afdeling die ik nog nergens anders ben tegengekomen. Ik denk nog graag terug aan de bakwedstrijden en natuurlijk aan alle vlaai die iedereen om de meest idiote redenen moest meebrengen. Rogier Trompert, dank voor het beschikbaar stellen van je tijd en tekeningen en het ontwerpen van mijn kaft. Last but not least, Judith Sieben. We begonnen tegelijk op de afdeling, en zonder jouw was alles heel anders geweest. We hebben het die eerste jaren toch maar mooi even geflikt samen. Dank voor alles wat hiervoor genoemd staat, maar ook dank voor de dingen die ik hier niet onder woorden kan brengen, maar waarvan ik zeker weet dat jij weet wat ik bedoel. 
In 2012 maakte ik de overstap naar de afdeling Anatomie van het Radboud UMC in Nijmegen. Dirk Ruiter, je uitnodiging voor een gesprek kwam voor mij geheel onverwacht, maar het kostte je weinig moeite mij over te halen. Enorm bedankt voor het openzetten van deze deur. Tamas Kozicz, huidig hoofd van de afdeling, dank voor het begrip tijdens de periode waarin ik een moeilijke beslissing over mijn toekomst in Nijmegen moest nemen. Jan Kooloos, soms is het een beetje eng hoe goed je mij lijkt te kennen. Dank voor je kritische noot en oprechte belangstelling. Ook bedankt, samen met Albert van Linge, Anne-Marie Cappellen van Walsum, Amanda Kiliaan, Leonieke Palmen en Denise Doomernik, dat jullie altijd bereid zijn om al mijn vragen te beantwoorden. Annelieke Schepens-Franke \& Marc Vorstenbosch, dank dat ik jullie kamergenoot mocht worden. Het is fantastisch dat we niet alleen onze passie voor het geven van anatomieonderwijs kunnen delen, maar net zo makkelijk brainstormen over onderzoek en kletsen over de ups en downs van het ouderschap. Collega's, jullie ontvingen mij met open armen en gaven mij de mogelijkheid om de cirkel rond te maken. Het moederschap veranderde mij, en mijn plannen voor de toekomst. Ik hoop echter dat een klein samenwerkingsverband op onderwijs(kundig onderzoeks)gebied in stand gehouden kan worden.

Binnen beide afdelingen anatomie zijn er twee speciale groepen mensen waar ik graag apart aandacht aan wil besteden. Allereerste het 'technisch personeel': Leon Huiberts \& Johan Hekking (Maastricht) en Vera Gelsing, Dionne Christiaans \& Laura Adolfse-Verschoor (Nijmegen). Zonder jullie is ons werk als anatoom, zowel op het gebied van onderzoek als onderwijs, onmogelijk. Gedurende al die jaren waren jullie mij steun en toeverlaat, of het nou ging om het klaarzetten van materiaal of het delen van een lach en een traan. Daarnaast ook mijn enorme dank aan de secretariële ondersteuning, Greta Gerrits \& Renée Gruisen (Maastricht) en Manon Noppeney \& Jack Theeuws (Nijmegen). Dank voor jullie kennis van de organisatie, de antwoorden op mijn vragen, de hulp bij het maken van planningen, het verwerken van al het papierwerk, maar ook voor het bieden van een luisterend oor. Als de spin in het web wordt jullie invloed op het functioneren van de afdeling in mijn ogen soms onderschat.

Wat ben ik trots dat ik door mijn onderzoek deel ben gaan uitmaken van de afdeling Onderwijsontwikkeling \& -Onderzoek van de Universiteit Maastricht! Alleerst moet ik al mijn mede-PhD studenten bedanken. Floris van Blankenstein, Joost Dijkstra, Juliëtte Hommes, Mariëlle Jippes, Mariëtte van Loon en Robbert Duvivier, dank voor alle gezellige momenten, alle steun en alle tips. Daarnaast dank ik Ellen Kok, Janneke Frambach, Jorrick Beckers, Katerina Bohle-Carbonell, Lorette Stammen, Marjo van Zundert en Rachelle Kamp ook voor het feit dat ik altijd mocht komen binnenvallen op de AIO kamer en van jullie lege werkplekken gebruik mocht maken. Jullie maakten het mogelijk dat op een kamer met 6 personen serieus gewerkt kon worden, maar er ook 
altijd tijd was voor het bespreken van ieders priveperikelen. Speciale dank verder aan de PhD's waarmee ik samen het KO-clubje vormde. We hebben met elkaar ontzettend veel geleerd over het doen van kwalitatief onderzoek. Jonne van der Zwet, dank voor het KO-initiatief en voor het delen van je mama-wijsheden. Wie in de toekomst jou als werknemer krijgt mag zijn/haar handjes dichtknijpen. Jeantine de Feijter, de paar dagen Schotland samen met Renée zal ik nooit vergeten. Ik weet zeker dat je een fantastische internist wordt/bent. Irene Slootweg, je bent een bijzonder mens. Vooral dank voor het gesprek dat we hadden in de wijnbar in Praag, ik denk daar nog vaak aan terug. We zijn in de loop van de tijd naar elkaar toe gegroeid en ik hoop je krullen en je lach nog vaak tegen te komen.

Alle collega's van O\&O, dank voor jullie hulp, steun, adviezen, (minder) serieuze kletspraatjes op de gang of tijdens een congres. Dank voor het feit dat jullie allemaal zo bereikbaar en toegankelijk zijn. In het bijzonder Ton de Goeij, dank voor de samenwerking aan het hoofdstuk voor 'het PBL boek'. Maar ook dank voor je steun. Ik ben zeer vereerd dat je de voorzitter van de beoordelingscommissie van mijn proefschrift wilde zijn. Mascha Verheggen, iedere keer als ik binnen de faculteit een nieuwe rol op mij nam kwamen we elkaar weer tegen. Het is bijzonder hoe jij alle ballen van werk en gezin in de lucht blijft houden. Dank voor je gedrevenheid en je inzet. Mirjam Oude-Egbrink, we hebben niet veel samengewerkt maar ik wil je danken voor je interesse in hoe het met mij gaat elke keer als we elkaar tegenkomen. Ook bedankt dat je plaats wilde nemen in de beoordelingscommissie van mijn proefschrift. Tim Dornan, although I know you can read (and speak) Dutch, I feel it is more personal writing this in English. Thank you for sharing your research expertise, network and infectious enthusiasm with me. I hope we will stay in touch when work or the wind takes you elsewhere.

Als laatste het team van mensen bij O\&O die mij ondersteund hebben in de totstandkoming van dit proefschrift. Allereerst de statistici. Ron Hoogeboom, dank voor je hulp bij hoofdstuk 5. Jimmie Leppink, dank voor je hulp bij hoofdstuk 7 en daarnaast je niet aflatende geduld om al mijn andere statistische vragen geduldig en helder uit te leggen. Mereke Gorsira, dank voor de correctie van mijn Engels taalgebruik en het beperken van het aantal woorden van al mijn artikelen. Je bent helaas niet meer onder ons, maar je wordt gemist en zal niet vergeten worden. Lilian Swaen \& Nicky Verleng, het dynamische duo van het secretariaat. Jullie waren nooit te beroerd om mij te helpen als ik weer eens langs kwam waaien en lieten je niet afschrikken door de soms haast onmogelijke taak om en afspraak te plannen in de drukke agenda's van mij en mijn team.

Een belangrijke rol in het uitvoeren van mijn promotieonderzoek is gespeeld door mijn student-assistenten. Ida Smailbegovic, je was mijn eerste echte rechterhand. Je bent al net zo idioot nauwkeurig en dol op het werken met kleurtjes als ik. Ik heb ook 
ontzettend veel van jou geleerd. Inge Verheijen, wij hebben het langst samengewerkt en je hebt enorm veel werk verzet. Je liet je niet uit het veld slaan door ook mijn onervarenheid met coderen van textuele data. Ghita Puts, jij hebt in weinig tijd heel veel gedaan. Je hebt zelfs het uitvoeren van enkele onderdelen van mijn experiment compleet overgenomen toen ik dat niet kon. Dames, jullie hebben het alledrie tot coauteur geschopt, waaraan iedereen kan zien hoeveel jullie voor mij(n onderzoek) hebben betekend, dank daarvoor. Ik blijf graag op de hoogte over hoe het met jullie gaat!

Naast mijn student-assistenten natuurlijk een speciale woord van dank aan de studenten die vrijwillig aan mijn studies hebben meegewerkt. Maar ik ben eigenlijk alle studenten dankbaar. In het algemeen voor jullie altijd eerlijke feedback, maar in het bijzonder ook jullie blijken van waardering voor mijn inzet om jullie te helpen leren. Dat geeft mij meer energie en voldoening dan elke andere beloning.

Alle huidige en oud collega's van het Skillslab van de Universiteit Maastricht (jullie zijn met zo veel dat ik jullie hier helaas niet allemaal persoonlijk kan noemen), dank voor de samenwerking en alles wat jullie mij geleerd hebben over fysische diagnostiek, medische beeldvorming en klinisch redeneren. Ik pluk daar nog dagelijks de vruchten van. Mijn speciale dank gaat uit naar Maarten Verwijnen, vanaf het begin was je betrokken bij mijn carrière op de UM. Ik mocht altijd bij je binnen lopen om mijn grote en kleine problemen aan je voor te leggen. Als hoofd van de afdeling was jouw kijk op de zaak een belangrijke informatiebron voor mij. Dank voor al je ondersteuning.

Met enkelen van jullie heb ik naast/na het Skillslab ook op andere vlakken samengewerkt. Marijke Kruithof, dank voor je inzet en de samenwerking als het gaat om het mentorschap van de ITM studenten en je betrokkenheid. Geraldine van Kasteren, dank dat je mijn enthousiasme wilde inzetten in het project in Jemen. Ik hoop dat er nog enkele mogen volgen. Jan van Dalen, dank voor je getoonde vertouwen in mij door MHPE Egypte aan mij over te dragen, maar vooral dank dat je me in deze klus wil ondersteunen.

Als laaste van mijn (oud)collega's wil ik graag alle blok- \& clustercoördinatoren en artsen bedanken, in het speciaal Ben Janssen, Edouard Bevers, Daisy Jonkers, Pim Dassen, Simon Robben en Bas Verhoeven, voor de fantastische samenwerking en alles wat ik van jullie geleerd heb over de inhoud, organisatie en toetsing van een geneeskundeopleiding. Dit hielp mij om het onderwerp van mijn proefschrift in een breder kader te kunnen plaatsen.

Vrienden en vriendinnen, jullie hebben er even op moeten wachten (dat zal jullie niet verbazen, want jullie weten dat ik nooit woorden te kort kom), maar dit is eindelijk 
jullie paragraaf. Bij deze wil ik jullie danken voor alle momenten dat jullie mij (niet) lieten praten. Hanneke Bergsma, ooit stapten we met nog drie onbekenden in een roeiboot en wat vind ik het fijn dat het contact gebleven is. Soms spreken we elkaar maanden niet, om daarna gewoon verder te gaan waar we gebleven waren. Met onze verre reizen, huisrenovaties en gezinnen deelt ons leven veel, al gebeurd het voor jou in Friesland en voor mij in Limburg. Ik beloof dat ik jou, Wietse, Sophie en Jesse nu echt snel kom opzoeken. Eelco Weijmans, toen we Amsterdam voor Maastricht verruilden en dus ook onze schaatsclub verlieten, wisten we niet met wie we contact zouden blijven houden. Ook bij jou geldt dat complete radiostilte afgewisseld kan worden met logeerpartijen en kookfestijnen. Dank daarvoor. Marc Bongers \& Eveline Nelissen, jullie behoren tot het clubje nieuwe vrienden die we hier in Limburg hebben gemaakt. lets drinken op een terras, samen eten, genieten van muziek of over een braderie kuieren, het is altijd gezellig. We hopen in de toekomst nog veel van dat soort momenten te kunnen delen. Chantal Prevot en Ana-Paula Bof, we hebben elkaar nog geen twee jaar geleden leren kennen op de 'pufclub'. Ik ben zo blij dat het contact gebleven is, om ervaringen uit te wisselen en Basil, Isa en Robin samen te zien opgroeien. Ernest Boskovic, Mersad Kobaslija, Githa Breikers, Lilian Klompen, Paul Breed en alle andere vrienden en collega's van Jan, dank dat jullie hem regelmatig op sleeptouw nemen zodat ik de afstandsbediening een paar uurtjes voor mezelf heb. Eva van Dijk, we kennen elkaar nu bijna 15 jaar. In sommige opzichten lijken we op elkaar, in andere zijn we elkaars tegenpolen. We hebben van alles samen meegemaakt, en de vele emoties van onze hoogte- en dieptepunten gedeeld. Je was getuige op mijn bruiloft en al is het contact soms wat intensiever en soms wat minder, ik ben dankbaar dat je mijn vriendin bent.

En dan mijn twee paranimfen. Renée Stalmeijer, door het toeval of het lot volgden we samen de cursussen voor nieuwe medewerkers op de Universiteit Maastricht. Door jou maakte ik kennis met onderwijskuding onderzoek, met alle gevolgen van dien. Je (mensen)kennis, je inlevingsvermogen, je omgevingsbewustzijn, je diplomatie, je oog voor detail, je inzet, ik heb overal al gebruik van mogen en kunnen maken en daar ben ik je ontzettend dankbaar voor. Zonder jou was het de afgelopen jaren een heel stuk moeilijker geweest. Ik kijk ernaar uit om de komende tijd onder jouw leiding te mogen werken. Maar daarnaast ben ik je dankbaar voor alle kopjes thee die we dronken, de films die we keken, de wandelingen die we makten, de verbouwingsklussen die we uitvoerden en de korte vakantietjes die we ondernamen. Ik hoop dat er nog vele mogen volgen! Anne-Wil Siegmund, wij kennen elkaar al heel lang en onze vriendschap is in de loop van de jaren alleen maar verstevigd. Je bent een duizend-en-één-dingen vriendin, van kletsen op de bank tot dansen op Pinkpop. Je bent mijn spiegel en mijn toetssteen, ook omdat we qua karakter behoorlijk op elkaar lijken. Dat ik weleens zeg dat je 'bij ons meubilair hoort' 
is een compliment voor het feit dat we in elkaars gezelschap altijd helemaal onszelf kunnen zijn. Je had een belangrijke rol op mijn bruiloft en nu weer op mijn promotie. Het is fijn dat je er altijd weer voor mij wil zijn, dank!

Ouders van Jan, Hans \& Anneke de Bres, jullie ook enorm veel dank. Jullie maakten van jullie zoon de man die ik liefheb. Jullie zijn altijd bereid om ons met raad en daad bij te staan, of het nu gaat om een hamer en kwast, hark en schoffel of garde en pollepel. En daarnaast zijn jullie ook nogeens een fantastische opa en oma. Erik, Eva, Meike \& Joris de Bres, met de vorming van onze gezinnen is het contact intensiever geworden. Jan en ik leren veel van het ouderschap door naar jullie voorbeeld te kijken, en doen daar ons voordeel mee. Het is een eer dat jullie ons weleens vragen een stukje te komen zeilen, want in die omstandigheid moet je erop kunnen vertrouwen dat dingen niet al te snel uit de klauwen lopen.

Danielle Bergman, we zien elkaar niet veel, maar als we samen zijn dan wordt iedereen gek van ons geratel. Ik ben er trots op hoe je op je werk steeds weer de nieuwe situatie stevig tegemoet treedt. Ook vind ik het fantastisch om je omringd te zien door zo'n enorm grote en enthousiaste vriendenclub. Dank voor de gezellige en de serieuse zaken. Kus van je zus! Jeroen Faber, het is leuk om te zien hoe jij en Jan jullie passie voor whisky en wielrennen delen. Je humor maakt me altijd verschrikkelijk aan het lachen en je maakt mijn zusje blij. Dank daarvoor.

Papa en mama, naarmate het einde van het dankwoord naderd, wordt het moeilijker om 'dank je wel' te zeggen. Want een 'dank je wel' dekt niet de lading als het gaat om wat jullie voor mij betekend hebben. Dank voor het vormen van de basis van mijn bestaan, waarvan ik veilig kon vertrekken maar waarop ik ook altijd weer mag terugvallen. Dank dat jullie altijd voor ons klaar staan, of het nu gaat om een goed advies, een verbouwingsklus of een middagje oppassen. Het is zo mooi om jullie nu als opa en oma in de weer te zien. Dank dat jullie hebben laten zien hoe je positief met tegenslagen kan omgaan en hoe liefde alles kan overwinnen. Dit proefschrift heb ik aan jullie opgedragen, want ik heb alles in mijn leven kunnen bereiken omdat ik op jullie schouders kon staan.

Jan, mijn lief, de titel van 'ons' liedje zegt het eigenlijk al, je bent mijn 'bridge over troubled water'. Je laat je niet uit het veld slaan als ik weer eens het roer moet of wil omgooien. Je dwingt mij, soms tot mijn grote irritatie maar altijd ten goede, om de verschillende kanten van een zaak te bekijken. Je helpt me knopen doorhakken en stoppen met piekeren. Het is heerlijk om samen met jou te genieten van de sauna, het bos, een stad of lekker eten. Je kan koken, wassen, zagen, timmeren en hebt groene 
vingers; wat wil een vrouw nog meer? En dan blijk je ook nog de allerbeste papa die ik als mama kan wensen. Ik hoop nog vele decennia met jou door het leven te gaan. Robin, mijn grote kleine jongen. Zo mooi, zo lief, zo bijzonder, ons wonder. Je hebt mijn wereld op zijn kop gezet, maar ook mijn leven richting gegeven. Ik ben zo ontzettend trots op je. Wat er ook gebeurd, ik zal altijd eerst jouw mama zijn. Mijn mannen, ik ben zo dankbaar dat jullie deel uitmaken van mijn leven, ik hou van jullie!

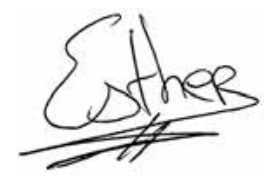



Curriculum Vitae 
Curriculum Vitae 


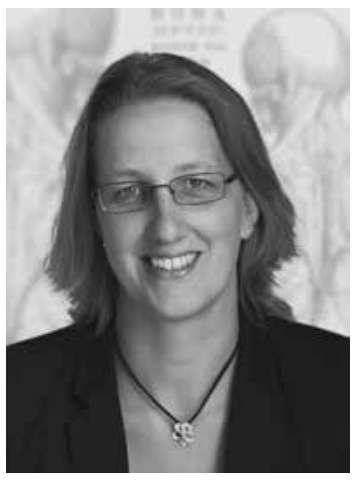

Esther M. Bergman was born on the 20th of November 1979 in Haarlem, the Netherlands. She spent her childhood in Hoorn and attended Atheneum at Atlas College Hoorn, locatie OSG, which she completed in 1998. After spending a gap year in Australia, she studied Human Movement Sciences at the Vrije Universiteit in Amsterdam. Meanwhile, she became a qualified sports masseuse and worked as a student assistant teaching anatomy to medical students. After her graduation in 2003, she took a part-time job as an anatomy and physiology teacher at the Amstel Academie in Amsterdam and obtained a didactic degree.

Between 2005 and 2011, she was a teacher at the Department of Anatomy \& Embryology at the Faculty of Medicine (now Faculty of Health, Medicine and Life Sciences, FHML) at Maastricht University. In 2012 she took up the position of assistant professor at the Anatomy Department of the Radboud University Medical Centre Nijmegen. Currently she works at the same department and is involved in many research and educational activities.

From 2007 to 2014 she worked on her PhD project described in this thesis at the department of Educational Development and Research at the FHML of Maastricht University. In the future, she will continue to work for this department, developing education and teaching various (international) courses.

She married her husband Jan de Bres in 2008 and they had their son Robin in 2012. Together they love to undertake activities like swimming, walking, going to a museum, a restaurant, the sea or the zoo. In her free time, she enjoys reading, dancing, running, photography and cooking. 

She Dissertation Series 
She Dissertation Series 
The SHE Dissertation Series publishes dissertations of PhD candidates from the School of Health Professions Education (SHE) who defended their PhD theses at Maastricht University. The most recent ones are listed below. For more information go to: www.maastrichtuniversity.nl/she.

Van Loon, M.H. (08-05-2014) Fostering Monitoring and Regulation of Learning

Frambach, J.M. (26-03-2014) The cultural complexity of problem-based learning across the world

Hommes, J.E. (26-02-2014) How relations, time \& size matter in medical education

Van der Zwet, J. (30-01-2014) Identity, Interaction and Power. Explaining the affordances of doctor-student interaction during clerkships

Watling, C.J. (22-01-2014) Cognition, Culture, and Credibility. Deconstructing Feedback in Medical Education

Winston, K. (12-12-2013) Remediation Theory and Practice: Transforming At-Risk Medical Students

Kamp, R.J.A. (28-11-2013) Peer Feedback to Enhance Learning in Problem-Based Tutorial Groups

Junod Perron, N. (24-10-2013) Towards a learner-centered approach to postgraduate communications skills teaching

Pratidina Susilo, A. (24-10-2013) Learning to be the Patient Advocate: The Development of a Communication Skills Course to Enhance Nurses' Contribution to the Informed Consent Process

Alves de Lima, A. (23-10-2013) Assessment of clinical competence: Reliability, Validity, Feasibility and Educational Impact of the mini-CEX

Sibbald, M. (09-10-2013) Is that your final answer? How doctors should check decisions Ladhani, Z. (05-07-2013) Competency based education and professional competencies: a study of institutional structures, perspectives and practices in Pakistan

Jippes, M. (01-02-2013) Culture matters in medical schools: How values shape a successful curriculum change

Duvivier, R. J. (12-12-2012) Teaching and Learning Clinical Skills. Mastering the Art of Medicine

De Feijter, J.M. (09-11-2012) Learning from error to improve patient safety

Prescott, L. (09-11-2012) Ensuring the Competence of Dental Practitioners through the Development of a Workplace-Based System of Assessment

Cilliers, F.J. (05-09-2012) The Pre-assessment Learning Effects of Consequential Assessment: Modelling how the Examination Game is Played

Spanjers, I. A.E. (05-07-2012) Segmentation of Animations: Explaining the Effects on the Learning Process and Learning Outcomes

Al-Kadri, H.M.F. (28-06-2012) Does Assessment Drive Students' Learning? 
Leppink, J. (20-06-2012) Propositional manipulation for conceptual understanding of statistics

Van Zundert, M.J. (04-05-2012) Conditions of Peer Assessment for Complex Learning

Claramita, M. (30-03-2012) Doctor-patient communication in a culturally hierarchical context of Southeast Asia: A partnership approach

Kleijnen, J.C.B.M. (21-03-2012) Internal quality management and organizational values in higher education

Persoon, M.C. (19-01-2012) Learning in Urology; The influence of simulators and human factors

Pawlikowska, T.R.B. (21-12-2011) Patient Enablement; A Living Dialogue

Sok Ying Liaw, (14-12-2011) Rescuing A Patient In Deteriorating Situations (RAPIDS): A programmatic approach in developing and evaluating a simulation-based educational program

Singaram, V.S. (7-12-2011) Exploring the Impact of Diversity Factors on Problem-Based Collaborative Learning

Balslev, T. (24-11-2011) Learning to diagnose using patient video cases in paediatrics: Perceptive and cognitive processes

Widyandana, D. (19-10-2011) Integrating Pre-clinical skills training in skills laboratory and primary health care centers to prepare medical students for their clerkships

Durning, S.J. (09-09-2011) Exploring the Influence of Contextual Factors of the Clinical Encounter on Clinical Reasoning Success (Unraveling context specificity)

Govaerts, M.J.B. (08-09-2011) Climbing the Pyramid;Towards Understanding Performance Assessment

Stalmeijer, R. E. (07-07-2011) Evaluating Clinical Teaching through Cognitive Apprenticeship

Malling, B.V.G. (01-07-2011) Managing word-based postgraduate medical education in clinical departments

Veldhuijzen, J.W. (17-06-2011) Challenging the patient-centred paradigm: designing feasible guidelines for doctor patient communication

Van Blankenstein, F. (18-05-2011) Elaboration during problem-based, small group discussion: A new approach to study collaborative learning

Van Mook, W. (13-05-2011) Teaching and assessment of professional behavior: Rhetoric and reality

De Leng, B. (8-12-2009). Wired for learning. How computers can support interaction in small group learning in higher education

Maiorova, T. (29-05-2009). The role of gender in medical specialty choice and general practice preferences

Bokken, L. (04-03-2009). Innovative use of simulated patients for educational purposes 
Wagenaar, A. (18-09-2008). Learning in internships. What and how students learn from experience

Driessen, E. (25-06-2008). Educating the self-critical doctor. Using portfolio to stimulate and assess medical students' reflection

Derkx, H. (18-06-2008). For your ears only. Quality of telephone triage at out-of-hours centres in the Netherlands

Niessen, Th. (30-11-2007). Emerging epistemologies: making sense of teaching practice

Budé, L. (05-10-2007). On the improvement of students' conceptual understanding in statistics education

Niemantsverdriet, S. (26-07-2007). Learning from international internships: A reconstruction in the medical domain

Marambe, K. (20-06-2007). Patterns of student learning in medical education - A Sri Lankan study in traditional curriculum

Pleijers, A. (19-01-2007). Tutorial group discussion in problem-based learning

Sargeant, J. (21-09-2006). Multi-source feedback for physician learning and change

Dornan, T. (12-06-2006). Experience-based learning

Wass, V. (12-05-2006). The assessment of clinical competence in high stakes examinations

Prince, K. (21-04-2006). Problem-based learning as a preparation for professional practice 


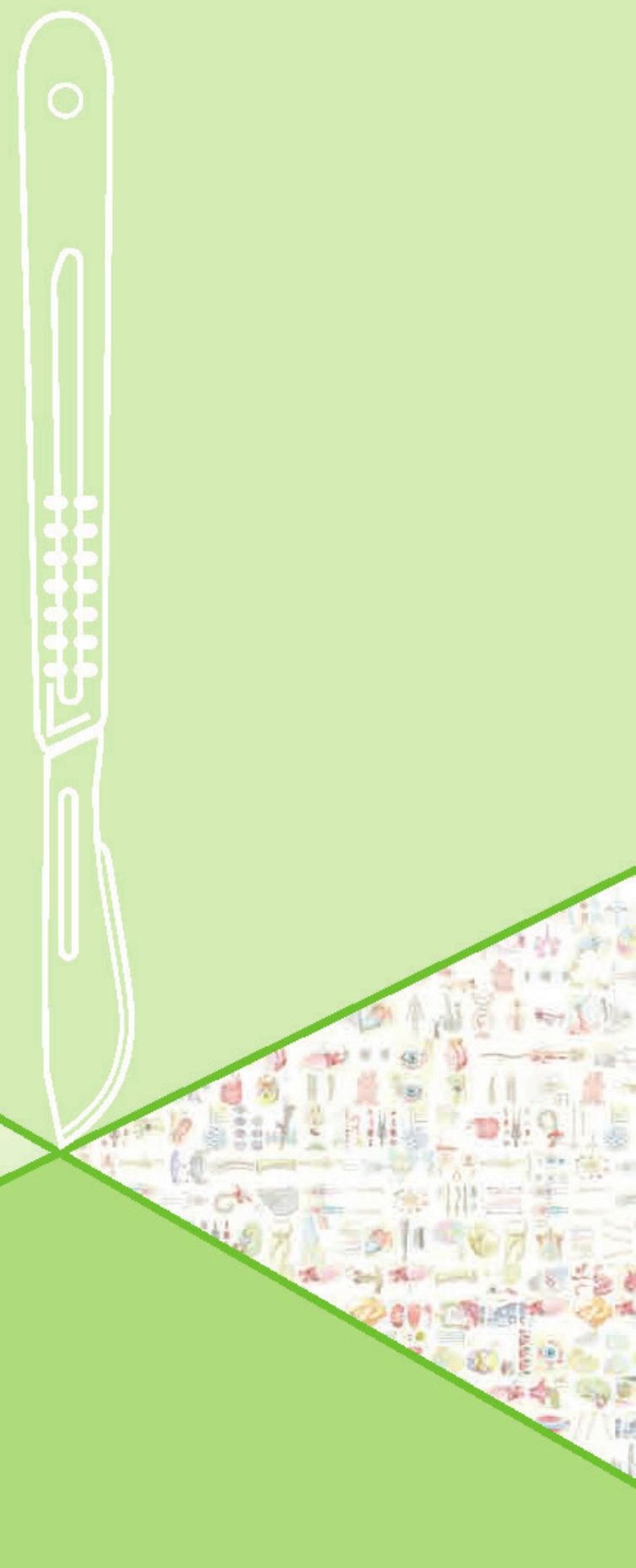

